\title{
Advanced Utility Mercury-Sorbent Field-Testing Program
}

\author{
Final Report
}

October 1, 2003 - December 31, 2007

Dr. Ronald R. Landreth, Recipient Project Director

September 15, 2011

DOE Award No. DE-FC26-03NT41990

Submitted by Albemarle Environmental, $\mathrm{f} / \mathrm{k} / \mathrm{a}$ Sorbent Technologies Corporation 1664 E. Highland Road, Twinsburg, $\mathrm{OH} 44087$ 


\section{DISCLAIMER}

This report was prepared as an account of work sponsored by an agency of the United States Government. Neither the United States Government nor any agency thereof, nor any of their employees, makes any warranty, express or implied, or assumes any legal liability or responsibility for the accuracy, completeness, or usefulness of any information apparatus, product, or process disclosed, or represents that its use would not infringe privately owned rights. Reference herein to any specific commercial product, process, or service by trade name, trademark, manufacturer, or otherwise does not necessarily constitute or imply its endorsement, recommendation, or favoring by the United States Government or any agency thereof. The views and opinions of the authors expressed herein do not necessarily state or reflect those of the United States Government or any agency thereof. 


\begin{abstract}
This report summarizes the work conducted from September 1, 2003 through December 31, 2007 on the project entitled Advanced Utility Mercury-Sorbent Field-Testing Program. The project covers the testing at the Detroit Edison St. Clair Plant and the Duke Power Cliffside and Buck Stations. The St. Clair Plant used a blend of subbituminous and bituminous coal and controlled the particulate emissions by means of a cold-side ESP. The Duke Power Stations used bituminous coals and controlled their particulate emissions by means of hot-side ESPs.

The testing at the Detroit Edison St. Clair Plant demonstrated that mercury sorbents could be used to achieve high mercury removal rates with low injection rates at facilities that burn subbituminous coal. A mercury removal rate of $94 \%$ was achieved at an injection rate of $3 \mathrm{lb} / \mathrm{MMacf}$ over the thirty day long-term test. Prior to this test, it was believed that the mercury in flue gas of this type would be the most difficult to capture. This is not the case.

The testing at the two Duke Power Stations proved that carbon- based mercury sorbents can be used to control the mercury emissions from boilers with hot-side ESPs. It was known that plain PACs did not have any mercury capacity at elevated temperatures but that brominated B-PAC did. The mercury removal rate varies with the operation but it appears that mercury removal rates equal to or greater than $50 \%$ are achievable in facilities equipped with hot-side ESPs.
\end{abstract}

As part of the program, both sorbent injection equipment and sorbent production equipment was acquired and operated. This equipment performed very well during this program. In addition, mercury instruments were acquired for this program. These instruments worked well in the flue gas at the St. Clair Plant but not as well in the flue gas at the Duke Power Stations. It is believed that the difference in the amount of oxidized mercury, more at Duke Power, was the difference in instrument performance. Much of the equipment was purchased used and all of the equipment has nearly reached the end of its useful service. 


\section{TABLE OF CONTENTS}

Disclaimer

Abstract. 3

Table of Contents. 4

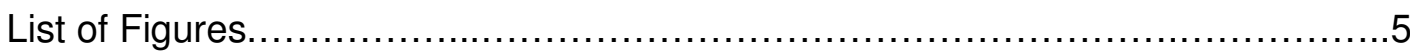

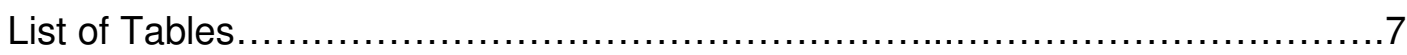

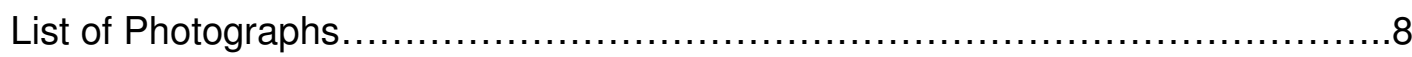

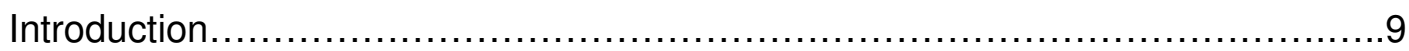

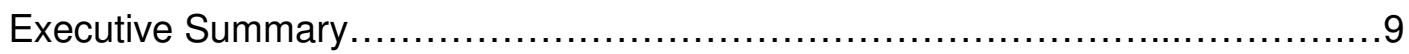

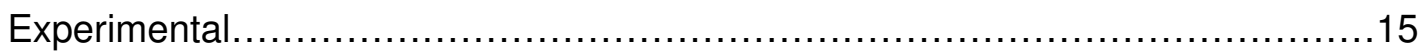

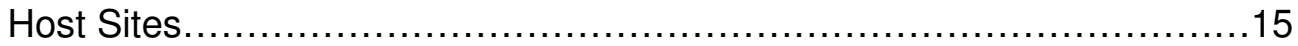

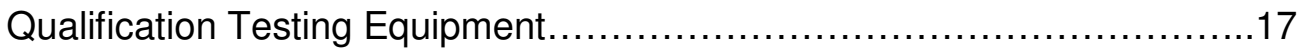

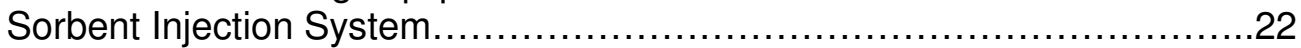

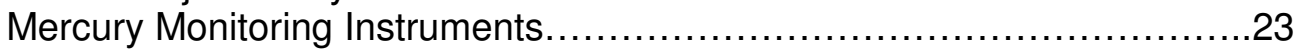

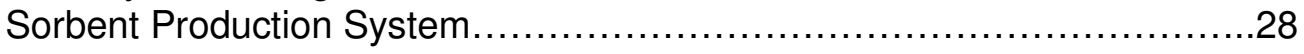

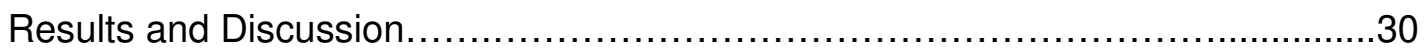

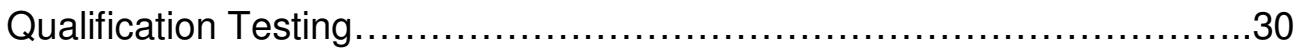

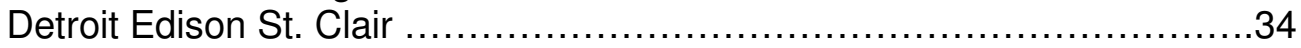

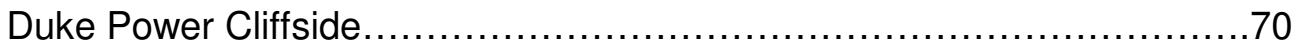

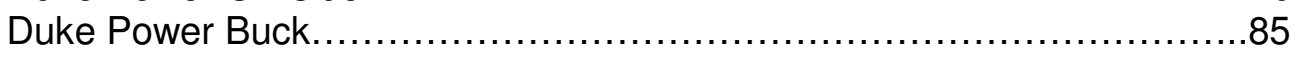

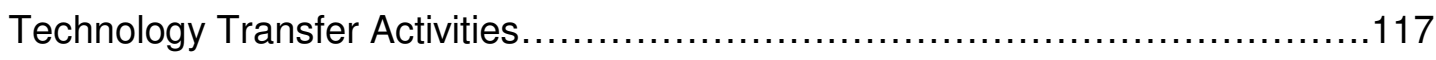

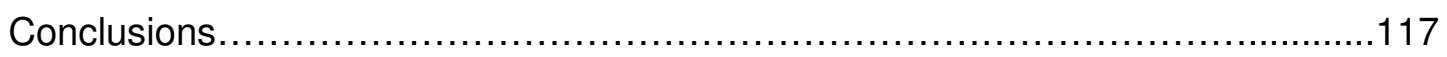

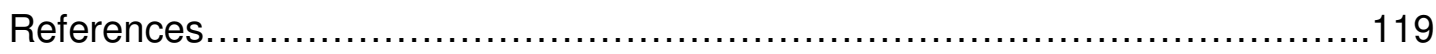




\section{니ST OF FIGURES}

1. Diagram of the Duct-Injection System

2. Pilot Duct-Injection System Hg Removal Results Plotted with the Results from Brayton Point and Pleasant Prairie

3. The EPRI/Apogee PoCT System Used at the We Energies Pleasant Prairie Power Plant

4. Diagram of the Sorbent Injection System

5. Diagram of Baldwin Inertial Separator

6. Diagram of the PS Analytical Dry Conversion Process

7. Diagram of the Sorbent Production System

8. Duct-Injection System Tests with Sorbents $A 0$ and $A 1$

9. Duct-Injection System Tests with Sorbents A0, A3, A5, A1 and A1.5

10. Mercury Removal Results from Pleasant Prairie Slipstream Tests

11. Detroit Edison St. Clair Unit 1 ESP 1A Ductwork Modeled

12. Ports Installed in Unit 1 ESP 1A Ductwork

13. Flue Gas Flow in Unit 1 ESP 1A Ductwork

14. Single Point Injection in Unit 1 ESP 1A Ductwork

15. Potential Lance Locations Evaluated in Unit 1 ESP 1 A Ductwork

16. Sorbent Distribution at the First Sample Plane in Unit 1 ESP 1A Ductwork

17. Side-by-Side Tests with One Conversion Module Operating in the Wet Mode and Two Mercury Analyzers

18. Side-by-Side Test with Two Conversion Modules, One Operating in the Wet Mode and One in the Dry Mode with Two Mercury Analyzers

19. Baseline $\mathrm{Hg}$ CEM Data (Corrected to $3 \% \mathrm{O}_{2}$ ) from the Detroit Edison St. Clair Power Plant from 7/25-8/1/04

20. Detroit Edison St. Clair Parametric Testing Mercury Removal Results Using Norit Darco FGD Sorbent

21. Detroit Edison St. Clair Parametric Testing Mercury Removal Results Using Sorbent Technologies A-5B and Norit Darco FGD Sorbents

22. Mercury Emissions in Pounds per Trillion BTUs

23. Inlet and Outlet $\mathrm{Hg} \mathrm{OHM}$ and CEM Data for 9/9/04

24. Detroit Edison St. Clair Long-Term Testing Mercury Removal Results Using Sorbent Technologies A-5B Sorbent at an Injection Rate of $3.0 \mathrm{lb} / \mathrm{MMacf}$

25. Inlet and Outlet $\mathrm{Hg} \mathrm{OHM}$ and CEM Data for 106/04 and 10/21/04

26. Mercury Method 324 Data from St. Clair Unit $1 \mathrm{~A}$

27. Lower-Cost B-Pac Mercury Removal Test on 10/11/04

28. Lower-Cost B-Pac Mercury Removal Test on 10/23/04

29. Fly Ash Mercury Data for ESPs $1 \mathrm{~A}$ and 1B

30. Fly Ash and CEM Hg Data during the Long-Term Test at St. Clair

31. Bromine in FI Ash Leachates

32. Mercury in Fly Ash Leachates

33. Boiler Load during the Long-Term Test at St. Clair

34. Preheater Outlet $\mathrm{O}_{2}$ during the Long-Term Test at St. Clair

35. Flue Gas Temperature at the Injection Location during the Long-Term Test

36. Flue Gas Flow Rate at the Point of Injection during the Long-Term Test

37. Flue Gas Opacity during Some Parametric Testing

38. Flue Gas Opacity during the Long-Term Test at St. Clair

39. Cliffside Total Hg CEM Outlet Data on 9/17/03

40. Fly Ash Compositions With, and Without, Sorbent 
41. Cliffside Total Hg CEM Curve for Low Load Trial on 9/18/03

42. Mercury Capture vs. Injection Rate at Cliffside and Brayton Point

43. Duke Power Cliffside Boiler No.2 Opacity on Two Days

44. Toxic Characteristic Leaching Procedure \& Water Leachates of Cliffside Ashes

45. Flue Gas Flow Rate on 12/8/04 at $12 \mathrm{MW}$

46. Flue Gas Flow Rate on 12/9/04 at $20 \mathrm{MW}$

47. Flue Gas Flow Rate on 12/9/04 at $25 \mathrm{MW}$

48. Mercury Sorbents Tests on 12/8/04 at Duke Power Cliffside Plant at an Injection Rate of $5.0 \mathrm{lb} / \mathrm{MMacf}$ at $12 \mathrm{MW}$

49. Mercury Sorbents Tests on 12/9/04 at Duke Power Cliffside Plant at an Injection Rate of $5.0 \mathrm{lb} / \mathrm{MMacf}$ at $20 \mathrm{MW}$ and $25 \mathrm{MW}$

50. Hg Concentration at Buck Unit 6 ESP Outlet

51. Boiler Load during the Parametric Test at Duke Power Buck Station

52. Injection Temperature during the Parametric Test at Duke Power Buck Station

53. Flue Gas Oxygen during the Parametric Test at Duke Power Buck Station

54. Six Minute Average Opacity during the Parametric Test at Buck Station

55. Load during the Long-Term Test at Duke Power Buck Station

56. Injection Temperature during the Long-Term Test (5/4-14/05)

57. Injection Temperature during the Long-Term Test (5/14-24/05)

58. Injection Temperature during the Long-Term Test (5/24-6/3/05)

59. Injection Temperature during the Long-Term Test (6/3-9/05)

60. Flue Gas Oxygen during the Long-Term Test at Duke Power Buck Station

61. Six Minute Average Opacity during the Long-Term Test at Buck Station

62. Buck Long-Term Test on May 4, 2005 Injection of A-5B at $4 \mathrm{lb} /$ MMacf

63. Buck Long-Term Test on May 5, 2005 Before and After Injection Stop

64. Mercury CEM Data from Long-Term Test at Buck Station (5/8-16/05)

65. Mercury CEM Data from Long-Term Test at Buck Station (5/16-24/05)

66. Mercury CEM Data from Long-Term Test at Buck Station (5/24-6/1/05)

67. Mercury CEM Data from Long-Term Test at Buck Station (6/1-10/05)

68. Duke Power Long-Term Test Apogee and PSA Data - June 3, 2005

69. Leaching Results from Duke Power Buck Fly Ash 


\section{LIST OF TABLES}

1. Results from Slipstream Tests at Pleasant Prairie

2. Coal Data from the Baseline Period at the St. Clair Power Plant

3. Fly Ash Data from the Baseline Period at the St. Clair Power Plant

4. Fly Ash $\mathrm{Hg}$ Data (ppb) from the Baseline Period at the St. Clair Power Plant

5. Baseline Period Operating Data for St. Clair Unit 1

6. Mercury CEM Data from the Baseline Testing at St. Clair Unit $1 \mathrm{~A}$

7. Mercury OHM and CEM Data for $7 / 28 / 04$ at St. Clair Unit $1 \mathrm{~A}$

8. Coal Mercury during Parametric Testing

9. Parametric Mercury Sorbent Tests at St. Clair Unit $1 \mathrm{~A}$

10. Parametric Mercury Sorbent Tests Under Abnormal Conditions

11. Mercury OHM and CEM Data for $9 / 9 / 04$

12. Mercury OHM and CEM Data for $10 / 6 / 04 \& 10 / 21 / 04$ at St. Clair Unit $1 A$

13. Coal Data from St. Clair Unit $1 \mathrm{~A}$ during the Log-Term Test

14. Fly Ash Data from St. Clair Unit 1 A during the Long-Term Test

15. Long-Term Test Carbon Mass Balance

16. Long-Term Test Mercury Mass Balance

17. Post Long-Term Test Fly Ash Mercury Content

18. Coal, Ohm and CEM Data in $\mathrm{lb} / \mathrm{T}$ Btu

19. Halogen Data from the Testing at the St, Clair Unit $1 \mathrm{~A}$

20. Corrosion Coupon Data from the Testing at St. Clair Unit $1 \mathrm{~A}$

21. Duke Power Cliffside Plant Hot-Side ESP Hg Sorbent Trial Plan

22. Duke Power Cliffside Plant Test Conditions

23. Duke Power Cliffside Fly Ash Mercury Analyses

24. Duke Power Cliffside Mercury Testing Results

25. Cliffside II Test Plan December 2004

26. Coal Proximate Analyses during the Two Tests Conducted at the Cliffside Plant

27. Coal Mercury, Chlorine, and Fluorine Contents during the Two Tests Conducted at the Duke Power Cliffside Plant

28. Operating Conditions during the Parametric Tests

29. Fly Ash LOI during the Two Cliffside Tests

30. Fly Ash Mercury Data from the Two Cliffside Test Programs

31. Buck Baseline OHM Measurements - 4/27-28/05

32. Baseline Fly Ash $\mathrm{Hg}$

33. Buck Parametric Testing Results - Injection Data

34. Buck Parametric Fly Ash Analyses

35. Coal Analyses from the Parametric Testing Period at Buck Station

36. Buck Parametric Testing Results - Injection Data

37. Long-Term Test Coal Analyses Using Blend of Bituminous Coals

38. Long-Term Test Coal Analyses Using Blend of Bituminous/Subbituminous coals

39. Buck Long-Term Test Hg Removal Based Upon CEM

40. Buck Long-Term OHM Testing - 5/18/05

41. Buck Long-Term OHM Testing - 6/7/05

42. Mercury Removal Calculations

43. Mercury Removal for Selected Time Periods During the Test

44. Duke Power Buck Long-Term Fly Ash Hg Data

45. Duke Power Buck Long-Term Fly Ash Hg Data

46. Fly Ash Arsenic and Selenium Data from the Long-Term Test

47. Duke Power Buck Station Halogen Data

48. Duke Power Buck Station Dioxin Measurements during the Long-Term Test 


\section{LIST OF PHOTOGRAPHS}

1. Detroit Edison St. Clair Plant

2. Duke Power Cliffside Station

3. Duke Power Buck Station

4. View of the Sorbent Technologies Duct-Injection System

5. Analytical Portion of the Duct-Injection System

6. Sorbent Injection Trailer

7. PS Analytical Wet/Dry Mercury Conversion Module

8. Outlet Mercury CEM Building at the St. Clair Plant

9. Ohio Lumex Model RA-915+ Mercury Analyzer

10. Method 324 Instrument

11. PAC being Unloaded at the Sorbent Production Facility 


\section{INTRODUCTION}

The project was divided into six phases as follows:

Phase I: $\quad$ Project Plan Development

Phase II: $\quad$ Equipment Preparation

Phase III: $\quad$ Qualification Testing \& Support Activities

Phase IV: $\quad$ Field Trial at Detroit Edison's St. Clair Plant

Phase V: $\quad$ Field Trial at Duke Power's Cliffside and Buck Stations

Phase VI: $\quad$ Reporting \& Technology Transfer Activities

The first phase covered the effort to revise and finalize the project plan. Phase II comprised the effort to design, acquire and install the required equipment for sorbent injection, mercury monitoring, and sorbent production. The phase II efforts supported all phases of the test program. Phases IV and V covered the field testing at the Detroit Edison St. Clair Plant and the Duke Power Cliffside and Buck Stations. Finally, the Phase VI work was for the reporting and technology activities.

\section{EXECUTIVE SUMMARY}

This report summarizes the work conducted from September 1, 2003 through December 31, 2007 on the project entitled Advanced Utility Mercury-Sorbent Field-Testing Program (Cooperative Agreement No. DE-FC26-03NT41990). This project was focused upon two of the major issues regarding the use of mercury sorbents. These issues are the efficient capture of mercury from facilities using lower rank coals and from facilities using hot-side ESPs. Prior to these tests, it was believed that it was impossible to either get high mercury removal rates when the facility fired low rank coal or any mercury removal when treating the flue gas at the elevated temperature present in a hot-side ESP application. These tests were to prove these assumptions incorrect.

The testing at the Detroit Edison St. Clair Plant addressed the first of these issues, efficient mercury capture from a facility which primarily burns a subbituminous coal. Detroit Edison's St. Clair Plant is representative of a large umber of U.S. coal-fired power plants requiring easily-retrofitted mercury emission control. The plant burns a typical Powder River Basin subbituminous coal, with a small amount of bituminous coal typically blended in, and has only a cold-side electrostatic precipitator for air pollution control.

The project work at St. Clair was divided into baseline, parametric, and long-term mercury control testing. Operation of the new mercury S-CEMs was evaluated in the baseline portion of the project as well as the normal operating conditions of Unit $1 \mathrm{~A}$, the boiler/ESP system, in which the injection program was conducted.

Norit Darco FGD plain activated carbon (now Norit Darco Hg) was evaluated in the parametric testing to provide a baseline for the comparison with other sorbents evaluated. A number of variations of the Sorbent Technologies' B-PAC brominated carbon mercury sorbent were evaluated at different injection rates in the short-term tests. It was found that $70 \%$ mercury removal could be achieved with a B-PAC injection rate of only $1.0 \mathrm{lb} / \mathrm{MMacf}$, while $90 \%$ mercury removal could be achieved with an injection rate of $3.0 \mathrm{lb} / \mathrm{MMacf}$. It was also discovered that with brominated carbons a slightly higher mercury removal rate was achieved when the boiler was firing $100 \%$ 
subbituminous coal as compared to the plant's normal $85 \%$ subbituminous $/ 15 \%$ bituminous coal blend, in contrast to prior expectations.

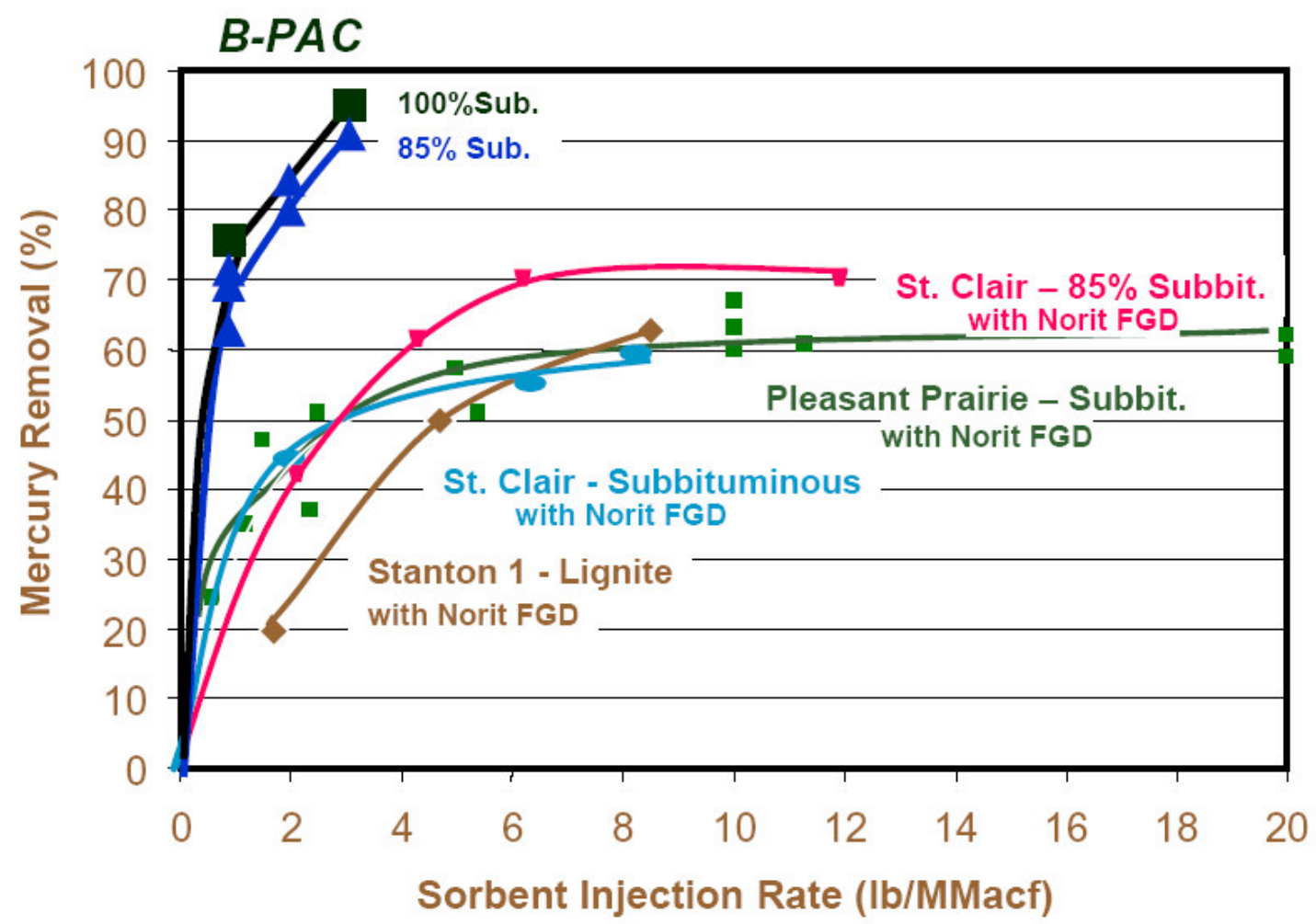

The results for the standard B-PAC sorbent from the parametric testing are presented in the figure below for comparison with the results from plain PAC at St. Clair and at Pleasant Prairie, another full-scale demonstrations using low rank coal.

The standard B-PAC brominated carbon sorbent was selected for the long-term testing. This sorbent was injected at a rate of $3.0 \mathrm{lb} / \mathrm{MMacf}$ for thirty consecutive days. There were no unplanned injection stoppages attesting to the reliability of the injection system. The result was an average $94 \%$ total mercury removal rate for the 30 day period as shown in the figure below. About $91 \%$ of the $\mathrm{Hg}$ removal can be attributed to the B-PAC sorbent. Fly ash mercury analyses and OHM stack tests confirm these results.

The long-term test results are presented in the figure below. 


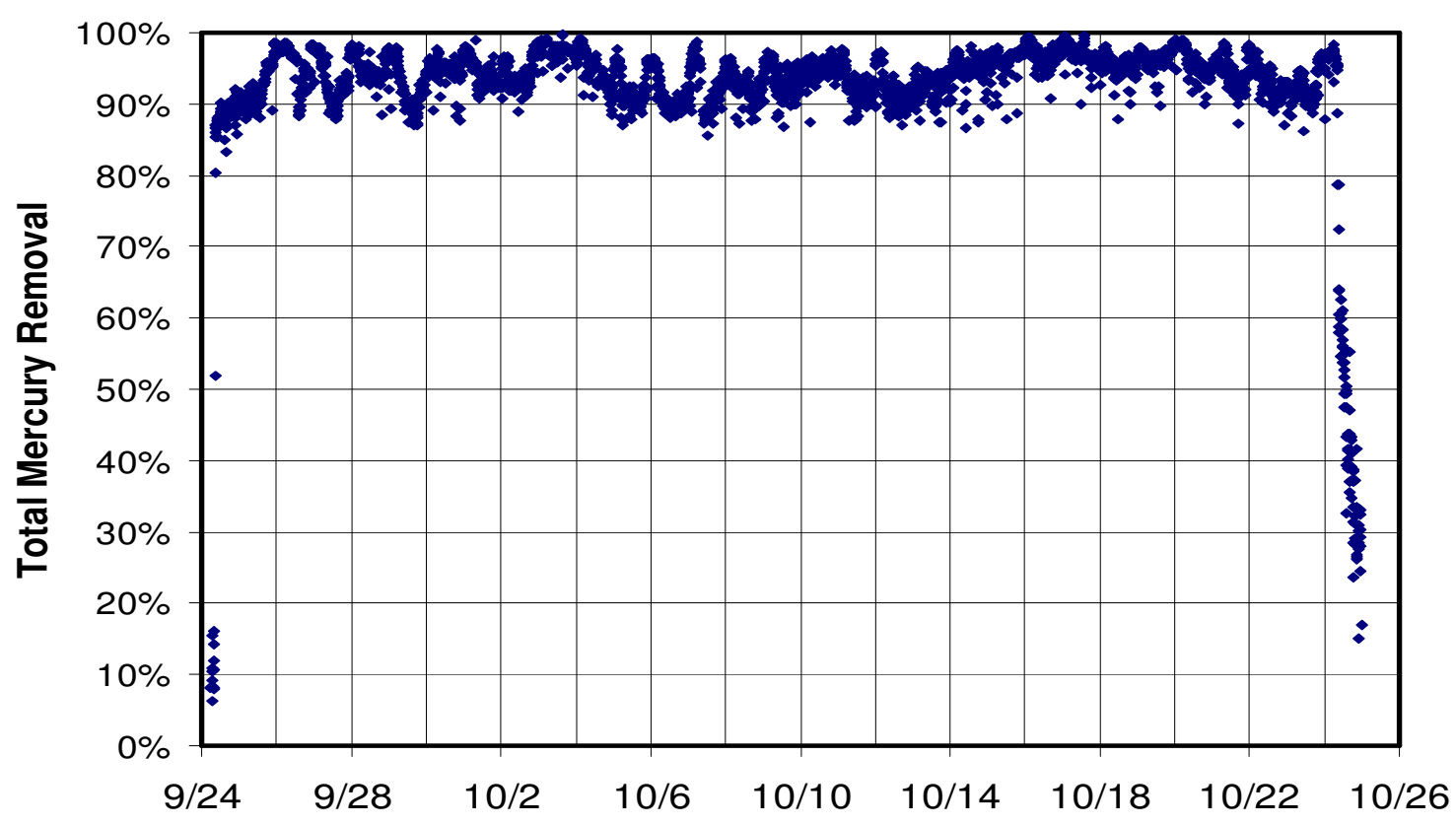

There were no observed detrimental impacts on the boiler operation or equipment during these tests. Corrosion coupons installed for the entire long-term test did not exhibit any corrosion.

The mercury control costs associated with this control technology are dominated by the cost of the sorbent consumed. These costs were estimated at this site to be about $\$ 3,700 / \mathrm{lb} \mathrm{Hg}$ for $70 \%$ mercury removal and $\$ 11,500 / \mathrm{lb} \mathrm{Hg}$ for $94 \%$ mercury removal. See the example calculation below for $70 \%$ mercury removal for a median subbituminous coal plant with $7 \mu \mathrm{g} / \mathrm{Nm}^{3}$ of gas-phase mercury at the sorbent injection point.

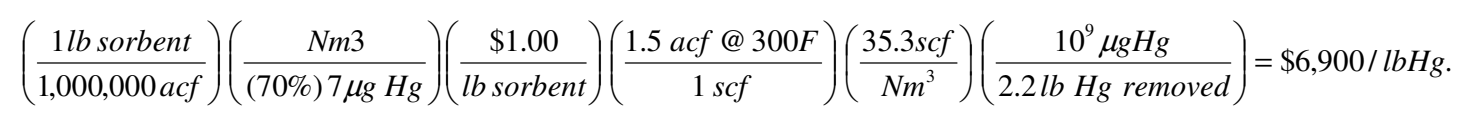

Note that DOE "baseline" costs for mercury control were set at $\$ 50,000$ to $\$ 70,000 / \mathrm{lb}$ of $\mathrm{Hg}$ removed. ${ }^{(1)}$ Clearly, the B-PAC sorbent provided much higher mercury removal at a much lower cost than has been previously estimated.

This first extended full-scale test of B-PAC injection upsets a long-held industry view that retrofit mercury control at plants burning subbituminous coals will be difficult and expensive.

The second issue addressed in this program was the use of brominated sorbents for the capture of mercury in the elevated temperatures present in a hot-side ESP. The first evaluation of brominated sorbents in a hot-side application was performed at the Duke Power Cliffside Plant. For these short-term tests, a temporary small-scale injection system was provided by Sorbent Technologies, while mercury S-CEMs were provided and operated by Western Kentucky University, another project partner. Ontario Hydro Method mercury speciation tests were performed by Trigon Engineering Consultants. 
This was the first successful use of a sorbent to capture mercury at the high temperatures of a hot-side ESP. The very short-term tests demonstrated a potential for brominated carbon sorbents to reduce the mercury emissions of boilers equipped with such hot-side ESPs. At least $40 \%$ mercury removal was indicated at normal operating conditions and at least $80 \%$ mercury removal was achieved at low load, as shown in the following figure.

\section{Duke Power Cliffside Plant Hg S-CEM Curve for Low Load Trial on 9/18/03}

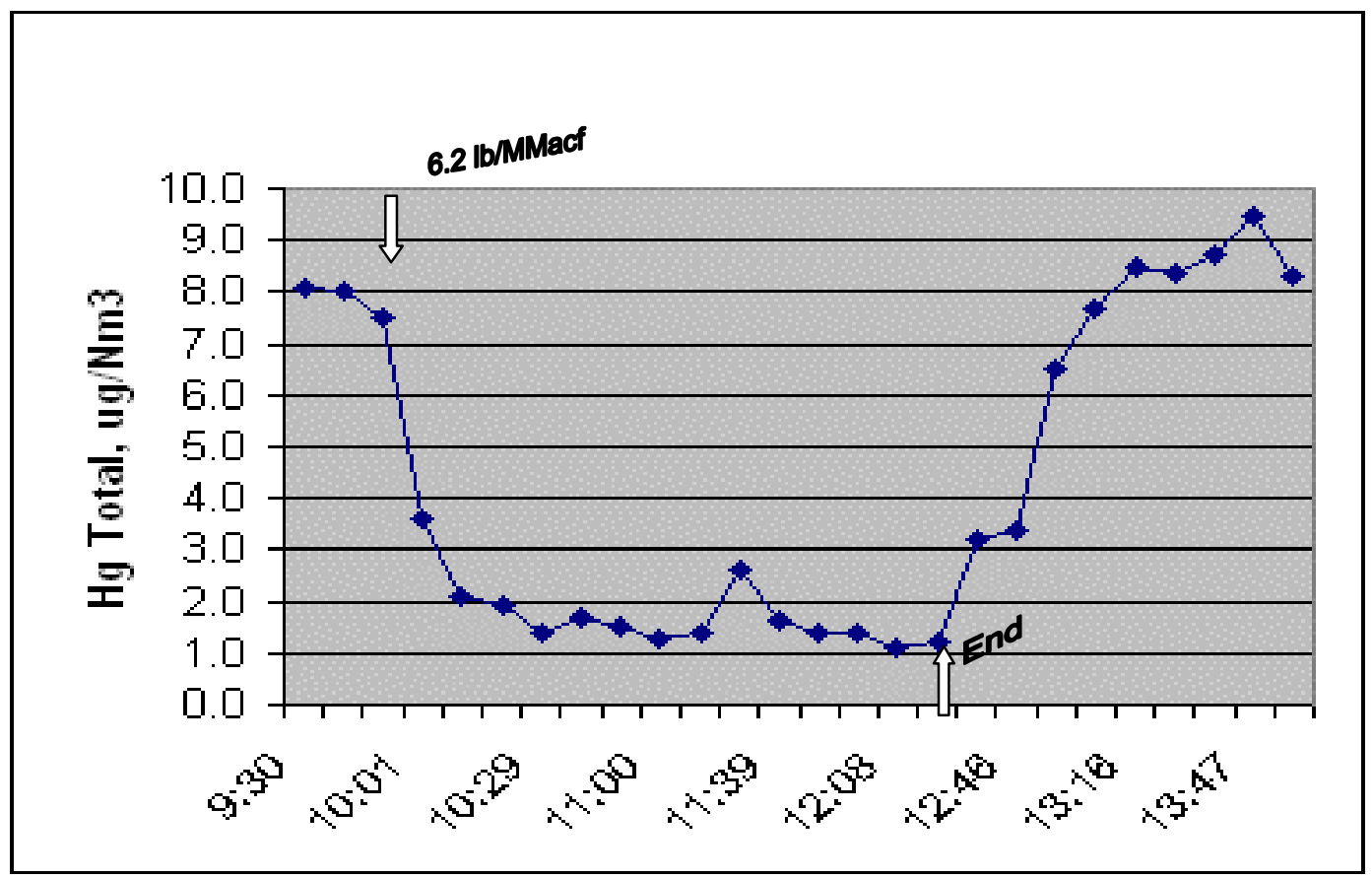

Consequently, in December of 2004, a second qualification test was conducted at the Cliffside Plant with sorbents designed for the hot-side application (H-PAC). At low load, the Sorbent Technologies H-PAC sorbents performed similarly to the sorbents used in the first test at Cliffside, with between $69 \%$ and $73 \%$ mercury removal while injecting at $5 \mathrm{lb} /$ MMacf. However, the materials in the new tests performed better than previously at higher loads. Between $64 \%$ and $73 \%$ mercury removal was achieved while injecting at $20 \mathrm{MW}$ at an injection rate of $5 \mathrm{lb} / \mathrm{MMacf}$ and between $51 \%$ and $59 \%$ mercury removal was similarly achieved at $25 \mathrm{MW}$. In the earlier test at Cliffside, a mercury removal rate of only $49 \%$ was achieved at $20 \mathrm{MW}$ with about a $6 \mathrm{lb} / \mathrm{MMacf}$ injection rate. These results were sufficiently encouraging that the project team decided to proceed with longterm testing on a hot-side ESP at Duke's Buck Plant.

The testing at the Buck Station consisted of a short baseline measurement and parametric testing program followed by the long-term 30-day injection test. The parametric testing was brief because of the amount of work performed previously at the Cliffside Station.

The results from a typical parametric injection test are shown in the figure below. 
$\mathrm{Hg}$ Concentration at Buck Unit 6 ESP Outlet

(April 27-28 Corrected to 3\%)

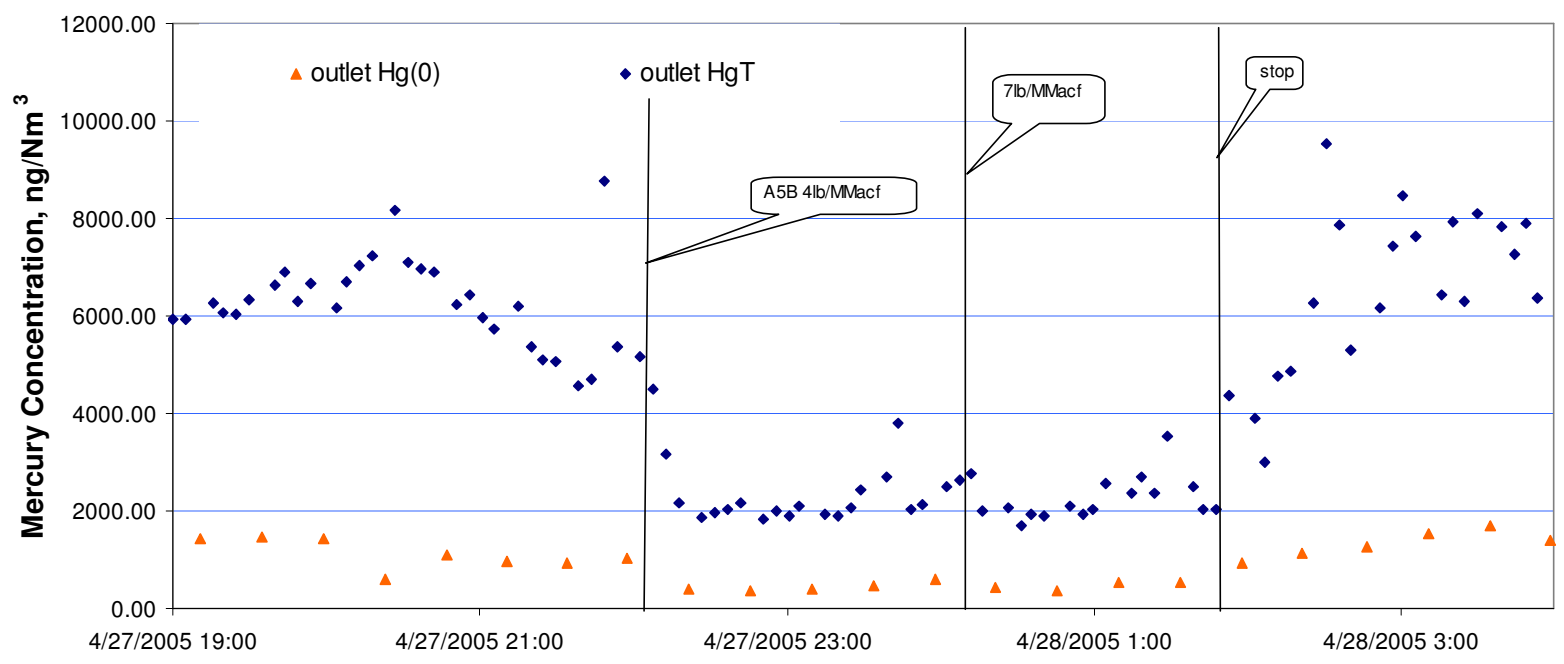

The parametric injection tests demonstrated that a mercury removal rate of approximately $60 \%$ could be achieved with the injection of a brominated sorbent at an injection rate of about $5.0 \mathrm{lb} /$ MMacf.

The boiler operation changed radically from the parametric test to the long-term test. Normally, a blend of low and high ash bituminous coals is used at the Buck Station as it was during the parametric test program. Unfortunately, the low ash coal was in low supply during the long-term test and the coal ash content nearly doubled. This caused numerous boiler operating problems. In addition, Buck Unit 6 experienced three outages during the long-term test. These problems greatly complicated the long-term test but did not stop it.

A mercury removal rate of about $50 \%$ was achieved at an injection rate of $5.0 \mathrm{lb} / \mathrm{MMacf}$ of H-PAC. This removal rate appeared to be affected by the operation of the boiler and varied from a low of $25 \%$ to a high of $80 \%$. For three days during the long-term trial, the $\mathrm{H}-\mathrm{PAC}$ sorbent was injected at a rate of $10.0 \mathrm{lb} / \mathrm{MMacf}$. Under these conditions, a mercury removal efficiency of $70 \%$ was achieved.

Testing was conducted at both the Detroit Edison St. Clair Plant and the Duke Power Buck Station for chlorinated and brominated dioxins. This work was funded by the United States EPA and performed by an outside contractor. It was found that the levels of dioxins in the flue gas from these plants were very low and that the use of brominated sorbents did not appear to impact these levels.

The fly ash from both of the plants was tested by the TCLP methodology in order to define whether mercury was leached from these materials. In all cases, the mercury in the leachate was very low and comparable to that from fly ash which did not contain the mercury sorbent. 
[This page intentionally blank.] 


\section{EXPERIMENTAL}

\section{HOST SITES}

\section{Detroit Edison St. Clair Plant}

The Detroit Edison St. Clair Power Plant is located in East China Township, Michigan on the banks of the St. Clair River northeast of Detroit, Michigan and directly across from Canada. The power plant consists of six active boilers with a gross generating capacity of $1390 \mathrm{MW}$. There are four identical boilers (Units $1-4$ ) with a capacity of $160 \mathrm{MW}$, each of which were built in the 1950's, and two larger boilers (300 MW and $450 \mathrm{MW}$ ) which were built in the 1960's. The mercury testing program at the St. Clair Power Plant was conducted in Unit 1.

Unit 1 was originally designed to burn bituminous coal but was converted to a blend of subbituminous and bituminous coals in 1975 in order to reduce sulfur emissions.

Currently, the blend is composed of $85 \%$ subbituminous coal from Montana and $15 \%$ bituminous coal from the eastern United States. Sustained $100 \%$ subbituminous operation is not currently possible due to the build up of deposits within the boiler. The conversion to the coal blend reduced the full coal generating capacity of Unit 1 from 160 MW to $145 \mathrm{MW}$, due to limitations in coal grinding and drying capacity. Oil over-firing is used to reach the full $160 \mathrm{MW}$ capacity, when it is needed.

At the same time as the coal switch, new electrostatic precipitators (ESPs) were installed on Unit 1. The flue gas from Unit 1 is split in half and directed through two identical, but separate, cold-side ESPs. The flue gas is recombined after the induced draft fans and directed up a common stack.

Photograph 1. Detroit Edison St. Clair Plant

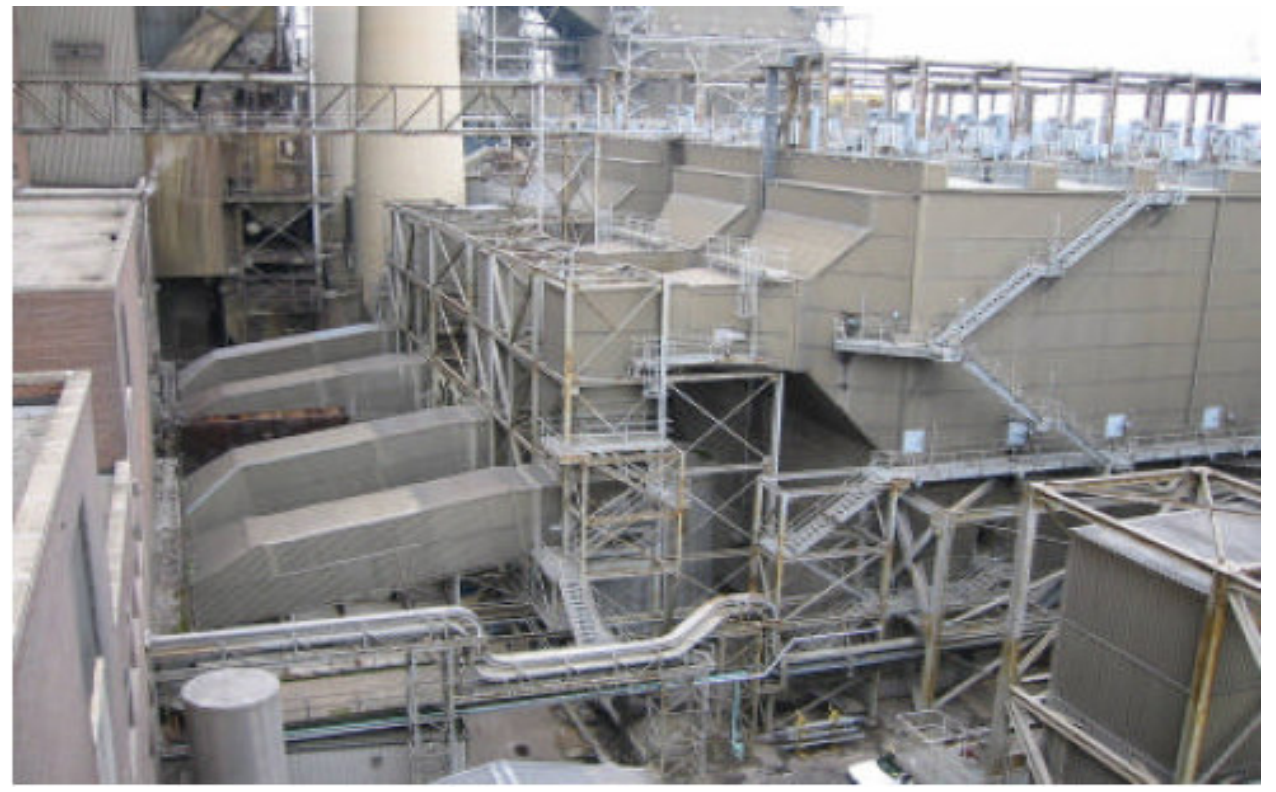


In Photograph 1, the flue gas exits the building on the left after having already passed through the air preheaters. The two gas streams are conveyed over, up and into separate EPS. The mercury sorbent injection trials were conducted on the ESP 1A gas stream thus making the effective capacity treated $80 \mathrm{MW}$.

The ESPs are large by design to handle wide variations in coal selection. Each ESP has a design SCA of $700 \mathrm{ft}^{2} / \mathrm{Kacfm}$, when all fields are operable. ESP $1 \mathrm{~A}$ had fields 1 and 3 down during the mercury testing program, reducing the effective SCA to a still relatively large $467 \mathrm{ft}^{2} / \mathrm{Kacfm}$. The ESP operates at approximately $300^{\circ} \mathrm{F}$ while collecting about 3.5 tons of fly ash per hour. Some of the fly ash is sold for flowable fill applications while the rest is used as landfill.

\section{Duke Power Cliffside Station}

Boiler 2 at the Duke Power Cliffside Plant was selected for the hot-side ESP qualification test. Only short-term parametric mercury sorbent testing was performed at this location. However, the results determined whether the long-term test would be performed at the Duke Power Buck Station, equipped with a hot-side ESP, or the Duke Power Allen Station, equipped with a cold-side ESP. The former was chosen for the full-scale tests since the testing at the Cliffside Station proved that mercury sorbents had the potential to control the mercury emissions in hot-side ESPs.

Cliffside 2 has a capacity of $40 \mathrm{MW}$. The boiler is tangentially fired and uses low-sulfur Eastern bituminous coal. The coal contains approximately $0.08 \mathrm{ppm}$ of mercury and 500 ppm of chlorine. The typical mercury content of the flue gas is $5-10 \mu \mathrm{g} / \mathrm{Nm}^{3}$ of which most is in the oxidized form. The hot-side ESP is very small with an SCA of only 240 $\mathrm{ft}^{2} /$ Kacfm from two fields. The plant is shown in Photograph 2.

\section{Photograph 2. Duke Power Cliffside Station}

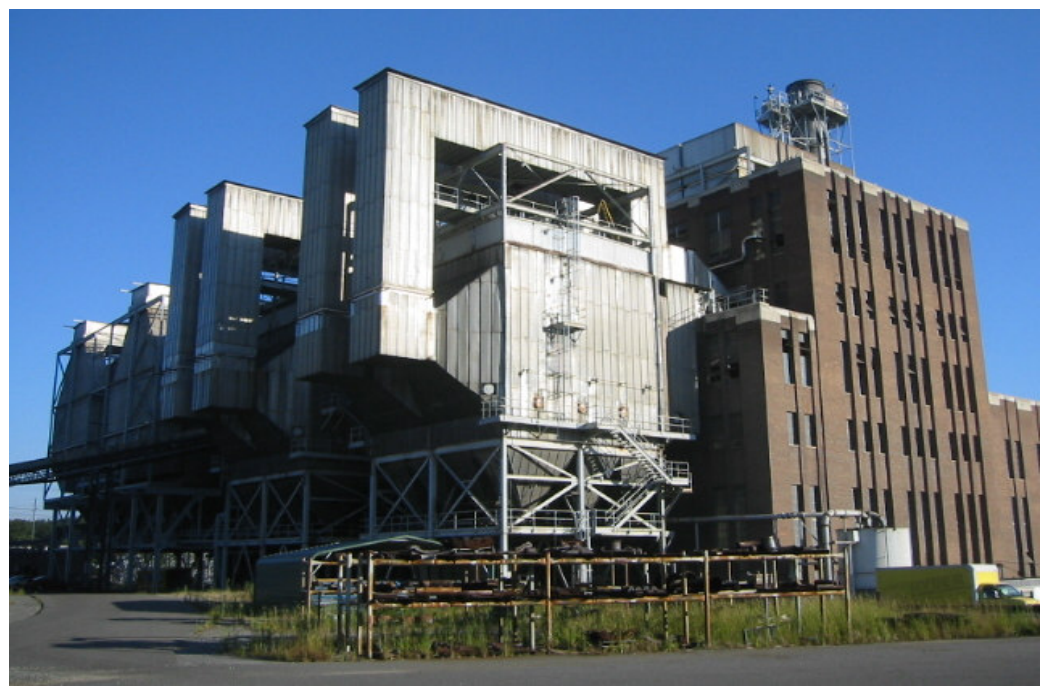


Boiler 2 is the second one from the rear. Boiler 2 is a peaking boiler which normally only operates at full load during the daylight hours on weekdays during high electric usage months and usually not at all on weekends. It was constructed in 1939 and refurbished in the 1980s.

\section{Duke Power Buck Station}

The full-scale mercury sorbent injection field-test was carried out at Duke Power's Buck Station Unit 6. This unit has a gross capacity of $142 \mathrm{MW}$. The Buck Plant is located in Salisbury, N.C. and is shown in Photograph 6. Unit 6 is on the left of photograph.

\section{Photograph 3. Duke Power Buck Station}

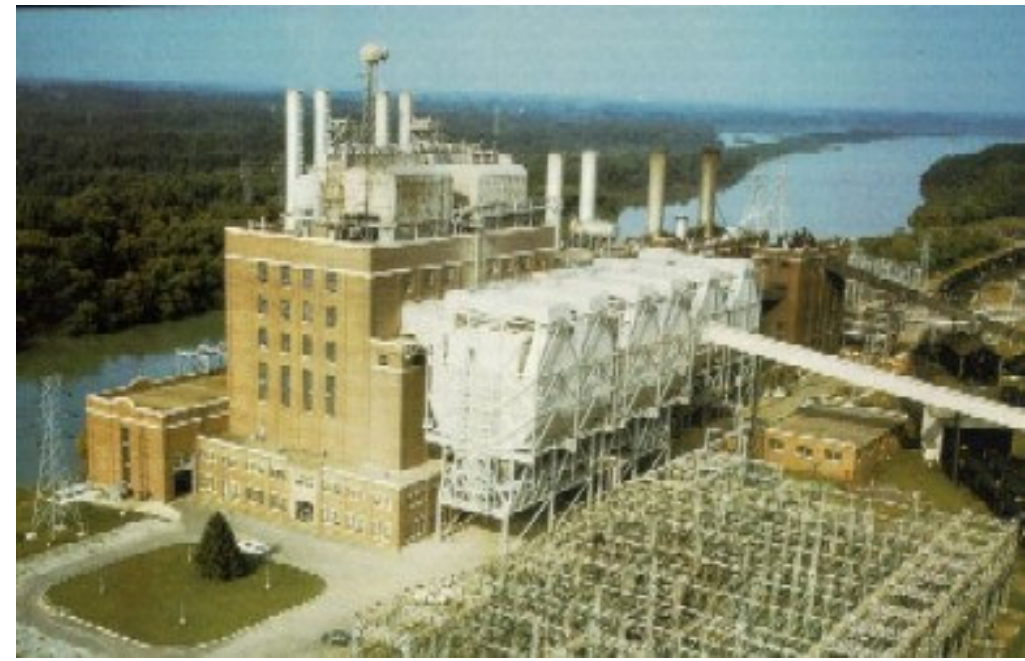

This boiler was built in 1952 by Combustion Engineering. The boiler is tangentially fired and burns a low-sulfur, Eastern bituminous coal. The coal typically contains about 0.08 ppm of mercury, but this can vary by plus or minus $50 \%$. The average chlorine content of the coal is about $1000 \mathrm{ppm}$. The boiler was retrofitted with two small parallel hot-side ESPs to collect the fly ash. Each ESP has an SCA of $240 \mathrm{ft}^{2} / \mathrm{K}$ acfm. The fly ash collected in these ESPs typically contains more than 5\% LOI and is not sold.

\section{QUALIFICATION TESTING EQUIPMENT}

Albemarle Environmental, $\mathrm{f} / \mathrm{k} / \mathrm{a}$ Sorbent Technologies Corporation already has a pilotscale duct-injection pilot plant system for evaluating sorbents in cold-side ESP applications. An EPRI portable test facility sited at a utility boiler burning subbituminous coal was also used to gather data for the cold-side ESP application. Each of these systems is described below.

\section{Pilot-Scale Duct-Injection Testing}

Albemarle Environmental, f/k/a Sorbent Technologies Corporation's duct-injection system tests mercury sorbents in the actual in-flight mode. The installed components included a: 
- Humidifier/cooler;

- Insulated pipe "ducting" to provide sorbent residence time and wall contact area;

- Sorbent feeding system to accurately feed at very low rates without agglomeration; and

- Cold-Side ESP (without rapping) to remove any sorbent from the sample stream.

A diagram of the duct-injection system is presented in Figure 1. The system is also shown in Photographs 4 and 5.

Figure 1. Diagram of the Duct-Injection System

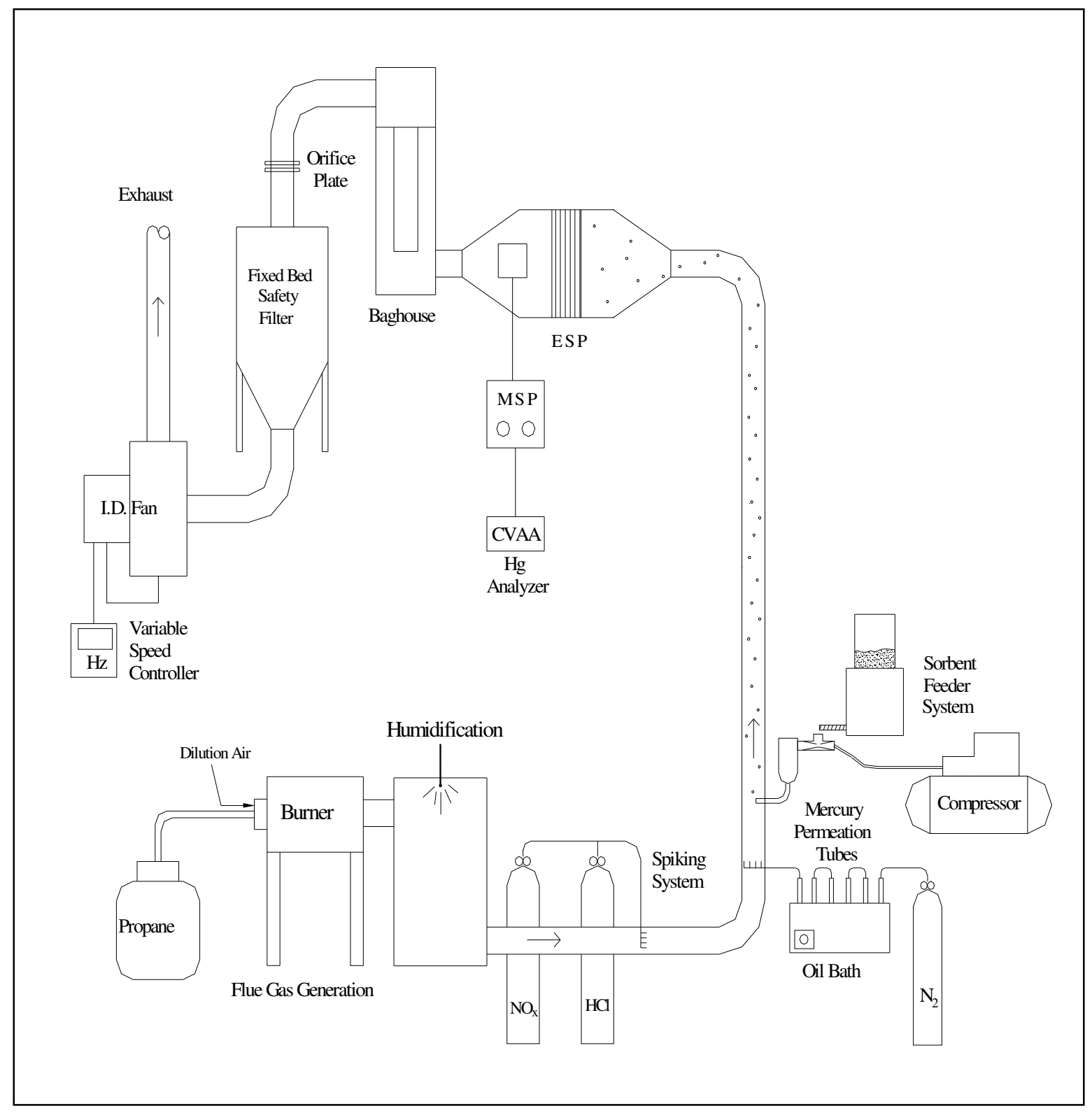


The following operating parameters are typically utilized in the duct-injection system:

- Flow Rate:

- Sorbent residence time:

- $\mathrm{Hg}$ concentration:

- $\mathrm{SO}_{2}$ concentration:

- $\mathrm{NO}_{x}$ concentration:

- $\mathrm{HCl}$ concentration:

- $\mathrm{H}_{2} \mathrm{O}$ concentration:

- Temperature at injection point:

- Temperature at outlet sampling point:
55 to $60 \mathrm{acfm}$

$2-2.5$ seconds

$22-26 \mu \mathrm{g} / \mathrm{Nm}^{3}$

variable up to $1400 \mathrm{ppmv}$ variable up to $600 \mathrm{ppmv}$ variable up to $50 \mathrm{ppmv}$

$4 \mathrm{wt} \%, 6.5 \mathrm{vol} \%$ $330 \pm 10^{\circ} \mathrm{F}$ $270 \pm 10^{\circ} \mathrm{F}$

The duct-injection system provides a simulated flue gas comparable to that from a coal fired boiler, with the exception of fly ash. An Ohio Lumex Zeeman-corrected mercury analyzer has been adapted by its manufacturer for use in monitoring the gas-phase mercury concentrations in the system.

Photograph 4. View of the Duct-Injection System

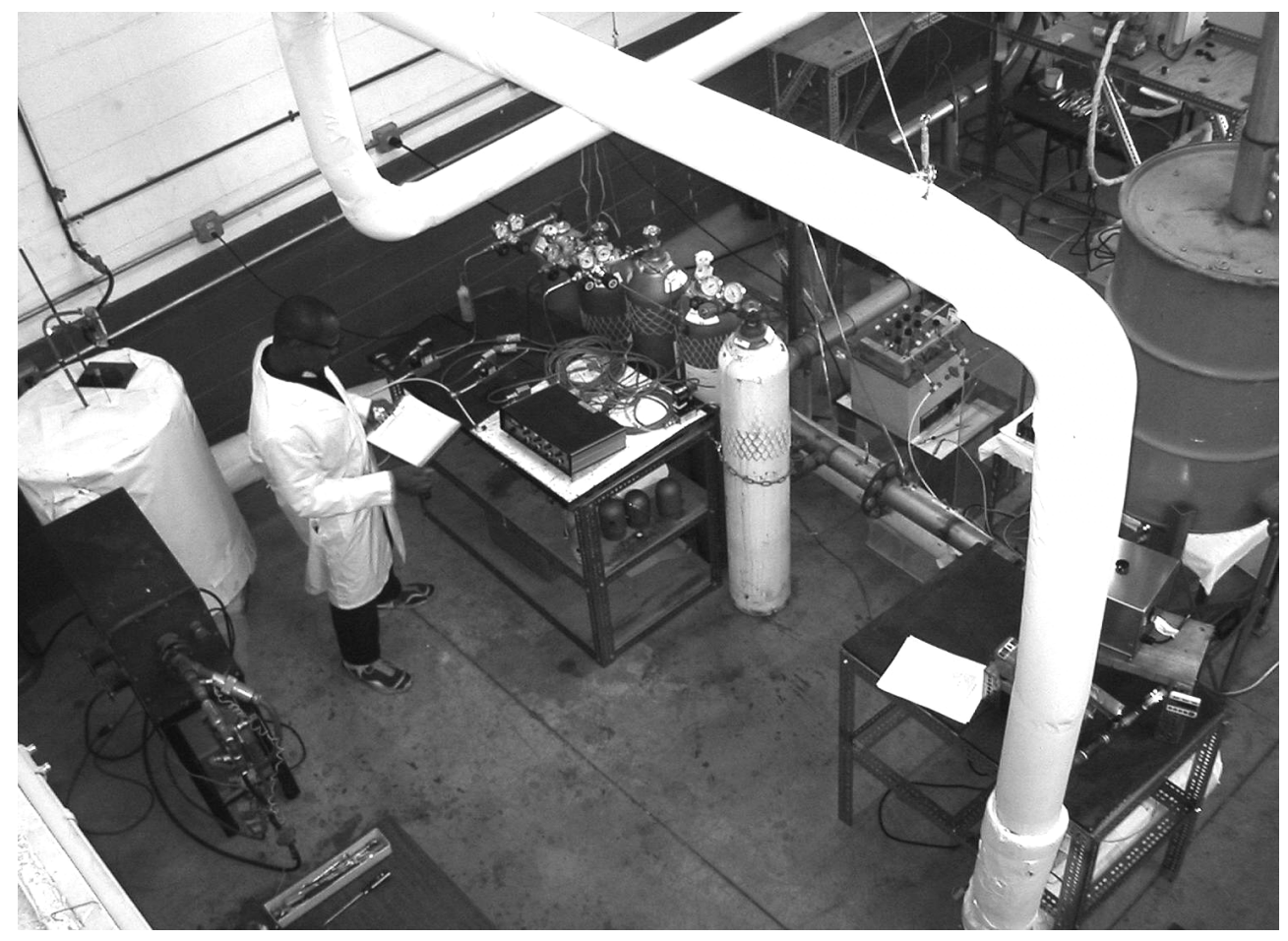




\section{Photograph 5. Analytical Portion of the Duct-Injection System}

(ESP Top Right)

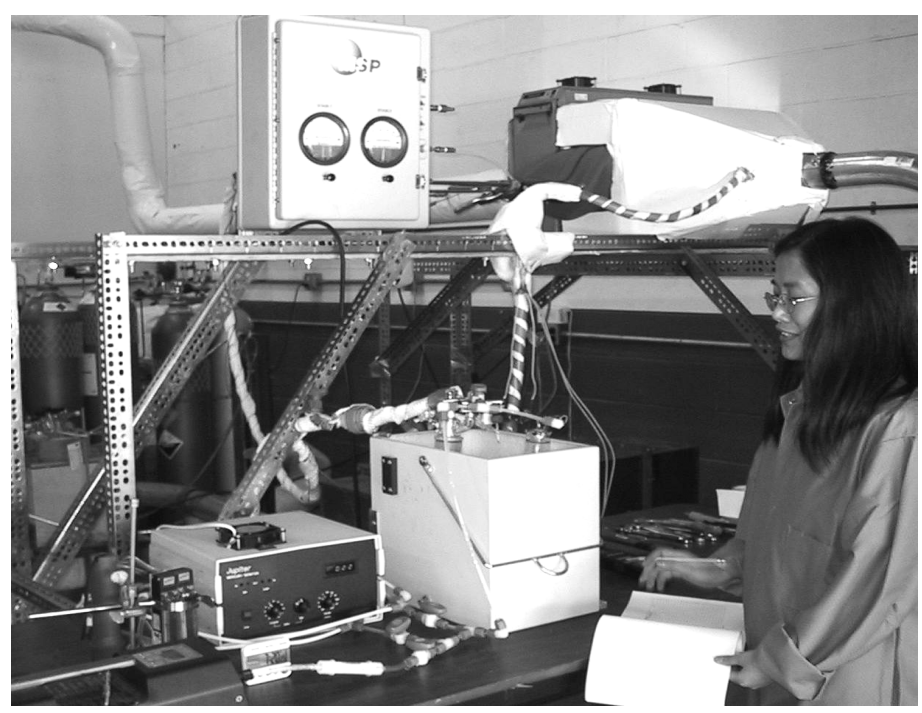

Norit Darco FGD PAC (now Norit Darco Hg) was tested in the duct-injection system to provide a yardstick for mercury removal comparisons with system to performance to that observed in full-scale field tests. The mercury removal results for the Norit Darco FGD PAC in the duct-injection system are presented in Figure 2.

Figure 2. Pilot Duct-Injection System Hg Removal Results Plotted with the Results from Brayton Point and Pleasant Prairie

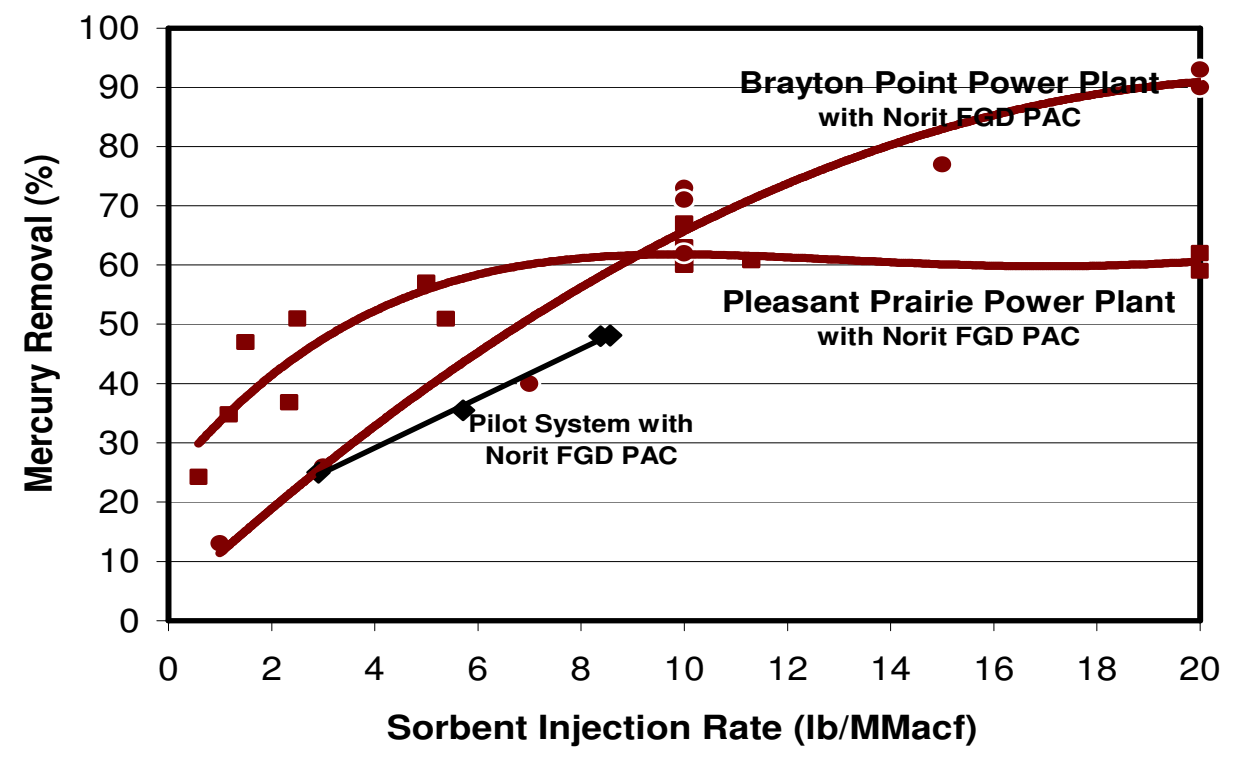


The mercury removal results using the same plain PAC sorbent that was used in the earlier Brayton Point and Pleasant Prairie full-scale tests are presented in Figure 2 for comparison purposes. The mercury removal results from the duct-injection system are slightly below those achieved in the two full-scale tests. It is believed that the difference is due, in large part, to the added mercury removal that comes from the build-up of sorbent deposits as full-scale tests continue. These deposits have been found to provide as much as $10 \%$ extra mercury removal. The Albemarle Environmental, $\mathrm{f} / \mathrm{k} / \mathrm{a}$ Sorbent Technologies duct-injection system is not operated long enough to allow for the build-up of deposits and any sorbent remaining after a run is either removed or saturated with mercury so that it will not have any impact on the next test. Still, the ductinjection system does provide results comparable to full-scale tests. In this program, the duct-injection system was used in a series of sorbent qualification tests to identify the sorbents for the full-scale trials. It also was used to confirm the quality of sorbents prepared in the sorbent preparation system.

\section{Slipstream Qualification Testing with EPRl's PoCT System}

The "Pollution Control Test" (PoCT) system is owned by the Electric Power Research Institute and operated by Apogee Scientific, Inc. It was temporarily installed at the We Energies' Pleasant Prairie Plant, where the first DOE full-scale duct-injection trials were held. In the PoCT slipstream tests, the plant flue gas was drawn off after the ESP, so the gas did not contain fly ash, but the tests could confirm the more extensive tests on Sorbent Technologies pilot duct-injection system, which only used a simulated subbituminous flue gas. A diagram of the system is presented in Figure 3.

\section{Figure 3. The EPRI/Apogee PoCT System Used at We Energies' Pleasant Prairie Power Plant}

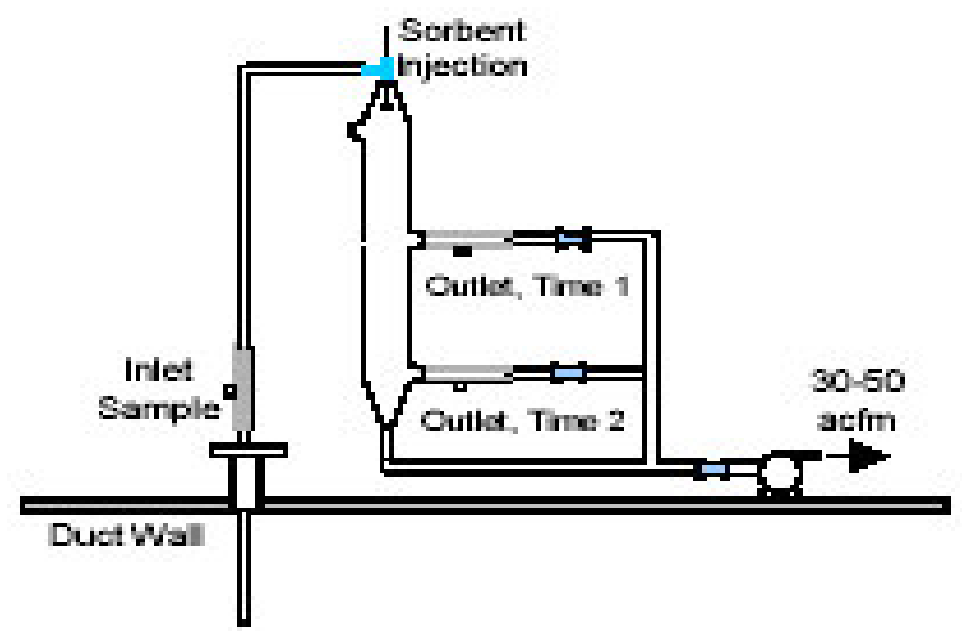

The in-flight module system is very simple in design. Flue gas is drawn from a duct after it has passed through the plant cold-side ESP. The flow rate of the flue gas through the pilot system is between 30-50 acfm. Sorbent is injected at the entrance to an open 
chamber. For these tests, the injection temperature was always about $300^{\circ} \mathrm{F}$. The mercury concentration in the flue gas is measured at three locations. The first is the inlet to the simulated duct before the sorbent injection location, the second and third locations are situated downstream at intervals, in this case, corresponding to in-flight residence times of 1.6 or 3.6 seconds. A mercury cold vapor atomic absorption spectrometer is used for all of the mercury measurements.

\section{SORBENT INJECTION SYSTEM}

The functions of the sorbent injection system are:

1. To provide for sorbent loading to a day storage hopper from either super sacks or pneumatic trucks.

2. To deliver the sorbent from the day storage hopper to a feeder system hopper.

3. To gravimetrically feed sorbent at selected rates into an eductor injection system.

4. To provide dilute phase conveying of the sorbent through the sorbent distributor and to the injection lances.

The operating principals behind the sorbent injection system are the same as have been used in most other full-scale mercury sorbent injection trials. These injection systems are based upon dilute phase injection, as is this one. The only significant change is that, for the sake of feeding accuracy, gravimetric control is used instead of volumetric control. The bulk density of PAC based sorbents varies greatly causing the injection rate to vary in volumetrically controlled systems. The gravimetric design of this injection system overcomes this issue. The layout of the Albemarle Environmental, $f / k / a$ Sorbent Technologies sorbent injection system is shown in Figure 4.

Figure 4. Diagram of the Sorbent Injection System

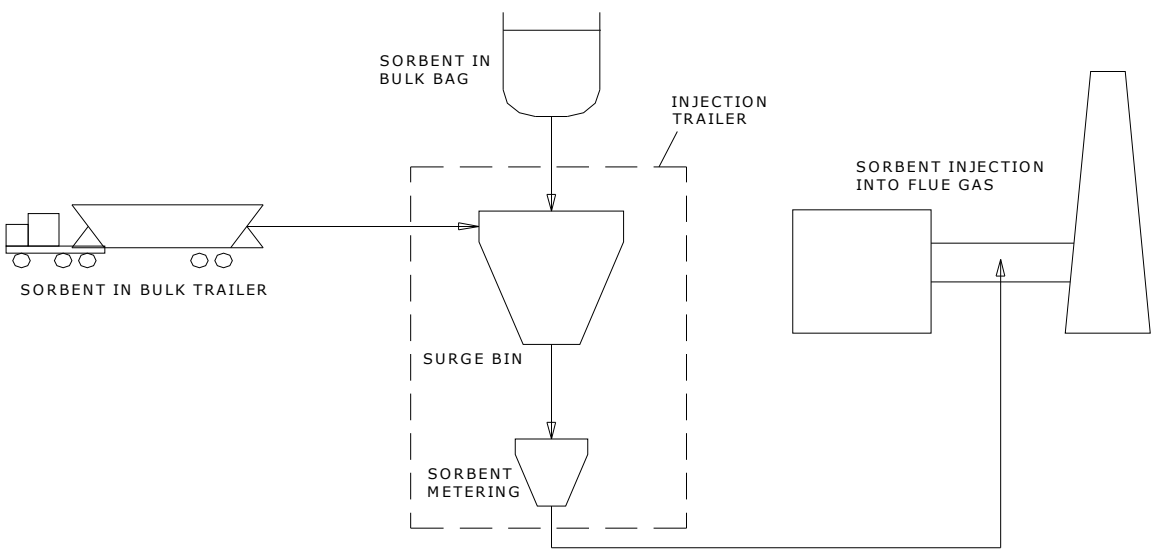


The day storage hopper, feeder hopper, gravimetric feeder and eductor are all enclosed in a trailer. A bin vent filter is provided to capture any dust generated by material handling. This filter is located on top of the day hopper. Blowers are used to provide the air flow necessary to convey the sorbent from a tanker to the day storage hopper and to convey the sorbent from the feeder to the injection lances. The first of these blowers is located outside of the trailer. All controls for the operation of the injection system are in an isolated area within the trailer. An inside view of the injection trailer is presented in Photograph 6.

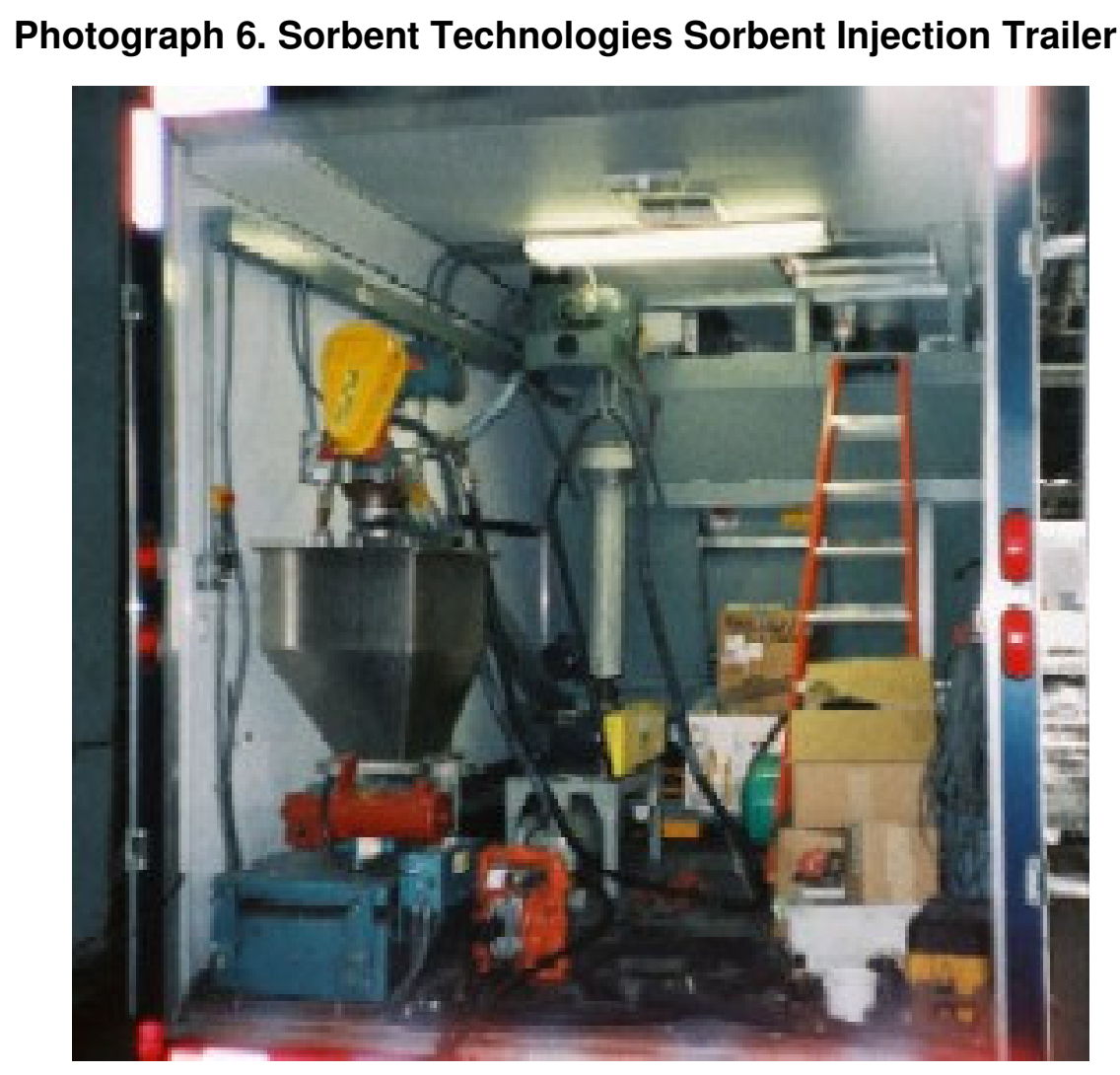

The injection system was designed with the ease of installation and disassembly in mind. Only electricity and injection ports are required from the host site to support its operation. Most of the key components are installed in a movable trailer. The injection system was designed to have a sorbent injection rate range from as low as $15 \mathrm{lb} / \mathrm{hr}$ to a high of over $600 \mathrm{lb} / \mathrm{hr}$. In this manner, the same injection system was used at the Detroit Edison St. Clair Plant and the Duke Power Cliffside and Buck Stations.

\section{MERCURY MONITORING INSTRUMENTS}

The mercury semi-continuous emission monitors (CEMs) were obtained from PS Analytical. The equipment includes two semi-continuous mercury emission monitors, two wet/dry mercury conversion modules and two inertial sampling probes. 


\section{Flue Gas Sampling}

A Baldwin Model 3300 inertial separator was used to provide a particulate free gas sample for the CEM mercury measurement. A diagram of the device is shown in Figure 5.

Figure 5. Diagram of Baldwin Inertial Separator

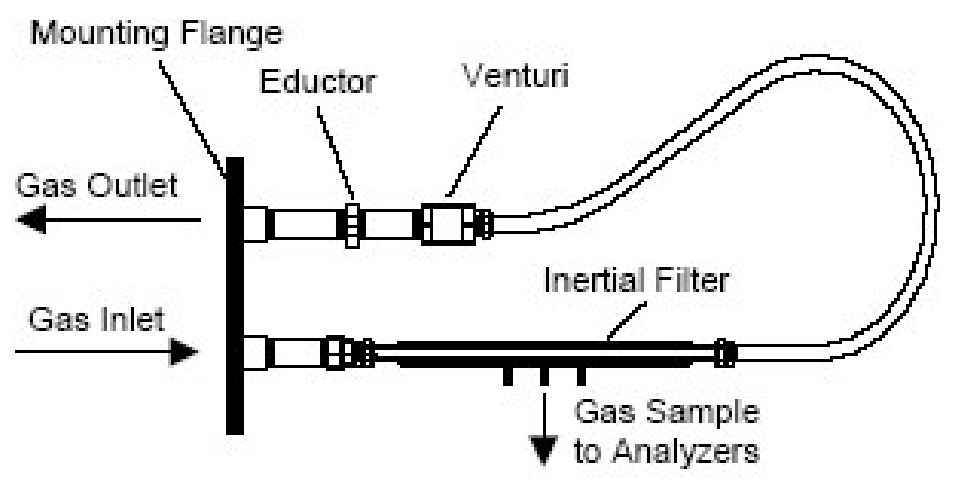

Flue gas is drawn into the system by means of an eductor. The flow rate is measured by a Venturi meter and adjusted to provide an axial gas flow through the inertial separator of 70 to 100 feet per second. A gas sample is extracted at a low inertial filter face velocity of 0.006 feet per second. The particulate matter follows the gas streamline and is thus separated from the gas sample. The gas removed from the duct is returned after use. The entire inertial separator is in an enclosure and maintained at $400^{\circ} \mathrm{F}$ to avoid any condensation issues.

The new inertial separators worked well in the testing at the Detroit Edison St. Clair Plant but had to be replaced with the conventional design QSIS probes for the testing at the Duke Power Stations. It is believed that the high percentage of oxidized mercury in the flue gas of the Duke Power Station was the cause of the problem.

\section{Mercury CEMs}

The latest version of the PS Analytical mercury monitoring equipment was used for this test program. The sample gas was conveyed through a heated line from the inertial separator to the conversion module where the oxidized mercury species were either converted to elemental mercury in order to provide a total gas phase mercury measurement or removed from the gas to allow for the measurement of elemental mercury. The PS Analytical mercury conversion modules, can operate in the traditional wet chemistry method, as well as by a new, parallel dry method. The dry system uses a thermolytic converter to convert the oxidized mercury to elemental. A diagram of the process is shown in Figure 6. 
Figure 6. Diagram of the PS Analytical Dry Conversion Process

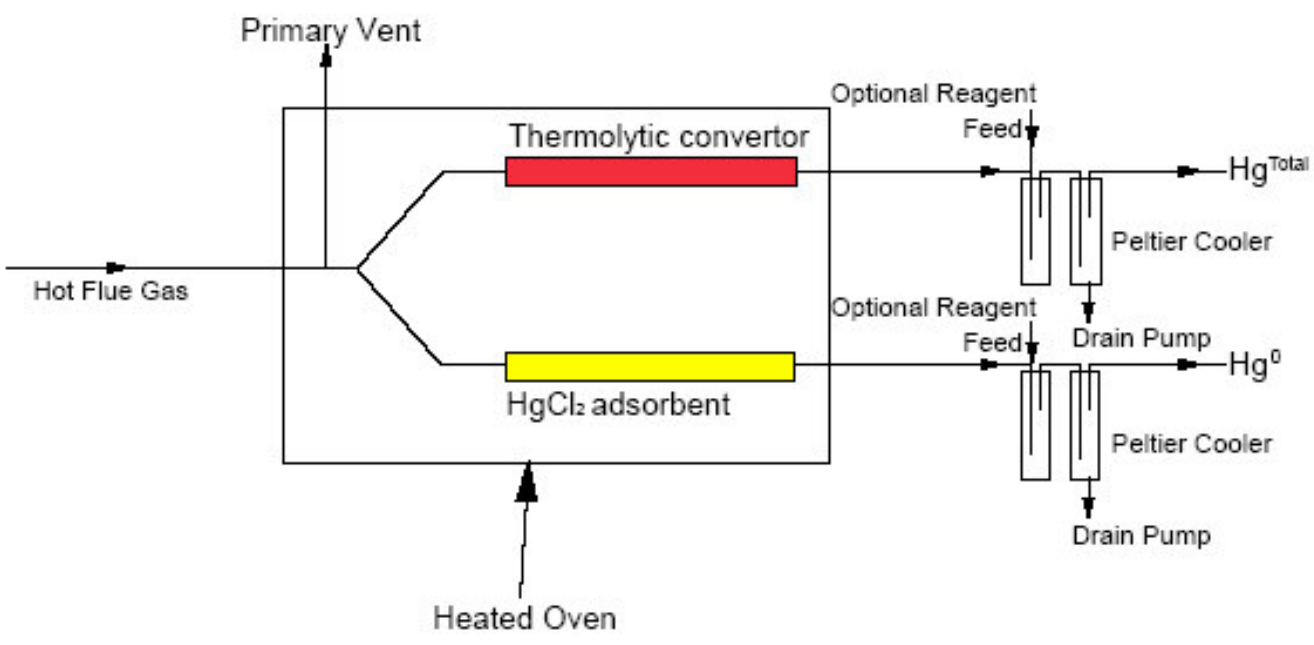

The conversion modules could be operated in the wet mode, the dry mode or alternating back and forth. The wet/dry mercury conversion modules used in this project were Serial Numbers 001 and 002 . One of the wet/ dry conversion modules is shown in Photograph 7.

\section{Photograph 7. PS Analytical Wet/Dry Mercury Conversion Module}

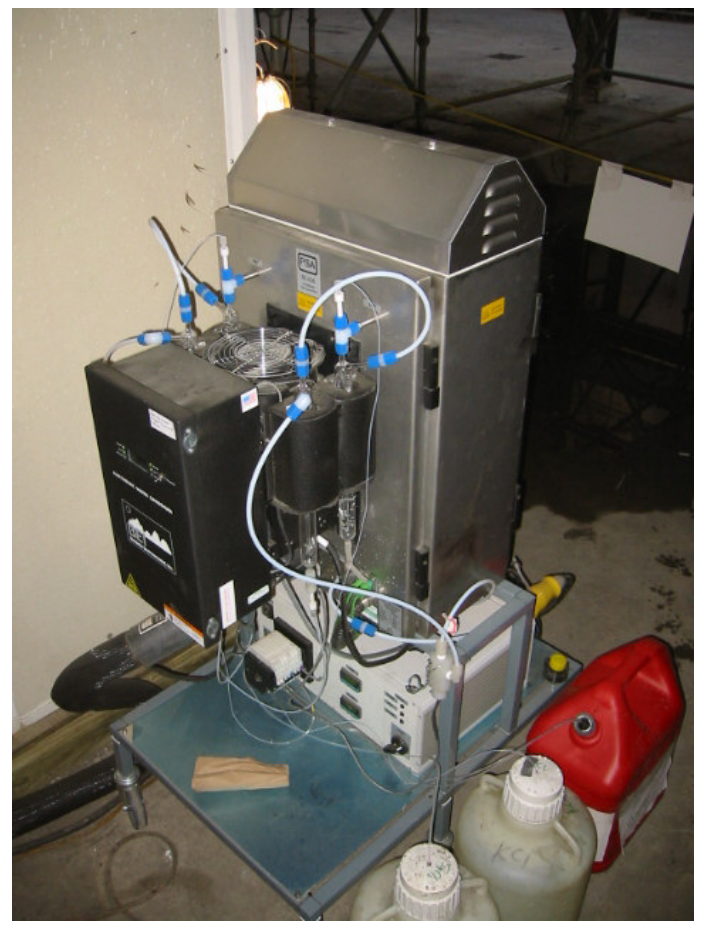


The dry conversion process is being developed to eliminate two of the main problems associated with mercury CEMs; wet chemicals and their wastes.

The gas from the mercury conversion module was directed to a PS Analytical Sir Galahad II EX mercury analyzer. The gas sample is drawn across a gold trap in which the mercury is collected. After a prescribed sampling time, the trap is heated in order to release the mercury which is measured by atomic fluorescence. The system is calibrated at least once per day using mercury standards. The analyzer provides one mercury measurement every five minutes, thus it is a semi-continuous emission monitor. If both elemental and oxidized mercury are being analyzed, repeat measurements are ten minutes apart.

Two mercury CEMs were acquired for these tests. Each analyzer was placed inside in order to provide climate control. The analyzer building at the outlet of Detroit Edison St. Clair Unit 1 ESP 1A system is shown in Photograph 8.

Photograph 8. Outlet Mercury CEM Building at the St. Clair Plant

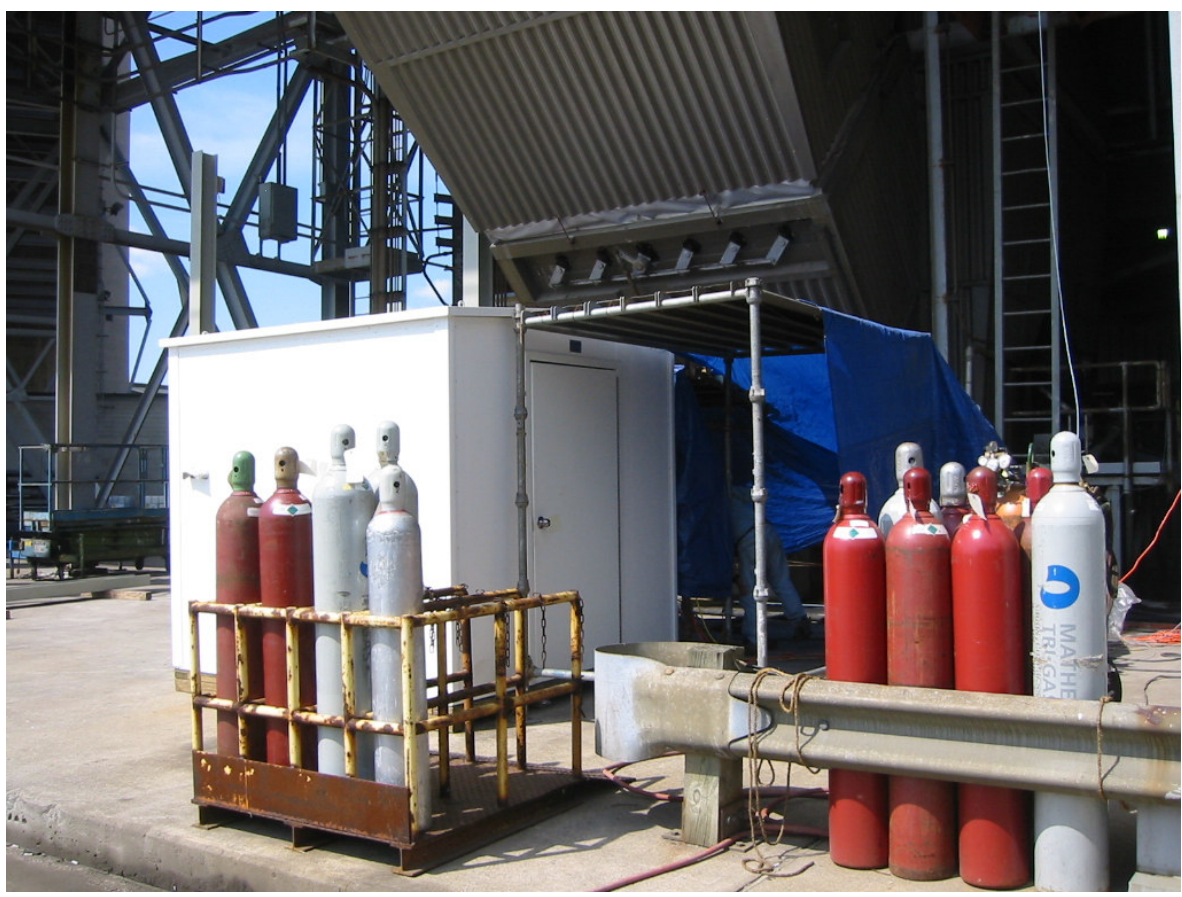

Western Kentucky University, a project partner, provided all of the personnel to operate the mercury CEMs. The mercury data collected was all corrected to $3 \%$ oxygen before submittal to Sorbent Technologies.

\section{Coal and Fly Ash Mercury Analyses}

Coal and fly ash samples were taken throughout the baseline, parametric, and long-term testing at the power plants. The coal samples were analyzed for mercury in the utility laboratories using microwave acid digestion followed by ICP-MS analysis. 
The fly ash samples were analyzed for mercury by using an Ohio Lumex Model RA-915+ Mercury Analyzer (Photograph 9).

Photograph 9. Ohio Lumex Model RA-915+ Mercury Analyzer

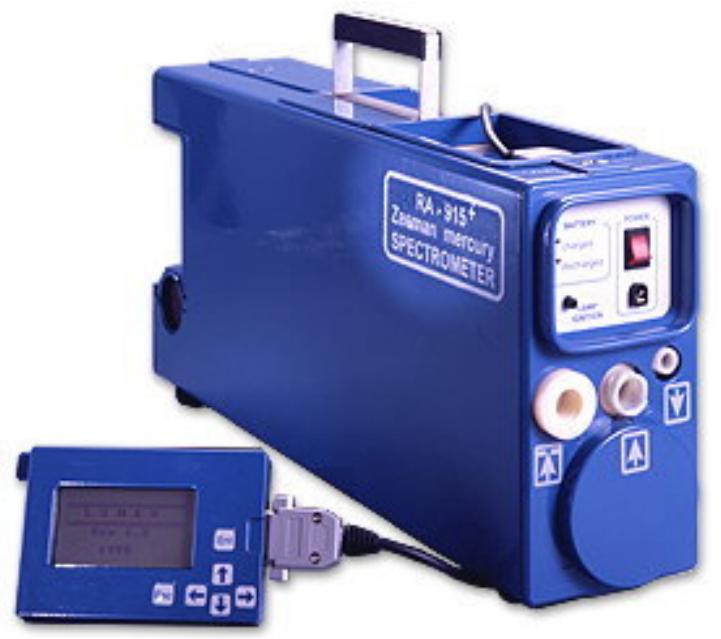

The Ohio Lumex mercury analyzer is an atomic absorption spectrometer with Zeeman background correction. The Zeeman background correction eliminates the need for gold traps to concentrate the mercury. The instrument is calibrated with NIST standards and has a detection limit of $500 \mathrm{ng} / \mathrm{Kg}$.

\section{OHM Testing}

The Ontario Hydro Method (OHM) mercury testing was contracted to METCO Environmental for the testing at the Detroit Edison St. Clair Plant and to O'Brien \& Gere for the testing at the Duke Power Buck Station. These companies provided the lowest bid in response to a Request for Proposal covering this testing. The sampling followed the procedures set forth in the Code of Federal Regulations, Title 40, Chapter I, Part 60, Appendix A, Methods 1, 2, 3B, 4 and 5, and the Ontario Hydro Method, revised July 7, 1999. Simultaneous triplicate two- hour tests were performed at the gas "inlet" (before the sorbent Injection) and "outlet" locations at the St. Clair Power Plant Unit 1 ESP 1A. Simultaneous triplicate testing was not possible at the Buck Station. At Buck, most of the testing was performed in one the two twin ESP stacks: one carrying the treated flue gas and the other the untreated flue gas.

Method 26A tests for halogens in the flue gas were also performed on the flue gas from St. Clair Plant and Buck Station.

\section{Method 324 Testing}

Detroit Edison leased a Method 324 instrument from EPRI Solutions for testing throughout their plants. This instrument was only available the last few days of the longterm test at the St. Clair Plant. The instrument is used at the St. Clair Plant is shown in Photograph 10. 
Photograph 10. Method 324 Instrument

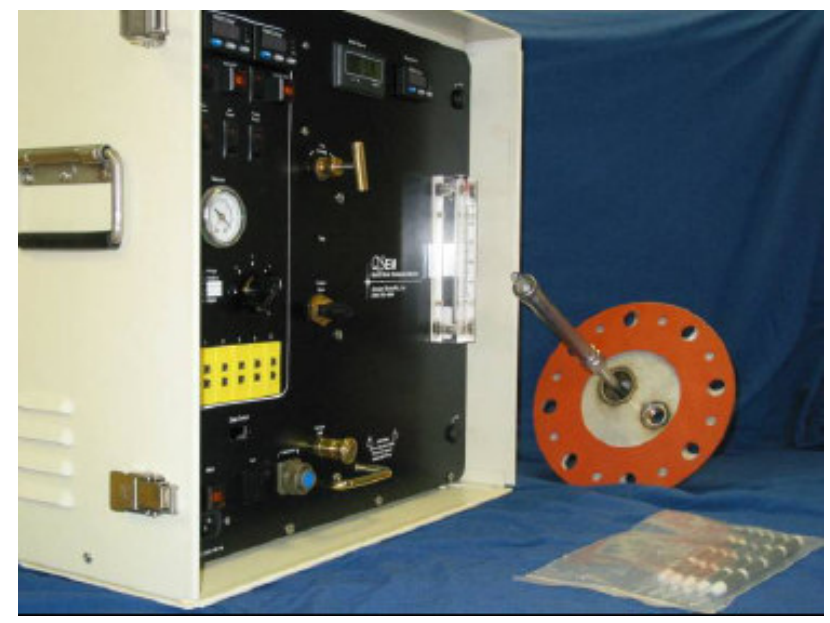

The instrument pulls a measured amount of flue gas, proportional to the flue gas flow rate, through a mercury trap for a specified period of time. The trap is sent for mercury analysis and the result translated into a mercury concentration by dividing by the amount of gas sampled. The sampling procedure is defined the United States EPS in Title 40, CFR Part 60, Appendix A.

Sorbent Technologies acquired their own Method 324 sampling device midway through the testing at the Buck Station. It operated in the same manner as the device pictured above.

\section{SORBENT PRODUCTION SYSTEM}

Albemarle Environmental, $\mathrm{f} / \mathrm{k} / \mathrm{a}$ Sorbent Technologies manufacturers all of its sorbents in its facility located in Twinsburg, Ohio. The sorbent production system is in the same building complex as are the main Sorbent Technologies offices and laboratories. A general diagram of the sorbent preparation system is shown in Figure 7.

Figure 7. Diagram of the Sorbent Production System

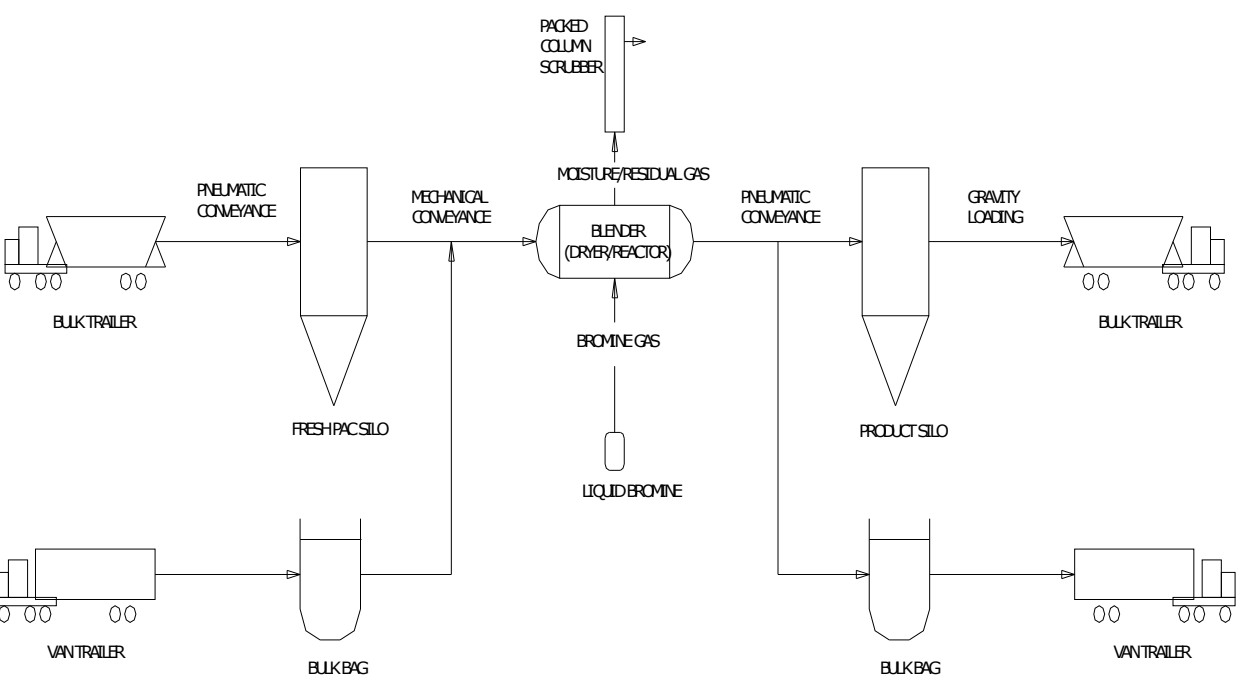


The sorbent production system was developed by Albemarle Environmental, $\mathrm{f} / \mathrm{k} / \mathrm{a}$ Sorbent Technologies through over seven years of experimentation prior to the DOE demonstration project. The detailed operation of the system is proprietary and is covered by a patent ${ }^{(1)}$, however, the concept is fairly simple. Albemarle Environmental, $\mathrm{f} / \mathrm{k} / \mathrm{a}$ Sorbent Technologies' sorbents (trademarked B-PAC ${ }^{\mathrm{TM}}$ ) are powdered activated carbons (PACs) which have been processed through a bromine treatment to greatly enhance their mercury performance and cost-effectiveness.

The substrate PAC can be received by either super sack or bulk tanker and the processed B-PAC ${ }^{\mathrm{TM}}$ can be shipped to the power plant in either super sacks or by bulk tanker. This dual material handling capability is necessary to facilitate the smaller quantities of several sorbents that are required during the parametric variation testing portions of the program and the larger quantities that are required of a single sorbent during the long-term tests.

The PAC from either the fresh storage silo or a super sack is conveyed mechanically to the bromination reactor. The plain PAC is reacted with bromine in this device. The finished sorbent is conveyed pneumatically either to a finished-product silo before loading into a bulk tanker or into super sacks and into a van trailer for shipment to the test sites.

The capacity of this plant can easily be increased when demand warrants. A truckload of PAC is shown being unloaded into the raw material silo in Photograph 11. The elevated product silo used for filling tanker trucks is in the background.

\section{Photograph 11. PAC being Unloaded at the Sorbent Production Facility}

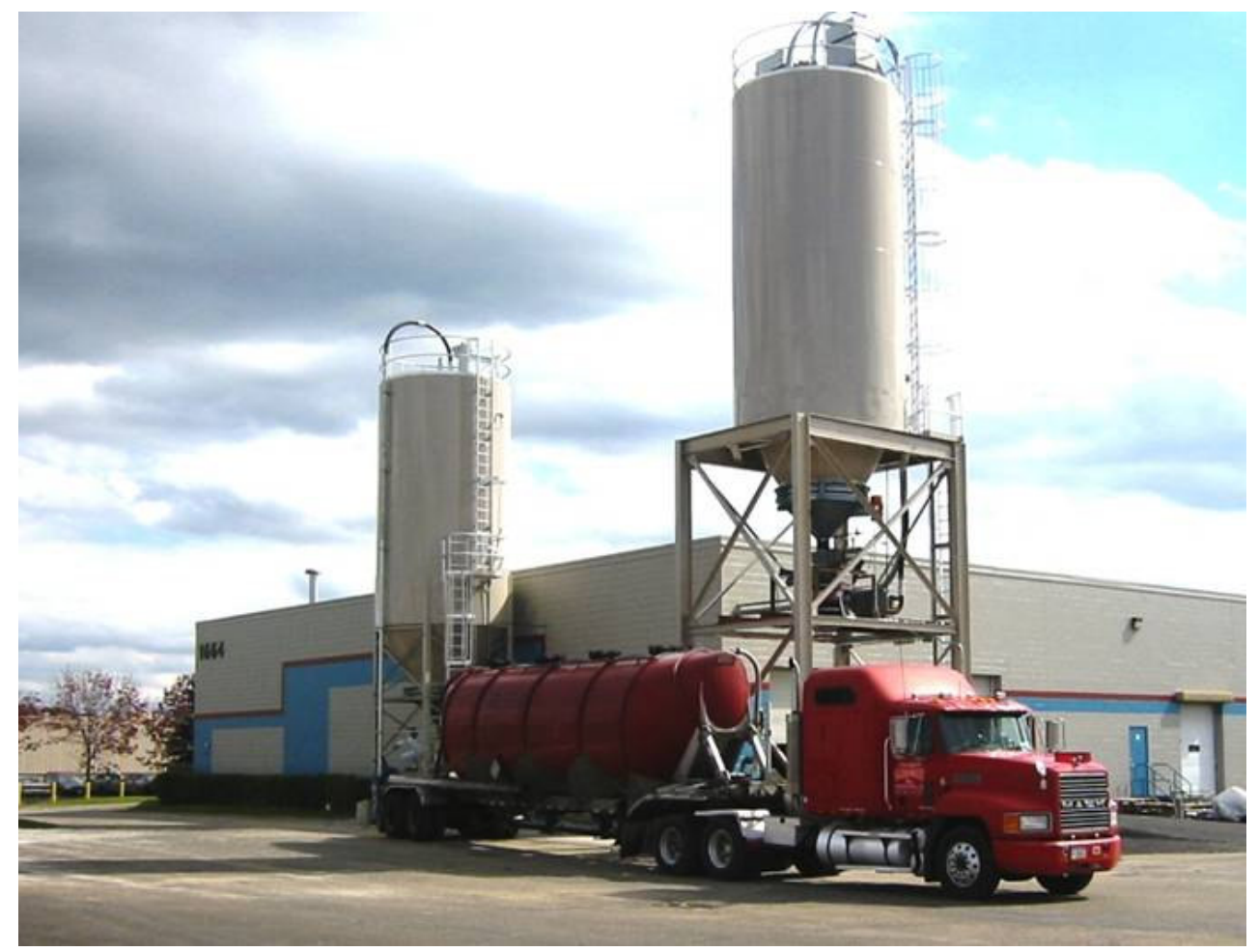




\section{RESULTS AND DISCUSSION}

\section{Qualification Testing}

The Albemarle Environmental, f/k/a Sorbent Technologies' B-PAC brominated mercury sorbents are powdered activated carbons that have been brominated. The sorbent results below for the laboratory pilot system are for types $A 1, A 3, A 5$, and $A 15$, with the various designations indicating different combinations of base carbon, degrees of bromination, or manufacturing variations. Plain Norit Darco FGD PAC (now Norit Darco $\mathrm{Hg}$ ) is referred to here as Type A0. The duct-injection mercury removal results for the Type $\mathrm{A} 0$ and $\mathrm{A} 1$ sorbents are indicated in Figure 8.

Figure 8. Duct-Injection System Tests with Sorbents A0 and A1

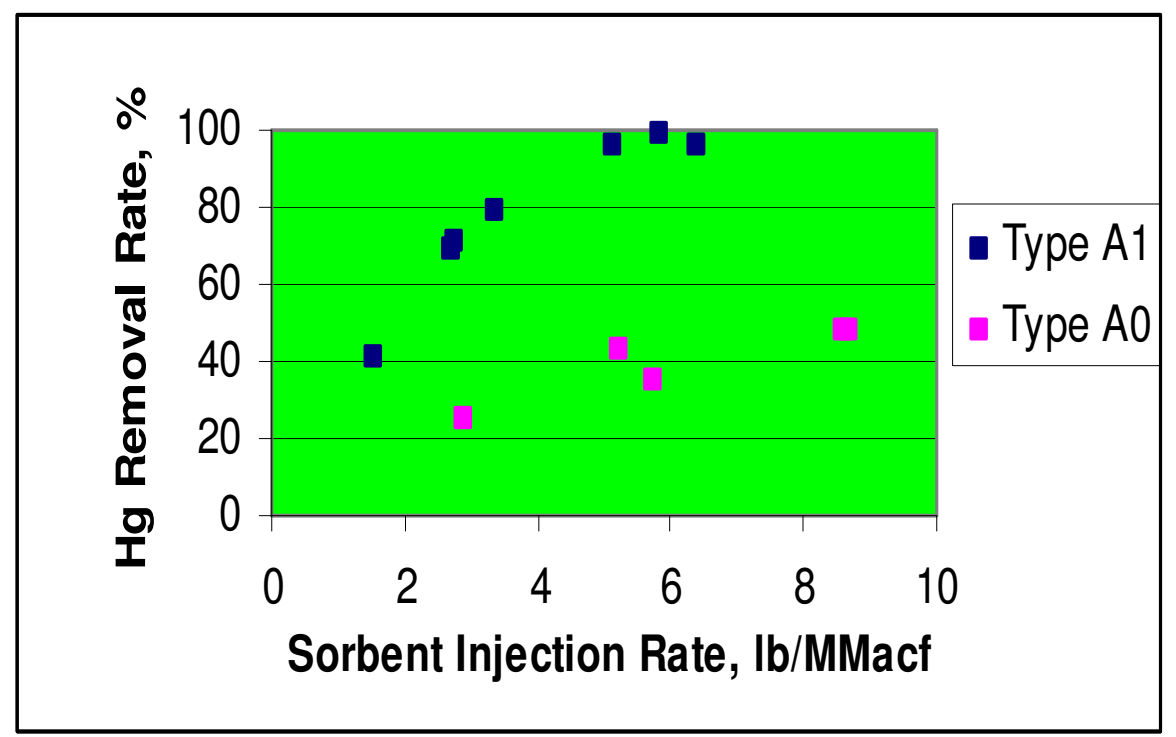

In the duct-injection pilot system, the Type A1 sorbent significantly outperformed the A0 sorbent, achieving about $70 \% \mathrm{Hg}$ removal versus $25 \% \mathrm{Hg}$ removal at an injection rate of $3 \mathrm{lb} / \mathrm{MMacf}$. The Type A1 sorbent achieved $80 \%$ mercury removal at an injection rate of $3.4 \mathrm{lb} / \mathrm{MMacf}$ and $94 \% \mathrm{Hg}$ removal at an injection rate of $5.8 \mathrm{lb} / \mathrm{MMacf}$. The A0 sorbent never achieved even $50 \% \mathrm{Hg}$ removal at an injection rate near $9 \mathrm{lb} / \mathrm{MMacf}$.

There are two points together at about $70 \% \mathrm{Hg}$ removal and an injection rate of 3 $\mathrm{lb} /$ MMacf. These are duplicate runs performed three months apart, indicting the reproducibility of the test method.

The pilot duct-injection results for all of the sorbents discussed in this section are presented in Figure 9. 
Figure 9. Duct-Injection System Tests

with Sorbents A0, A1, A3, A5, and A15

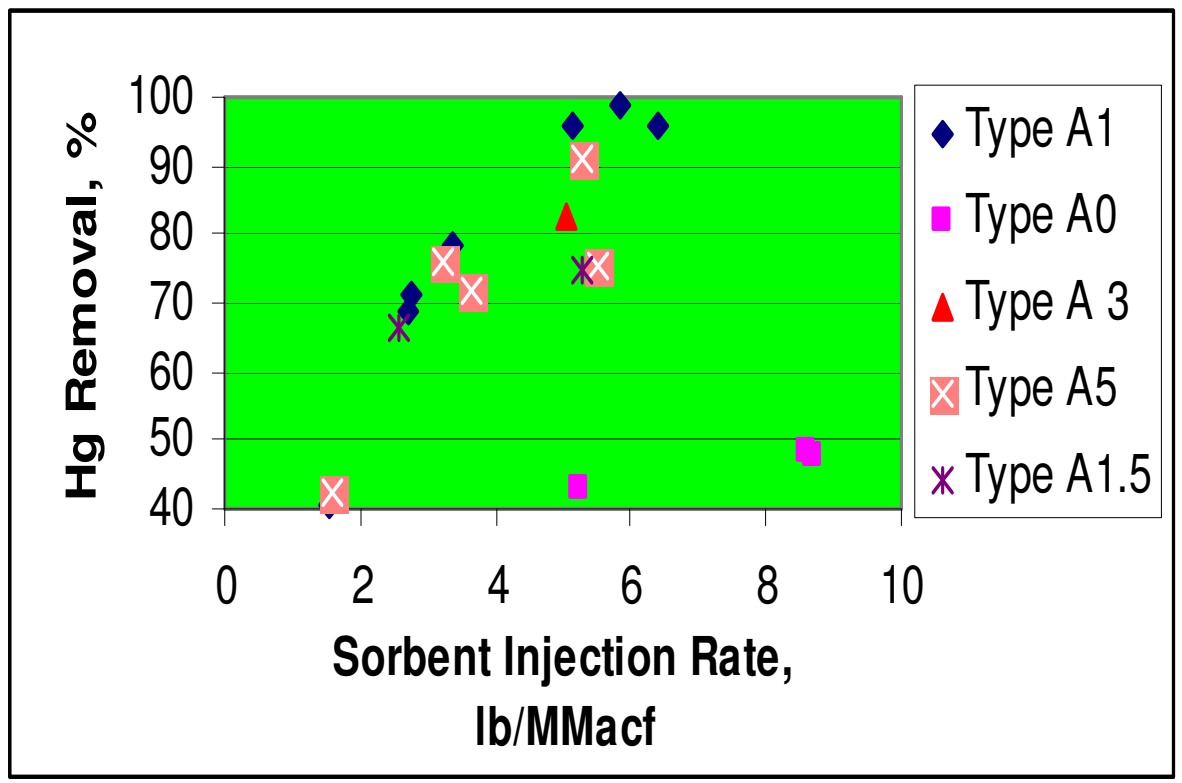

Not all of the various Type A sorbents provided the same degree of mercury removal. Some performed better than others. The search for the most cost-effective combination of production variables for brominated carbon sorbent will continue. The sorbents to be used at St. Clair will be the least expensive version of B-PAC likely to provide highest mercury removal rates. It is likely that different sorbent combinations will ultimately be called for in different power plant applications. Consequently, several B-PAC sorbents will be evaluated in the parametric portion of the trials at the Detroit Edison St. Clair Power Plant.

\section{Slipstream Qualification Testing with EPRI's PoCT System}

The opportunity arose to have a subcontractor, Apogee Scientific, test a number of B-PAC variations on a slipstream of actual subbituminous-coal flue gas at the We Energies Pleasant Prairie Plant, which hosted the first full-scale DOE activated carbon injection trials.

A total of nine sorbents were tested in the pilot tests at the We Energies' Pleasant Prairie Plant. Seven of the nine sorbents were manufactured by Albemarle Environmental, $\mathrm{f} / \mathrm{k} / \mathrm{a}$ Sorbent Technologies Corporation (STC) while the other two were commercial materials. The STC sorbents tested were denoted A -5B (currently the STC standard), A-6 (a firstgeneration concrete-friendly sorbent), $A-3 N$, variants of $A-5$ called $A-5 A$ and $A-5 B Z$, and a variant of A-6 (A-6F). One of the commercial materials was Norit Darco FGD (now Norit Darco $\mathrm{Hg}$ ), for a yardstick, and the other sorbent was an iodinated activated carbon from Calgon named CB, which is commercially available only in small quantities. The test results are presented in Figure 10. 
Figure 10. Mercury Removal Results from Pleasant Prairie Slipstream Tests

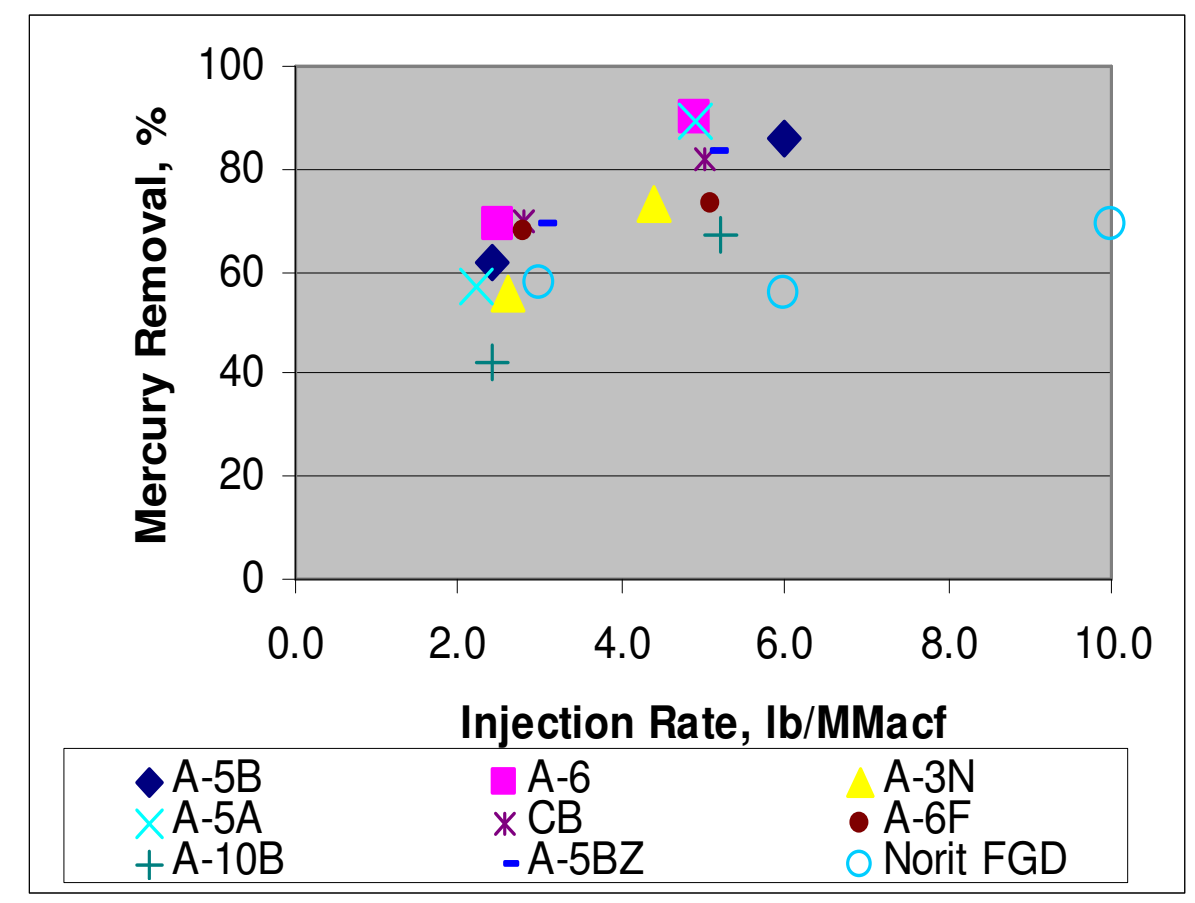

In the PoCT testing, all of the brominated sorbents performed better than Norit Darco $\mathrm{Hg}$. The A-6 "concrete-friendly" sorbent achieved $90 \%$ mercury removal in the 3.6 second residence time at an injection rate of $4.9 \mathrm{lb} / \mathrm{MMacf}$, while the A-5B sorbent achieved $86 \%$ mercury removal at an injection rate of $6.0 \mathrm{lb} / \mathrm{MMacf}$. The Norit Darco FGD sorbent could only achieve a mercury removal rate of $56 \%$ at an injection rate of $6.0 \mathrm{lb} / \mathrm{MMacf}$. Even at the high injection rate of $10 \mathrm{lb} / \mathrm{MMacf}$, this plain carbon could only capture $69 \%$ of the mercury. The iodinated Calgon CB PAC did better, but was still not as well as the A-6 or A-5B sorbents. The A-3N, A-5BZ, and A-10B sorbents did not perform quite as well as the $A-5 B$ or $A-6$ versions, but still did better than did the plain Norit Darco Hg PAC.

The numeric results from the testing at Pleasant Prairie are presented in Table 1. 


\section{Table 1. Results from Slipstream Tests at Pleasant Prairie}

\begin{tabular}{|c|c|c|}
\hline Sorbent & $\begin{array}{c}\frac{\text { Injection }}{\text { Rate, Ib/MMacf }} \\
\underline{\text { Ib }}\end{array}$ & $\frac{\text { Mercury Removal, }}{\underline{\%}}$ \\
\hline$A-1$ & 2.4 & 42 \\
\hline$A-1$ & 5.2 & 67 \\
\hline$A-3 N$ & 2.6 & 56 \\
\hline$A-3 N$ & 4.4 & 73 \\
\hline$A-5 A$ & 2.2 & 57 \\
\hline$A-5 A$ & 4.9 & 89 \\
\hline$A-5 B$ & 2.4 & 62 \\
\hline$A-5 B$ & 6.0 & 86 \\
\hline$A-5 B Z$ & 3.0 & 69 \\
\hline$A-5 B Z$ & 5.1 & 83 \\
\hline A-6 & 2.5 & 69 \\
\hline$A-6$ & 4.9 & 90 \\
\hline$A-6 F$ & 2.8 & 68 \\
\hline A-6F & 5.1 & 73 \\
\hline Calgon lodinated CB & 2.8 & 70 \\
\hline Calgon lodinated CB & 5.0 & 82 \\
\hline Norit Darco Hg & 3.0 & 58 \\
\hline Norit Darco Hg & 6.0 & 56 \\
\hline Norit Darco Hg & 10.0 & 69 \\
\hline
\end{tabular}




\section{Detroit Edison St. Clair Plant}

The testing at the Detroit Edison St. Clair Plant Unit 1 was divided into three sections: Baseline Measurements, Parametric Testing, and Long-Term Testing. Sorbent Technologies personnel, along with Western Kentucky University and PS Analytical personnel, all arrived at the St. Clair Plant starting on June 1, 2004. All of the instruments were new and had to be built and installed before the tests could begin. In addition, PS Analytical had to train Western Kentucky University and Sorbent Technologies personnel in the operation of these instruments. The baseline testing lasted until August 1, 2004.

The baseline testing was divided into three phases. During the first phase, the new mercury CEMs were set-up and the dry conversion system was tested for the first time. The instruments were all the latest version of the PS Analytical mercury monitors. The oxidized-Hg conversion systems could operate in either the conventional wet mode or the new dry mode. The second phase of the baseline testing consisted of side-byside testing of the new mercury CEMs using both the wet and dry mode of mercury conversion. The third phase consisted of operating the mercury CEMs 24-hours per day to collect baseline mercury data. During this latter phase, the first set of OHM tests and halogen tests were performed.

\section{CFD Modeling}

Fuel Tech is a partner in this DOE mercury project and they were charged with the computational fluid dynamic (CFD) modeling of the gas flows in the ductwork at the St. Clair Plant. The results were used to assist Sorbent Technologies in placing the injection lances in the optimum location to generate a uniform sorbent distribution within the ductwork. A uniform distribution of sorbent to flue gas should provide the maximum mercury removal.

The St. Clair Plant Unit1 ESP 1A was studied by Fuel Tech personnel. Gas flow and temperature measurements were collected in May 2004 for use in the CFD model. The section of the ductwork modeled is shown in Figure 11.

Figure 11. Detroit Edison St. Clair Unit 1 ESP 1A Ductwork Modeled

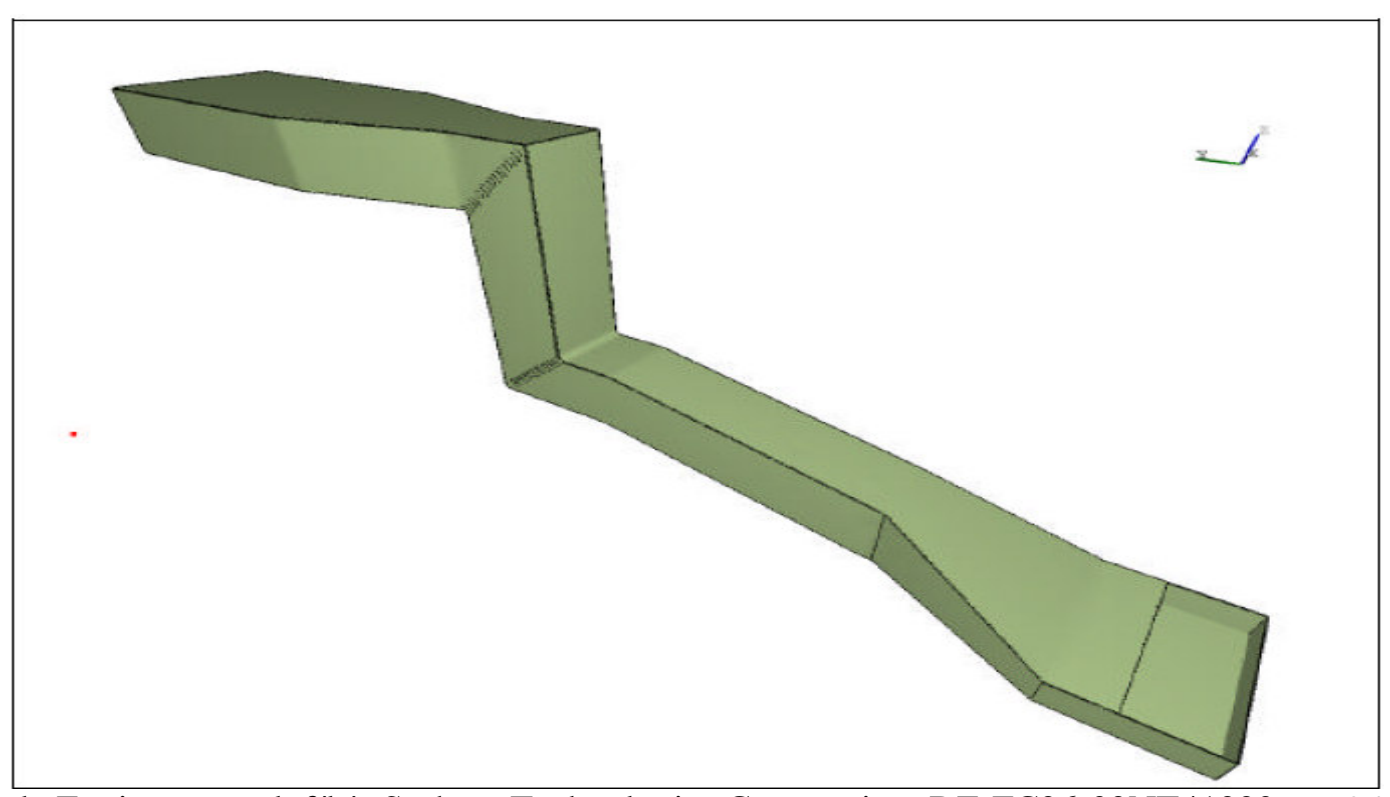

Albemarle Environmental, f/k/a Sorbent Technologies Corporation DE-FC26-03NT41990 34 
The gas flow is from right to left in this figure. It starts immediately after the flue gas is split and ends at the ESP plenum. The view above is from the opposite side of the ductwork as shown in Photograph 1. The flue gas first traverses a section of gradually rising ductwork before turning vertical and then horizontal. There are turning vanes in each turn.

A series of 4" ports were installed for the flow and temperature testing and for the mercury trials. These ports are located in the gradually rising section of ductwork and are shown in Figure 12.

Figure 12. Ports Installed in the Unit 1 ESP 1A Ductwork

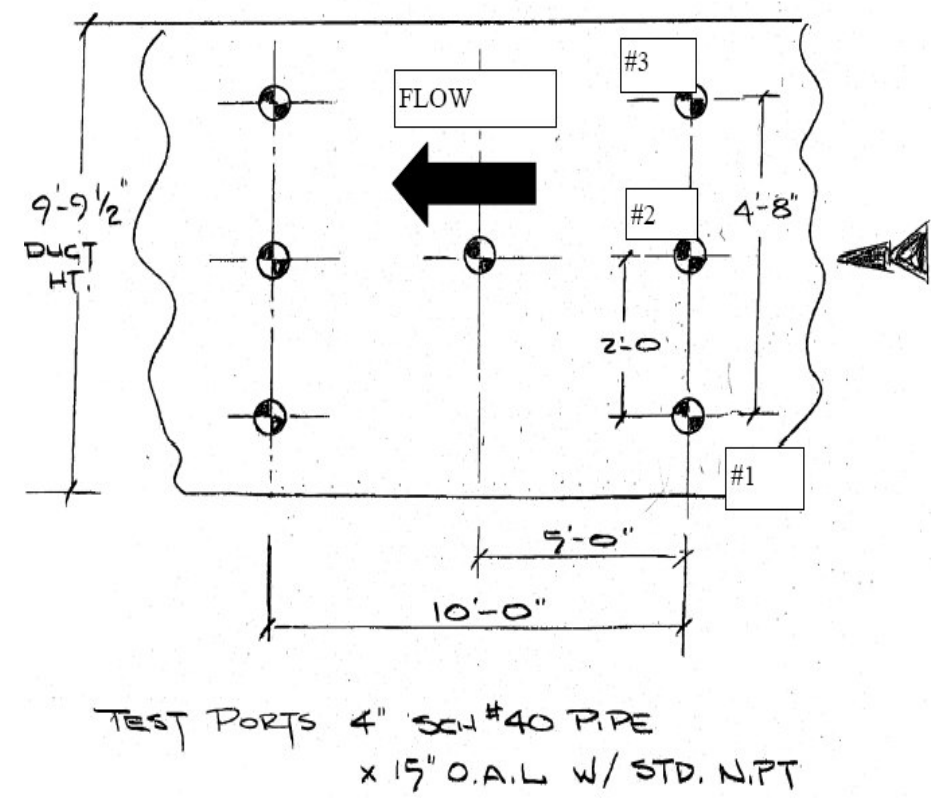

All of the ports in Figure 12 plus more in the vertical section of the ductwork were used for the temperature and flow testing conducted by Fuel Tech. Ports 1-3 were later used for the OHM mercury testing, while the three ports on the left (4-6) were used for sorbent injection. Port 4 is the lowest port. The middle port (not numbered) was for the continuous flow and temperature measurement instruments used in controlling the sorbent injection rate.

The flow in the ductwork was found to be biased, with highest flow in the lower left hand corner of the duct (near Port 4) and the lowest in the opposite corner. This flue gas flow is depicted in Figure 13 for the plane of Ports 4-6, which is the plane of sorbent injection. Orange indicates high flow and blue, low flow, with green an intermediate flue gas flow rate. The flow pattern becomes more uniform as the flue gas passes downstream but never fully becomes uniform. This biased flow pattern would play a key role in the recommended placement of the injection lances. 
Figure 13. Flue Gas Flow in Unit 1 ESP 1A Ductwork

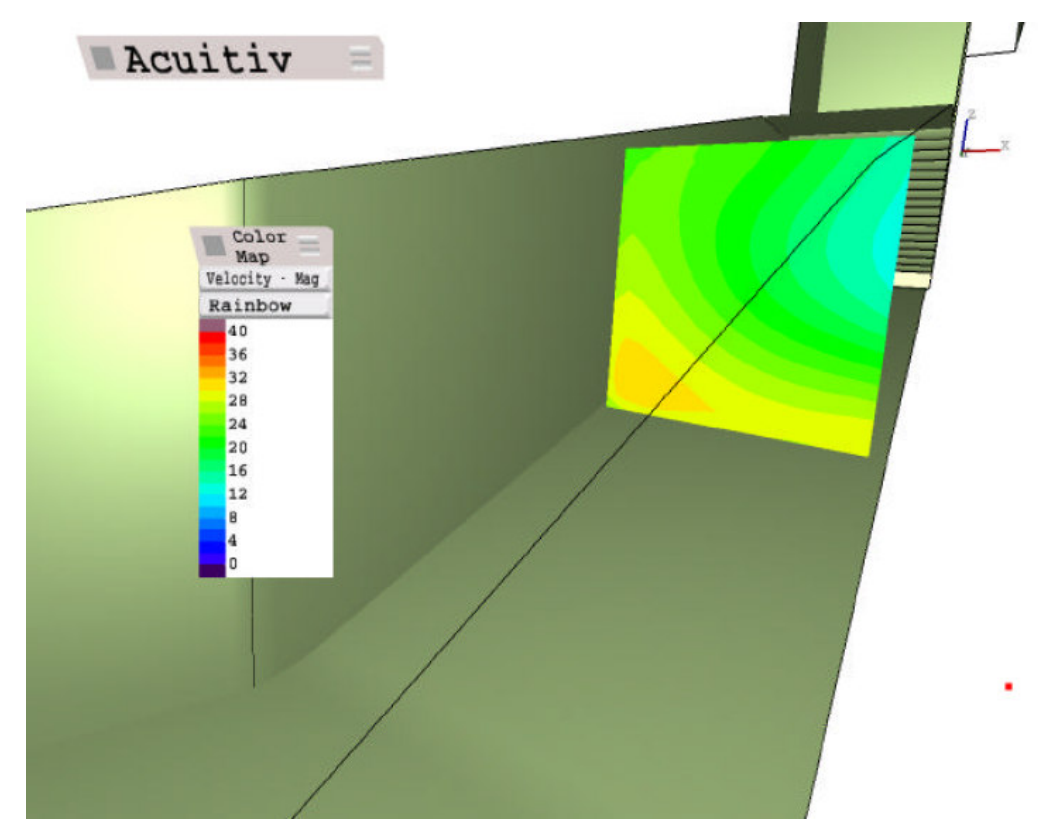

The gas stream, as expected, is very turbulent and rapidly distributes any material injected into it. This is clearly shown in Figure 14 for a single point of injection. Note the "Sample Plane" used in this figure. Sample planes were used for determining the distribution of the sorbent at different locations downstream of the injection point.

\section{Figure 14. Single Point Injection in Unit 1 ESP 1A Ductwork}

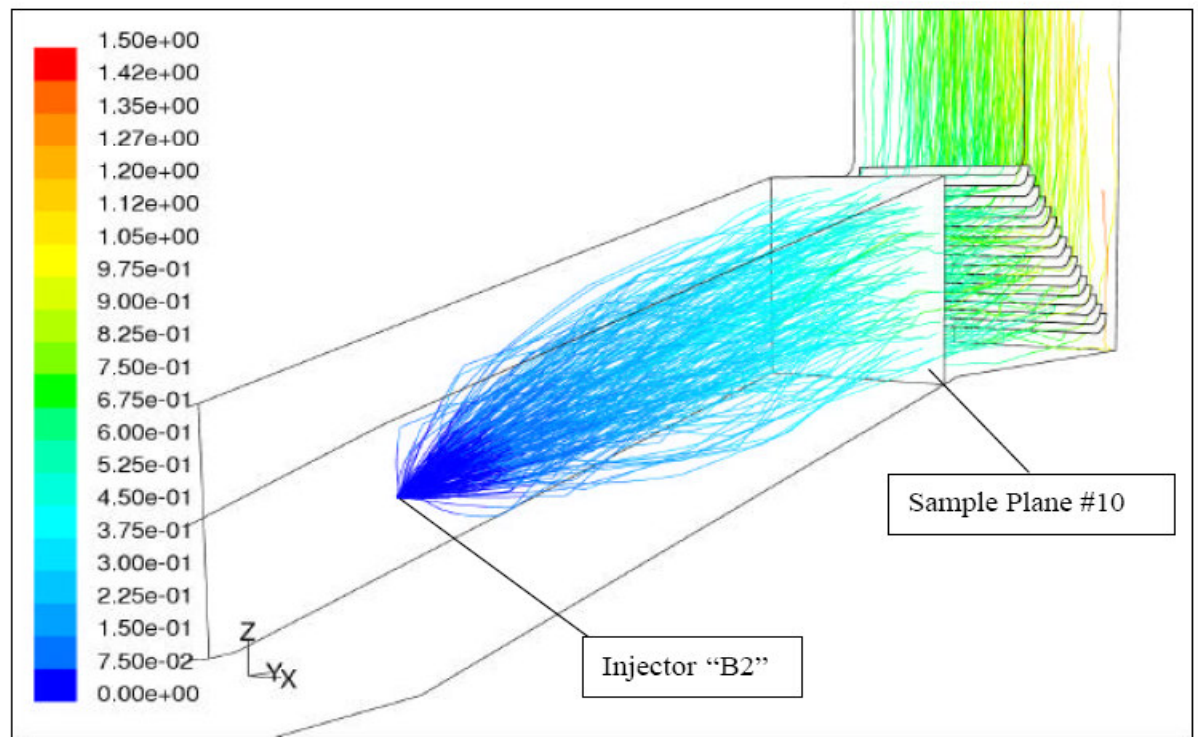


Fuel Tech modeled a variety of sorbent injection velocities from $1 \mathrm{~m} / \mathrm{s}$ to $25 \mathrm{~m} / \mathrm{s}$ and found that there was very little penetration of the injection stream into the gas stream even at the highest injection velocity. The injection velocity used at the Detroit Edison St. Clair power plant was about $20 \mathrm{~m} / \mathrm{s}$ through each lance.

At the direction of Sorbent Technologies, Fuel Tech next modeled a variety of injection locations and number of injection lances in operation. The injection locations are shown in the Figure 15.

\section{Figure 15. Potential Lance Locations Evaluated in Unit 1 ESP 1A Ductwork}

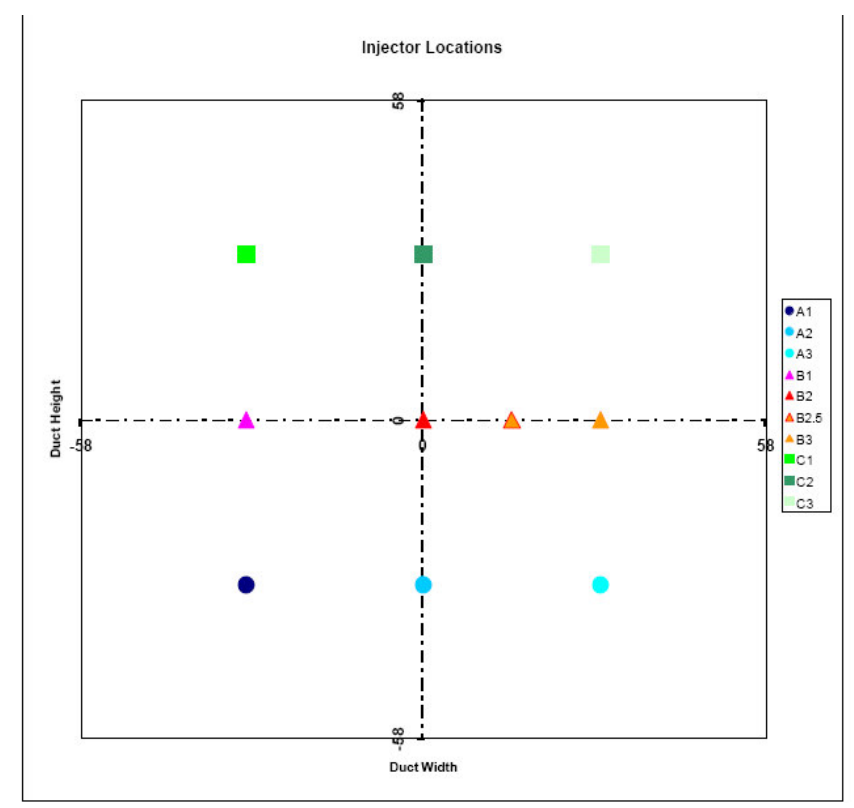

The orientation of the duct is the same as in Figure 13, with the lower left hand corner of the duct near Port 4 having the highest gas velocities. The height of the locations was fixed by the existing ports. The lower level are the A locations; A1 being closet to Port 4 and $A 3$ the farthest away. The middle levels are the B locations and the top level the $C$ locations. Later, the use of an A0 location was evaluated. The A0 location was 12" below location A1.

The distribution of the sorbent in the ductwork was evaluated with between 3 to 9 injection lances in operation. The CFD model predicted the number of sorbent particles in each of 100 grid boxes at several sample planes downstream of the injection plane. The distribution values were converted into a sorbent density number by dividing by the volume of the flue gas passing through each grid. The object was to obtain the most uniform sorbent distribution on a mass flow basis at the nearest sample plane. It was discovered that the best distribution was achieved with six lances located at points $\mathrm{A} 0$, A3, B1, B2.5, C1 and C2. The sorbent concentration distribution at the Sample Plane is shown in Figure 16. 


\section{Figure 16. Sorbent Distribution at the First Sample Plane in Unit $1 \mathrm{ESP} 1 \mathrm{~A}$ Ductwork}

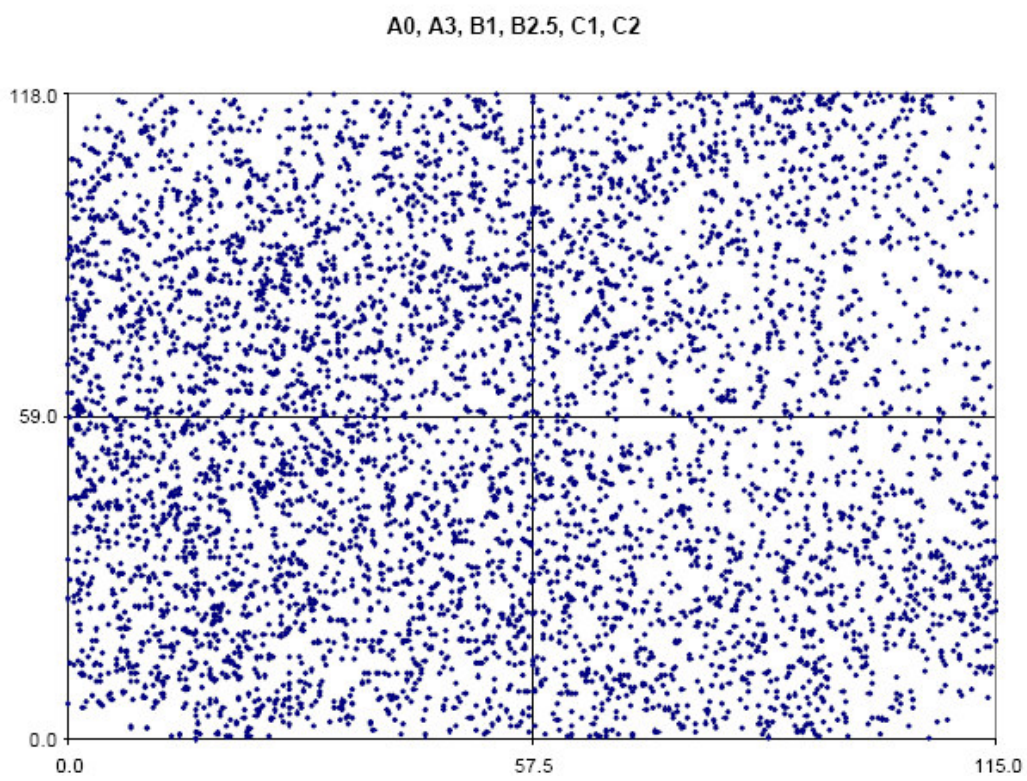

The sorbent distribution improves the farther downstream the particles proceed. The use of the A0 location proved important in providing a good sorbent distribution in the high flow area. Consequently, Detroit Edison St. Clair personnel hot-tapped another port below Port 4 so that a lance could be installed at location $\mathrm{A} 0$.

Finally, Fuel Tech modeled the system with the injection lances in place. There was little difference in the flow patterns, so the lances themselves have very little impact upon the flue gas flow pattern or the sorbent distribution.

\section{Safety}

Detroit Edison St. Clair Power Plant personnel provided safety and environmental awareness training to all of the Albemarle Environmental, $\mathrm{f} / \mathrm{k} / \mathrm{a}$ Sorbent Technologies, Western Kentucky University, METCO Environmental, and Fuel Tech personnel who worked at the site. A pre-job check-in log was maintained by Albemarle Environmental, $\mathrm{f} / \mathrm{k} / \mathrm{a}$ Sorbent Technologies through out the program. As a result of the dedicated effort of all parties concerned, there were no lost-time accidents or environmental events during the entirety of the testing program.

\section{Baseline Testing}

\section{Mercury CEM Start-Up}

The CEM start-up activities began on June 18 and ran through July 2, 2004. The purpose of the effort was to burn-in the new CEMs, collect preliminary mercury data, and test the dry/wet conversion modules. There were the normal start-up problems 
associated with new systems, requiring minor repairs and adjustments in order to make the systems operate properly. As expected, there were also issues with the dry conversion systems, which prompted a slight delay in the completion of the side-by-side tests and the baseline testing.

\section{Side-by-Side Testing}

The side-by-side mercury CEM tests were conducted from July 19 through 23, 2004. During these tests, both mercury monitors and conversion modules were installed in the outlet monitor building so that they could measure the mercury in the same gas stream coming from the same inertial separator. The first test conducted was a side-by-side test of the two analyzers measuring the $\mathrm{Hg}^{(\mathrm{T})}$ concentration in the gas from one conversion module being operated in the traditional wet method. The results from this test are presented in Figure 17.

Figure 17. Side-by-Side Test with One Conversion Module Operating in the Wet Mode and Two Mercury Analyzers

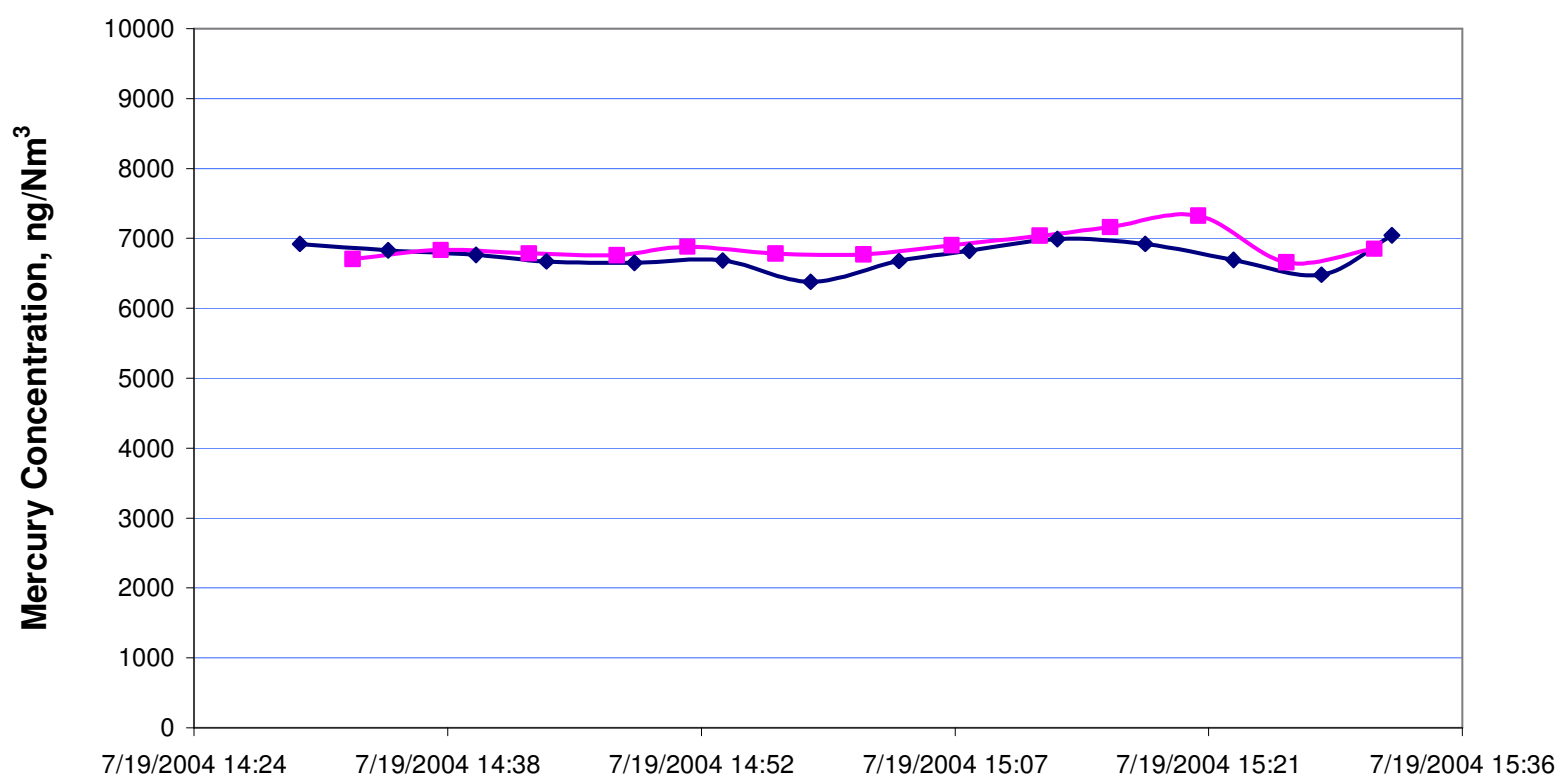

The comparison of the results from the two mercury analyzers was excellent, the averages for the test period being within $2 \%$ of each other. This difference is well within the manufacturer's tolerance and may have decreased if the test were performed for a longer period of time.

A second test was to compare the operation of the two systems when one conversion module was operating in the dry mode and the other in the wet mode. Any difference beyond that demonstrated in the test above would be as a result of differences in the performance of the conversion modules. The results from this test are presented in Figure 18. 
Figure 18. Side-by-Side Test with Two Conversion Modules, One Operating in the Wet Mode and One in the Dry Mode with Two Mercury Analyzers

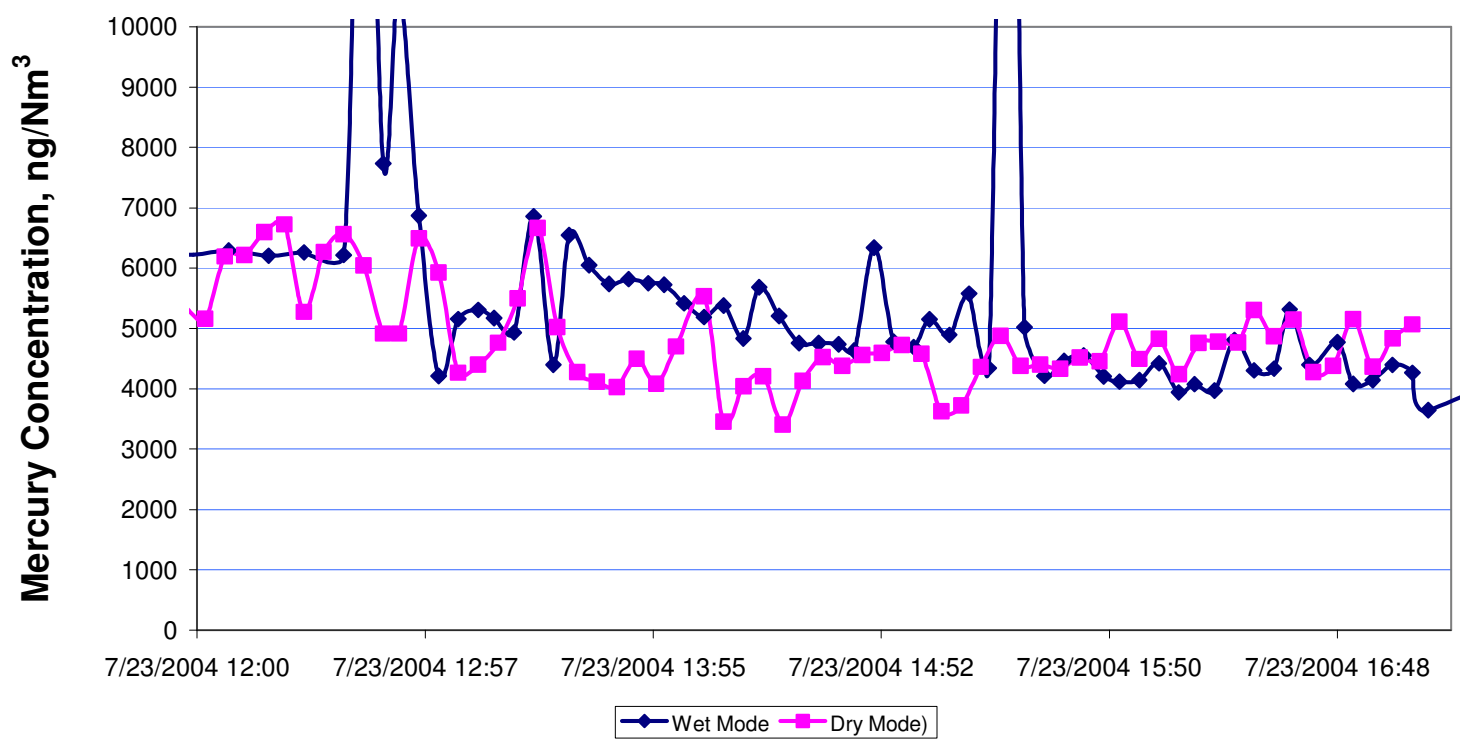

The mercury data from the two conversion methods tracked each other well. The dry conversion appeared to produce fewer spikes, which are always present when using standard wet conversion method. The average mercury concentration over the test period using the dry conversion method was $4852 \mathrm{ng} / \mathrm{Nm}^{3}$ as compared to $5056 \mathrm{ng} / \mathrm{Nm}^{3}$ using the wet conversion method, or only $4 \%$ apart. The spikes from the wet conversion method were removed from the data in order to make these calculations. Thus, the dry conversion method appears to have potential for replacing the wet conversion method. The only concern about this method is long-term system reliability, which has not yet been tested.

Albemarle Environmental, $\mathrm{f} / \mathrm{k} / \mathrm{a}$ Sorbent Technologies decided to operate the CEMs in the wet conversion mode for these trials to insure that the data could be directly compared to that generated in previous tests. The dry conversion mode was used more fully in other test programs. Once the dry conversion method is fully developed, it will be a large step forward for mercury monitoring technology as two major sources of problems, chemicals and their wastes, will be eliminated.

\section{Baseline Data Collection}

The baseline mercury data collection was conducted from July 25 through August 1 , 2004. The OHM and halogen tests were performed on July $28^{\text {th }}$. The coal data for this period is presented in Table 2, along with samples from 9 random days during the baseline period when the plant's standard coal blend was in use. A coal sample was taken in the morning of each day from each of five storage coal feed silos and a composite sample made for analysis. All of the coal analyses were performed in the Detroit Edison laboratories. 
Table 2. Coal Data from the Baseline Period at the St. Clair Power Plant

\begin{tabular}{ccc|ccccc} 
& Mercury & Total & \multicolumn{5}{c|}{ Dry Basis } \\
Date & hg(ppm) & Moist & Ash & Vol & FC & Sulfur & Btu \\
\hline $7 / 25 / 2004$ & 0.042 & 25.89 & 5.78 & 41.27 & 52.95 & 0.55 & 12,474 \\
$7 / 26 / 2004$ & 0.049 & 23.05 & 5.79 & 40.74 & 53.47 & 0.57 & 12,611 \\
$7 / 27 / 2004$ & 0.051 & 23.05 & 6.05 & 40.83 & 53.12 & 0.67 & 12,662 \\
$7 / 28 / 2004$ & 0.054 & 24.47 & 6.39 & 40.32 & 53.29 & 0.62 & 12,617 \\
$7 / 29 / 2004$ & 0.068 & 22.37 & 6.51 & 40.38 & 53.11 & 0.79 & 12,690 \\
Average & & & & & & & \\
9 Days & 0.059 & 22.89 & 6.42 & 40.34 & 53.24 & 0.75 & 12,560 \\
Previous & & & & & & &
\end{tabular}

Unit 1 fired $100 \%$ subbituminous coal on the weekend of July 24-25. This can be clearly seen in the low mercury, ash, and sulfur values, plus the elevated moisture and volatile matter content of the coal sampled on July 25 th. The transition back to the $85 \% / 15 \%$ coal blend was completed sometime on Monday July 26. The coal mercury level increased from $0.042 \mathrm{ppm}$ on July $25^{\text {th }}$ to $0.068 \mathrm{ppm}$ on July $29^{\text {th }}$. The low mercury level on July $25^{\text {th }}$ was due to the use of $100 \%$ subbituminous coal, but the increase thereafter must be due to an increase in mercury in the coal blend. The average mercury content of the previous samples averaged $0.059 \mathrm{ppm}$, in the middle of the data for these days.

Unit 1 is equipped with two ESPs; ESP $1 \mathrm{~A}$ and ESP 1B. This program was conducted in the ESP $1 \mathrm{~A}$ ductwork. ESP $1 \mathrm{~A}$ has six fields with two hoppers under each field to collect the fly ash. Field 1 of ESP $1 \mathrm{~A}$, the first field, was not operational throughout the program. It served as a drop-out chamber for any large particles in the flue gas and little fine sorbent was collected by it. The majority of the fly ash, and injected sorbent, is collected in Field 2, with lesser amounts being collected in the downstream fields 3 and 4. The two ESPs serving Unit 1 have a common fly ash removal system which continuously operates. It takes less than 20 minutes to circulate through all of the hoppers in both ESPs. The fly ash in back fields, Fields 5 and 6, are removed only once per day due to the tiny amount collected there. Samples were always taken from Fields 1 through 4, since the vast majority of the fly ash was collected in these fields during the baseline period. Occasionally, samples were also taken from the back hoppers for completeness sake.

Fly ash samples were taken from the ESP $1 \mathrm{~A}$ fields on ten days between June $23^{\text {rd }}$ and July $29^{\text {th }}$. The average composition of the fly ash by field is presented in Table 3 . This fly ash data was generated in the Detroit Edison laboratories.

Table 3. Fly Ash Data from the Baseline Period at the St. Clair Power Plant

\begin{tabular}{|c|c|c|c|c|c|c|c|c|c|c|c|c|}
\hline ESP & Unburned & Dry & & & & & & & & & & \\
\hline Field & Carbon & LOI & $\mathrm{SiO2}$ & Al203 & TiO2 & $\mathrm{Fe} 2 \mathrm{O3}$ & $\mathrm{CaO}$ & $\mathrm{MgO}$ & K2O & $\mathrm{Na2O}$ & SO3 & P205 \\
\hline$\overline{1}$ & 0.53 & 0.48 & 46.5 & 16.9 & 1.1 & 9.7 & 10.4 & 2.4 & 0.9 & 4.5 & 2.8 & 0.6 \\
\hline 2 & 0.78 & 1.10 & 40.5 & 20.6 & 1.3 & 7.4 & 13.3 & 3.3 & 1.0 & 5.8 & 3.1 & 1.0 \\
\hline 3 & 0.72 & 1.35 & 34.6 & 21.6 & 1.4 & 7.2 & 16.3 & 4.0 & 1.0 & 6.4 & 4.5 & 1.1 \\
\hline 4 & 0.34 & 1.04 & 26.3 & 20.7 & 1.4 & 6.7 & 19.7 & 4.8 & 0.9 & 7.4 & 7.6 & 1.2 \\
\hline 5 & 0.21 & 1.20 & 24.8 & 20.0 & 1.4 & 6.6 & 18.4 & 4.6 & 1.1 & 7.7 & 10.1 & 1.3 \\
\hline 6 & 0.19 & 1.45 & 23.8 & 19.6 & 1.4 & 6.9 & 18.3 & 4.5 & 1.1 & 7.5 & 11.1 & 1.3 \\
\hline
\end{tabular}


The fly ash in Field 1 resembles sand in size and composition. The fly ash is primarily composed of $\mathrm{SiO}_{2}, \mathrm{Al}_{2} \mathrm{O}_{3}, \mathrm{CaO}$, and $\mathrm{Fe}_{2} \mathrm{O}_{3}$. The $\mathrm{SiO}_{2}$ and $\mathrm{Fe}_{2} \mathrm{O}_{3}$ content of the ash decreases as you proceed back in the ESP while the $\mathrm{CaO}$ content increases. The $\mathrm{Al}_{2} \mathrm{O}_{3}$ content of the ash is fairly constant across all ESP fields. The fly ash is high in $\mathrm{Na}_{2} \mathrm{O}$ which increases farther back in the ESP. The unburned carbon content of the fly ash peaks in Fields 2 and 3 and declines the farther back in the ESP you proceed. The fly ash LOI (loss on ignition) is high in Fields 2 and 3 due to the unburned carbon but is the highest in Fields 5 and 6 due to high levels of carbonates and sulfates in the last two fields. Most of the compositional differences from field to field are probably due to the size separating ability of ESPs. The size of the fly ash decreases with field. Sulfates are generally of a very small size and thus are concentrated in the last ESP fields.

Albemarle Environmental, $\mathrm{f} / \mathrm{k} / \mathrm{a}$ Sorbent Technologies personnel performed the fly ash mercury analyses using an Ohio Lumex RA-915+. The mercury data for the baseline samples, sorted by field, are presented in Table 4.

Table 4. Fly Ash Hg Data (ppb) from the Baseline Period at the St. Clair Plant

\begin{tabular}{|c|c|c|c|c|c|c|c|}
\hline & Average & & & & & & \\
\hline ESP Field & of 12 days & $\mathbf{7 / 2 4 / 2 0 0 4}$ & $\mathbf{7 / 2 5 / 2 0 0 4}$ & $\mathbf{7 / 2 6 / 2 0 0 4}$ & $\mathbf{7 / 2 7 / 2 0 0 4}$ & $\mathbf{7 / 2 8 / 2 0 0 4}$ & $\mathbf{7 / 2 9 / 2 0 0 4}$ \\
\hline 1 & 103 & 90 & 27 & 109 & 62 & 15 & 110 \\
\hline 2 & 302 & 78 & 65 & 369 & 206 & 221 & 460 \\
\hline 3 & 323 & 161 & 78 & 233 & 203 & 211 & 422 \\
\hline 4 & 107 & & & & & & \\
\hline 5 & 50 & & & & & & \\
\hline 6 & 40 & & & & & & \\
\hline
\end{tabular}

The averages for samples taken on 12 days between June 22 and July 23, 2004, are provided for comparison with the data for baseline period. All of these samples were taken when the standard coal blend was in use. The mercury distribution in the fly ash closely matches the distribution of the unburned carbon content shown in Table 2 . Fields 2 and 3 had the highest unburned carbon content and also the highest mercury content. Fields 1 and 4 had the next highest unburned carbon content and the next highest mercury content. The fly ash mercury content, however, was highly variable with one standard deviation of the average values being at least $40 \%$ for the first three fields.

Unit 1 fired $100 \%$ subbituminous coal on the weekend of July 24-25. The fly ash unburned carbon content is usually very low when operating in this mode and low mercury levels were observed in the fly ash during these days. The fly ash mercury level was higher on the next days reflecting the higher mercury content in the coal and the higher unburned carbon in the fly ash. It should be noted that the mercury content of the fly ash on 7/29/04 was much higher than the rest of the samples, reflecting the high mercury level observed in the coal on that date (see Table 2).

The mercury data from the CEMs for the baseline period is presented in the Figure 19. Data is shown for the inlet and outlet locations for elemental mercury, $\mathrm{Hg}^{(0)}$, and for total gas phase mercury, $\mathrm{Hg}^{(\mathrm{T})}$. The data is corrected to $3 \%$ oxygen content so that the inlet and outlet data can be directly compared. The outlet gas stream is about 2 to $3 \%$ higher in oxygen than the inlet due to air leakage into the ESP. 
Figure 19. Baseline Hg CEM Data (Corrected to $3 \%$ O2) from the Detroit Edison St. Clair Power Plant from 7/25-8/1/04

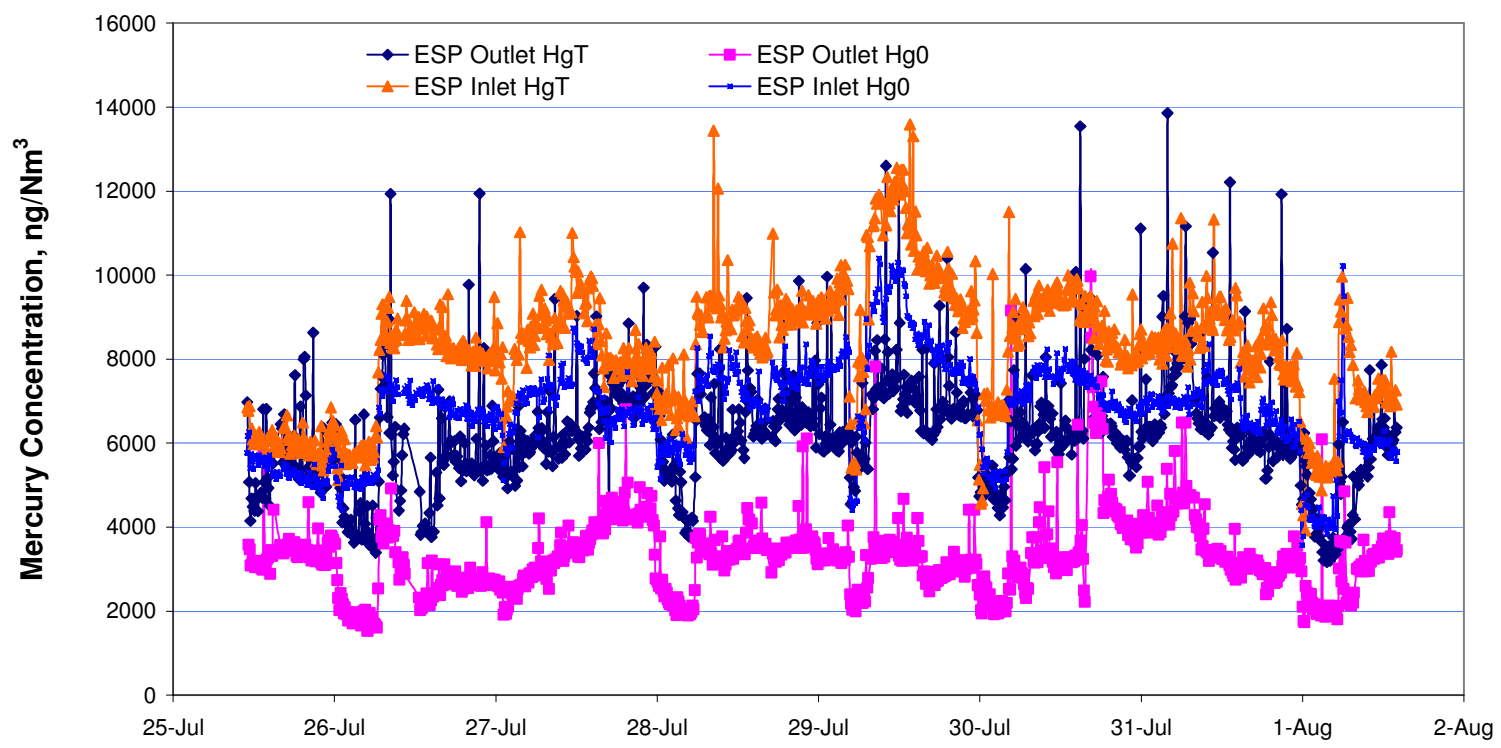

It can be observed from the figure that the mercury levels varied over the baseline period, as would be expected from the variation in coal mercury content. In addition, the inlet mercury concentrations were higher than the outlet level indicating that there was some native capture of mercury by the fly ash being produced.

In order to better analyze the data, the baseline data was broken in to periods of similar boiler load. Unit 1 usually drops load in the evenings when demand is lower. The operating data from the baseline test period, broken into the periods of similar load, is shown in the Table 5.

Table 5. Baseline Period Operating Data for St. Clair Unit 1

\begin{tabular}{|c|c|c|c|c|c|c|c|}
\hline Date & Time EDST & MW & Opacity & SO2, ppm & NOx, ppm & $\underline{\mathrm{CO} 2, \%}$ & Preheater Inlet 02, \% \\
\hline $7 \overline{25 / 04}$ & $11: 00-23: 55$ & $\overline{124}$ & 2.8 & 167 & 297 & 8.7 & 5.6 \\
\hline $7 / 26 / 04$ & $1: 00-06: 19$ & 49 & 2.7 & 145 & 193 & 5.0 & $10_{+}$ \\
\hline $7 / 26-27 / 04$ & $06: 40-00: 48$ & 141 & 2.4 & 289 & 260 & 9.4 & 4.2 \\
\hline $7 / 27 / 04$ & $01: 05-02: 29$ & 56 & 2.7 & 177 & 197 & 5.5 & 9.7 \\
\hline $7 / 27 / 04$ & $02: 46-06: 03$ & 80 & 2.5 & 240 & 218 & 7.1 & 7.7 \\
\hline $7 / 27 / 04$ & 09:02 - 23:04 & 142 & 2.6 & 292 & 323 & 8.9 & 5.5 \\
\hline $7 / 28 / 04$ & $00: 06-05: 22$ & 48 & 2.7 & 160 & 188 & 5.1 & $10+$ \\
\hline $7 / 28 / 04$ & $05: 40-07: 38$ & 132 & 2.6 & 286 & 286 & 8.7 & 5.2 \\
\hline $7 / 28 / 04$ & $07: 40-23: 59$ & 142 & 3.1 & 310 & 298 & 9.0 & 5.2 \\
\hline $7 / 29 / 04$ & $00: 30-5: 20$ & 127 & 3.1 & 291 & 285 & 9.0 & 5.2 \\
\hline $7 / 29 / 04$ & $08: 09-17: 56$ & 145 & 3.1 & 319 & 235 & 9.4 & 4.5 \\
\hline 7/29/04 & $18: 14-23: 59$ & 128 & 3.2 & 324 & 230 & 9.1 & 4.6 \\
\hline 7/30-31/04 & $05: 14-15: 33$ & 140 & 3.0 & 306 & 239 & 9.1 & 5.2 \\
\hline $7 / 31 / 04$ & $15: 50-18: 38$ & 162 & 3.9 & 350 & 217 & 9.2 & 5.4 \\
\hline 7/31/04 & $18: 43-23: 59$ & 140 & 3.7 & 352 & 261 & 8.9 & 4.7 \\
\hline $8 / 1 / 04$ & $01: 13-6: 11$ & 50 & 3.5 & 197 & 180 & 5.1 & $10+$ \\
\hline $8 / 1 / 04$ & $07: 03-14: 00$ & 142 & 3.6 & 360 & 282 & 9.1 & 4.8 \\
\hline
\end{tabular}


The baseline test period was broken into 17 periods of fairly stable load. The load varied from the minimum load of 48 megawatts (MW) to the full coal load of about $145 \mathrm{MW}$ to the maximum load with additional oil firing of $160 \mathrm{MW}$. The opacity level was low for all of these periods, as it was throughout all of the testing, including that with sorbent injection. This will be subsequently demonstrated with further data from the parametric and long-term mercury sorbent injection tests. The low opacity of the emissions can be attributed to the large size of the ESP and the favorable resistivity of the fly ash.

The oxygen level of the flue gas leaving the boiler varied with load. At high loads, the oxygen level was about $5 \%$, while it more than doubled at low loads since the flue gas flow rate was not varied with load. The $\mathrm{CO}_{2}, \mathrm{NO}_{x}$ and $\mathrm{SO}_{2}$ levels demonstrated the impact of dilution with load. The $\mathrm{SO}_{2}$ levels were no higher than $360 \mathrm{ppm}$ even at high loads, reflecting the impact of using low sulfur subbituminous coal.

The mercury data for the 17 periods of stable boiler load is presented in Table 6 . The mercury data is only from the $1 \mathrm{~A}$ ESP system.

\begin{tabular}{|c|c|c|c|c|c|c|c|c|}
\hline Date & $\frac{\text { Time Period, }}{\text { EDST }}$ & $\underline{\mathrm{HgT}}$ & $\frac{\text { Inlet }}{\underline{\mathrm{Hg} 0}}$ & $\% \mathrm{HgO}$ & $\underline{\mathrm{HgT}}$ & $\frac{\text { Outlet }}{\underline{\mathrm{Hg} 0}}$ & $\% \mathrm{HgO}$ & $\begin{array}{c}\text { Native } \\
\text { HgT Removal, \% } \\
\end{array}$ \\
\hline $7 / 25 / 04$ & $11: \overline{00-23: 55}$ & 6044 & 5342 & $88.4 \%$ & 5574 & 3434 & $61.6 \%$ & $7.8 \%$ \\
\hline $7 / 26 / 04$ & $1: 00-06: 19$ & 5806 & 5089 & $87.7 \%$ & 4154 & 1847 & $44.5 \%$ & $28.5 \%$ \\
\hline $7 / 26 / 04$ & $06: 40-00: 48$ & 8224 & 6942 & $84.4 \%$ & 5802 & 2878 & $49.6 \%$ & $29.5 \%$ \\
\hline $7 / 27 / 04$ & 01:05 - 02:29 & 6939 & 5961 & $85.9 \%$ & 5472 & 2224 & $40.6 \%$ & $21.1 \%$ \\
\hline $7 / 27 / 04$ & 02:46 - 06:03 & 8561 & 7113 & $83.1 \%$ & 5817 & 2674 & $46.0 \%$ & $32.1 \%$ \\
\hline 7/27/04 & 09:02 - 23:04 & 8581 & 7187 & $83.8 \%$ & 6840 & 4059 & $59.3 \%$ & $20.3 \%$ \\
\hline $7 / 28 / 04$ & 00:06 - 05:22 & 6966 & 5825 & $83.6 \%$ & 4937 & 2235 & $45.3 \%$ & $29.1 \%$ \\
\hline $7 / 28 / 04$ & $05: 40-07: 38$ & 8977 & 7573 & $84.4 \%$ & 6677 & 3585 & $53.7 \%$ & $25.6 \%$ \\
\hline $7 / 28 / 04$ & 07:40 - 23:59 & 9063 & 7466 & $82.4 \%$ & 6679 & 3565 & $53.4 \%$ & $26.3 \%$ \\
\hline $7 / 29 / 04$ & $00: 30-5: 20$ & 9513 & 7888 & $82.9 \%$ & 6225 & 3145 & $50.5 \%$ & $34.6 \%$ \\
\hline $7 / 29 / 04$ & 08:09 - 17:56 & 11211 & 9119 & $81.3 \%$ & 7362 & 3391 & $46.1 \%$ & $34.3 \%$ \\
\hline $7 / 29 / 04$ & $18: 14-23: 59$ & 9454 & 7673 & $81.2 \%$ & 6910 & 3085 & $44.6 \%$ & $26.9 \%$ \\
\hline $7 / 30 / 04$ & 05:14 - 15:33 & 8820 & 7242 & $82.1 \%$ & 6833 & 3962 & $58.0 \%$ & $22.5 \%$ \\
\hline $7 / 31 / 04$ & $15: 50-18: 38$ & 8135 & 6519 & $80.1 \%$ & 5930 & 3052 & $51.5 \%$ & $27.1 \%$ \\
\hline $7 / 31 / 04$ & $18: 43-23: 59$ & 7884 & 6376 & $80.9 \%$ & 6188 & 3015 & $48.7 \%$ & $21.5 \%$ \\
\hline $8 / 1 / 04$ & $01: 13-6: 11$ & 6015 & 4873 & $81.0 \%$ & 3964 & 2323 & $58.6 \%$ & $34.1 \%$ \\
\hline $8 / 1 / 04$ & 07:03 - 14:00 & 7193 & 5936 & $82.5 \%$ & 5807 & 3219 & $55.4 \%$ & $19.3 \%$ \\
\hline
\end{tabular}

The inlet $\mathrm{Hg}^{(\mathrm{T})}$ concentration varied by nearly a factor of two over the baseline test period. The low inlet mercury concentrations were all at low loads. However, the inlet mercury concentration, even in periods with similar loads, varied by as much as $50 \%$. Presumably, this variation is due to the variation in the inlet coal mercury content. The inlet gas was composed of more than $80 \% \mathrm{Hg}^{(0)}$ of the total gaseous mercury. In fact, the $\mathrm{Hg}^{(0)}$ composed nearly $90 \%$ of the total gaseous mercury for the first period during which $100 \%$ subbituminous coal was being used.

The outlet $\mathrm{Hg}^{(\mathrm{T})}$ concentrations exhibited a percentage variation similar to the inlet concentrations but there was a loss across the ESP of about $30 \%$ when burning the standard $85 \% / 15 \%$ coal blend. This loss is the plant's native mercury removal from 
capture by the unburned carbon in the fly ash. The native removal for the first period, when burning $100 \%$ subbituminous coal, was less than $10 \%$.

Typically, the fraction of $\mathrm{Hg}^{(0)}$ present in the outlet flue gas was reduced from about $80 \%$ to about $50 \%$ between the inlet and outlet measurements. This indicates that elemental mercury entering the ESP was being partially oxidized during the passage through the ESP.

A set of OHM mercury sample trains, three in the inlet and three in the outlet, were taken on July 28, 2004. The OHM mercury tests were all performed simultaneously. The averaged results from these tests are presented in Table 7.

Table 7. Mercury OHM and CEM data for 7/28/04 at St. Clair Unit 1A (ng Hg/ $\mathrm{Nm}^{3}$, corrected to $3 \% \mathrm{O}_{2}$ )

$\frac{\stackrel{\text { Inlet HgT }}{\text { CEM }}}{9,043} \quad \frac{\text { OHM }}{8,903}$

Native Hg Removal by CEM data

Native Hg Removal by OHM data

$\frac{\stackrel{\text { Inlet Hg0 }}{\text { CEM }}}{7,634} \quad \frac{\text { OHM }}{7,183}$

7,183

\section{(A) One Outlet OHM data point discarded}

The mercury CEM data is only for the hours of the OHM testing. All of the data is corrected to $3 \% \mathrm{O}_{2}$ to allow for comparison of inlet and outlet data. One of the outlet $\mathrm{OHM}$ data points was spurious, very high, and was not used in the calculations. The inlet mercury concentrations, both $\mathrm{Hg}^{(\mathrm{T})}$ and $\mathrm{Hg}^{(0)}$, measured by the two techniques appear comparable.

This could not be said for the outlet mercury data, however. The CEM data indicated a $32 \%$ native removal of mercury across ESP $1 \mathrm{~A}$. The OHM data, on the other hand, indicated a $26 \%$ increase in mercury across this ESP. METCO Environmental could not explain the results. Albemarle Environmental, $\mathrm{f} / \mathrm{k} / \mathrm{a}$ Sorbent Technologies strongly believes that these OHM results are in error. This highlights the problem with using $\mathrm{OHM}$ tests for CEM calibration. First, the results were not obtained until the program was well into parametric testing. Second, the OHM measurements showed high variability and a net $\mathrm{Hg}$ gain. Sorbent Technologies chose not to correct the CEM data based upon the OHM data.

(In the ICR testing performed on St. Clair Unit 4 in 1999, which is identical to Unit 1, the native mercury removal across the ESP that was observed was over $20 \%$, although the coals, sampling locations and operating conditions used in 1999 were different from those used today.)

The baseline OHM mercury data indicated that, for the sampling locations used, there was not a significant concentration of particulate mercury in either the inlet or outlet flue gas of ESP $1 \mathrm{~A}$. The inlet particulate mercury concentration was about $1 \%$ of the total and the outlet was essentially $0 \%$. 


\section{Parametric Testing}

The purpose of the parametric testing program was to evaluate the mercury removal performance as a function of injection rate and coal fired, and to evaluate several different versions of the Albemarle Environmental, $\mathrm{f} / \mathrm{k} / \mathrm{a}$ Sorbent Technologies B-PAC mercury sorbents. Based on these results, the mercury sorbent to be used in the longterm testing and its injection rate would be determined. Standard Norit Darco FGD PAC was used as a baseline sorbent for comparative purposes, as it has been in most previous full-scale tests.

The parametric testing began on August 5 and ran through September 23, 2004. A total of 46 tests were performed over 26 days. Unit 1 was operated on each testing day at a stable load, as close to full coal load as possible, for a period of 6 to 8 hours. This required a considerable amount of scheduling and adjustment on the part of Detroit Edison, for which Sorbent Technologies is very grateful. All of the tests were conducted using the $85 \%$ subbituminous $/ 15 \%$ bituminous coal blend, except for those conducted on the weekends of $8 / 21-22 / 04$ and $9 / 11-12 / 04$, when $100 \%$ subbituminous coal was utilized. A typical test lasted about two hours at one injection rate, although some were longer. The outlet $\mathrm{Hg}$ CEM data before the test was compared to the mercury data after it stabilized during an injection test in order to define the mercury removal due to the sorbent and, thus, separating out the native removal for that day.

It was quickly discovered that it was impossible to obtain representative fly ash samples from the ESP hoppers during the short parametric tests. The injected sorbent, mixed with the plant fly ash, was not uniformly moving through the system with "plug" flow, as evidenced by significantly lower marginal increases in carbon in collected fly ash. Thus, fly ash analyses were abandoned during the parametric part of the program. Clearly, the mercury content of the fly ash jumped during periods of injection, but the degree could not be accurately determined. Fly ash analyses and mercury mass balances were a focus of the long-term program during which the problem of obtaining representative fly ash samples was eliminated by steady, continuous sorbent injection.

Coal samples were taken each day of parametric testing. The results of the mercury tests are summarized in Table 8.

Table 8. Coal Mercury during Parametric Testing

\begin{tabular}{|c|c|c|}
\hline Coal & Avg.Hg, ppm & Range, ppm \\
\hline lend & 0.053 & 0.032 to 0.074 \\
\hline ubbituminous & 0.041 & NA \\
\hline
\end{tabular}

The mercury content of the blended coal averaged close to that identified in the baseline testing, but had a wider range. The $100 \%$ subbituminous coal was only used on four days during the parametric testing and averaged about the same mercury content as that found on the first day of the baseline test (July $25^{\text {th }}$ ).

The Norit Darco FGD (now Norit Darco Hg) plain activated sorbent was injected on six different days during 9 tests at rates from 2.0 to $12.0 \mathrm{lb} / \mathrm{MMacf}$. The results are presented in Figure 20. The results from the Wisconsin Electric Pleasant Prairie fullscale test with $100 \%$ subbituminous coal and from the Stanton Station 1 full-scale test with $100 \%$ lignite are also presented for comparison. Note that the mercury removal 
results are due to sorbent only; i.e. native removal is not included in these mercury removal results.

Figure 20. Detroit Edison St. Clair Parametric Testing Mercury Removal Results Using Norit Darco FGD Sorbent

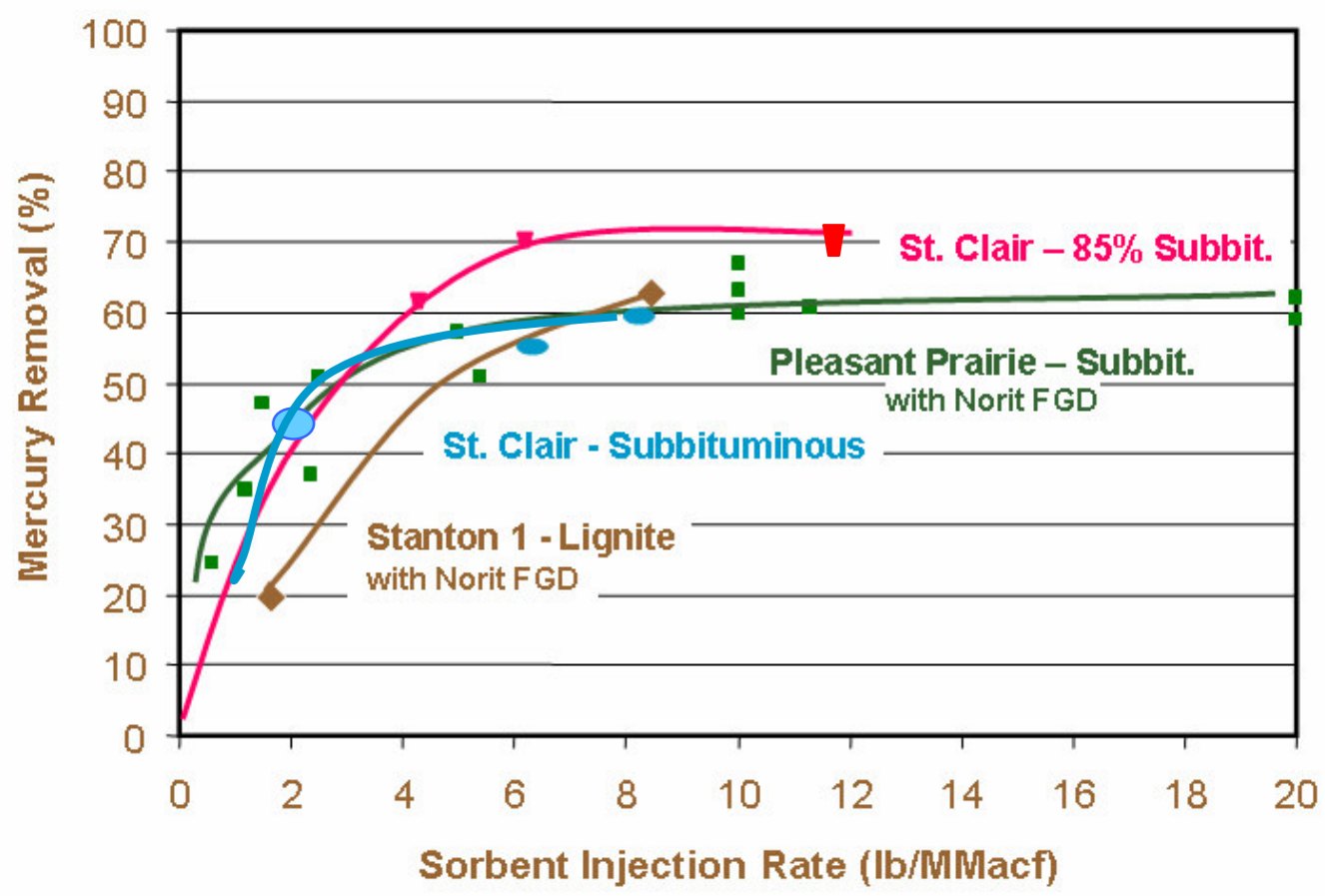

The results for mercury removal tests at the St. Clair Power Plant using the Norit sorbent and utilizing $100 \%$ subbituminous coal fall on the mercury removal curve from the Pleasant Prairie test and are slightly better than the Stanton Station 1 test results. The mercury removal plateaus at about $60 \%$ mercury removal at an injection rate of approximately $6.0 \mathrm{lb} / \mathrm{MMacf}$ and does not increase at higher injection rates. The mercury removal results at the St. Clair Power Plant when firing the coal blend were slightly better, achieving $70 \%$ mercury removal at an injection rate of $6.0 \mathrm{lb} / \mathrm{MMacf}$. Again, this mercury removal rate did not increase even when the injection rate was increased to $12.0 \mathrm{lb} /$ MMacf. This finding has been observed in other tests.

The standard Albemarle Environmental, f/k/a Sorbent Technologies B-PAC ${ }^{T M}$ mercury sorbent is internally denoted as "A-5B." The parametric mercury removal results from the testing with this sorbent are presented in Figure 21. Mercury removal results can be contrasted with that of standard Norit Darco FGD. 
Figure 21. Detroit Edison St. Clair Parametric Testing Mercury Removal Results Using Sorbent Technologies A-5B and Norit Darco FGD Sorbents

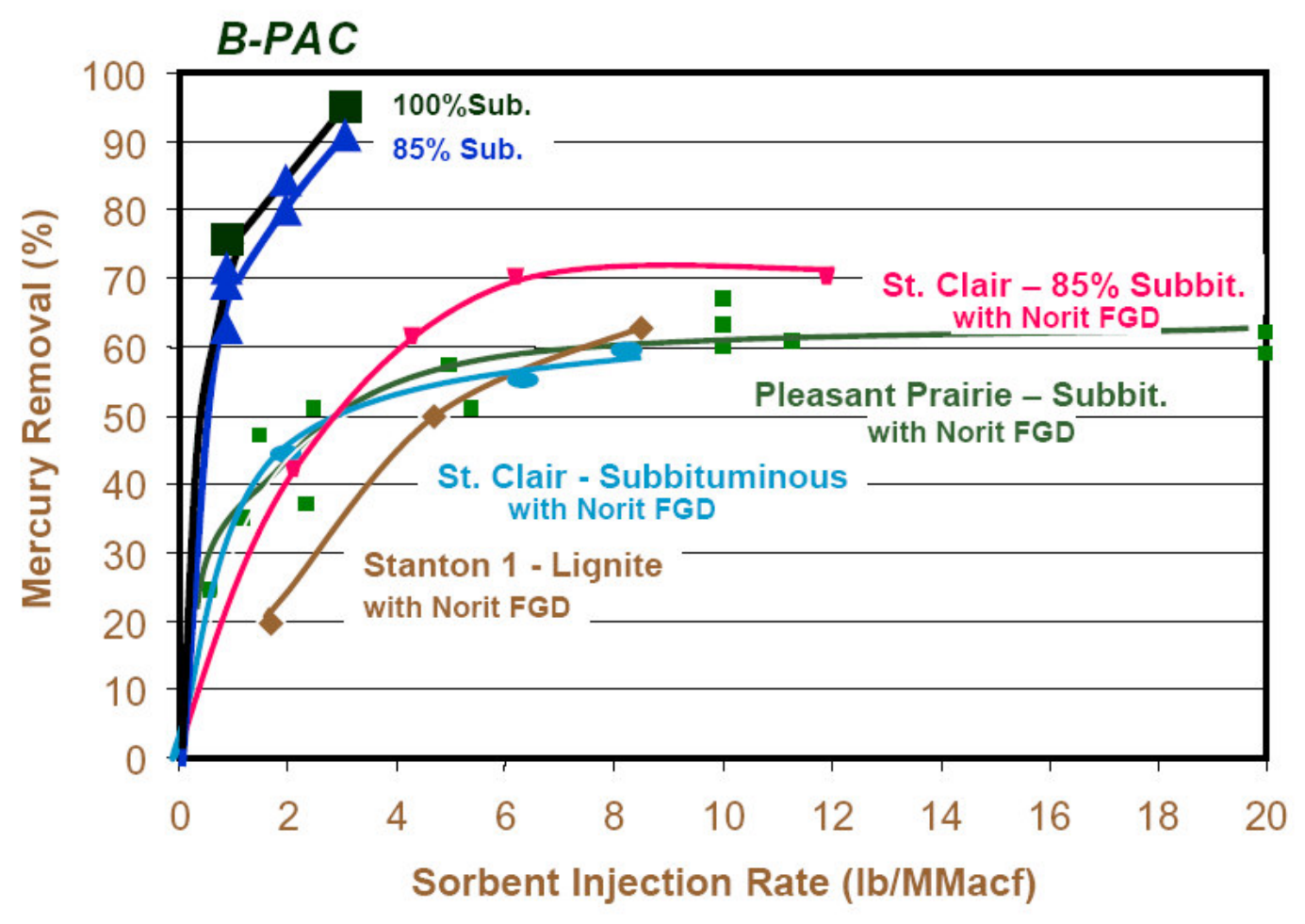

The A-5B sorbent provided about $70 \%$ mercury removal at an injection rate of 1.0 $\mathrm{lb} / \mathrm{MMacf}$ and $90 \%$ mercury removal at $3.0 \mathrm{lb} / \mathrm{MMacf}$ with the standard $85 \%$ subbituminous coal blend. Slightly higher mercury removals were achieved when $100 \%$ subbituminous coal was being utilized. These results are a major accomplishment in that $90 \%$ mercury removal was achieved at injection rates only a small fraction of what the plain PAC needed to achieve $60 \%$ to $70 \%$ mercury removal.

The parametric test results can be converted to pounds of mercury per trillion BTU heat input using the coal data. The results are presented in Figure 22. In this case, the results are presented for the median $100 \%$ subbituminous coal. An emission rate of just over $1.0 \mathrm{lb} \mathrm{Hg} / \mathrm{TBtus}$ was accomplished with a B-PAC injection rate of $1.0 \mathrm{lb} / \mathrm{MMacf}$. Mercury emissions below 1.0 and $0.5 \mathrm{lb} \mathrm{Hg} / \mathrm{TB}$ tus were reached with injection rates of 2.0 and $3.0 \mathrm{lb} /$ MMacf, respectively. 
Figure 22. Mercury Emissions in Pounds per Trillion BTUs

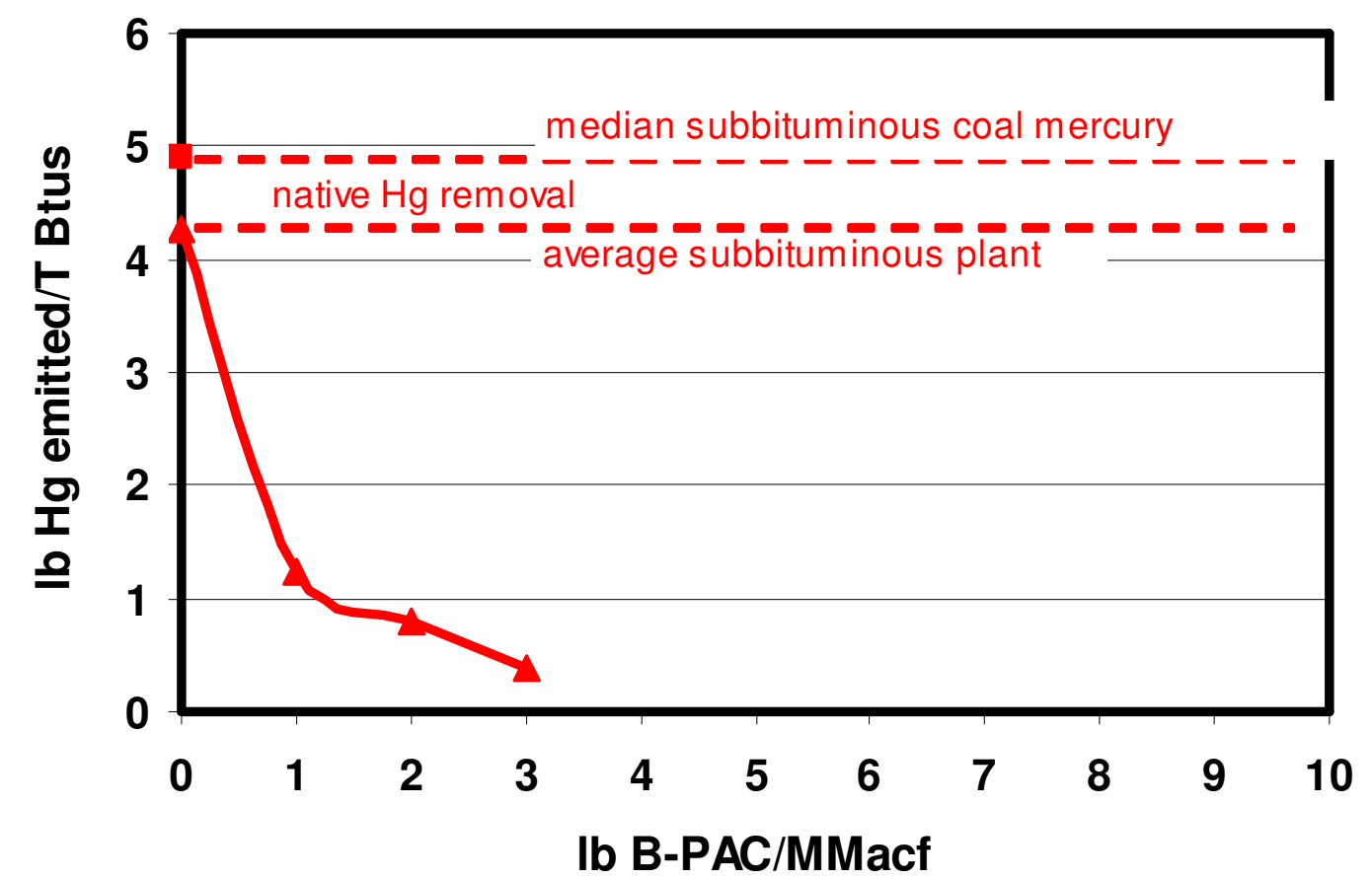

Albemarle Environmental, $\mathrm{f} / \mathrm{k} / \mathrm{a}$ Sorbent Technologies evaluated a number of different versions of the B-PAC sorbents using, for example, activated carbon substrates from different manufacturers. The results for from the tests with the different sorbents under normal boiler operating conditions are presented in Table 9. While the individual sorbent characterizations remain confidential, all were different variations of Sorbent Technologies standard brominated carbons.

Table 9. Parametric Mercury Sorbent Tests at St. Clair Unit 1A

\begin{tabular}{|c|c|c|c|c|c|c|}
\hline Date & $\frac{\text { Start }}{\text { Time }}$ & $\frac{\text { End }}{\text { Time }}$ & Sorbent & jection Rate, & Hg Removal Due & Coal Utilized \\
\hline $8 / 26 / 2004$ & $7: 20$ & $9: 20$ & $A-5 B$ & 1.0 & 71 & $85 \% / 15 \%$ Blend \\
\hline $8 / 26 / 2004$ & $9: 20$ & $11: 33$ & $A-5 B$ & 3.0 & 91 & $85 \% / 15 \%$ Blend \\
\hline 8/27/2004 & $7: 07$ & $9: 26$ & $A-5 B$ & 1.0 & 70 & $85 \% / 15 \%$ Blend \\
\hline 8/27/2004 & $10: 26$ & $12: 20$ & $A-5 B$ & 2.0 & 81 & $85 \% / 15 \%$ Blend \\
\hline $9 / 13 / 2004$ & $8: 15$ & $11: 00$ & $A-5 B$ & 1.0 & 70 & $85 \% / 15 \%$ Blend \\
\hline $9 / 13 / 2004$ & $12: 35$ & $2: 34$ & $A-5 B$ & 3.0 & 89 & $85 \% / 15 \%$ Blend \\
\hline $9 / 23 / 2004$ & $7: 13$ & $10: 36$ & $A-5 B$ & 1.0 & 69 & $85 \% / 15 \%$ Blend \\
\hline $9 / 12 / 2004$ & $8: 12$ & $10: 22$ & $A-5 B$ & 1.0 & 71 & $100 \%$ Subbitumino \\
\hline $9 / 12 / 2004$ & $10: 22$ & $12: 54$ & $A-5 B$ & 3.0 & 84 & $100 \%$ Subbitumino \\
\hline 9/9/2004 & $6: 46$ & $1: 59$ & $A-5 C$ & 3.0 & 92 & $85 \% / 15 \%$ Blend \\
\hline $9 / 10 / 2004$ & $7: 50$ & $10: 30$ & $A-5 C$ & 1.0 & 73 & $85 \% / 15 \%$ Blend \\
\hline $9 / 10 / 2004$ & $10: 30$ & $1: 00$ & $A-5 C$ & 2.0 & 85 & $85 \% / 15 \%$ Blend \\
\hline
\end{tabular}




$\begin{array}{ccccccc}\text { 9/11/2004 } & 10: 18 & 12: 48 & \text { A-5C } & 1.0 & 77 & 100 \% \text { Subbituminous } \\ \text { 9/11/2004 } & 12: 48 & 2: 58 & \text { A-5C } & 3.0 & 93 & 100 \% \text { Subbituminous } \\ & & & & & 72 & 85 \% / 15 \% \text { Blend } \\ \text { 8/30/2004 } & 3: 48 & 6: 00 & \text { B } & 1.0 & 61 & 85 \% / 15 \% \text { Blend } \\ & & & & & 78 & 85 \% / 15 \% \text { Blend } \\ \text { 9/14/2004 } & 7: 09 & 9: 56 & \text { C } & 1.0 & & \\ \text { 9/14/2004 } & 9: 56 & 12: 30 & \text { C } & 3.0 & 47 & 85 \% / 15 \% \text { Blend } \\ & & & & 1.0 & 71 & 85 \% / 15 \% \text { Blend } \\ \text { 9/15/2004 } & 8: 00 & 10: 26 & \text { D } & 3.0 & 68 & 85 \% / 15 \% \text { Blend } \\ \text { 9/15/2004 } & 10: 26 & 12: 30 & \text { D } & & 87 & 85 \% / 15 \% \text { Blend } \\ & & & & 1.0 & 53 \% / 15 \% \text { Blend } \\ \text { 9/16/2004 } & 6: 57 & 9: 17 & \text { E } & 3.0 & 73 & 85 \% / 15 \% \text { Blend } \\ \text { 9/16/2004 } & 9: 17 & 11: 38 & \text { E } & & 83 & 85 \% / 15 \% \text { Blend } \\ & & & & 1.0 & 65 & 85 \% / 15 \% \text { Blend }\end{array}$

During the parametric testing program, there was a week during which the native mercury removal across ESP $1 \mathrm{~A}$ was as high as $67 \%$. Attempts were made to discover the cause of this event, without result. The high native removal appeared to have the effect of reducing the performance of the B-PAC sorbents, although the total mercury removal was nearly as it was under normal operating conditions. The results for the tests performed under abnormal operating conditions are presented in Table 10.

Table 10. Parametric Mercury Sorbent Tests Under Abnormal Conditions

\begin{tabular}{|c|c|c|c|c|c|c|c|}
\hline Date & $\frac{\text { Start }}{\text { Time }}$ & $\frac{\text { End }}{\text { Time }}$ & Sorbent & $\begin{array}{l}\text { Injection } \\
\text { Rate, } \\
\text { Ib/MMacf }\end{array}$ & $\begin{array}{l}\text { Hg Removal Due } \\
\text { to Sorbent, \% }\end{array}$ & $\begin{array}{c}\text { Total Hg } \\
\text { Removal, \% } \\
\end{array}$ & Coal Utilized \\
\hline $9 / \overline{3 / 2004}$ & $\overline{10: 45}$ & $\overline{1: 56}$ & $\overline{A-5 B}$ & 3.0 & 76 & 90 & $8 \overline{5 \% / 15 \% \text { Blend }}$ \\
\hline $9 / 7 / 2004$ & $12: 49$ & $4: 01$ & $A-5 B$ & 1.0 & 57 & 82 & $85 \% / 15 \%$ Blend \\
\hline 8/31/2004 & $8: 18$ & $12: 57$ & G & 3.0 & 75 & 88 & $85 \% / 15 \%$ Blend \\
\hline $9 / 2 / 2004$ & $8: 27$ & $11: 00$ & G & 1.0 & 33 & 69 & $85 \% / 15 \%$ Blend \\
\hline $9 / 1 / 2004$ & 9:00 & $11: 19$ & $\mathrm{H}$ & 1.0 & 32 & 64 & $85 \% / 15 \%$ Blend \\
\hline $9 / 1 / 2004$ & $11: 19$ & $2: 59$ & $\mathrm{H}$ & 3.0 & 71 & 85 & $85 \% / 15 \%$ Blend \\
\hline 9/2/2004 & $11: 19$ & $1: 48$ & I & 1.0 & 38 & 71 & $85 \% / 15 \%$ Blend \\
\hline $9 / 3 / 2004$ & $7: 40$ & $9: 48$ & 1 & 1.0 & 38 & 74 & $85 \% / 15 \%$ Blend \\
\hline $9 / 8 / 2004$ & $9: 07$ & $11: 47$ & $J$ & 1.0 & 57 & 70 & $85 \% / 15 \%$ Blend \\
\hline 9/8/2004 & $11: 47$ & $2: 05$ & J & 3.0 & 79 & 85 & $85 \% / 15 \%$ Blend \\
\hline
\end{tabular}


A set of Ontario Hydro Method (OHM) tests was conducted on September 9, 2004. Mercury sorbent was being injected during the entire OHM test period in an effort to confirm the mercury removal being achieved by the sorbent. The data from this test is compared with that from the CEM during the same period in Table 11. All of the mercury data is corrected to $3 \%$ oxygen to allow for direct comparison of inlet and outlet data.

\section{Table 11. Mercury OHM and CEM data for 9/9/04 (Corrected to $3 \% \mathrm{O}_{2}$ )}

$$
\stackrel{\text { Inlet HgT }}{\frac{\text { CEM }}{5794}} \quad \frac{\text { OHM }}{4296}
$$

(A)

$\frac{\text { Inlet Hg0 }}{\text { CEM }} \frac{\text { OHM }}{3840} \quad \frac{}{3452}$

(A)

Outlet HgT
$\frac{\text { CEM }}{458} \quad \frac{\text { OHM }}{499}$

$92.1 \%$

$88.4 \%$

Total Hg Removal by CEM data

Total Hg Removal by OHM data

\section{Outlet HgO \\ $\frac{\text { CEM }}{216} \quad \frac{\text { OHM }}{144}$}

\section{(A) One spurious OHM data point omitted}

The $\mathrm{OHM}$ and CEM data for the inlet $\mathrm{Hg}^{(\mathrm{T})}$ concentrations were significantly different in these tests, but the rest of the data compared favorably. The CEM data indicated that the mercury removal on this date was $92 \%$ while the OHM data indicated it was $4 \%$ lower at $88 \%$. The OHM data thus confirms the high mercury removal of the B-PAC sorbent being injected.

One concern with the OHM testing is the high variability of the average results. The $\mathrm{OHM}$ data and CEM data is presented in Figure 23 along with two standard deviation error bars on the OHM data.

Figure 23. Inlet and Outlet $\mathrm{Hg}$ OHM and CEM Data for 9/9/04
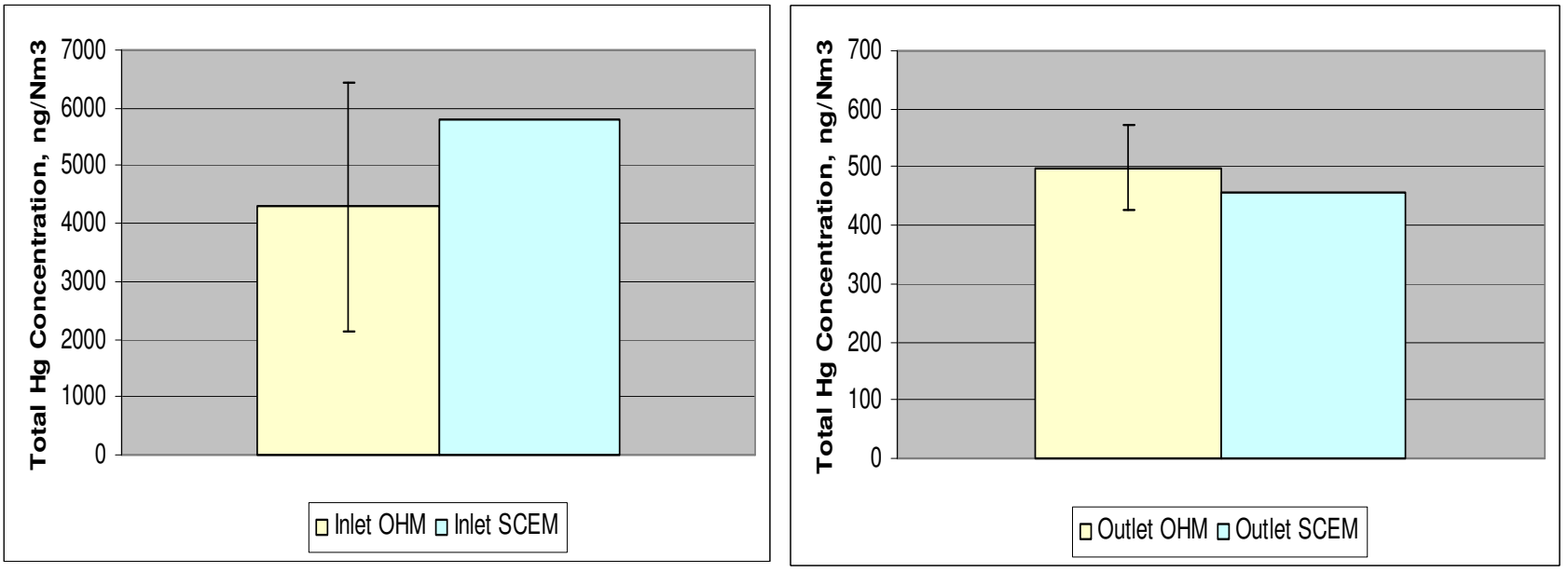
The inlet OHM mercury average is lower than the inlet CEM data, but the CEM data is within the two sigma error bars, which were large for this test. The outlet OHM data appears to be what should be expected with a fairly small absolute error.

The standard A-5B B-PAC sorbent performed very well in the parametric testing and was chosen for use in the long-term test. A constant injection rate of $3.0 \mathrm{lb} / \mathrm{MMacf}$ was selected. A mercury removal rate due to sorbent of about $90 \%$ was expected based upon the parametric testing. The total mercury removal rate (sorbent and native) was expected to be about $92.5 \%$ based upon the average $25 \%$ native removal identified in the baseline testing.

\section{Long-Term Testing}

The long-term testing at the Detroit Edison St. Clair Power Plant Unit 1 ESP $1 \mathrm{~A}$ began at 8:30 a.m. EST on September 24 and ran 30 days until 8:30 a.m. EST on October 24, 2004. The injection system was operated in the manner to automatically follow the flue gas flow rate and maintain a sorbent injection rate of $3.0 \mathrm{lb} /$ MMacf. The sorbent injection system operated around the clock for the 30 days without any problems or stoppages.

With B-PAC injected at $3 \mathrm{lb} / \mathrm{MMacf}$, over the 30-day period, the instantaneous total vapor-phase mercury removal varied between about $88 \%$ and $98 \%$, depending on the plant's operating conditions. Based upon the $\mathrm{Hg}$ CEMs measurements, the long-term average mercury removal was $94 \%$. The data is presented in Figure 24 . This is total mercury removal since native and sorbent mercury removal cannot be distinguished once the long-term testing began. Native mercury removal was about $10 \%$ before the test began and about $30 \%$ when it ended.

Figure 24. Detroit Edison St. Clair Long-term Testing Mercury Removal Results Using Sorbent Technologies A-5B Sorbent at an Injection Rate of 3.0 lb/MMacf

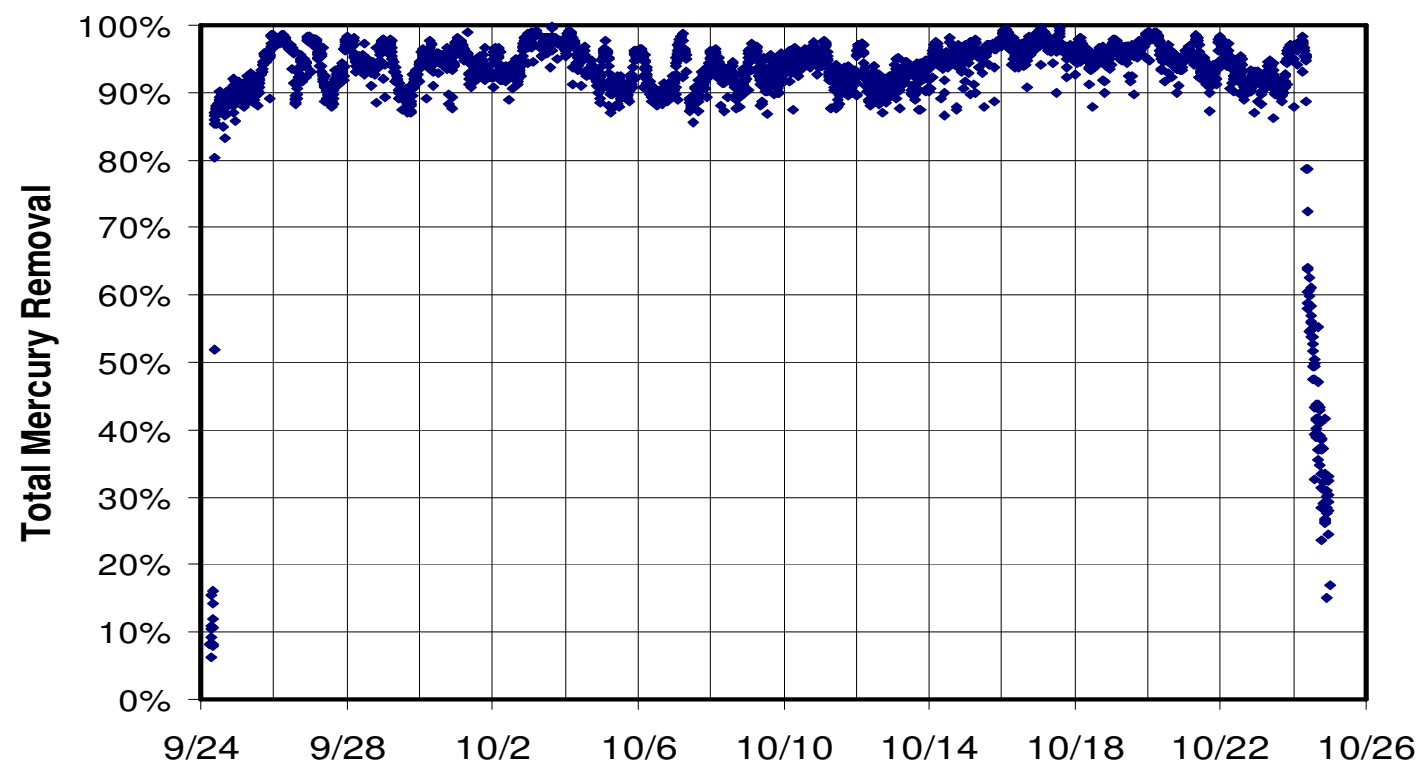


Two sets of OHM tests were conducted during the long-term testing. The results of these tests are presented in Table 12.

Table 12. Mercury OHM and CEM data for 10/6/04 \& 10/21/04 at St. Clair Unit 1A (Corrected to $3 \% \mathrm{O}_{2}$ )

\begin{tabular}{|c|c|c|c|c|c|c|c|c|}
\hline \multirow[b]{2}{*}{ Date } & \multicolumn{2}{|c|}{ Inlet HaT } & \multicolumn{2}{|c|}{ Inlet $\mathrm{HgO}$} & \multicolumn{2}{|c|}{ Outlet HgT } & \multicolumn{2}{|c|}{ Outlet $\mathrm{HgO}$} \\
\hline & CEM & OHM & CEM & $\mathrm{OHM}$ & CEM & $\mathrm{OHM}$ & CE $\bar{M}$ & OHM \\
\hline $1 \overline{0 / 6 / 04}$ & $\overline{7907}$ & $\overline{8077}$ & $\overline{6382}$ & $\overline{7108}$ & $\overline{827}$ & $\overline{929}$ & $\overline{371}$ & $\overline{378}$ \\
\hline $10 / 21 / 04$ & 5984 & 4097 & 4580 & 2954 & 384 & 477 & 156 & 143 \\
\hline & & & & $10 / 6 / 04$ & $10 / 21 / 04$ & & & \\
\hline Total $\mathrm{Hg} \mathrm{R}$ & bv & ata & & $89.5 \%$ & $93.6 \%$ & & & \\
\hline
\end{tabular}

The results from the test on October 6 were very similar for both the CEM and OHM data. The inlet data for the test on October 25 were different from the CEM and the $\mathrm{OHM}$. The inlet OHM data was lower than the inlet CEM data, similar to that observed in the parametric testing. In any case, the calculated mercury removal rates were all very high. The inlet and outlet OHM data (with error bars) and the inlet and outlet CEM data are presented below.

Figure 25. Inlet and Outlet Hg OHM and CEM Data for 10/6/04 and 10/21/04
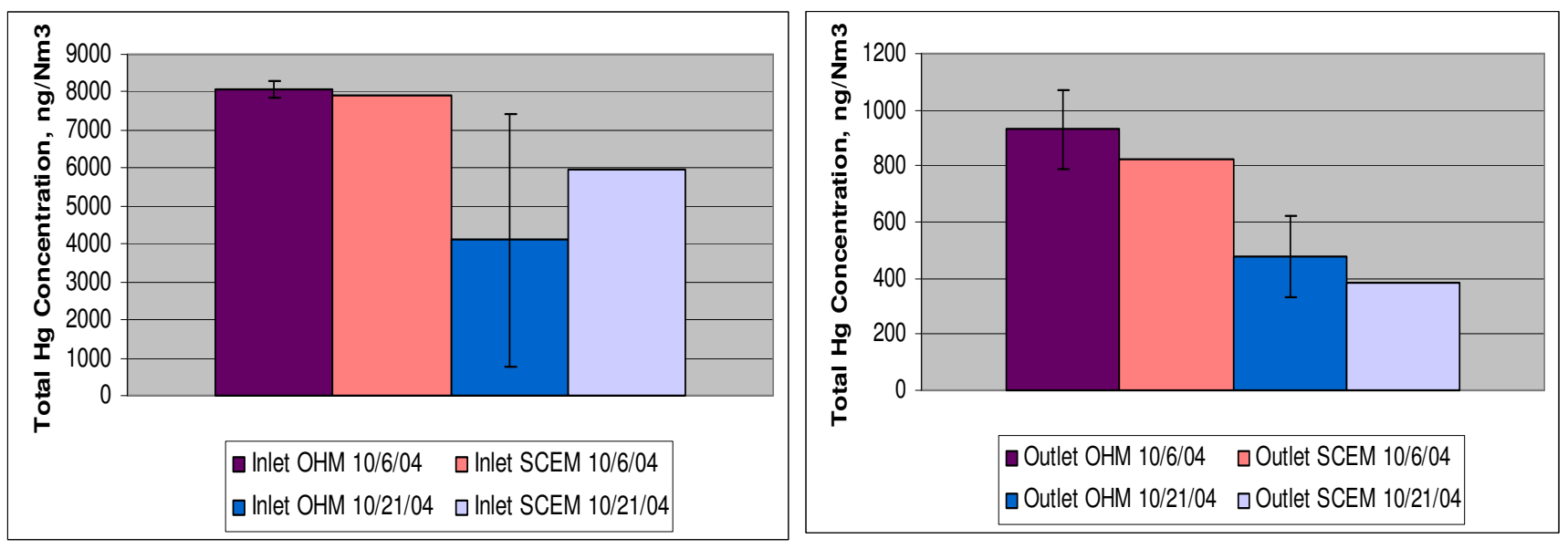

The inlet data provides the most striking comparison. The OHM and CEM inlet mercury values for 10/6/04 are very close and the two-sigma error bar on the OHM data is very small. The inlet OHM and CEM mercury data on 10/21/04, however, are not very close and the two-sigma error bar on the OHM data was huge. The CEM data fall well within the error bar. The outlet mercury OHM and CEM data is close for both test dates and the error bars on the OHM data are modest. Due to the high variability of the individual sample train measurements, the OHM results were not used to correct the CEM data throughout the program.

Detroit Edison took three Method 324 QuickCEM sorbent sampling-tube inlet and outlet measurements near the end of the 30-day test as an extra CEM check. The results from 
those measurements appear in Figure 26. The Method 324 analyses indicated slightly better mercury removal performance than the PSA semi-continuous analyzers.

Figure 26. Mercury Method 324 Data from St. Clair Unit 1A

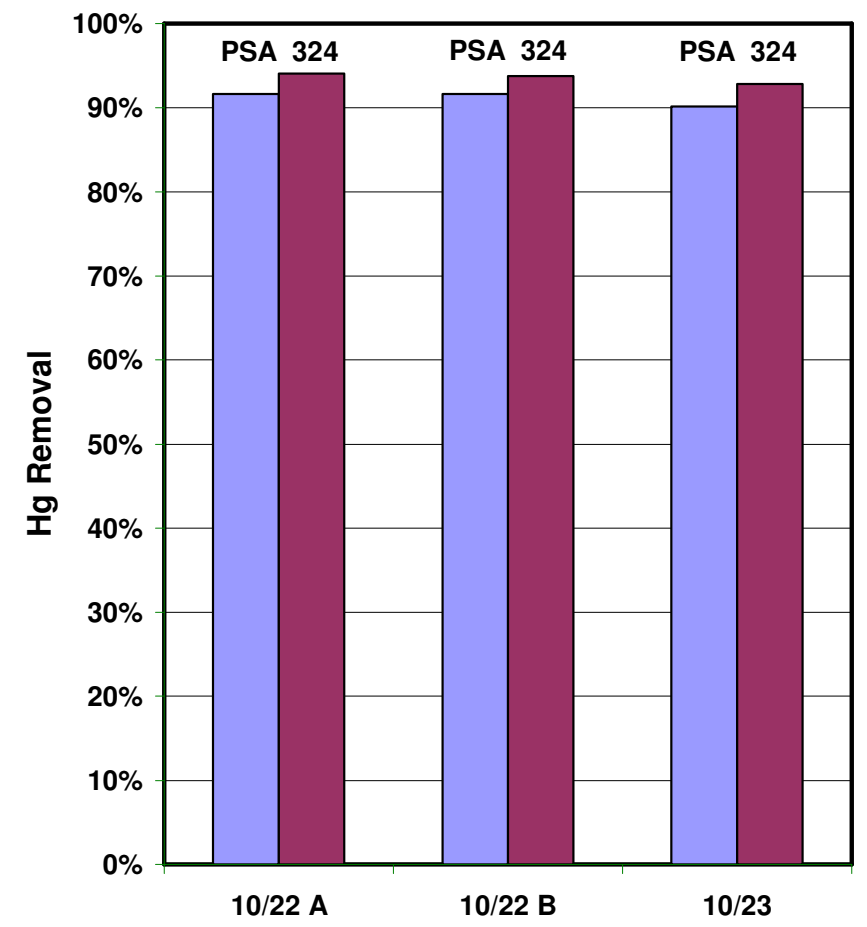

During the long-term testing, a number of brief coincident tests were performed. Two involved the evaluation of low-cost versions of the standard A-5B sorbent. These variations contain less bromine than standard B-PAC. To perform these tests, the day storage hopper was emptied and the lower-cost sorbent was added. There was no interruption of sorbent injection. The tests were performed on October 11 and 23. The data for these two days are presented in Figures 27 and 28.

Figures 27 \& 28. Lower-Cost B-PAC Mercury Removal Test on 10/11/04 \& 10/23/04
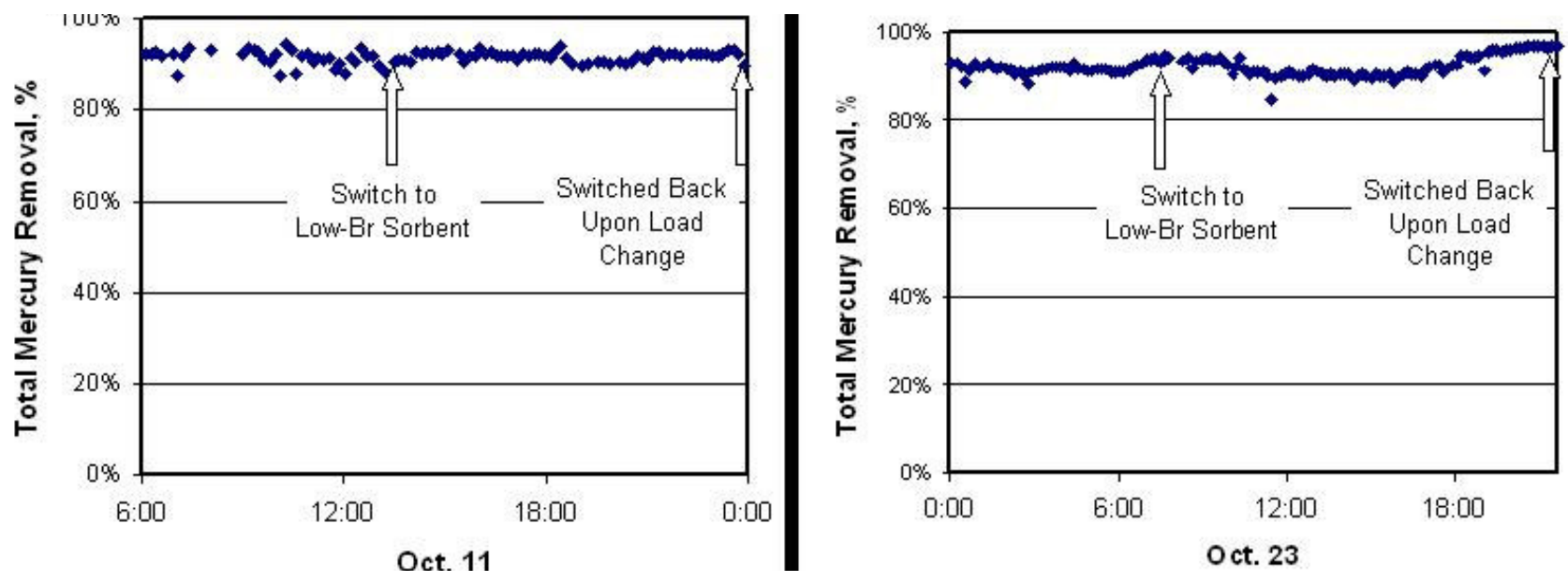
The switchover to the lower-cost B-PAC began at 13:30 on October 11 and at 7:30 on October 23 and ran through the end of the day when the plant load significantly changed. The total mercury removal on October 11 averaged $91.3 \%$ while the standard A-5B was being injected and $91.8 \%$ when the lower-cost B-PAC was in use. On October 23 , the total mercury removal during the A-5B use was $91.3 \%$ and it was $91.8 \%$ during use of the lower-cost B-PAC. Clearly, there was no major difference in these two sorbents in this application. The mercury removal for both sorbents was included in the long-term mercury removal data presented in Figure 24 since there was not a significant difference in the two sorbents.

Another experiment was carried out during the long-term run to evaluate the intermittent operation of the sorbent injection system as a potential means of reducing the effective injection rate. It is known that the impact of the sorbent does not end immediately upon the termination of injection. Thus, a high mercury removal might be achieved at a lower sorbent injection rate if the rate of recovery, after injection is ceased, is slower than the rate of removal increase when the injection is begun. In this test, the injection system was switched on and off every minute for a period of 64 minutes. Before and after the test, the mercury removal was $92 \%$. During the test, it decreased to $81 \%$. Effectively, the injection rate had been cut to $1.5 \mathrm{lb} /$ MMacf from $3.0 \mathrm{lb} /$ MMacf by switching the injection system on and off. A mercury removal of $81 \%$ is approximately what would be expected at a B-PAC injection rate of $1.5 \mathrm{lb} / \mathrm{MMacf}$. Thus, it appears that, for this application, the rate of mercury recovery was similar to the rate of mercury capture increase and this intermittent method of injection provided no benefit. The data for the 64 minutes of the test was not included in Figure 24 because of the significant impact on mercury removal during the test.

Daily coal samples were taken during the long-term test for analysis. The average composition of the coal samples is presented in Table 13 along with the value standard deviation. These analyses were performed by Detroit Edison in their laboratories.

Table 13. Coal Data from St. Clair Unit 1A during the Long-Term Test

\begin{tabular}{|lcc|ccccc|}
\hline & Total & $\mathrm{Hg}$ & \multicolumn{5}{|c|}{ Dry Basis } \\
\cline { 4 - 8 } & & \multicolumn{5}{c|}{ Volatile } \\
& Moisture & $\mathrm{ppm}$ & $\mathrm{Ash}$ & Matter & $\mathrm{F} / \mathrm{C}$ & Sulfur & Btu \\
\hline Average & 22.83 & 0.055 & 6.60 & 40.01 & 53.38 & 0.78 & 12592 \\
St. Dev. & 1.02 & 0.012 & 0.62 & 0.70 & 0.56 & 0.18 & 89 \\
St. Dev., $\%$ & $4.5 \%$ & $21.1 \%$ & $9.3 \%$ & $1.8 \%$ & $1.0 \%$ & $23.6 \%$ & $0.7 \%$
\end{tabular}

The coal data is very representative of what is expected when using a blend of $85 \%$ subbituminous coal and $15 \%$ bituminous coal. The moisture level is high, averaging nearly $23 \%$, while the ash $(6.6 \%$ dry basis) and sulfur $(0.78 \%$ dry basis) are low. The coal Btu content was about 12,500 per pound on a dry basis. These values and their variability compare very well with those of the baseline period.

The coal mercury content averaged $0.055 \mathrm{ppm}$ on an as received basis, but was fairly variable with a standard deviation of $21 \%$. The coal mercury data from the long-term test also compares favorably with the baseline coal mercury data. 
Fly ash samples were taken daily from the various ESP field hoppers during the longterm test program. Selected samples were analyzed for their major components by Detroit Edison and analyzed for mercury by Sorbent Technologies. Compositional analysis of the fly ash samples collected during the long-term testing is presented in Table 14.

Table 14. Fly Ash Data from St. Clair Unit 1A during the Long-Term Test

\begin{tabular}{|c|c|c|c|c|c|c|c|c|c|c|}
\hline \multirow{2}{*}{$\begin{array}{l}\text { ESP } \\
\text { Field }\end{array}$} & \multirow[b]{2}{*}{$\mathrm{SiO} 2$} & \multirow[b]{2}{*}{$\mathrm{Al} 203$} & \multirow[b]{2}{*}{$\mathrm{TiO2}$} & \multirow[b]{2}{*}{$\mathrm{Fe} 2 \mathrm{O} 3$} & \multirow[b]{2}{*}{$\mathrm{CaO}$} & \multirow[b]{2}{*}{$\mathrm{MgO}$} & \multirow[b]{2}{*}{ K2O } & \multirow[b]{2}{*}{$\mathrm{Na} 2 \mathrm{O}$} & \multirow[b]{2}{*}{ SO3 } & \multirow[b]{2}{*}{ P205 } \\
\hline & & & & & & & & & & \\
\hline 1 & 48.5 & 17.1 & 1.1 & 9.8 & 9.3 & 2.2 & 1.0 & 3.4 & 1.9 & 0.7 \\
\hline 2 & 40.2 & 19.5 & 1.3 & 7.7 & 15.3 & 3.8 & 0.9 & 5.7 & 2.7 & 0.9 \\
\hline 3 & 35.0 & 19.9 & 1.4 & 7.1 & 17.2 & 4.3 & 0.9 & 6.4 & 4.6 & 1.0 \\
\hline 4 & 30.4 & 20.5 & 1.5 & 6.9 & 19.1 & 4.8 & 0.9 & 7.0 & 6.6 & 1.1 \\
\hline 5 & 28.9 & 19.9 & 1.5 & 7.0 & 19.4 & 4.8 & 0.9 & 6.5 & 8.0 & 1.2 \\
\hline 6 & 26.6 & 20.1 & 1.5 & 6.7 & 20.1 & 5.1 & 0.9 & 7.1 & 8.4 & 1.4 \\
\hline
\end{tabular}

The fly ash composition during the long-term test, independent of the increased carbon and mercury content due to the sorbent, was very similar to that measured during the baseline testing. The compositional differences of the fly ash, from field to field, are probably due to segregation by size and are not impacted by sorbent injection.

\section{Mercury Mass Balance}

The fly ash mercury data is important in that it can be used to create a mercury mass balance to confirm the mercury removal results of other measuring techniques. During the long-term testing, an opportunity arose to sample not only the fly ash from the six fields of ESP $1 \mathrm{~A}$, but also from the six fields of ESP 1B, which did not see injected sorbent and could provide baseline (i.e. native $\mathrm{Hg}$ removal) comparisons. The fly ash mercury data for both ESP 1A and ESP 1B are presented in Figure 29.

Figure 29. Fly Ash Mercury Data for ESPs 1A and 1B

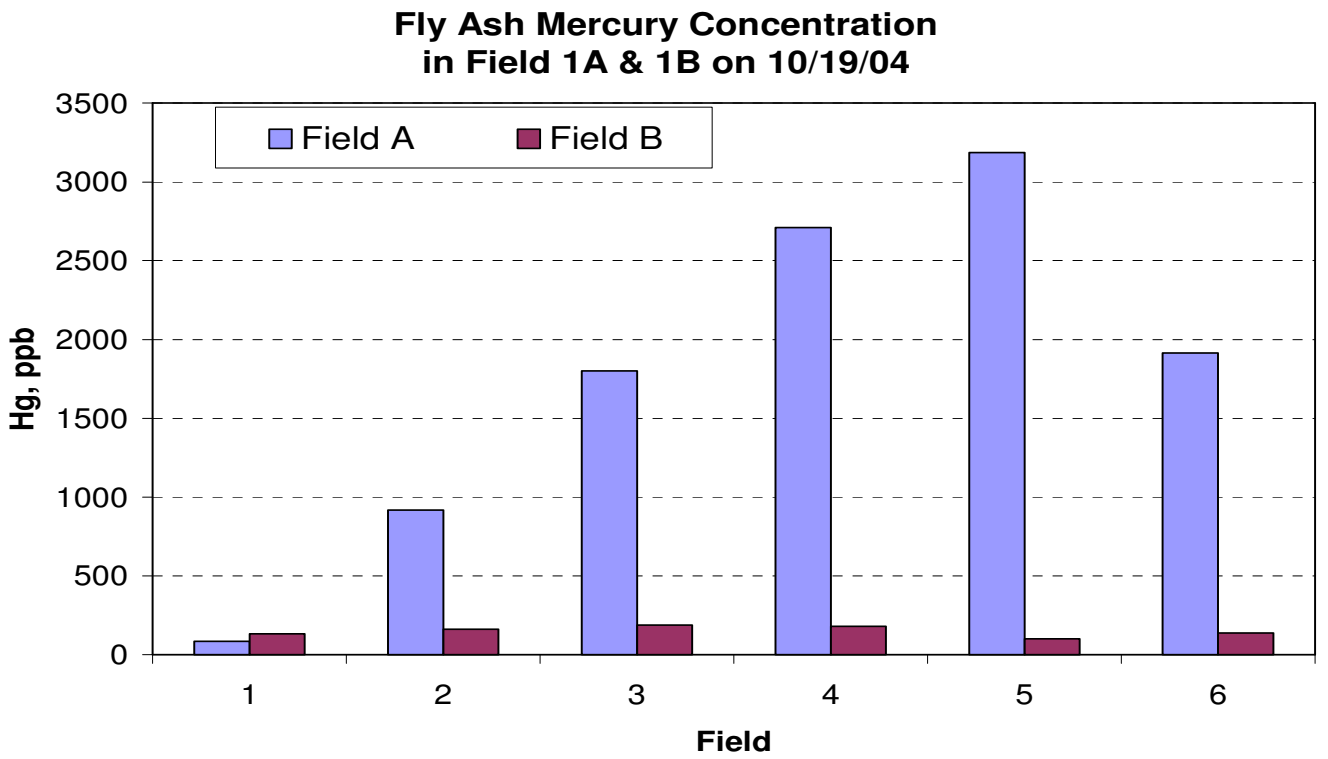


The impact of sorbent injection can be clearly seen. The fly ash $\mathrm{Hg}$ level in ESP 1B does not exceed $250 \mathrm{ppb}$ in any field but does so in all fields except Field 1 in ESP $1 \mathrm{~A}$.

In order to convert the fly ash mercury data into a mercury mass balance, the mass distribution of the fly ash in the fields must be known. Sorbent Technologies personnel, with the assistance of Detroit Edison personnel, conducted several tests to estimate the distribution of the fly ash by field in ESP $1 \mathrm{~A}$. Fields 1 and 3 were inoperable during the long-term test program. Field 1 acted as a drop out chamber with the material collected there resembling sand with a bulk density twice that of the fly ash collected in the other fields. Field 3 was not powered during the trial, but the rapper system remained in operation and a significant amount of fly ash, charged in Field 2, was collected in Field 3. It was estimated that the based upon hopper evacuation times that the mass distribution of the fly ash in ESP $1 \mathrm{~A}$ was $10 \%$ in Field $1,70 \%$ in Field 2, approximately $10 \%$ in Field 3 and $10 \%$ in Field 4 . The back two fields collected very little fly ash and, unlike the first four fields, the hoppers serving back fields were emptied only once per day. This distribution of fly ash by field for ESP $1 \mathrm{~A}$ was used in mass balance calculations.

A carbon mass balance was determined using the unburned carbon content of the fly ash and the fly ash distribution in the hoppers. The carbon mass balance provides a method of evaluating the mass balance assumptions and factors which will also be used in the mercury mass balance. The data for the carbon mass balance analysis is presented in Table 15.

Table 15. Long-Term Test Carbon Mass Balance

\begin{tabular}{|c|c|c|c|c|c|c|c|c|}
\hline Field & 1 & 2 & 3 & 4 & $\begin{array}{l}\text { Average } \\
\text { Due to } \\
\text { Sorbent }\end{array}$ & $\begin{array}{c}\text { Daytime } \\
\text { MW }\end{array}$ & $\begin{array}{c}\text { Fly } \\
\text { Ash, } \\
\text { thh }\end{array}$ & $\begin{array}{c}\text { Sorbent } \\
\text { Injected, } \\
\text { t/h }\end{array}$ \\
\hline 9/28 & 0.52 & 2.13 & 4.59 & 5.64 & 1.72 & 133 & 1.605 & 0.032 \\
\hline $9 / 30$ & 0.84 & 2.62 & 5.77 & 5.34 & 2.18 & 111 & 1.340 & 0.033 \\
\hline $10 / 2$ & 6.19 & 0.72 & 3.01 & 4.95 & 1.07 & 117 & 1.412 & 0.017 \\
\hline $10 / 4$ & 0.28 & 2.10 & 5.27 & 5.55 & 1.73 & 141 & 1.702 & 0.034 \\
\hline $10 / 11$ & & 2.88 & 6.86 & 6.62 & 2.52 & 138 & 1.666 & 0.048 \\
\hline $10 / 12$ & 0.46 & 2.61 & 6.40 & 5.08 & 2.17 & 129 & 1.557 & 0.039 \\
\hline $10 / 15$ & 0.71 & 4.02 & 8.00 & 6.04 & 3.44 & 126 & 1.521 & 0.060 \\
\hline $10 / 21$ & & 2.86 & 7.28 & 7.55 & 2.64 & 111 & 1.340 & 0.040 \\
\hline $10 / 23$ & & 1.56 & 5.70 & 4.29 & 1.24 & 118 & 1.424 & 0.020 \\
\hline Average & & & & & & & & 0.036 \\
\hline
\end{tabular}

The fly ash unburned carbon content and the fly ash distribution by field was used to determine an average unburned carbon content of the fly ash. The average unburned carbon content was reduced by the amount normally present without sorbent injection $(0.85 \%)$ to define the increased unburned carbon only due to sorbent. ESP $1 \mathrm{~A}$ collects approximately 3500 pounds of fly ash per hour when St. Clair Unit 1 is operating at the full coal load of $145 \mathrm{MW}$. The power generation rate during the daytime hours when the 
samples were collected was used to determine how much fly ash was generated on each day based upon a ratio compared with full coal load. Finally, the amount of sorbent injected was predicted based upon the average unburned carbon content of the fly ash. The B-PAC sorbent used in this test program contains only $88 \%$ carbon (with the majority of the remainder being ash). This factor was considered in calculating the amount of carbon injected. In this case, the calculation predicts that the injection rate was 0.036 tons per hour or 72 pounds per hour. The actual injection rate according to the gravimetric feeder data was 67 pounds per hour, providing a carbon mass balance of $107 \%$. This is a very good carbon mass balance considering all of the assumptions.

The mercury mass balance was determined in a similar manner. In this case, the mercury content of the fly ash in the first four fields was used to calculate an average fly ash mercury concentration. The baseline fly ash mercury content was not subtracted from the calculated average fly ash mercury content since a total mercury mass balance is being calculated. Again, the ratio of the daytime power generation rate and the full coal generation rate is used to convert the full coal usage rate (70 tons per hour) into a coal usage rate on a given day. Similarly, the daytime power generation rate is used to calculate a fly ash production rate for each day. It should be noted that the mercury content of the grinding rejects is higher than the coal but the amount of rejects (approximately 150 pounds per day) is insignificant in comparison to the amount of coal used. The data for the mercury mass balance is presented in Table 16.

\section{Table 16. Long-Term Test Mercury Mass Balance}

$\mathrm{Hg}$ in Fly Ash (ppb)

\begin{tabular}{|c|c|c|c|c|c|c|c|c|c|c|}
\hline Field & 1 & 2 & 3 & 4 & average & $\begin{array}{c}\mathrm{Hg} / \mathrm{coal} \text {, } \\
\mathrm{ppb}\end{array}$ & $\begin{array}{c}\text { Daytime } \\
\text { Load, } \\
\text { MW }\end{array}$ & $\begin{array}{c}\text { Fly } \\
\text { Ash, } \\
\text { t/h }\end{array}$ & $\begin{array}{c}\mathrm{Hg} \text { in } \\
\text { ash, } \\
10^{-6 t / h r}\end{array}$ & $\begin{array}{c}\mathrm{Hg} \text { in } \\
\text { coal, } \\
10^{-6 \mathrm{t} / \mathrm{hr}}\end{array}$ \\
\hline $9 / 24$ & & & & & & 60 & 135 & & & 1.955 \\
\hline $9 / 26$ & 34 & 1557 & 1737 & 2260 & 1493 & 50 & 75 & 0.905 & 1.351 & 0.905 \\
\hline $9 / 27$ & & & & & & 65 & 125 & & & 1.961 \\
\hline $9 / 28$ & 70 & 781 & 1671 & 2751 & 996 & & 133 & 1.605 & 1.598 & \\
\hline $9 / 29$ & & & & & & 35 & 134 & & & 1.132 \\
\hline $9 / 30$ & 78 & 687 & 1214 & 1840 & 794 & & 111 & 1.34 & 1.064 & \\
\hline $10 / 1$ & & & & & & 48 & 111 & & & 1.286 \\
\hline $10 / 2$ & 1192 & 81 & 883 & 2228 & 487 & 59 & 117 & 1.412 & 0.687 & 1.666 \\
\hline $10 / 3$ & & & & & & 65 & 129 & & & 2.024 \\
\hline $10 / 4$ & 64 & 1347 & 2914 & 1374 & 1378 & 66 & 141 & 1.702 & 2.346 & 2.246 \\
\hline $10 / 7$ & & & & & & 51 & 135 & & & 1.662 \\
\hline $10 / 9$ & & & & & & 45 & 132 & & & 1.434 \\
\hline $10 / 11$ & & 916 & 1679 & 2590 & 1068 & 69 & 138 & 1.666 & 1.779 & 2.298 \\
\hline $10 / 12$ & 96 & 1072 & 1577 & 2861 & 1204 & & 129 & & 1.874 & \\
\hline $10 / 13$ & & & & & & 50 & 123 & & & 1.484 \\
\hline $10 / 15$ & 57 & 1372 & 1422 & 2978 & 1406 & 67 & 126 & 1.521 & 2.139 & 2.038 \\
\hline $10 / 17$ & & & & & & 50 & 130 & & & 1.569 \\
\hline $10 / 19$ & & & & & & 41 & 120 & & & 1.188 \\
\hline $10 / 21$ & & 825 & 1607 & 2652 & 1003 & 41 & 111 & 1.34 & 1.344 & 1.099 \\
\hline $10 / 22$ & & & & & & 76 & 135 & & & 2.477 \\
\hline \multirow[t]{2}{*}{$10 / 23$} & & 522 & 2042 & 2895 & 859 & & 118 & 1.424 & 1.223 & \\
\hline & & & & & 1069 & 55 & & 1.499 & 1.541 & 1.672 \\
\hline
\end{tabular}


Some days with only coal analysis and some days with only fly ash analysis were included to provide better averages for the test program. The calculated average mercury input to the boiler through coal during the long-term test program was $1.67 \times 10^{-6}$ tons per hour as compared to the mercury captured in the fly ash of $1.54 \times 10^{-6}$ tons per hour. Thus, the mercury mass balance predicts that the $92.2 \%$ of the mercury entering St. Clair Unit 1 was captured. The mercury CEM data determined that the mercury capture rate was $94.2 \%$. Thus, the mercury mass balance provides a very good confirmation of the mercury removal rates determined by the mercury CEMs.

Another correlation of the mercury in the fly ash can be seen in Figure 30. In this figure, the average daily inlet $\mathrm{Hg}$ CEM mercury measurements is plotted on the same graph as the average daily fly ash mercury content. The fly ash mercury content followed the trend of the inlet $\mathrm{Hg}$ CEM data with higher levels observed when higher inlet mercury levels were observed. The outlet $\mathrm{Hg}$ CEM data is also presented for completeness. As would be expected from the high mercury removal rate achieved in the long-term test, the outlet mercury concentrations were very low throughout the test.

Figure 30. Fly Ash and CEM Hg Data during the Long-Term Test at St. Clair

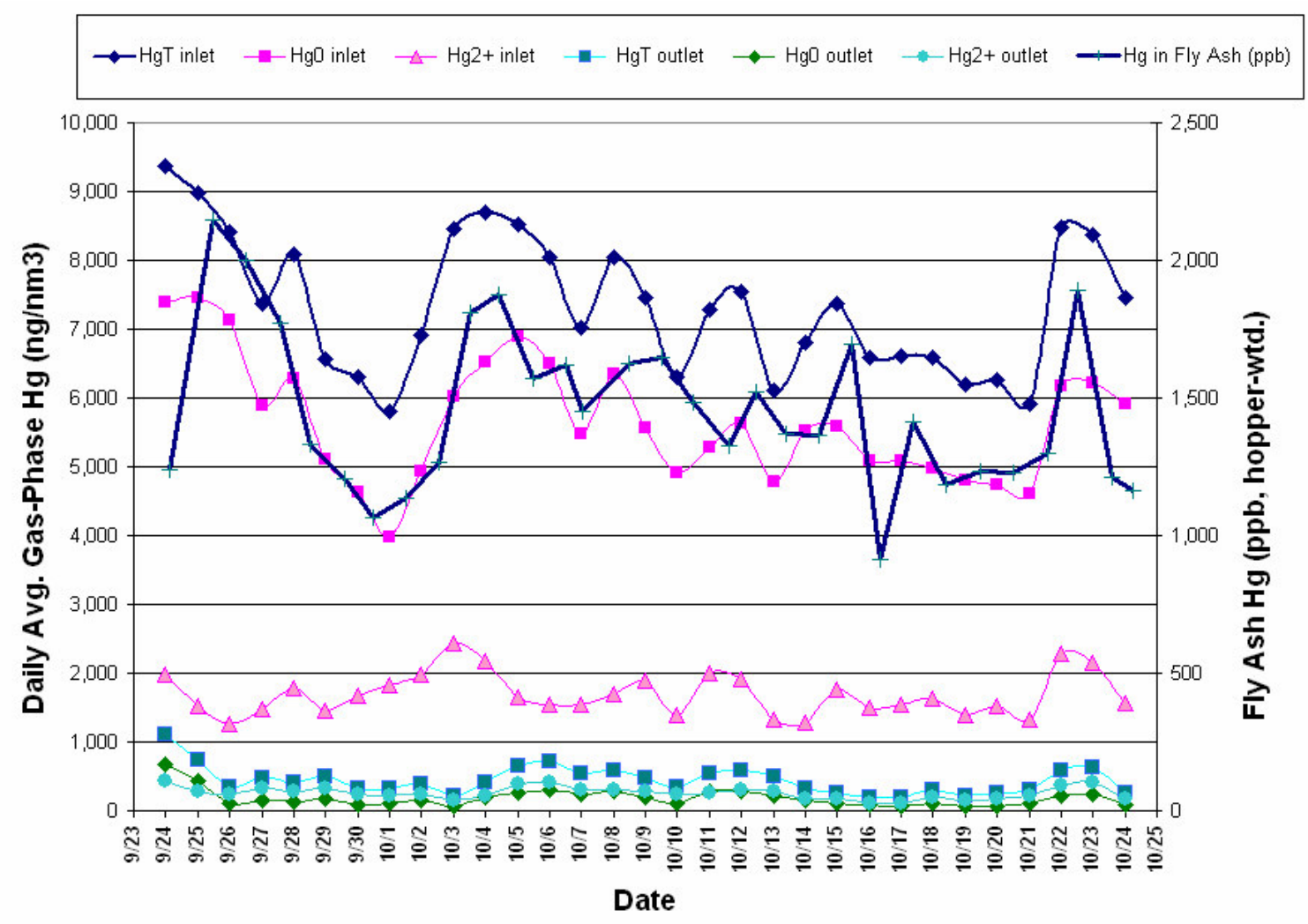

It has been noted in other test programs that the sorbent injected into an ESP can remain for weeks if not months in the system before it is removed. Detroit Edison personnel collected fly ash samples from the six fields of ESP 1A on three different days in the three weeks after sorbent injection was terminated. The long-term test ended on October 24, 2004. Sorbent Technologies analyzed these fly ash samples for mercury. Results are presented in Table 17. 
Table 17. Post Long-Term Test Fly Ash Mercury Content

\begin{tabular}{|c|c|c|c|c|c|c|}
\hline \multicolumn{7}{|c|}{ Fly Ash Hg content(ppb) } \\
\hline & Field & Field & Field & Field & Field & Field \\
Date & $\mathbf{1}$ & $\mathbf{2}$ & $\mathbf{3}$ & $\mathbf{4}$ & $\mathbf{5}$ & $\mathbf{6}$ \\
\hline $11 / 5 / 2004$ & 9 & 42 & 42 & 453 & 924 & 2258 \\
\hline $11 / 12 / 2004$ & 2 & 31 & 80 & 298 & 370 & 909 \\
\hline $11 / 17 / 2004$ & 7 & ND & 49 & 36 & 80 & 484 \\
\hline
\end{tabular}

Note: the long-Term test ended 10/24/2004

The first set of samples was collected on November 5, 2004, twelve days after sorbent injection was ended. The mercury levels in Fields 1-3 had recovered to their preinjection level but not those in Fields 4-6. In fact, the mercury content of the fly ash in Field 6 was still near that observed during the injection trial. The fly ash samples collected on November 12 and 17 (18 days and 23 days, respectively, after injection was stopped) show a continued decline in the fly ash mercury content. It is assumed that the main reason for the continued high mercury levels in the fly ash is inefficient ash removal from the hoppers. It was discovered during the parametric test that it was impossible to obtain a truly representative fly ash sample when only injecting for a few hours since any sample contained an unknown percentage of fly ash generated when sorbent was not being injected. Fields 5 and 6 are only evacuated daily, instead of continuously as are the hoppers in the other fields, and this probably increased the longevity of fly ash generated from the long-term test in these fields.

One additional calculation was made in order to evaluate the mercury data from this test program. The coal data for the day of each OHM test was used to determine the pounds of mercury per trillion Btu input. The OHM and CEM data was converted to these units using an F-factor method. The results of these calculations are presented in Table 18.

\section{Table 18. Coal, OHM and CEM Data in Ib/T Btu}

\begin{tabular}{|c|c|c|c|c|c|c|c|}
\hline Test & & Coal Btu/lb & Coal & Coal & Coal & Inlet OHM & $\begin{array}{l}\text { Inlet } \\
\text { CEM }\end{array}$ \\
\hline$\overline{\text { Period }}$ & Date & as Received & $\underline{\mathrm{Ib} / \mathrm{T} \text { Btu }}$ & $\underline{\mathrm{Hg}}, \mathrm{ppm}$ & $\underline{\mathrm{lb} \mathrm{Hg} / \mathrm{T} \mathrm{Btu}}$ & lb Hg/T Btu & $\mathrm{lb} \mathrm{Hg} / \mathrm{T} \mathrm{Btu}$ \\
\hline Baseline & $07 / 29 / 04$ & 9513 & $1.05 \mathrm{E}+08$ & 0.054 & 5.7 & 6.3 & 6.4 \\
\hline Parametric & 09/09/04 & 9857 & $1.01 E+08$ & 0.044 & 4.5 & 3.1 & 4.2 \\
\hline Long-Term & $10 / 06 / 04$ & 9896 & $1.01 E+08$ & 0.051 & 5.2 & 5.8 & 5.7 \\
\hline Long-Term & $10 / 21 / 04$ & 9546 & $1.05 E+08$ & 0.041 & 4.3 & 2.7 & 3.9 \\
\hline
\end{tabular}

The coal and inlet CEM data compare favorably on all four days of testing while the coal and inlet OHM data compare well only on the two days when the OHM data is close to the CEM data. On two days, the inlet OHM was substantially below the coal and CEM mercury data. These are also the days when the OHM data had the highest variability. This data is another argument for the OHM data being incorrect on the two days in question. It should also be noted that the outlet OHM measurement for the baseline test was about $8.0 \mathrm{lb} \mathrm{Hg} / \mathrm{T} \mathrm{Btu}$, far above any of the inlet data. Due to the inaccuracy of the OHM mercury data, it was not used to correct the CEM data throughout the program. 


\section{Bromine Off-Gassing}

In addition to the OHM testing, METCO Environmental performed Method 26A halogen testing at St. Clair on four occasions. The halogen testing was only performed at the outlet location on three of the four tests. For one test during the long-term injection run, the halogen testing was performed at both the inlet and outlet locations. The halogen test data is presented in Table 19.

\section{Table 19. Halogen Data from the Testing at St. Clair Unit 1A}

\begin{tabular}{|c|c|c|c|}
\hline $\begin{array}{l}\text { Without } \\
\text { Sorbent }\end{array}$ & $\begin{array}{l}\text { Baseline } \\
07 / 28 / 04\end{array}$ & & $\begin{array}{c}\text { Inlet }- \text { Long-Term } \\
10 / 21 / 04\end{array}$ \\
\hline $\mathrm{HF}$ & 1.0 & & 0.4 \\
\hline $\mathrm{HCl}$ & 8.1 & & 3.6 \\
\hline $\mathrm{Cl}_{2}$ & $<0.1$ & & 0.3 \\
\hline $\mathrm{HBr}$ & 0.1 & & $<0.1$ \\
\hline $\begin{array}{l}\text { With B-PAC } \\
@ 3 \mathrm{lb} / \mathrm{MMacf}\end{array}$ & $\begin{array}{l}\text { Parametric } \\
09 / 09 / 04\end{array}$ & $\begin{array}{c}\text { Long-Term } \\
10 / 06 / 04\end{array}$ & $\begin{array}{c}\text { Long-Term } \\
10 / 21 / 04\end{array}$ \\
\hline $\mathrm{HF}$ & 2.2 & 0.1 & 0.4 \\
\hline $\mathrm{HCl}$ & 5.9 & 6.0 & 4.3 \\
\hline $\mathrm{Cl}_{2}$ & 0.1 & 0.2 & 0.4 \\
\hline $\mathrm{HBr}$ & 1.0 & 0.3 & 0.2 \\
\hline
\end{tabular}

Though the error bars for this data are probably relatively great, there did not appear to be significant hydrogen bromide evolution, at least during the long-term run. Without sorbent injection, baseline $\mathrm{HBr}$ was measured at $0.1 \mathrm{ppm}$ and an inlet sample during the long-term run resulted in a $<0.1 \mathrm{ppm}$ reading. $\mathrm{HBr}$ measurements at the ESP outlet during long-term injection were only 0.3 and $0.2 \mathrm{ppm}$. Note that bromine was not detected in any of the measurements.

\section{Possible HBr Corrosion Issues}

If significant $\mathrm{HBr}$ was released from $\mathrm{B}-\mathrm{PAC}$, duct and ESP corrosion is possible. Barry Dooley, a corrosion expert at EPRI, had indicated that, even if $100 \%$ of the bromine were to leave the activated carbon and enter the gas stream, there would be no impact on corrosion because $\mathrm{SO}_{3}$ was the driving force behind such corrosion. Nevertheless, four carbon steel corrosion coupons were installed as per EPRI recommendations for 30 days during the baseline testing period and four more for 30 days during the long-term test. After removal, the coupons were cleaned and reweighed, per ASTM methods. The average weight change results are in Table 20.

Table 20. Corrosion Coupon Data from the Testing at St. Clair Unit 1A (4 each, 30 days)

\begin{tabular}{|l|c|}
\hline & Average $\Delta$ Weight \\
\hline Baseline Period & $+0.13 \%$ \\
\hline Continuous B-PAC Injection & $+0.13 \%$ \\
\hline
\end{tabular}


The average weight gain from both sets of coupons was the same, $0.13 \%$. Of the eight samples, only one coupon experienced any weight loss at all and the loss was very slight. Based on weight loss for the time period tested, there was no corrosion evident due to the use of brominated sorbents.

\section{Bromine and Mercury in Leachates from St. Clair Fly Ash Containing B-PAC}

Fly ashes containing some of the sorbents that were tested in the parametric runs and the long-term B-PAC run were leached with deionized water (DI), an acetic acid solution (Toxic Characteristic Leaching Procedure, TCLP), and an alkaline $\mathrm{Na}_{2} \mathrm{CO}_{3}$ solution (Synthetic Groundwater leaching Procedure, SGLP) and the leachates were examined for bromide. The results appear in Figure 31 below. In the SGLP tests, leachates of the fly ash without sorbents contained about $20 \mathrm{ppm} \mathrm{Br}$ and that of the fly ash containing plain carbon contained about $10 \mathrm{ppm} \mathrm{Br}^{-}$., but little $\mathrm{Br}^{-}$was found in the DI and TCLP leachates of either sample. About 20 to $30 \mathrm{ppm} \mathrm{Br}$ was found in the SGLP B-PAC leachates and from 10 to $20 \mathrm{ppm}$ in the DI and TCLP leachates of these fly ashes.

None of these concentrations are significant for a halide. For perspective, the Earth's oceans contain an average about $70 \mathrm{ppm} \mathrm{Br}$.

Figures 31 \& 32 . Bromine and Mercury in Fly Ash Leachates
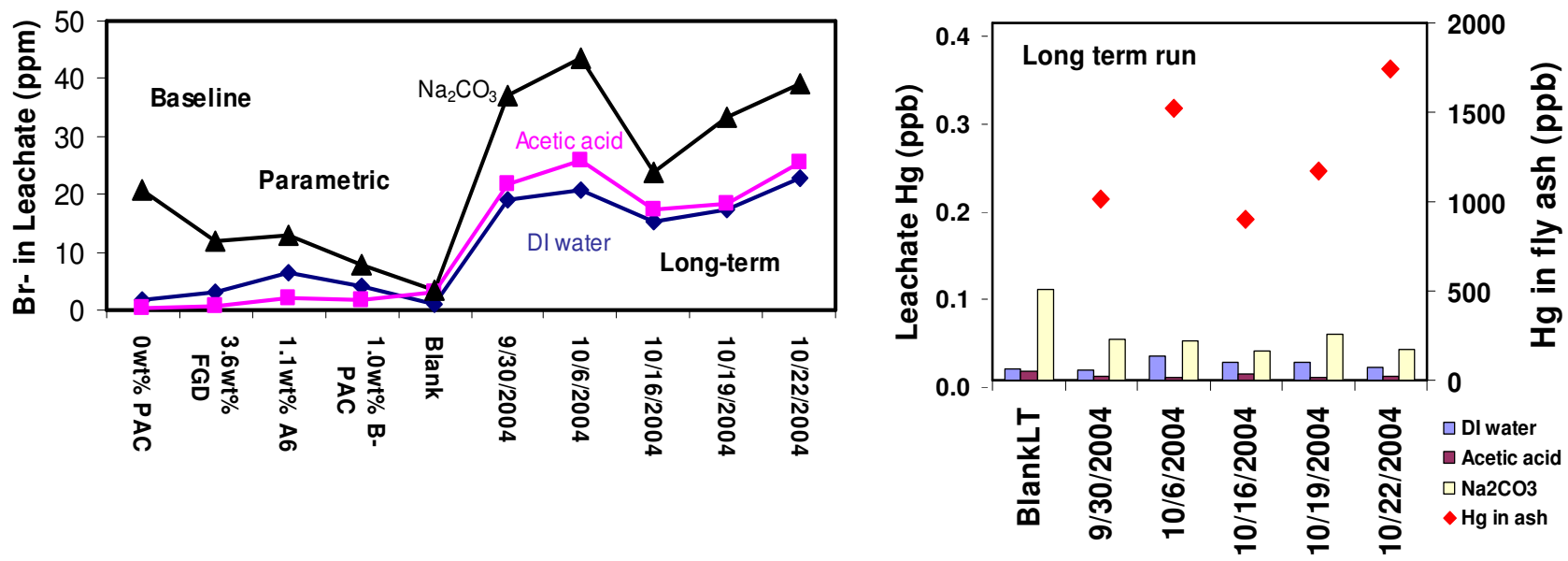

Project fly ashes were also tested for released mercury in the various leachates. Data from the long-term run fly ashes containing B-PAC appear above in Figure 32. Mercury did not appear to leach from the sorbents in the fly ash: the detected mercury levels were all extremely low, despite relatively high $\mathrm{Hg}$ in the fly ash samples. In fact, from comparisons with the blank samples, with the deionized water and alkaline samples it appeared that the mercury flux was from the leaching solution to the solids. The sorbents appeared to still have unutilized mercury adsorption capacity and were adsorbing the trace mercury that came in with the leaching solutions. 


\section{Operation of the St. Clair Boiler 1 During the Long-Term Test Period}

Detroit Edison St. Clair Unit 1 operated normally for the entire period of the long-term test. The boiler operation was under AGC (Automatic Governance Control) for most of the long-term test period. In this manner, the boiler load could be automatically varied, within limits, by a remote computer system matching production to the needs of the power grid. The boiler was under the control of the site operators when not in AGC. There were no requirements made on boiler operation during the long-term test. The injection system was to adjust to the boiler load to maintain the desired $3.0 \mathrm{lb} / \mathrm{MMacf}$ injection rate. This will be the standard method of operation once mercury control technology is commercially used. The control technology should be transparent to generating power. The boiler load in gross MW is presented in Figure 33.

The boiler load during the long-term test had its normal pattern generally varying between $120 \mathrm{MW}$ and $145 \mathrm{MW}$, as needed, during the day and dropping to between 40 $\mathrm{MW}$ and $50 \mathrm{MW}$ at night. The oil was over-fired along with coal on October 18 in order to achieve the maximum load of $160 \mathrm{MW}$, which was maintained for about four hours. The mercury removal on this day was the same as for the others during the long-term test indicating that the oil injection had no impact upon mercury sorbent injection.

The flue gas oxygen content follows the opposite trend to load, since air flow is not decreased in proportion to boiler load in order to avoid depositing fly ash in the ductwork at low loads. The flue gas oxygen content measured at the preheater outlet is presented in Figure 34.

The flue gas oxygen content as measured at the preheater outlet is about $6 \%$ at the higher loads and at least $10 \%$ at the lower loads. The oxygen monitor at this location has a high span of $10 \%$.

Albemarle Environmental, f/k/a Sorbent Technologies provided the instrumentation to measure the temperature and flow of the flue gas at the point of sorbent injection. The instrument location is the center port of the seven shown in Figure 15. The flue gas temperature at the injection location is presented in Figure 35.

The flue gas temperature has the same pattern as the boiler load in that the highest temperatures are recorded at the highest load. The flue gas temperature has the opposite pattern of the flue gas oxygen content. The net result of these opposite trends is that the flue gas flow rate does not exhibit the pattern of high flows during the daytime and low flow during the night but is rather stable as can be seen in Figure 36. 
Figure 33. Boiler Load during the Long-Term Test
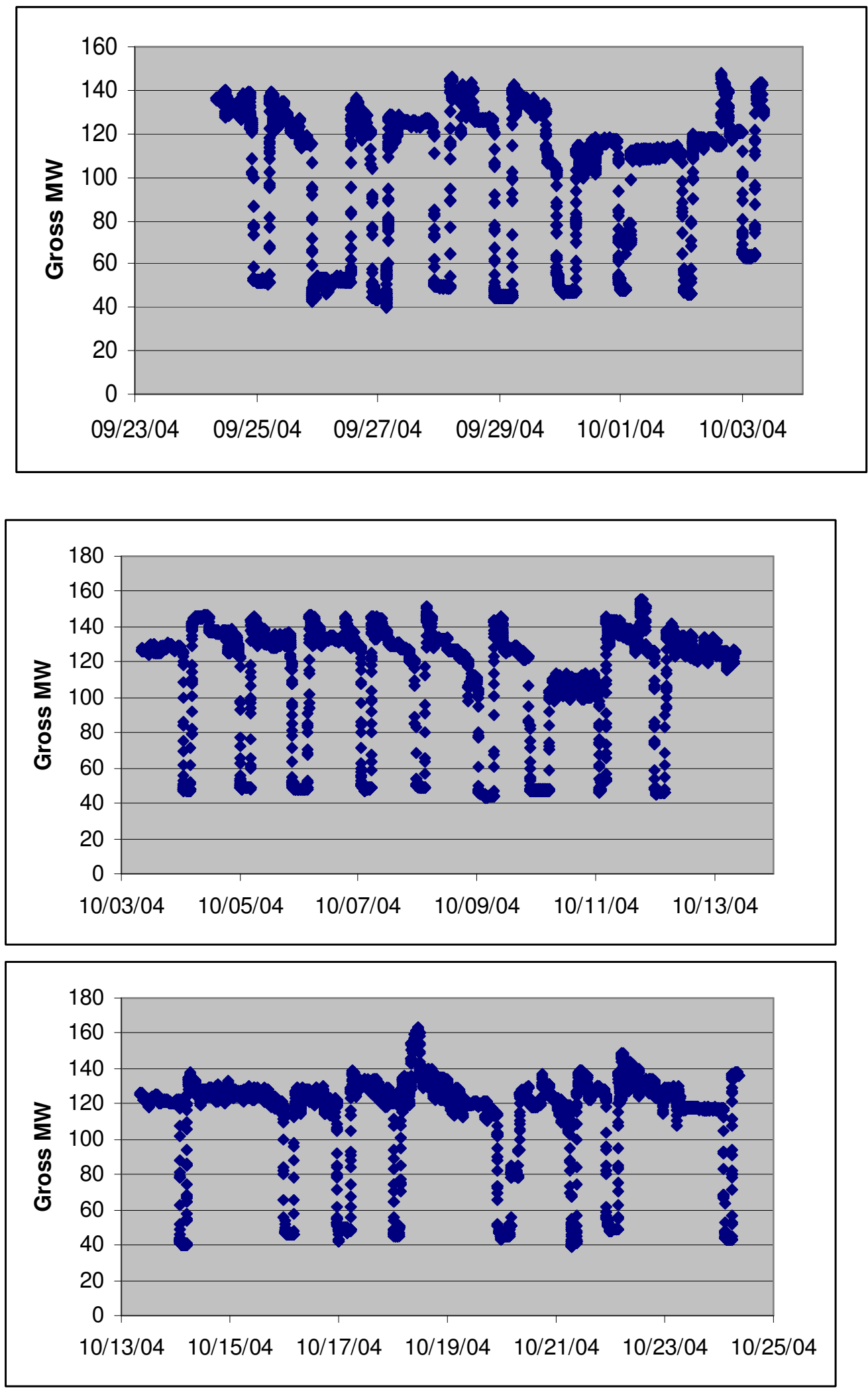
Figure 34. Preheater Outlet $\mathrm{O}_{2}$ during the Long-Term Test
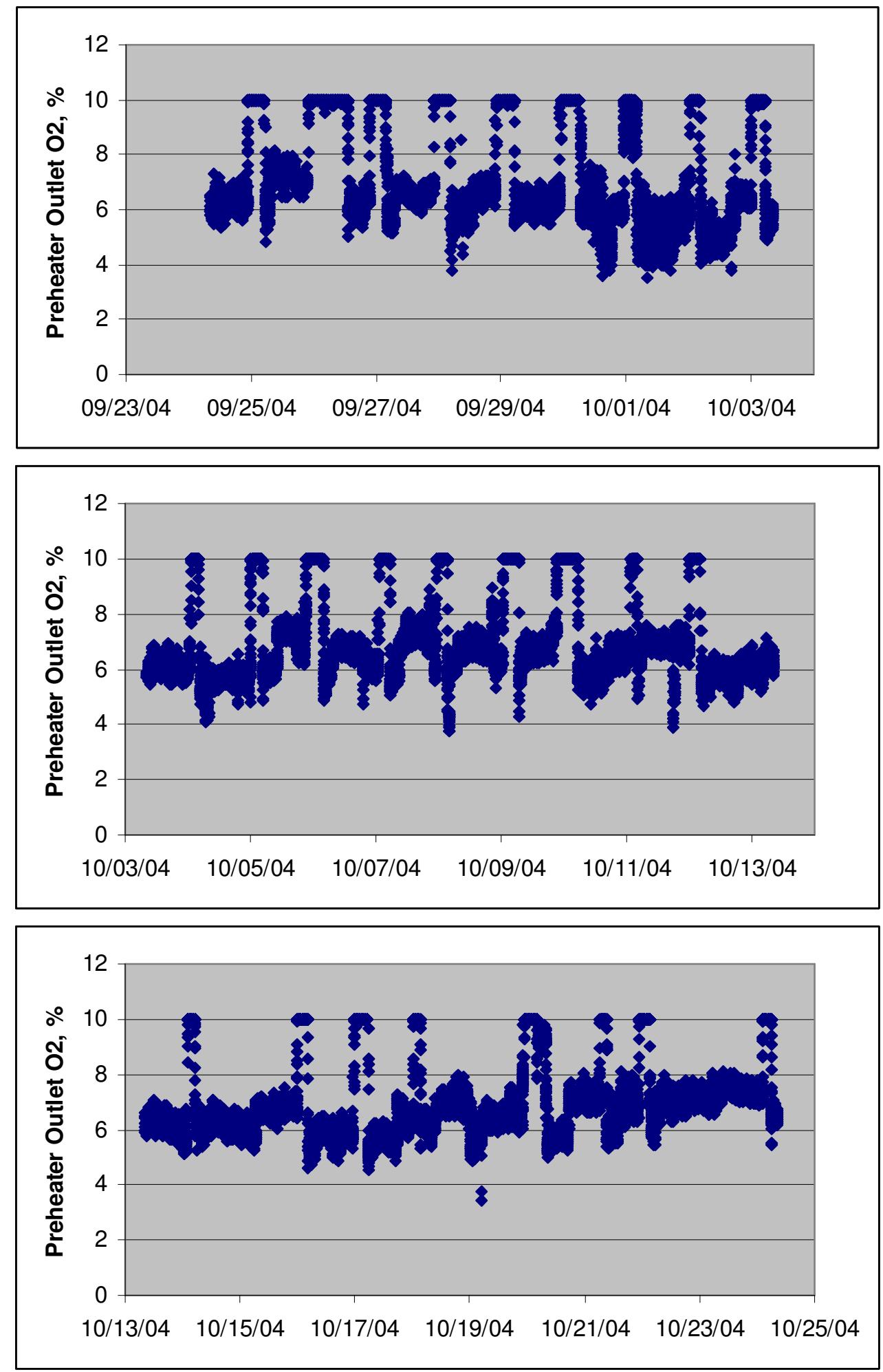
Figure 35. Flue Gas Temperature at Injection during the Long-Term Test
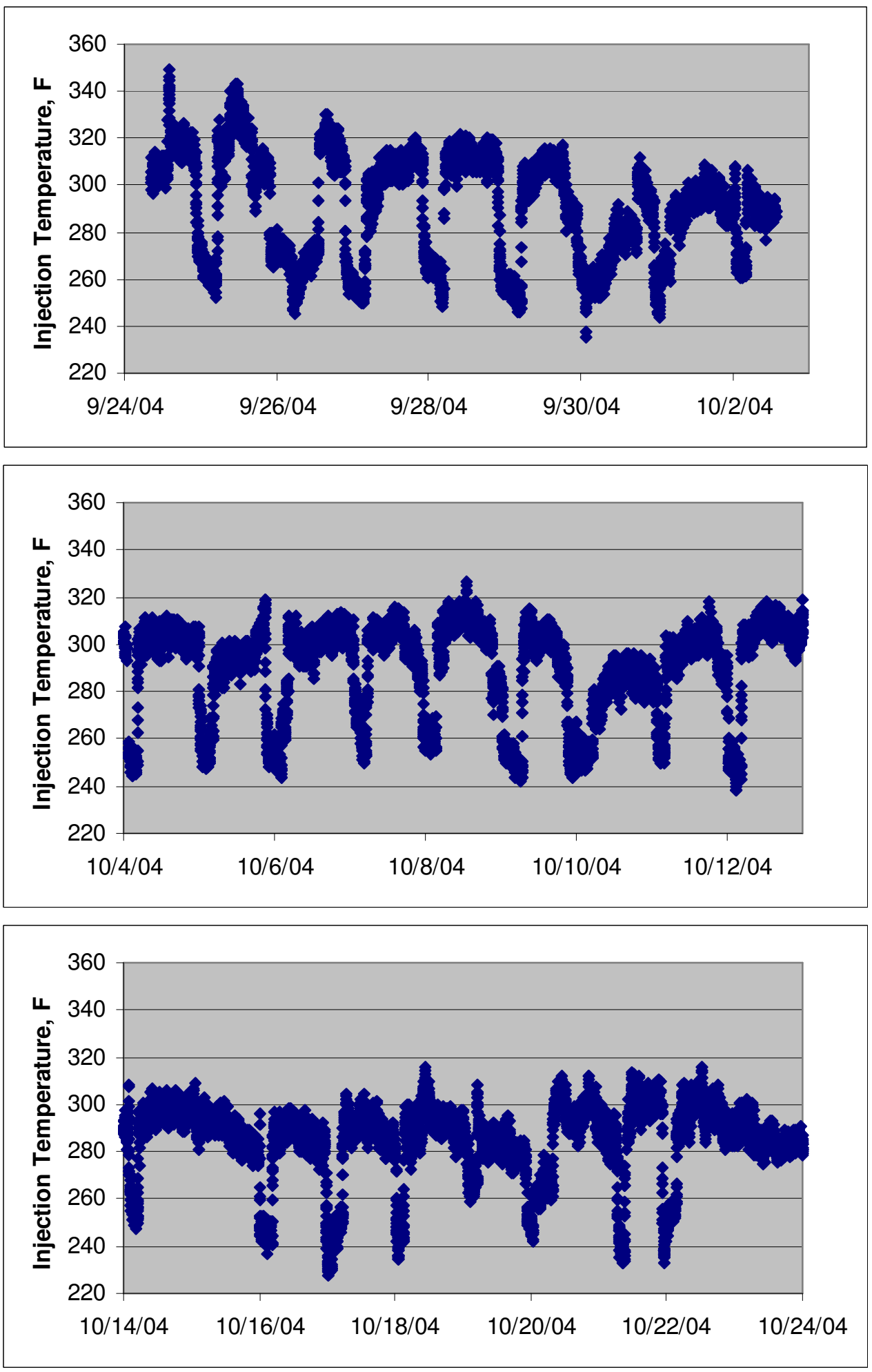
Figure 36. Flue Gas Flow Rate at the Point of Injection during the Long-Term Test
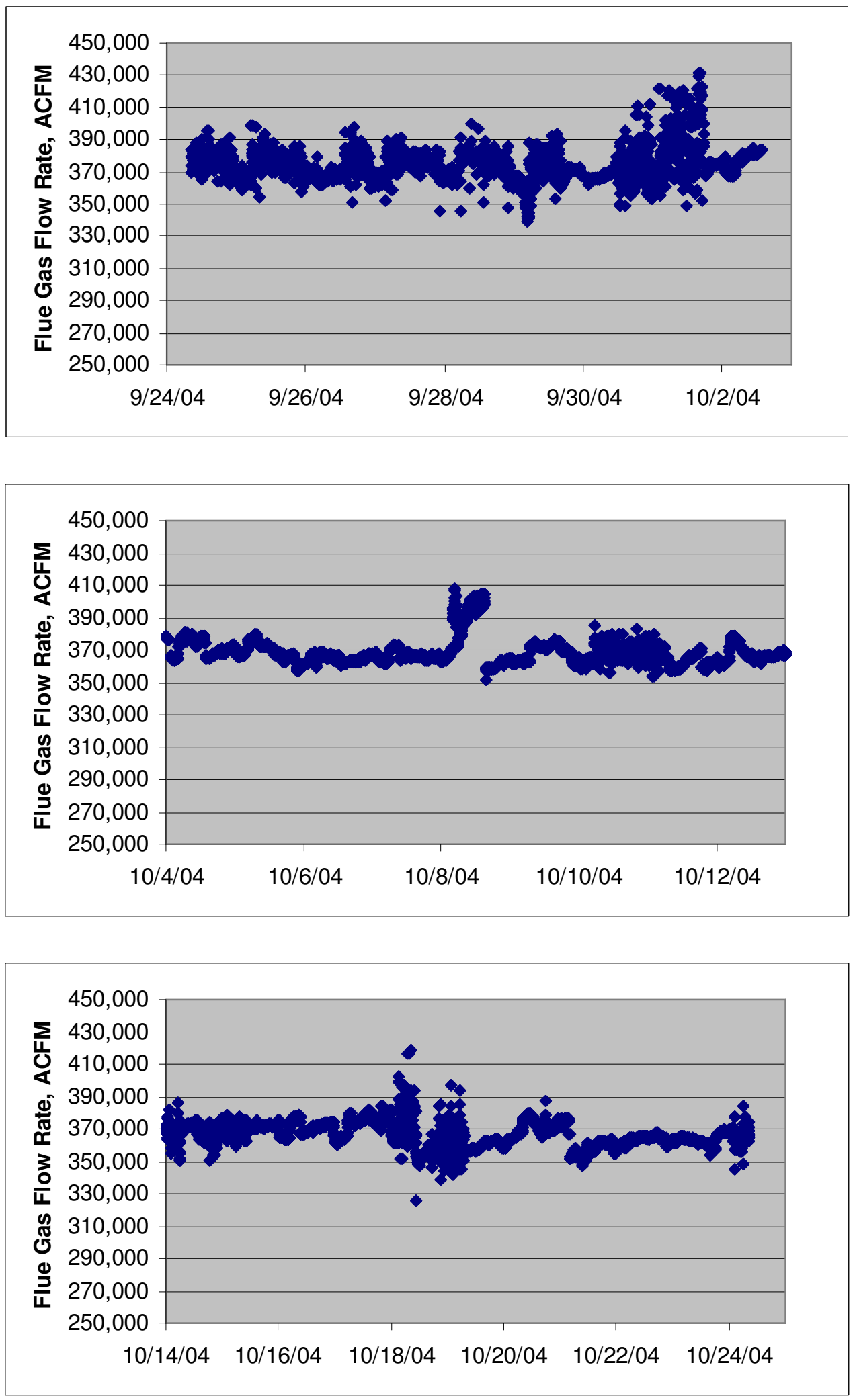


\section{Possible ESP Effects}

The cold-side ESP at the Detroit Edison St. Clair Power Plant Unit 1A was only fully operating four of the six available fields. Field 1 was acting essentially as a dropout chamber while Field 3 collected fly ash which had been charged in Field 2 . The rappers on Field 3 were maintained in operation. Even with two fields out of service, the SCA of ESP 1A was still large and it was expected that there would be no impact of sorbent injection, amounting to only about a $2 \%$ increase in particulate load, on the flue gas opacity. None was observed in the parametric program in August, even when injecting Norit Darco FGD PAC at an injection rate of $12 \mathrm{lb} /$ MMacf. See the opacity plot below.

\section{Figure 37. Flue Gas Opacity during Some Parametric Testing}

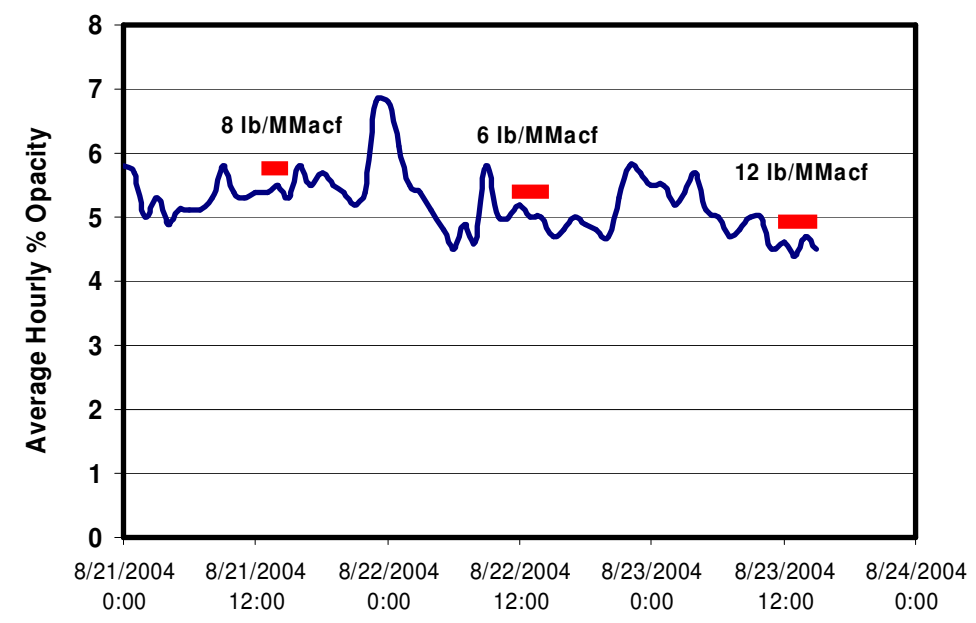

During the September long-term run, the plant background opacity was even lower. Plant opacity measured during the long-term test is presented in Figure 39. There was no evidence of increased particulate emissions due to the sorbent injection.

Figure 38. Flue Gas Opacity during the Long-Term Test at St. Clair

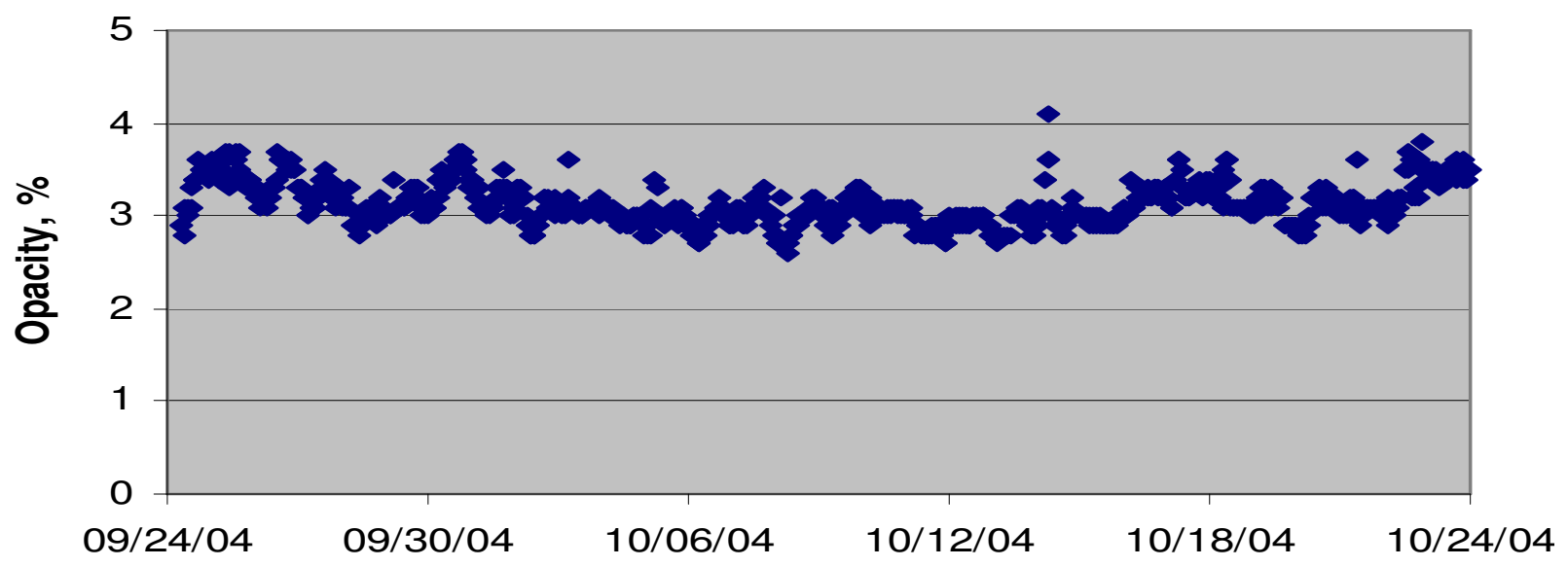




\section{Mercury Control Cost Analysis}

\section{Capital Costs}

The capital equipment and installation effort at St. Clair was relatively minimal and do not conflict with estimates of $\$ 1.5 / \mathrm{kW}$ or less for retrofitted activated carbon systems, including mercury measurement.

\section{Operating \& Maintenance Costs}

Because so little capital equipment was necessary at St. Clair, operating and maintenance costs were, and will be, the dominant costs in control systems such as this. By far the dominant O\&M cost for mercury control using sorbent injection will be the cost of the sorbent.

In these tests at the Detroit Edison's St. Clair Power Plant, a mercury removal rate of $70 \%$ could be achieved at a B-PAC injection rate of $1.0 \mathrm{lb} / \mathrm{MMacf}$ and a long-term mercury removal rate of over $90 \%$ was observed with an injection rate of $3.0 \mathrm{lb} / \mathrm{MMacf}$. These results are when the boiler was firing a $85 \%$ subbituminous $/ 15 \%$ bituminous coal blend. Slightly higher results were achieved when $100 \%$ subbituminous coal was in use.

For these calculations, the data for the coal blend is utilized. A mercury concentration at the point of injection of $5 \mu \mathrm{g} / \mathrm{Nm}^{3}$, under actual gas conditions, is also assumed in the calculation, and it is assumed that the B-PAC cost is $\$ 1.00 / \mathrm{lb}$.

The cost calculation for $70 \%$ mercury removal would be as follows:

$$
\left(\frac{1 \mathrm{lbsorbent}}{1,000,000 \mathrm{acf}}\right)\left(\frac{\mathrm{Nm} 3}{(70 \%) 5 \mu \mathrm{Hg}}\right)\left(\frac{\$ 1.00}{\text { lbsorbent }}\right)\left(\frac{1.5 \text { acf } @ 300 \mathrm{~F}}{1 \mathrm{scf}}\right)\left(\frac{35.3 \mathrm{scf}}{\mathrm{Nm}^{3}}\right)\left(\frac{10^{9} \mu \mathrm{Hg}}{2.2 \mathrm{lb} \mathrm{Hg} \text { removed }}\right)=\$ 6,900 / \mathrm{lbHg} \text {. }
$$

$94 \%$ mercury removal would similarly cost:

$$
\left(\frac{3 \mathrm{lbsorbent}}{1,000,000 \mathrm{acf}}\right)\left(\frac{\mathrm{Nm} 3}{(94 \%) 5 \mu \mathrm{Hg} g}\right)\left(\frac{\$ 1.00}{\text { lb sorbent }}\right)\left(\frac{1.5 \mathrm{acf} @ 300 \mathrm{~F}}{1 \mathrm{scf}}\right)\left(\frac{35.3 \mathrm{scf}}{\mathrm{Nm}^{3}}\right)\left(\frac{10^{9} \mu \mathrm{gHg}}{2.2 \mathrm{lb} \mathrm{Hg} \text { removed }}\right)=\$ 15,500 / \mathrm{lbHg} \text {. }
$$

These sorbent consumption costs are for Detroit Edison St. Clair, whose coal-Hg, and consequent $5 \mu \mathrm{g} / \mathrm{Nm}^{3}$ of gas-phase $\mathrm{Hg}$ at injection, are slightly lower than the median and average for subbituminous coal-burning plants. Costs would be even lower for the median and average subbituminous plants.

These costs are only a fraction of what has been previously predicted for the cost of retrofit mercury control with plain powdered activated carbon. See, for example, the historic "baseline" cost estimate of the Department of Energy of $\$ 50,000$ to $\$ 70,000$ per pound of $\mathrm{Hg}$ removed. ${ }^{(1)}$ 


\section{Duke Power Cliffside Station}

Testing was conducted on two different occasions at the Duke Power Cliffside Station Unit 2. The first test was conducted from 9/12-24/03. The purpose of this test was to obtain baseline mercury data and determine whether brominated PACs had the potential of capturing mercury at the elevated temperatures present in a hot-side ESP. The testing at the much larger Duke Power Buck Station Unit 6, also equipped with a hotside ESP, would only be conducted if the results from this qualification test at the Cliffside Station indicated that the sorbents had potential to capture a significant amount of mercury from the flue gas. The second set of tests at the Cliffside Station was conducted from 12/3-11/04. The purpose of these tests was to evaluate new brominated sorbents designed for hot-side applications $\left(\mathrm{H}-\mathrm{PAC}^{\mathrm{TM}}\right)$ at different operating conditions.

\section{Cliffside I-September 2003}

\section{Test Plan}

The test plan for the hot-side ESP test at the Cliffside Plant is presented in Table 21.

Table 21. Duke Power Cliffside Plant Hot-Side ESP Hg Sorbent Trial Plan

\begin{tabular}{|c|c|c|c|c|c|c|c|c|c|c|}
\hline & \multicolumn{2}{|c|}{ Friday $9 / 12 / 03$} & \multicolumn{2}{|c|}{ Saturday $9 / 13 / 03$} & \multicolumn{2}{|c|}{ Sunday $9 / 14 / 03$} & & & & \\
\hline & \multicolumn{2}{|c|}{ Day 1} & \multicolumn{2}{|c|}{ Day 2} & \multicolumn{2}{|c|}{ Day 3} & & & & \\
\hline & a.m. & $\frac{\text { p.m. }}{3.00}$ & a.m. & p.m. & a.m. & p.m. & & & & \\
\hline \multirow[t]{5}{*}{ Activities } & Travel & Safety & \multicolumn{2}{|c|}{ Equipment } & \multicolumn{2}{|c|}{ Equipment } & & & & \\
\hline & & Meeting & \multicolumn{2}{|c|}{ Assembly } & \multicolumn{2}{|c|}{ Check-out } & & & & \\
\hline & \multicolumn{2}{|c|}{ Monday $9 / 15 / 03$} & \multicolumn{2}{|c|}{ Tuesday 9/16/03 } & \multicolumn{2}{|c|}{$\frac{\text { Wednesday }}{9 / 17 / 03}$} & \multicolumn{2}{|c|}{ Thursday $9 / 18 / 03$} & \multicolumn{2}{|c|}{ Friday $9 / 19 / 03$} \\
\hline & \multicolumn{2}{|c|}{ Day 4} & \multicolumn{2}{|c|}{ Day 5} & \multicolumn{2}{|c|}{ Day 6} & \multicolumn{2}{|c|}{ Day 7} & \multicolumn{2}{|c|}{ Day 8} \\
\hline & a.m. & p.m. & a.m. & p.m. & a.m. & p.m. & a.m. & p.m. & a.m. & p.m. \\
\hline Sorbent & & None & $A-5$ & $A-5$ & A-1 & $A-11$ & A-1 & $A-1$ & $A-1$ & $A-1$ \\
\hline \multicolumn{2}{|c|}{ OHM Testing } & Yes & & Yes & & Yes & Yes & & Yes & \\
\hline \multirow[t]{2}{*}{ Activities } & CEM & Baseline & Sorbent & Sorbent & Sorbent & Sorbent & Sorbent & Sorbent & Sorbent & Sorben \\
\hline & $\begin{array}{c}\text { begins } \\
\text { Test } \mathrm{E}\end{array}$ & Testing & Injection & Injection & Injection & Injection & $\begin{array}{c}\text { Injection } \\
\text { Varying }\end{array}$ & $\begin{array}{l}\text { Injection } \\
\text { ad 11-40 }\end{array}$ & Injection & jection \\
\hline
\end{tabular}

\begin{tabular}{|c|c|c|c|c|c|c|c|c|}
\hline & $\frac{\text { Saturday } 9 / 20 / 03}{\text { Day } 9}$ & $\frac{\text { Sunday } 9 / 21 / 03}{\text { Day } 10}$ & $\frac{\text { Monda }}{\mathrm{D}}$ & $\frac{9 / 22 / 03}{11}$ & $\frac{\text { Tuesd }}{\mathrm{D}}$ & $\frac{/ 23 / 03}{2}$ & $\frac{\text { Wednesda }}{\text { Day }}$ & 24/03 \\
\hline orbent & a.m. & p.m. & $\frac{\text { a.m. }}{A-6}$ & $\frac{\text { p.m. }}{\text { A-6 }}$ & $\frac{\text { a.m. }}{A-5 F}$ & $\frac{\text { p.m. }}{\text { A-12 }}$ & a.m. & p.m. \\
\hline Sorbent & & & & & A-6 & A- 0 & & \\
\hline Activities & $\begin{array}{l}\text { Boiler Down } \\
\text { Equipment Repair } \\
\text { and Calibration }\end{array}$ & $\begin{array}{l}\text { Boiler Down } \\
\text { Equipment Repair } \\
\text { and Calibration }\end{array}$ & $\begin{array}{l}\text { Sorbent } \\
\text { Injection }\end{array}$ & $\begin{array}{l}\text { Sorbent } \\
\text { Injection }\end{array}$ & $\begin{array}{l}\text { Sorbent } \\
\text { Injection }\end{array}$ & $\begin{array}{l}\text { Sorbent } \\
\text { Injection }\end{array}$ & $\begin{array}{l}\text { Equipment } \\
\text { Disassembly }\end{array}$ & Travel \\
\hline
\end{tabular}

The plan called for arriving at the plant on Friday September 12, 2003 to attend a safety orientation meeting. All of the mercury monitoring equipment and the sorbent injection equipment was assembled and checked out over the next two days. Monday was a baseline measurement day during which the mercury CEM operation was initiated and a 
series of $\mathrm{OHM}$ tests performed. The injection trials began the next day and ran through Friday. A series of OHM tests were made on each of these days. The mercury CEM operation continued throughout the week. On the weekend, all of the equipment was inspected and recalibrated. The injection trials resumed on Monday September 22 and ran for two more days. The Hg CEM was in operation during these days, but no OHM tests were run. The equipment was disassembled on Wednesday September $24^{\text {th }}$ and the test crews departed.

A total of seven different sorbents were evaluated during the Cliffside tests, including the Norit Darco FGD PAC yardstick sorbent (now Norit Darco Hg). The other sorbents were prepared by Albemarle Environmental, $\mathrm{f} / \mathrm{k} / \mathrm{a}$ Sorbent Technologies in their facilities in Twinsburg, Ohio.

\section{Safety}

Duke Power Cliffside Plant personnel provided safety and environmental awareness training to all of the Albemarle Environmental, $f / k / a$ Sorbent Technologies Corporation personnel who worked on site. As a result of the dedicated effort of all concerned parties, there were no accidents or adverse environmental events during the testing program.

\section{Parametric Testing}

The various operating conditions tested in the Cliffside trials are shown in Table 22.

Table 22. Duke Power Cliffside Plant Test Conditions

\begin{tabular}{|c|c|c|c|c|c|}
\hline Date & Sorbent & $\begin{array}{c}\text { Injection } \\
\text { Rate, } \\
\text { lb/MMacf }\end{array}$ & $\begin{array}{l}\text { Power } \\
\text { Rate } \\
\text { MW }\end{array}$ & $\begin{array}{c}\text { Injection } \\
\text { Temp., } \\
\underline{F}\end{array}$ & $\begin{array}{c}\text { Flue Gas } \\
\text { Flow Rate, } \\
\text { acfm }\end{array}$ \\
\hline $9 / 15 / 03$ & None & NA & 40 & 655 & 294,000 \\
\hline 9/16/03 & $A-5$ & 3.3 & 40 & 686 & 304,000 \\
\hline 9/16/03 & $A-5$ & 7.1 & 40 & 686 & 304,000 \\
\hline 9/17/03 & $A-1$ & 1.8 & 40 & 686 & 299,000 \\
\hline 9/17/03 & $A-1$ & 3.3 & 40 & 686 & 299,000 \\
\hline $9 / 17 / 03$ & $A-1$ & 5.7 & 40 & 686 & 299,000 \\
\hline 9/17/03 & $A-11$ & 4.1 & 40 & 686 & 299,000 \\
\hline $9 / 18 / 03$ & $A-1$ & 6.2 & 12 & 530 & 77,000 \\
\hline 9/18/03 & $A-1$ & 4.9 & 20 & 572 & 129,000 \\
\hline $9 / 18 / 03$ & $A-1$ & $\begin{array}{r}3.8 \\
\text { Ramp } \\
\end{array}$ & 30 & 640 & 237,000 \\
\hline 9/19/03 & $A-1$ & 0 to 10.3 & 40 & 676 & 324,000 \\
\hline 9/19/03 & $A-1$ & 3.8 & 40 & 676 & 324,000 \\
\hline 9/22/03 & A- 6 & 4.9 & 40 & 665 & 305,000 \\
\hline 9/22/03 & $A-6$ & 4.0 & 40 & 665 & 305,000 \\
\hline 9/22/03 & $A-6$ & 5.6 & 40 & 665 & 305,000 \\
\hline 9/23/03 & A- 6 & 5.1 & 40 & 662 & 305,000 \\
\hline 9/23/03 & $A-5 F$ & 3.9 & 40 & 662 & 305,000 \\
\hline
\end{tabular}




$\begin{array}{cccccc}\text { 9/23/03 } & \text { A-12 } & 3.9 & 40 & 662 & 305,000 \\ & \text { Darco } & & & 662 & 305,000\end{array}$

When the boiler operated at $40 \mathrm{MW}$, the temperature at the injection location ranged between $655^{\circ} \mathrm{F}$ and $686^{\circ} \mathrm{F}$. The boiler also routinely operated at different loads down to about $12 \mathrm{MW}$, though lower-load operation was only tested one day. The flue gas flow rates at the injection location were difficult to measure accurately due to highly-skewed gas flow in the duct. As a result, the flow data from the stack was corrected for temperature and oxygen content to calculate the flue gas flow rates shown. The flow rate at the injection location was about 300,000 acfm under maximum load and about 75,000 acfm at minimum load.

During these short-term tests, the sorbents were injected at rates from 1.8 to 11.2 $\mathrm{lb} /$ MMacf under a variety of operating conditions. The average duration of a test was about two hours.

The mercury removal was evaluated using three methods. The data from the mercury CEM was used to make one of these calculations. The high-temperature inlet sampling system had problems throughout the test program, so only data from the stack outlet CEM was utilized for evaluating performance. The mercury concentrations at the stack before and during sorbent injection were compared to provide the mercury removal value by this method.

An example of the Hg CEM data, this for Wednesday September $17^{\text {th }}$, is shown in Figure 39. A series of injection trials was conducted on that day. The impact of sorbent injection is readily apparent. As soon as injection begins, the mercury level at the stack dropped. The mercury level plateaus soon after injection begins. Immediately after the injection process is terminated, the mercury level jumped back to near baseline levels.

Figure 39. Cliffside CEM Hg Total Outlet Data on 9/17/03

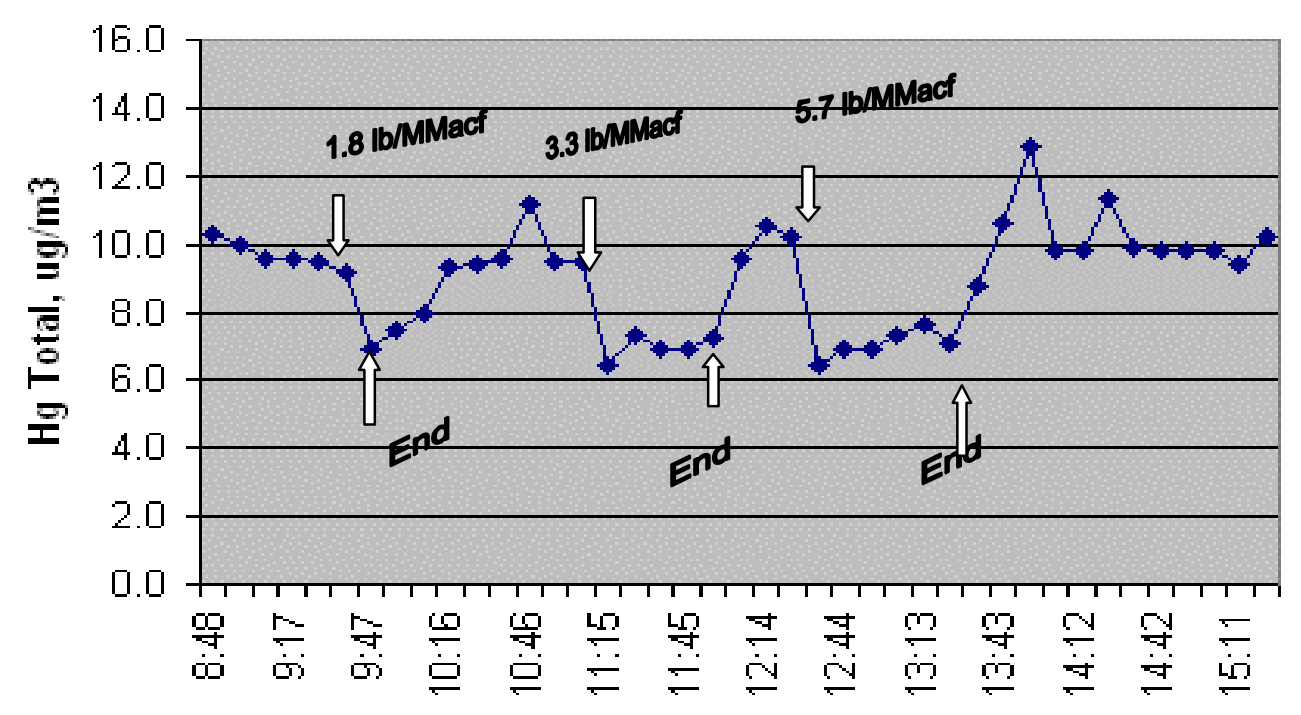

The second method of calculating mercury removal was by the use of the OHM test data. The inlet and outlet OHM mercury concentrations, corrected for oxygen, were 
compared to calculate the mercury removal from this data. Except for the baseline testing, the injection operation was started well before an OHM test began and stopped only after the OHM test was concluded.

The third method of calculating mercury removal was through the use of fly ash mercury concentration data. For the first four days of the project, manpower was available to perform the difficult task of fly ash sampling from the ESP hoppers. This effort is difficult in any boiler, but it is even more so at the elevated temperatures of a hot-side ESP. Obtaining samples only representing the period of the test is also difficult. Samples were taken from all hoppers and a composite was made to represent the front and back fields. The fly ash samples were split and analyzed for mercury by both Albemarle Environmental, $\mathrm{f} / \mathrm{k} / \mathrm{a}$ Sorbent Technologies Corporation and by Trigon Engineering Consultants. The results are presented in Table 23. (Note that as there may not be plug flow of sorbent through the system, representative amounts of sorbent and captured mercury may not be found in the fly ash samples collected in short-term tests such as these.)

\begin{tabular}{|llccc|}
\hline \multicolumn{5}{c}{ Table 23. Duke Power Cliffside Fly Ash Mercury Analyses } \\
Date & Condition & $\underline{\text { Location }}$ & $\underline{\text { Hg, ppb }}$ & $\underline{\text { Hg, ppb }}$ \\
9/15/03 & Baseline Test & Front Field & 6 & 17 \\
$9 / 15 / 03$ & Baseline Test & Back Field & 35 & 39 \\
& & & & \\
$9 / 16 / 03$ & A-5 Injection & Front Field & 110 & 98 \\
$9 / 16 / 03$ & A-5 Injection & Back Field & 233 & 193 \\
& & & & \\
$9 / 17 / 03$ & A-11 Injection & Front Field & 63 & 50 \\
$9 / 17 / 03$ & A-11 Injection & Back Field & 119 & 86 \\
& & & & \\
$9 / 18 / 03$ & A-1 Injection & Front Field & 642 & 596 \\
$9 / 18 / 03$ & A-1 Injection & Back Field & 148 & 131 \\
\hline
\end{tabular}

The fly ash mercury concentrations measured by the two different companies using different measurement methods compared favorably. There was very little mercury in the fly ash during the baseline day with the amount increasing for the first two days of injection and jumping higher for the first test on $9 / 18 / 03$. A simple mercury mass balance was made using the coal mercury level and the coal flow in order to calculate a mercury removal rate with this data.

Below is fly ash data comparing the LOI and mercury from each of the four hoppers from each of the two ESP fields with no injection (baseline) and B-PAC injection at low load. Cliffside has high unburned carbon, but this gets out almost no mercury. The fly ash incorporating sorbent, however, had high $\mathrm{Hg}$ concentrations. Little sorbent appeared to make it through the first field. 
Figure 40. Fly Ash Compositions With, and Without, Sorbent
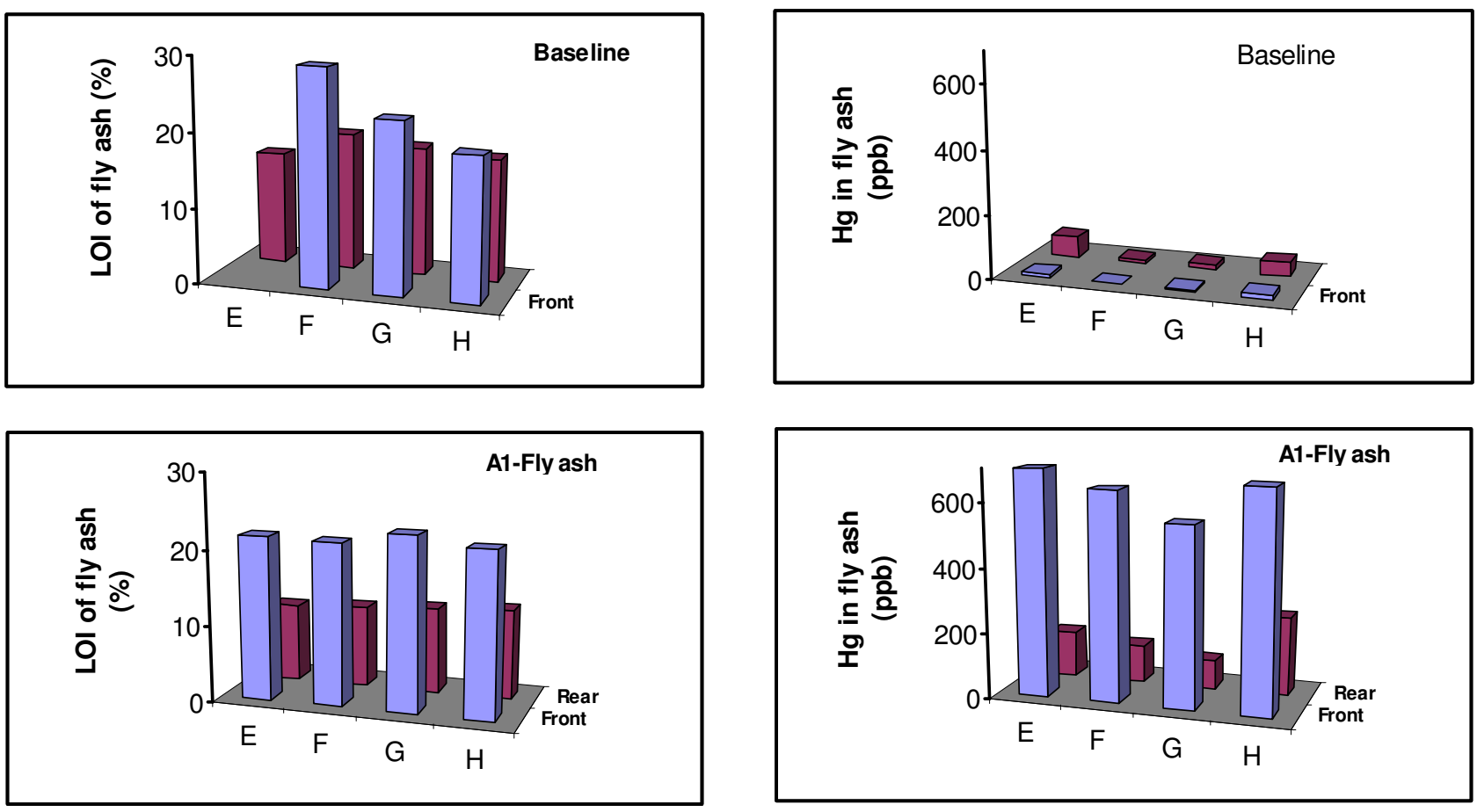

The mercury removal rates as calculated by the three means of measurement are presented in Table 24.

The baseline period was evaluated by all three methods of calculating mercury removal. The methods based upon the fly ash and CEM data both indicated that there was little native removal of mercury. Native mercury removal is that observed without the injection of sorbent. The OHM data indicated that there was $24 \%$. This is highly unlikely since there was very little mercury detected in the fly ash.

Mercury removal was calculated for every run using the $\mathrm{Hg}$ CEM data. At maximum load, a mercury removal rate of up to about $40 \%$ was observed. This mercury removal rate increased as the boiler load was reduced up to about $80 \%$. There were only four tests in which the mercury removal rate could be determined by all three methods. One was the baseline test as previously discussed. The other three were from injection tests. The results agree fairly well for two of the three tests. All the data for the test on 9/13/03 indicates that a low mercury removal rate was achieved while all the data for the test on 9/18/03 indicates that a high mercury removal rate was achieved. The OHM data for the test on 9/17/03 indicates that a high mercury removal rate was achieved, while the CEM data and the fly ash data indicate that a low mercury removal rate was achieved. 
Table 24. Duke Power Cliffside Mercury Testing Results

\begin{tabular}{|c|c|c|c|c|c|c|}
\hline Date & & $\begin{array}{l}\text { Injection } \\
\text { Rate, } \\
\text { lb/MMacf }\end{array}$ & $\begin{array}{c}\text { Power } \\
\text { Rate } \\
\text { MW }\end{array}$ & CEM, \% & $\frac{\text { Sorbent Hg Removal }}{\underline{\text { OHM, \% }}}$ & Fly Ash, \% \\
\hline $9 / 15 / 03$ & None & NA & 40 & -9 & 24 & 2 \\
\hline 9/16/03 & $A-5$ & 3.3 & 40 & NA & & \\
\hline 9/16/03 & $A-5$ & 7.1 & 40 & 6 & 0 & 13 \\
\hline 9/17/03 & $\mathrm{A}-1$ & 1.8 & 40 & 16 & & \\
\hline 9/17/03 & $A-1$ & 3.3 & 40 & 28 & & \\
\hline 9/17/03 & $A-1$ & 5.7 & 40 & 31 & & \\
\hline 9/17/03 & A-11 & 4.1 & 40 & 15 & 69 & 7 \\
\hline 9/18/03 & $\mathrm{A}-1$ & 6.2 & 12 & 78 & 77 & 80 \\
\hline 9/18/03 & $\mathrm{A}-1$ & 4.9 & 20 & 49 & & \\
\hline \multirow[t]{2}{*}{ 9/18/03 } & $A-1$ & 3.8 & 30 & 42 & & \\
\hline & & Ramp & & & & \\
\hline 9/19/03 & $A-1$ & 0 to 10.3 & 40 & 35 & 87 & \\
\hline 9/19/03 & $A-1$ & 3.8 & 40 & 39 & & \\
\hline 9/22/03 & $A-6$ & 4.9 & 40 & 29 & & \\
\hline 9/22/03 & $A-6$ & 4.0 & 40 & 27 & & \\
\hline 9/22/03 & $A-6$ & 5.6 & 40 & 24 & & \\
\hline 9/23/03 & $A-6$ & 5.1 & 40 & 19 & & \\
\hline 9/23/03 & $A-5 F$ & 3.9 & 40 & 27 & & \\
\hline 9/23/03 & $A-12$ & 3.9 & 40 & 22 & & \\
\hline 9/23/03 & $\mathrm{A}-0$ & 3.6 to 11.2 & 40 & 0 & & \\
\hline
\end{tabular}

There was one day when both CEM and OHM data were available. On this day (9/19), the CEM data indicated a moderate mercury removal level while the OHM data indicated a high mercury removal level. Unfortunately, there was no fly ash data for this day. In some test programs, only OHM and CEM mercury testing is performed. In that situation, any discrepancy in the two readings is hard to resolve. A third measure of mercury measurement is needed. Fly ash mercury analyses can supply this needed information if a representative sample can be obtained. The fly ash mercury data provides a high degree of confidence that the OHM data was in error on the baseline day of $9 / 15$ and, to a lesser degree, on the testing days of $9 / 17$ and probably $9 / 19$. The mercury CEM and fly ash data always compared very well.

There are several potential reasons that the OHM data could be incorrect. First, the OHM test was not designed for high temperature applications such as at the Cliffside Plant. Second, there was no location in the ductwork before ESP in which all of the standard sampling criteria could be met. In fact, the flow was very biased in the area of the inlet sampling, but it was the only inlet location available. Finally, the samplers used an external filter in a heated box through which to draw the flue gas. This box was many hundreds of degrees below the flue gas temperature and certainly biased their 
particulate mercury measurements, if not all of their inlet mercury data. In future testing, a filter in the ductwork will be used to avoid the latter problem.

The Hg CEM data for the injection trial conducted at low load is presented in Figure 41.

Figure 41. Cliffside Hg CEM Curve for Low Load Trial on 9/18/03

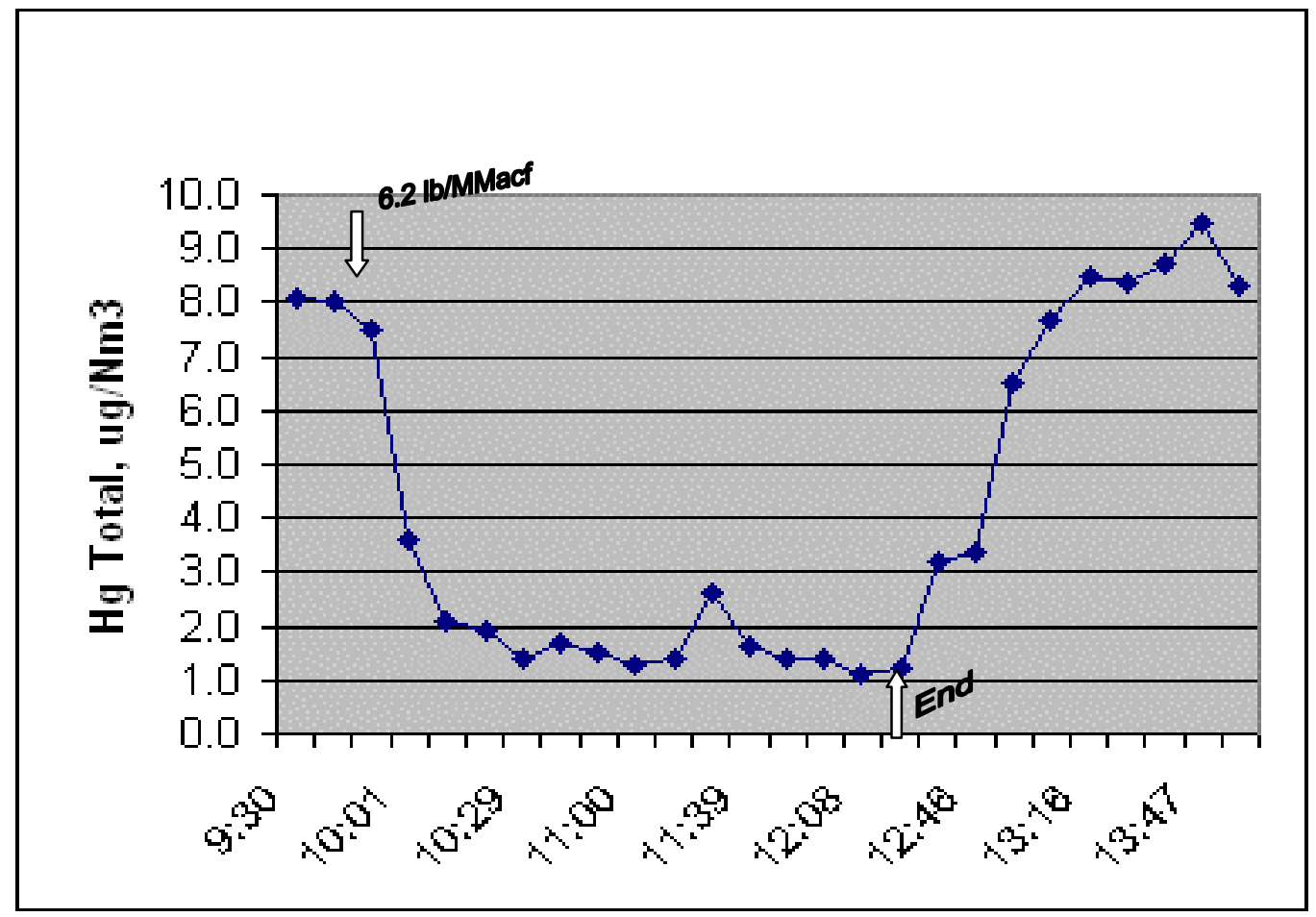

The B-PAC sorbent in this case performed much like it would in a cold-side application, achieving about $80 \%$ mercury removal. The plain PAC (Norit Darco Hg) gave no evidence of any mercury removal at all, as expected. The B-PAC sorbents provided fairly good results under the challenging plant conditions.

The mercury removal results for the standard A-5 B-PAC sorbent are shown in Figure 42. The data is presented on the same curve as the data from the Brayton Point fullscale demonstration test using plain Norit Darco FGD sorbent. This facility also used a low-sulfur bituminous coal, but was equipped with a cold-side ESP. The data from the Cliffside test for the hot-side application falls on the same curve as that for Brayton Point for the cold-side application. This clearly indicates that the mercury removal performance was good when compared to other tests which were conducted at much lower temperatures. 
Figure 42. Mercury Capture vs. Injection Rate at Cliffside and Brayton Pt.

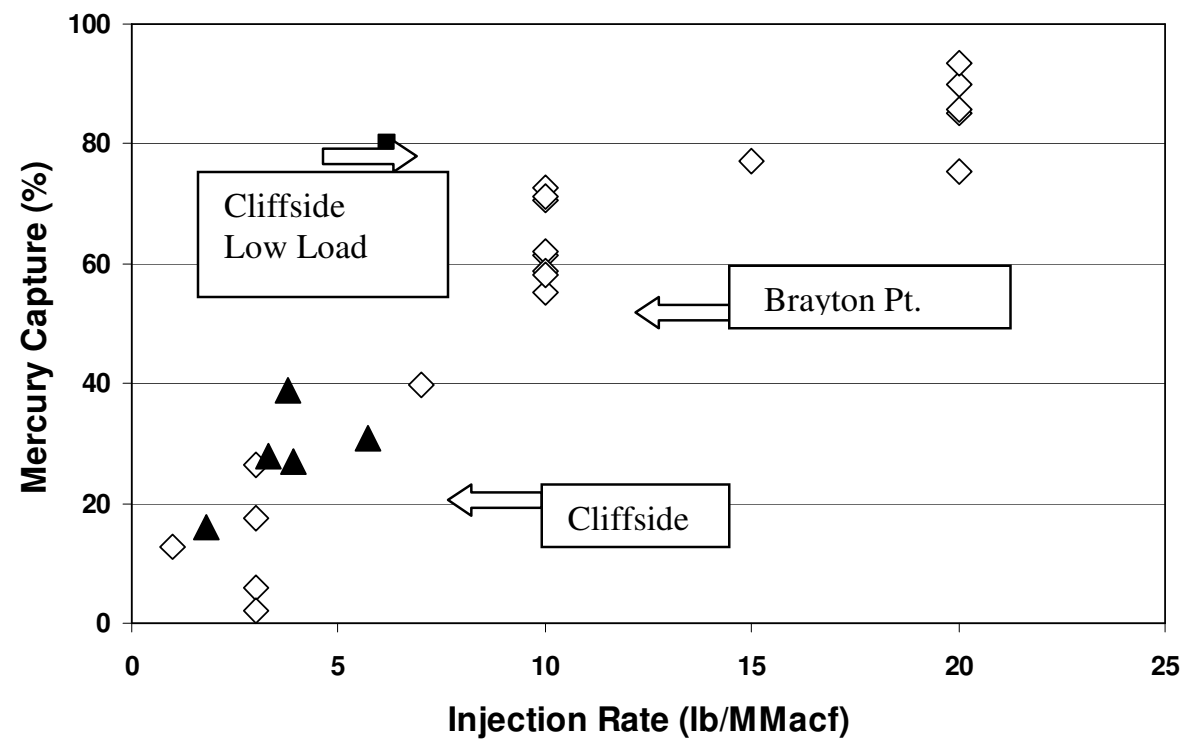

\section{Balance-of-Plant Effects}

Operations of the plant systems were closely monitored during the tests to detect any balance-of-plant effects. Of particular interest were possible impacts of sorbent injection on stack opacity and ESP operation. Sorbent injection added about 2 or $3 w t \%$ to the particulate load. Except for when the injection air was turned on for the first time, blowing accumulated fly ash off the turning vanes directly in front of the lances, there was no measurable impact upon ESP performance during the injection trials. Plant opacity for the baseline day and first day of injection, for example, are presented in Figure 43.

Figure 43. Duke Power Cliffside Boiler No. 2 Opacity on Two Days

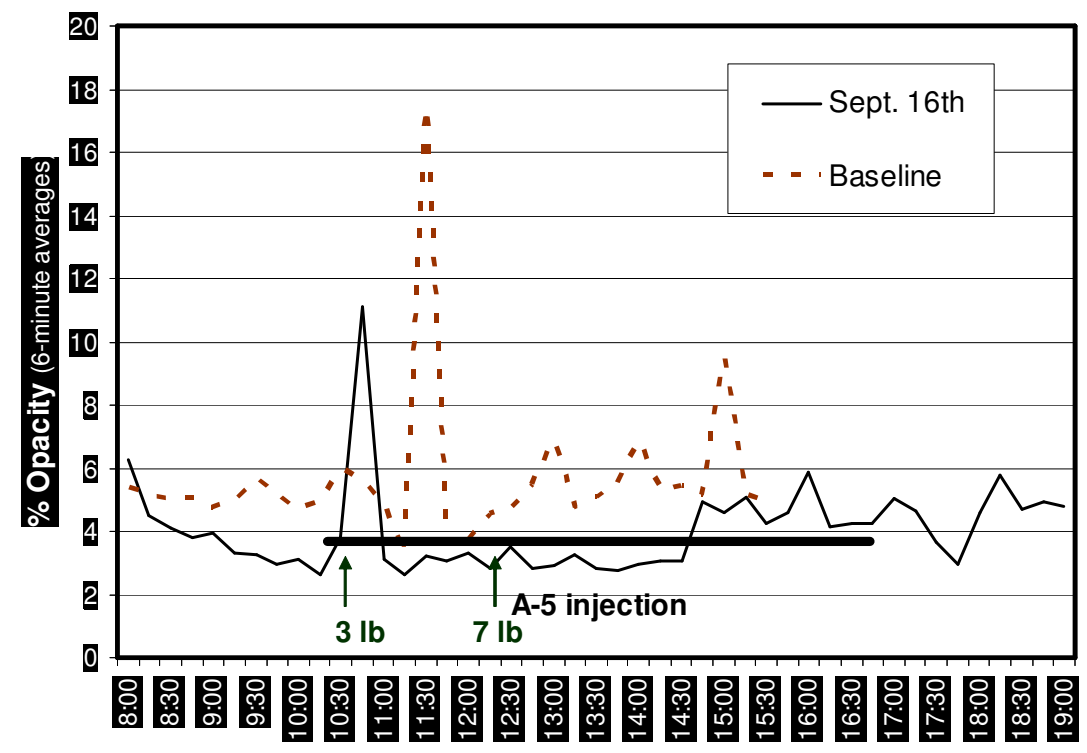


Another possible concern is that the mercury captured in the sorbent in the fly ash could be leached into the environment. Previous tests have shown that the mercury captured by carbon sorbents is very difficult to remove from the sorbent. This has been found to be especially true with the B-PAC ${ }^{\mathrm{TM}}$ sorbents. The fly ash sample containing the highest level of mercury in the Cliffside runs, $620 \mathrm{ppb}$, was subjected to the Toxic Characterization Leaching Procedure (TCLP) with acetic acid and distilled water. The resulting mercury concentrations in the leachates were very low, particularly after correcting for the mercury in the extraction solution blanks (Figure 44). The baseline ash did not contain sorbent, while the fly ash (FA) samples came from either the Front $[F]$ or Rear $[R]$ field hoppers.

Figure 44. Toxic Characteristic Leaching Procedure \& Water Leachates of Cliffside Ashes

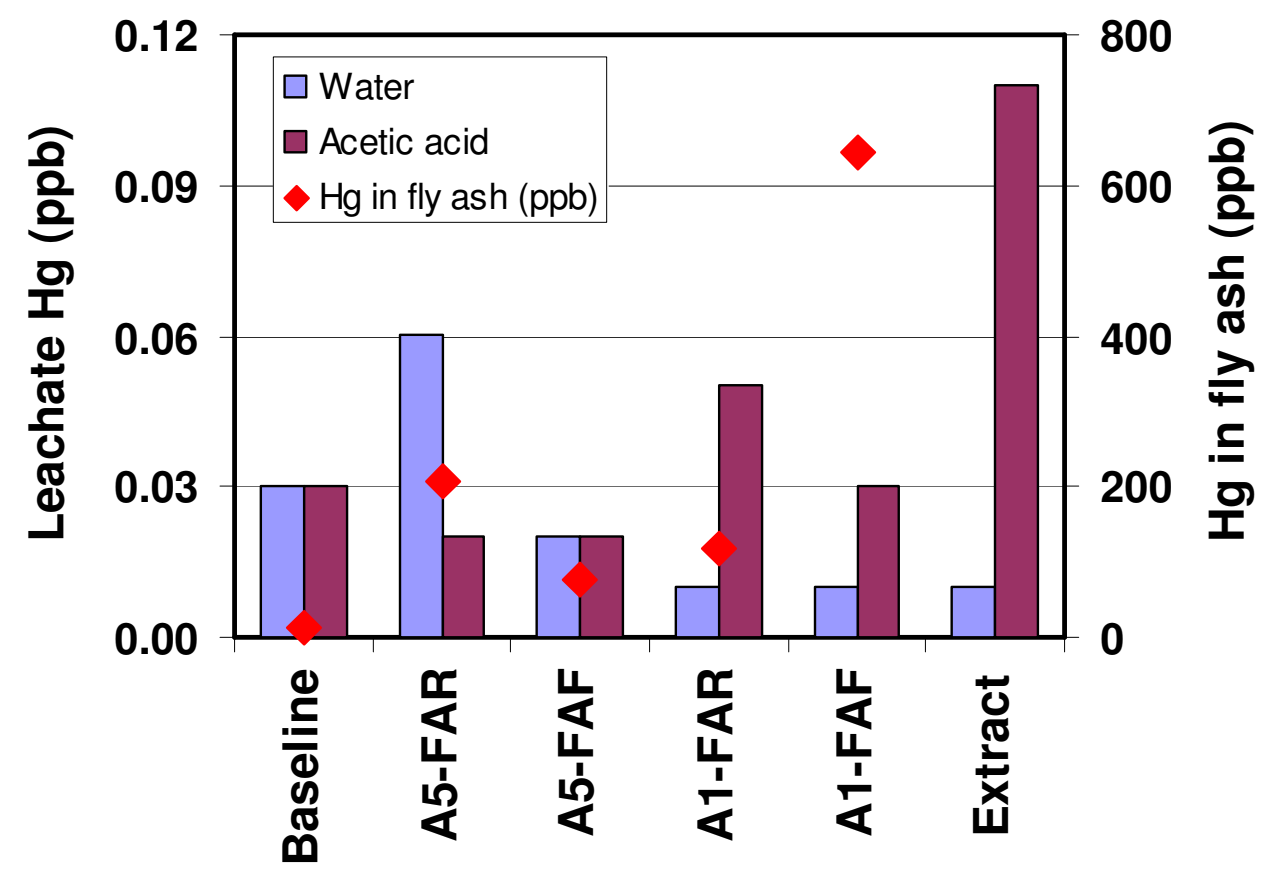

A sample of the sluice water was also taken at the same time as this fly ash sample and it contained less than $0.005 \mu \mathrm{g} / \mathrm{L}$ of mercury. Mercury leaching at Cliffside did not appear to be a problem.

Based upon the positive results of the Cliffside test, the project sponsors supported proceeding with the project's 30-day full-scale trial at the larger Buck Power Plant, which also uses a hot-side ESP for particulate control. 


\section{Cliffside II - December 2004}

\section{Test Plan}

The test plan for the second test at the Duke Power Cliffside Plant called for a maximum of four days of injection with only two sorbents. The scheme was to start each day injecting at a rate of $5 \mathrm{lb} / \mathrm{MMacf}$ and at a low boiler load. Then, the boiler load would be slowly increased while maintaining the same injection rate.

The test plan, as originally developed, is presented in Table 25 .

Table 25. Cliffside II Test Plan December 2004

\begin{tabular}{|c|c|c|c|}
\hline Day & Date & Activity & Boiler Load, MW \\
\hline Friday & $12 / 03 / 04$ & Arrive at Site & \\
\hline Saturday & $12 / 04 / 04$ & Assemble Equipment & \\
\hline Sunday & $12 / 05 / 04$ & Test-Out Equipment & \\
\hline Monday & $12 / 06 / 04$ & Baseline Testing & 10,15 , and 20 \\
\hline Tuesday & $12 / 07 / 04$ & Sorbent $\mathrm{A}-6$ at $5 \mathrm{lb} / \mathrm{MMacf}$ & 10,15 , and 20 \\
\hline Wednesday & $12 / 08 / 04$ & Sorbent $A-7$ at $5 \mathrm{lb} / \mathrm{MMacf}$ & 10,15 , and 20 \\
\hline Thursday & $12 / 09 / 04$ & Sorbent $\mathrm{A}-15$ at $5 \mathrm{lb} / \mathrm{MMacf}$ & 10,15 , and 20 \\
\hline Friday & $12 / 10 / 04$ & Repeats or Different Injection Rate & Boiler Down at 17:00 \\
\hline Saturday & $12 / 11 / 04$ & Disassemble Equipment and Depart & \\
\hline
\end{tabular}

Unfortunately, during this test program the Cliffside Boiler 2 was having operational problems. Thus, the test plan had to be modified, since the boiler was being force run for these tests and the operating time could not be extended. The boiler could not be operated stably at either $10 \mathrm{MW}$ or $15 \mathrm{MW}$ load nor could it achieve the full capacity load of $40 \mathrm{MW}$. It was possible to operate only at three stable loads. These boiler loads were $12 \mathrm{MW}, 20 \mathrm{MW}$ and $25 \mathrm{MW}$.

In addition to the boiler operating problems, the Hg CEMs had stability problems. In the end, no baseline data was gathered and only four injection tests were reliably performed. However, the results did fulfill most of the knowledge needs for the Buck test.

Two Albemarle Environmental, $\mathrm{f} / \mathrm{k} / \mathrm{a}$ Sorbent Technologies H-PAC sorbents were evaluated: A-6 and A-7. Both were tested at the $5 \mathrm{lb} / \mathrm{MMacf}$ injection rate at $12 \mathrm{MW}$ while the A-7 was also tested at $20 \mathrm{MW}$ and $25 \mathrm{MW}$ loads.

\section{Safety}

Duke Power Cliffside Plant personnel provided safety and environmental awareness training to all of the Albemarle Environmental, $\mathrm{f} / \mathrm{k} / \mathrm{a}$ Sorbent Technologies Corporation personnel who worked on site. As a result of the dedicated effort of all concerned parties, there were no accidents or adverse environmental events during the testing program.

\section{Parametric Testing}

Coal and fly ash samples were collected on the days that sorbent injection trials were performed. The coal samples were analyzed in the Duke Power laboratories while the 
fly ash samples were analyzed for mercury in the Albemarle Environmental, $\mathrm{f} / \mathrm{k} / \mathrm{a}$ Sorbent Technologies laboratories. The average coal proximate analysis for this test is presented in Table 26.

Table 26. Coal Proximate Analyses during the Two Tests Conducted at the Duke Power Cliffside Plant

\begin{tabular}{|cc|cccc|}
\hline $\begin{array}{c}\text { Test } \\
\text { Date }\end{array}$ & $\begin{array}{c}\text { As Received } \\
\text { Moisture, \% }\end{array}$ & $\begin{array}{c}\text { Heat Content } \\
\text { Btu/lb }\end{array}$ & $\underline{\text { Ash, \% }}$ & $\underline{\text { Sulfur, \% }}$ & $\underline{\text { V. M., \% }}$ \\
\cline { 2 - 5 } 9/2003 & 7.9 & 13,427 & 10.4 & 1.17 & 35.8 \\
$12 / 2004$ & 9.8 & 13,283 & 10.4 & 0.91 & 35.9 \\
\hline
\end{tabular}

The average coal proximate analysis for the first test at the Cliffside Plant is presented for comparison. The analyses are typical for a low sulfur bituminous coal from the Eastern United States. The coal for this test had an average "as received" moisture content about $2 \%$ higher than the coal used in the previous test. The sulfur content was nearly $30 \%$ higher in the first test. However, the coal heat content, ash, and volatile matter contents were very similar for the coals used in both test periods.

The average coal mercury, chlorine and fluorine contents are presented in Table 27.

Table 27. Coal Mercury, Chlorine and Fluorine Contents during the Two Tests Conducted at the Duke Power Cliffside Plant

\begin{tabular}{|c|c|c|c|}
\hline \multirow[b]{2}{*}{$\frac{\text { Test }}{\text { Date }}$} & \multicolumn{3}{|c|}{ Dry Basis } \\
\hline & $\frac{\mathrm{Hg}_{2}}{\mathrm{ppm}}$ & $\frac{\text { Chlorine }}{\text { ppm }}$ & $\frac{\text { Fluorine, }}{\text { ppm }}$ \\
\hline $9 / 2003$ & 0.102 & 511 & 119 \\
\hline $12 / 2004$ & 0.060 & 1074 & 83 \\
\hline
\end{tabular}

The coal used during the test conducted in 2004 had only $60 \%$ as much mercury as did the coal used in the test conducted in 2003. Conversely, the coal used in the earlier test period had less than half as much chlorine as did that used in the later test period. However, the coal chlorine level was high in both tests. The coal fluorine content was similar for the coals used in the two test periods.

The flue gas total gaseous mercury concentration, corrected to $3 \%$ oxygen, was generally between $7,000 \mathrm{ng} / \mathrm{Nm}^{3}$ and $10,000 \mathrm{ng} / \mathrm{Nm}^{3}$ in the first Cliffside test but was only about $2,500 \mathrm{ng} / \mathrm{Nm}^{3}$ in the second test. A total gaseous mercury flue gas content of at least $4,000 \mathrm{ng} / \mathrm{Nm}^{3}$ would be expected based upon the coal mercury content. The reason for the lower flue gas mercury levels observed is unknown.

The operating conditions for the four injection tests are presented in Table 28.

Table 28. Operating Conditions during the Parametric Tests

\begin{tabular}{|c|c|c|c|c|c|}
\hline Date & Sorbent & $\begin{array}{c}\text { Boiler } \\
\text { Load, MW }\end{array}$ & $\begin{array}{l}\text { Start } \\
\text { Time }\end{array}$ & $\begin{array}{l}\text { End } \\
\text { Time } \\
\end{array}$ & $\begin{array}{c}\text { Flow Rate, } \\
\text { acfm }\end{array}$ \\
\hline $12 / 08 / 04$ & $A-6$ & 12 & $\overline{8: 34}$ & $\overline{11: 46}$ & $\overline{161,000}$ \\
\hline $12 / 08 / 04$ & $A-7$ & 12 & $14: 10$ & $16: 44$ & 168,000 \\
\hline $12 / 09 / 04$ & $A-7$ & 20 & $12: 39$ & $15: 25$ & 193,000 \\
\hline $12 / 09 / 04$ & A-7 & 25 & $17: 01$ & $18: 40$ & 236,000 \\
\hline
\end{tabular}


The operators tried to keep the boiler operation as steady as possible for all of the tests. They were much more successful at higher loads than at lower loads. This instability is seen in the flue gas flow rates for the four tests which are presented in Figures 45-47.

Figure 45. Flue Gas Flow Rate on 12/8/04 at 12 MW

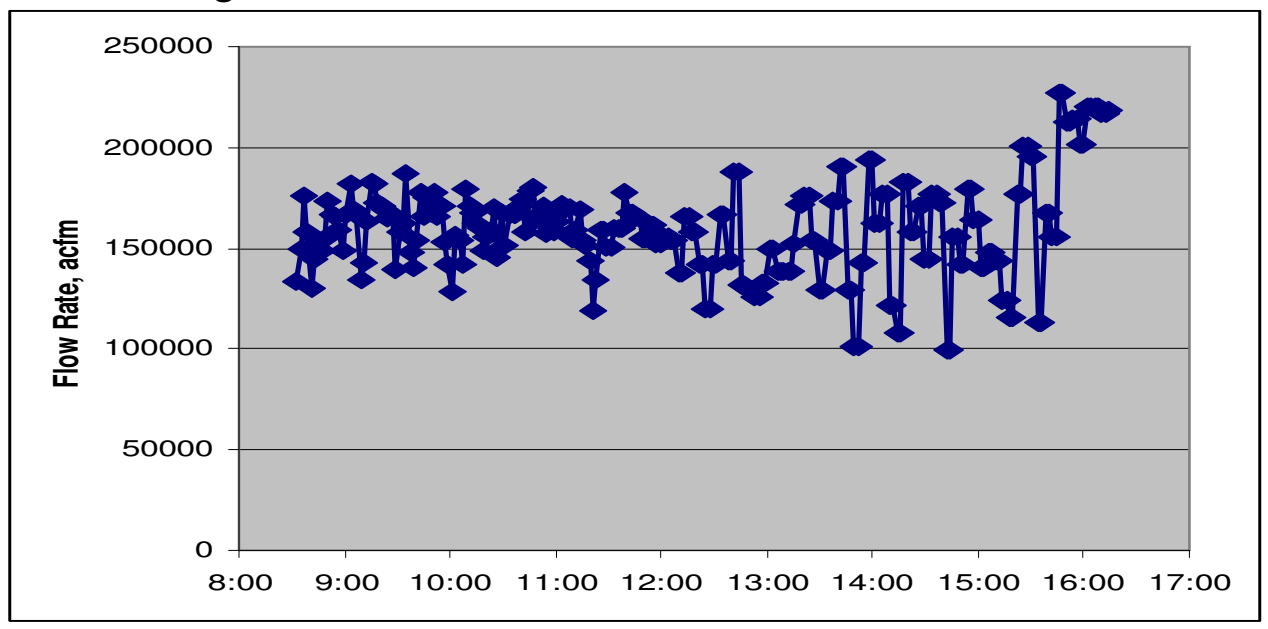

Figure 46. Flue Gas Flow Rate on 12/9/04 at 20 MW

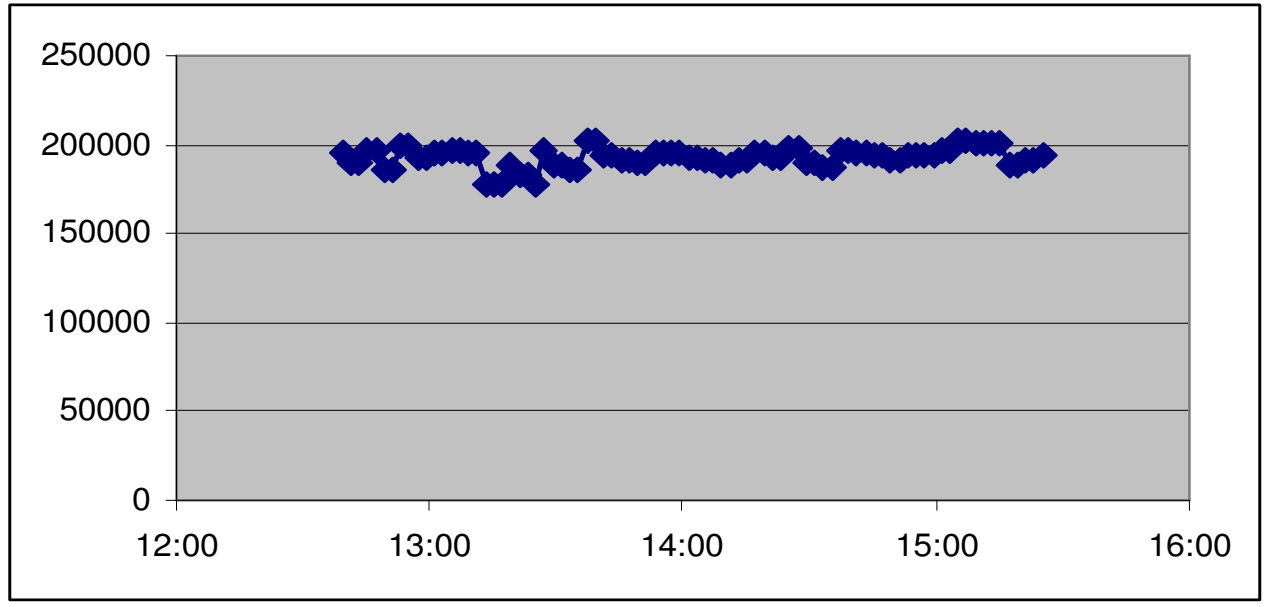

Figure 47. Flue Gas Flow Rate on 12/9/04 at 25 MW

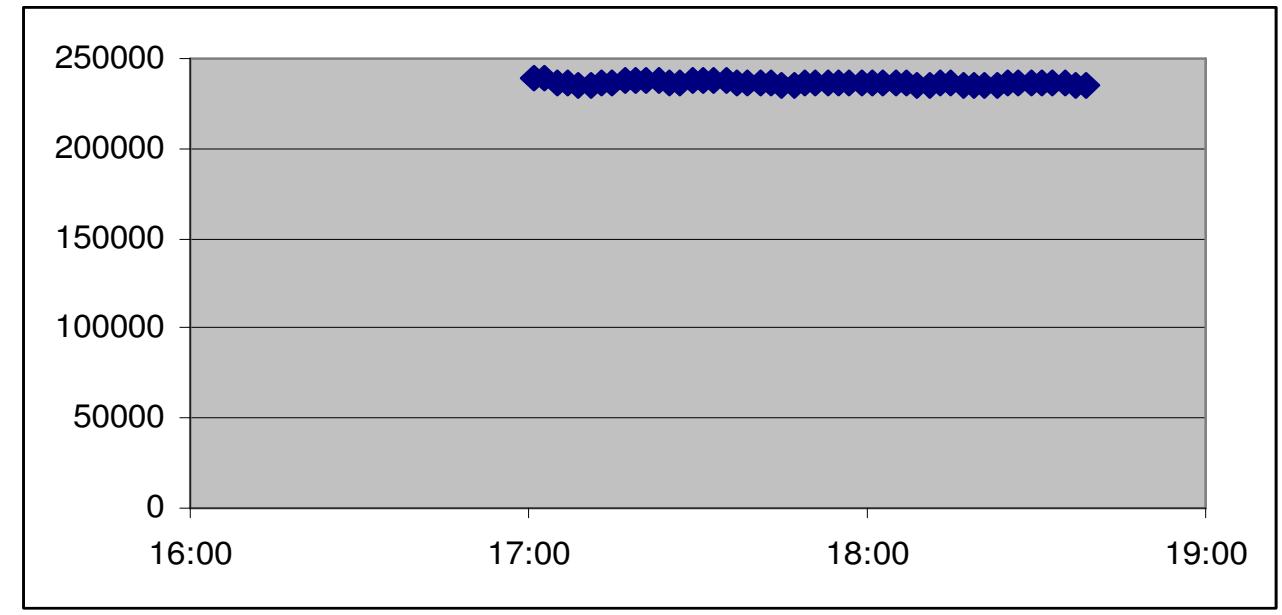


The flow rate was erratic while operating at $12 \mathrm{MW}$, but became more and more stable as the load was increased.

Fly ash samples were collected for LOI analysis during the testing. This data also indicates the difference in operation between the 2003 and 2004 tests. The data is presented in Table 29.

Table 29. Fly Ash LOI during the Two Cliffside Tests
$\begin{array}{ccc}\frac{\text { Test }}{2003} & \frac{\text { Condition }}{40 \mathrm{MW}} & \frac{10 \mathrm{l}, \%}{19.4} \\ 2003 & 40 \mathrm{MW} & 19.6 \\ & & \\ 2004 & \text { Baseline } & 14.4 \\ 2004 & 12 \mathrm{MW} & 12.3 \\ 2004 & 20 \mathrm{MW} & 9.8\end{array}$

The results from the two injection tests at $12 \mathrm{MW}$ are shown in Figure 48.

The total gaseous mercury baseline for these tests was $2350 \mathrm{ng} / \mathrm{Nm}^{3}$, on average. The mercury level dropped rapidly after injection of A-6 began and stabilized at $735 \mathrm{ng} / \mathrm{Nm}^{3}$. The calculated mercury removal rate for this test was $69 \%$ for this sorbent. After the injection ended, the mercury level began to slowly recover, much as it does in cold-side ESP applications. Due to time limitations, the second test was begun before the flue gas mercury content had fully recovered. The mercury level rapidly decreased when the injection of A-7 began and stabilized at $645 \mathrm{ng} / \mathrm{Nm}^{3}$. The calculated mercury removal rate for this test was $73 \%$. In the tests in 2003 , a mercury rate of $78 \%$, as measured by the $\mathrm{Hg}$ CEM, was achieved with an injection rate of $6.2 \mathrm{lb} / \mathrm{MMacf}$.

Figure 48. Mercury Sorbent Tests on 12/08/04 at the Duke Power Cliffside Plant at an Injection Rate of 5.0 lb/MMacf at $12 \mathrm{MW}$ Load

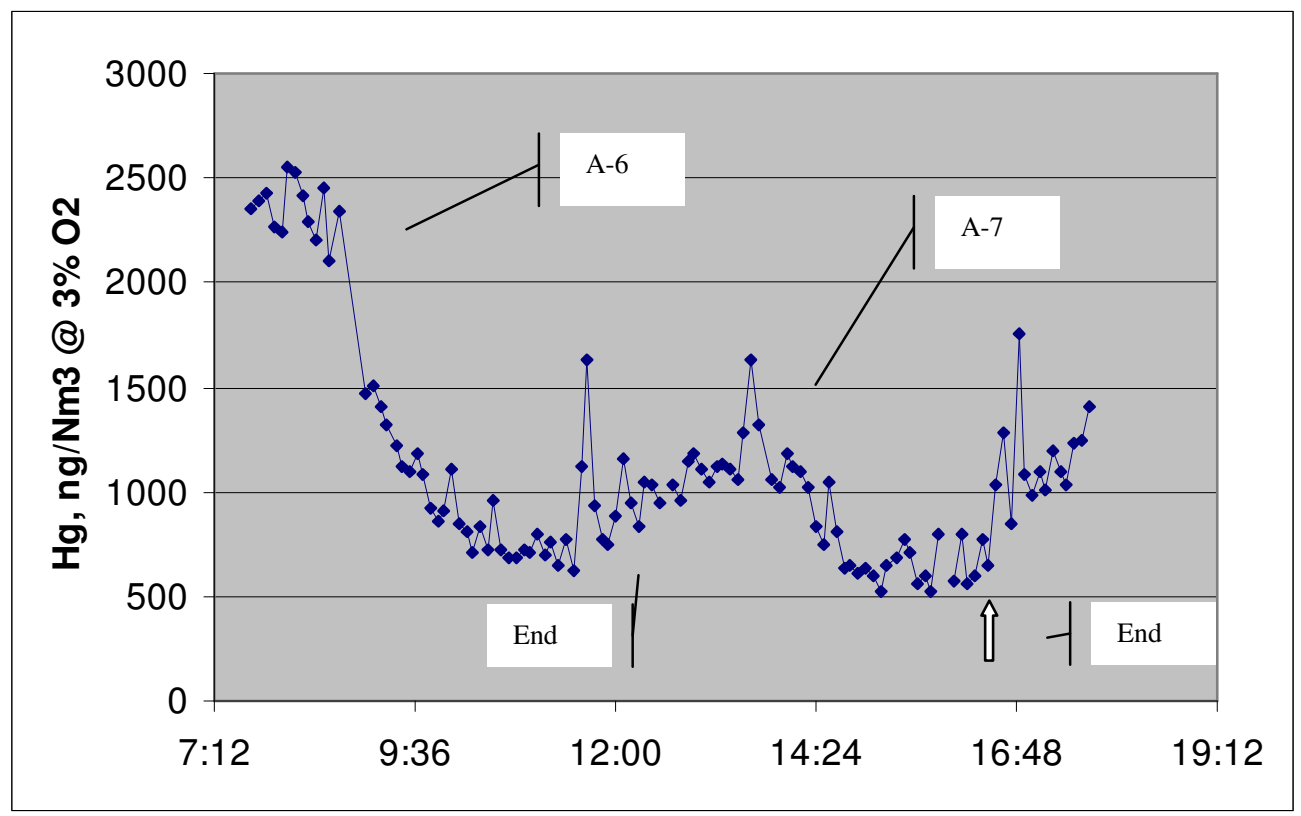


On December 9, 2004, it was possible to operate fairly stably at two loads; $20 \mathrm{MW}$ and $25 \mathrm{MW}$. The A-7 sorbent was injected at these two loads at a rate of $5.0 \mathrm{lb} / \mathrm{MMacf}$. The results from these tests are presented in Figure 49.

\section{Figure 49. Mercury Sorbent Tests on 12/09/04 at the Duke Power Cliffside Plant at an Injection Rate of 5.0 lb/MMacf at $20 \mathrm{MW}$ and $25 \mathrm{MW}$}

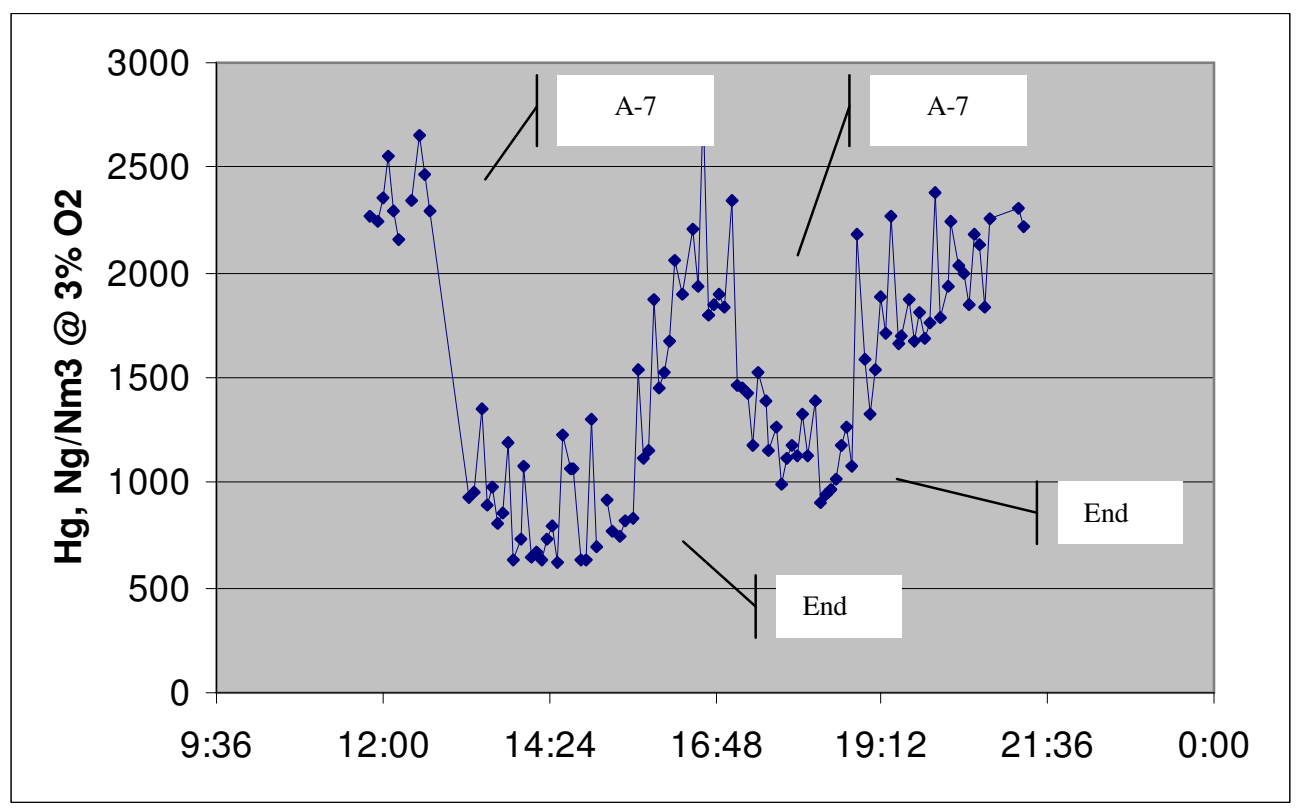

The total gaseous mercury baseline for these tests was $2365 \mathrm{ng} / \mathrm{Nm}^{3}$, on average. The final mercury level achieved in these tests is more difficult to define because of instrumentation spikes in the data. The data was evaluated in two manners. In the first, the average mercury level after the stabilization was used. In the second, the average of the data without the spikes was used. The mercury removal achieved in the first test at $20 \mathrm{MW}$ was determined to be between $64 \%$ and $73 \%$, using the two methods, and between $51 \%$ and $59 \%$ for the second test at $25 \mathrm{MW}$.

This denotes improved performance to that found for the sorbents used in the first Cliffside test where only $49 \%$ mercury removal was achieved at an operating load and injection rate very close to that used in this test.

Fly ash samples were collected on both days of these tests. The hot-side ESP controlling the particulate emissions from Cliffside Boiler 2 has only two fields. Four hoppers are used to collect the ash from each field. Samples from each hopper were collected, when possible, and analyzed for their mercury content by Sorbent Technologies personnel.

The fly ash mercury data from the two Cliffside test programs is presented in Table 30. 
Table 30. Fly Ash Mercury Data from the Two Cliffside Test Programs

\begin{tabular}{|c|c|c|c|}
\hline \multirow[b]{2}{*}{ Date } & \multirow[b]{2}{*}{ Activity } & \multicolumn{2}{|c|}{ Hg Concentration, ppb } \\
\hline & & Front Field & Back Field \\
\hline $09 / 15 / 03$ & Baseline Test & 6 & 35 \\
\hline 09/18/03 & $\mathrm{A}-1$ at $12 \mathrm{MW}$ & 642 & 148 \\
\hline $12 / 08 / 04$ & $\mathrm{~A}-6$ at $12 \mathrm{MW}$ & 413 & 223 \\
\hline $12 / 09 / 04$ & $\mathrm{~A}-7$ at $20 \mathrm{MW}$ & 217 & 230 \\
\hline
\end{tabular}

There were no representative baseline fly ash samples taken in this program, but if they would have been taken, we would expect the mercury levels in them to be very low as it was in the baseline samples collected in 2003.

The fly ash samples collected when the $78 \%$ mercury removal was achieved in 2003 showed over $600 \mathrm{ppb}$ of mercury in the first field ash and about a quarter of that amount in the back field. The fly ash sample collected on December 8, 2004, when the A-6 was being injected at $12 \mathrm{MW}$, contained slightly more than $400 \mathrm{ppb}$ in the front field and about half this amount in the back field. On December 9, the fly ash sample was collected during the test of A-7 when injecting into flue gas at $20 \mathrm{MW}$. This sample contained slightly more than $200 \mathrm{ppb}$ in the ash from both fields. No attempt was made to create a mercury mass balance from this data due to the lack of plug flow of sorbent through the system the difficulty in obtaining representative samples in such short-term tests. However, the mercury levels in the fly ash are elevated as would be expected when high rates of mercury removal are being achieved. It would be expected that the amount of mercury in the fly ash would be lower in the 2004 tests since there was less mercury in the coal. 


\section{Duke Power Buck Station}

The testing at the Buck Station Unit 6 was divided into three sections: Baseline Measurements, Parametric Testing, and Long-Term Testing. Albemarle Environmental, $\mathrm{f} / \mathrm{k} / \mathrm{a}$ Sorbent Technologies personnel, along with Western Kentucky University, PS Analytical and Baldwin Inc. personnel, all arrived at Buck starting on April 1, 2005.

The plan was to have all of the equipment, both injection and mercury monitoring, installed and ready to operate when the plant came back from a planned outage on April 3, 2005. There would be a week of baseline testing followed by a week of parametric testing followed by additional baseline testing during which the first OHM measurements would be made. This schedule was adapted in order to define the sorbent to be used in the long-term test as early as possible so that production rate could match the long-term usage rate.

As will be discussed below, the plan had to be modified several times to overcome the difficulties encountered.

\section{Safety}

All of the Albemarle Environmental, $\mathrm{f} / \mathrm{k} / \mathrm{a}$ Sorbent Technologies, Western Kentucky University and other contractor personnel received a safety briefing and orientation by Duke Power personnel. Unfortunately, there was one minor accident when a Western Kentucky University employee sustained a minor cut as he was helping to move a sampling probe. The employee was taken to the emergency room as a precautionary measure. He returned to the job site fit to work. Duke Power provided assistance in recording this event which was deemed not to be OSHA reportable.

\section{Baseline Measurements}

\section{$\underline{\text { Mercury Measurements }}$}

Albemarle Environmental, $\mathrm{f} / \mathrm{k} / \mathrm{a}$ Sorbent Technologies, as part of this project, purchased two sets of the latest version of the PS Analytical equipment. This included the new, small Baldwin inertial separators, the very first dry/wet mercury conversion modules (Serial Numbers 001 and 002) and the current version of the atomic fluorescence mercury analyzer. This equipment had worked well in the testing at the Detroit Edison St. Clair Plant. There had only been a limited opportunity to use the dry conversion system and it was hoped that it could be used more extensively in the Buck trials. The efforts to use the dry conversion system in the Buck application were in vain and the standard wet conversion system was used thereafter.

One of the mercury monitoring systems was used to sample the flue gas before injection in a location where the flue gas temperature was normally over $650^{\circ} \mathrm{F}$, when the boiler was at full load. It was impossible to keep this monitor clean and operating properly and eventually the instrument at this location was moved to a location on the untreated stack, since Buck used two ESPs to control the particulate emissions from the one boiler.

The first week of parametric testing was scheduled to begin on April 13, 2005. It did so but the outlet monitor continued to generate erratic results. It was determined that the cause of the problem was the inertial separators and the parametric testing was 
suspended until the old design QSIS inertial separators became available. The substitution of the inertial separators made the monitor performance better but not as smooth as was observed in the testing at the Detroit Edison St. Clair Plant.

The parametric testing resumed April 25 and ran through May 3, 2005. The testing was interrupted on April $27^{\text {th }}$ and $28^{\text {th }}$ in order to perform the first set of OHM measurements. The results of these measurements are presented in Table 31

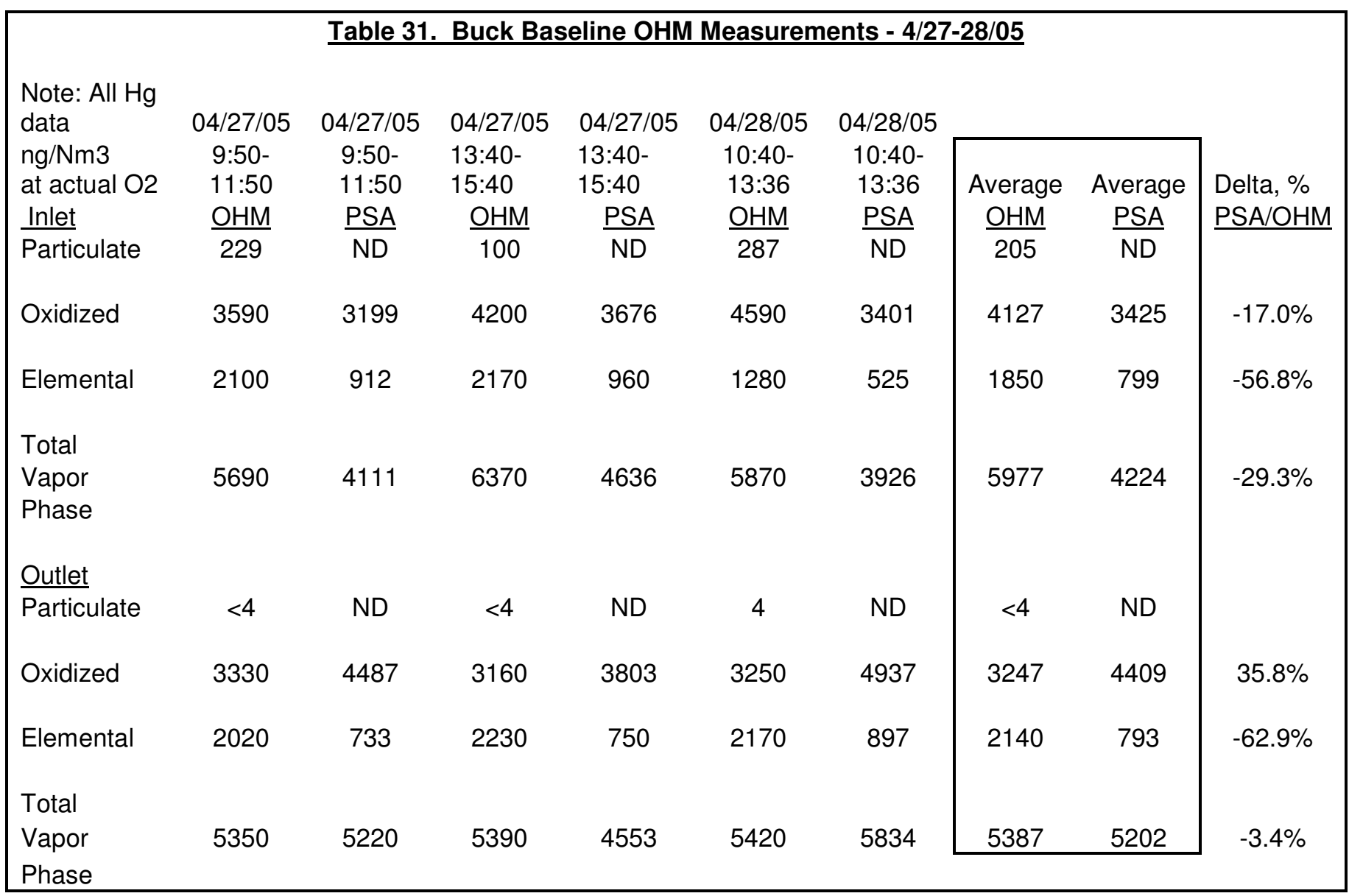

The OHM measurements could not be performed in triplicate simultaneously at the inlet and outlet due to the lack of sampling locations. Therefore, the tests were performed sequentially. The last test on April 27 had quality problems and was repeated on April 28.

There was very little particulate mercury at the inlet and essentially none at the outlet. This finding is consistent with the data from the Cliffside testing.

The total vapor phase mercury CEM and the OHM data were very different at the inlet location with the former being lower. This was another indication of the problems encountered in keeping the inlet monitor clean and operating. The total vapor phase mercury measured by the two techniques was comparable at the outlet location. 
The mercury speciation as measured by the two techniques was very different at both sampling locations. Much more oxidized mercury was measured by the CEM than was by the OHM measurements. The reason for this difference is unknown, although it is expected that the amount of oxidized mercury would be high based upon the use of $100 \%$ bituminous coal.

The two ESPs that serviced Buck 6 had 8 total hoppers divided into two fields. Hoppers 1-2 collected fly ash from the front field of the treated flue gas while Hoppers 3-4 did the same from the front field of the untreated ESP. Similarly, Hoppers 5-6 collected fly ash from the back field of the treated gas stream while Hoppers 7-8 collected fly ash from the back field of the untreated flue gas stream. In this manner, the collection of fly ash from Hoppers 3-4 at the same time samples were collected from Hoppers 1-2 provided a baseline measurement for each sampling period.

\section{Fly Ash Analyses}

Several samples were collected during the baseline period and analyzed for mercury. The results of these analyses are presented in Table 32.

\begin{tabular}{|ccc|}
\hline $\begin{array}{c}\text { Table } 32 \\
\text { Date }\end{array}$ & \multicolumn{3}{c|}{ Baseline Fly Ash $\mathbf{H g}$} \\
Hoppers & $\underline{\text { Hg, ppb }}$ \\
$4 / 8 / 05$ & $1 \& 2$ & 37 \\
$4 / 8 / 05$ & $3 \& 4$ & 28 \\
$4 / 8 / 05$ & $5 \& 6$ & 53 \\
$4 / 8 / 05$ & $7 \& 8$ & 74 \\
$4 / 11 / 05$ & $1 \& 2$ & 19 \\
$4 / 11 / 05$ & $3 \& 4$ & 17 \\
$4 / 27 / 05$ & $1 \& 2$ & 13 \\
$4 / 27 / 05$ & $3 \& 4$ & 22 \\
\hline
\end{tabular}

The majority of the fly ash was collected in the first field of these ESPs. The mercury content in the fly ash in the first field is very low. It is only slightly higher in the samples from the back field. It should be noted that the samples collected on April 27 were taken during the OHM measurements. The low levels of mercury in the fly ash are a clear indication of the low native mercury removal. This should be expected since these are hot-side ESPs. 


\section{Parametric Testing}

The parametric injection testing first began on April 13 but was delayed until April 25 to allow for the installation of different inertial separators. The parametric tests were conducted with three different sorbents at three different boiler loads. The sorbents used were the plain Norit Darco FGD (now Norit Darco Hg), and two H-PACs manufactured by Albemarle Environmental, $\mathrm{f} / \mathrm{k} / \mathrm{a}$ Sorbent Technologies. One sorbent was designated A-5B and the other A-10B. Both were brominated PACs. The breadth of the parametric testing was limited since much had been learned in the two tests at the Duke Power Cliffside Station.

\section{Mercury Measurements}

The three loads at which tests were performed were full load (140 MW), low load (60 $\mathrm{MW}$ ) and medium load (100 MW). These loads presented different flue gas temperatures and flue gas flow rates at which the tests were performed. A graph of a typical injection test is presented in Figure 50.

Figure 50. $\mathrm{Hg}$ Concentration at Buck Unit 6 ESP Outlet

( April 27-28 Corrected to 3\%)

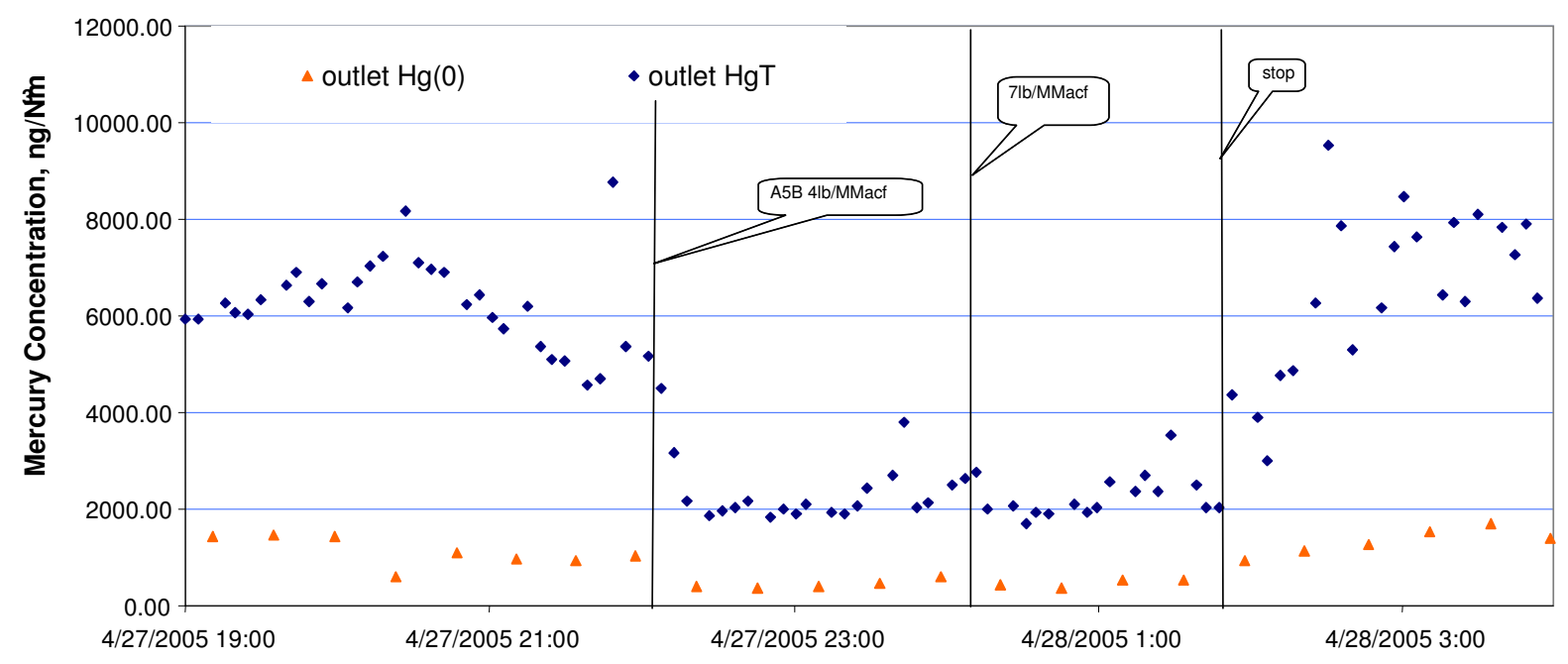

The figure shows the typical pattern of sorbent injection in that the outlet mercury level immediately drops and stays down. What is unusual is that the higher injection rate gave essentially no improvement in mercury removal. It is possible that the mercury level is increasing at the end of each injection tests. This rise in mercury level was seen in some tests but not others. The mercury level rapidly returns to the baseline level, if not above, after the injection is stopped.

The results from all of the parametric tests are presented in Table 33. The table contains the date and time of the test along with the boiler load, injection temperature, sorbent injected, injection rate, mercury concentration before and during the test and the calculated mercury removal. 


\begin{tabular}{|c|c|c|c|c|c|c|c|c|}
\hline & $\begin{array}{l}\text { Start } \\
\text { Time }\end{array}$ & $\begin{array}{c}\text { End/Change } \\
\text { Time }\end{array}$ & $\begin{array}{l}\text { Injection } \\
\text { Rate } \\
\text { lb/MMacf }\end{array}$ & $\begin{array}{l}\text { Boiler } \\
\text { Load MW }\end{array}$ & Sorbent & $\begin{array}{l}\text { Injection } \\
\text { Temn F }\end{array}$ & $\begin{array}{c}\text { Hg, } \\
\text { During } \\
\text { na/Nm3 }\end{array}$ & $\begin{array}{c}\mathrm{Hg} \\
\frac{\text { Removal, }}{\%}\end{array}$ \\
\hline$\frac{\text { Date }}{04 / 25 / 05}$ & $\frac{\text { IIme }}{11: 50}$ & $\frac{\text { IIme }}{12: 15}$ & & $\frac{\text { Load IVIVV }}{140}$ & sorbent & $\frac{\text { lemp., } \mathbf{r}}{\sim 640}$ & $\frac{5618}{5618}$ & \\
\hline 04/25/05 & $12: 15$ & $14: 30$ & 4.0 & 140 & $A-10 B$ & $\sim 640$ & 2958 & $47 \%$ \\
\hline 04/25/05 & $14: 30$ & $17: 45$ & 7.0 & 140 & $A-10 B$ & $\sim 640$ & 2425 & $57 \%$ \\
\hline 04/25/05 & $18: 43$ & 23:00 & & 140 & & $\sim 640$ & 5344 & \\
\hline 04/26/05 & 9:24 & $10: 10$ & & 140 & & 637 & 3903 & \\
\hline 04/26/05 & $10: 10$ & $13: 30$ & 7.0 & 140 & $A-5 B$ & 641 & 1424 & $64 \%$ \\
\hline $\begin{array}{c}04 / 27 / 05 \\
4 / 27-\end{array}$ & $21: 20$ & $22: 06$ & & 60 & & 532 & 4983 & \\
\hline $28 / 05$ & 22:06 & 0:06 & 4.0 & 60 & $A-5 B$ & 536 & 2180 & $56 \%$ \\
\hline 04/28/05 & $0: 06$ & $1: 40$ & 7.0 & 60 & $A-5 B$ & 539 & 2158 & $57 \%$ \\
\hline 04/28/05 & $13: 30$ & $14: 11$ & & 140 & & 622 & 5147 & \\
\hline 04/28/05 & $14: 11$ & $16: 45$ & 7.0 & 140 & $A-10 B$ & 630 & 2387 & $54 \%$ \\
\hline 04/28/05 & $20: 32$ & $21: 44$ & & 60 & & 535 & 5358 & \\
\hline $\begin{array}{c}04 / 28 / 05 \\
4 / 28-\end{array}$ & $21: 44$ & $23: 32$ & 4.0 & 60 & $A-10 B$ & 539 & 1871 & $65 \%$ \\
\hline $29 / 05$ & $23: 32$ & $1: 30$ & 7.0 & 60 & $A-10 B$ & 544 & 1996 & $63 \%$ \\
\hline 04/29/05 & $3: 45$ & $5: 30$ & & 60 & & 550 & 6772 & \\
\hline 04/29/05 & $18: 43$ & $19: 20$ & & 100 & & 591 & 4176 & \\
\hline 04/29/05 & $19: 20$ & $20: 44$ & 2.0 & 100 & $A-10 B$ & 593 & 2353 & $44 \%$ \\
\hline $\begin{array}{c}\text { 04/29/05 } \\
4 / 29-\end{array}$ & $20: 44$ & $22: 34$ & 7.0 & 100 & $A-10 B$ & 593 & 1606 & $62 \%$ \\
\hline $30 / 05$ & $22: 34$ & $0: 40$ & 10.0 & 100 & $A-10 B$ & 594 & 1627 & $61 \%$ \\
\hline 04/30/05 & $18: 54$ & $19: 24$ & & 100 & & 592 & 5804 & \\
\hline 04/30/05 & $19: 24$ & $21: 26$ & 2.0 & 100 & $A-5 B$ & 593 & 2644 & $54 \%$ \\
\hline 04/30/05 & $21: 26$ & $22: 47$ & 5.0 & 100 & $A-5 B$ & 591 & 2218 & $62 \%$ \\
\hline 04/30/05 & $22: 47$ & $23: 45$ & 7.0 & 100 & $A-5 B$ & 590 & 2151 & $63 \%$ \\
\hline 05/03/05 & $9: 57$ & $10: 36$ & & 140 & & 633 & 7207 & \\
\hline 05/03/05 & $10: 36$ & $13: 49$ & 7.0 & 140 & Norit & 625 & 7020 & $3 \%$ \\
\hline 05/03/05 & $13: 49$ & $14: 46$ & & 140 & & 617 & 7299 & \\
\hline
\end{tabular}

The Norit Darco FGD plain PAC (now Norit Darco Hg) provided very little in mercury removal. This was expected since the mercury capacity of plain PACs is very low at temperatures above $350^{\circ} \mathrm{F}$.

Surprisingly, there did not appear to be a big difference in H-PAC sorbent performance based upon temperature. Both H-PAC sorbents performed nearly same. There was not a great improvement in mercury removal as the injection rate was increased. It is unknown if this is presence of a mercury removal plateau or some other phenomena. At Cliffside, increased injection rate provided increased mercury removal. 
Fly Ash and Coal Analyses

The results of the fly ash mercury analyses are presented in Table 34 .

\begin{tabular}{|c|c|c|c|c|c|c|}
\hline \multirow[b]{2}{*}{ Date } & \multicolumn{5}{|c|}{ Table 34. Buck Parametric Fly Ash Analyses } & \multirow[b]{2}{*}{$\frac{\mathrm{Hg}}{\mathrm{ppb}}$} \\
\hline & Time & Load, MW & Location & Sorbent & Rate, lb/MMacf & \\
\hline 04/25/05 & $17: 30$ & 140 & $3 \& 4$ & & & 23 \\
\hline 04/25/05 & $17: 30$ & 140 & $1 \& 2$ & $A-10 B$ & 7 & 95 \\
\hline 04/26/05 & $13: 30$ & 140 & $3 \& 4$ & & & 17 \\
\hline 04/26/05 & $13: 30$ & 140 & $1 \& 2$ & $A-5 B$ & 7 & 53 \\
\hline 04/27/05 & $12: 00$ & 140 & $3 \& 4$ & & & 16 \\
\hline 04/27/05 & $12: 00$ & 140 & $1 \& 2$ & & & 14 \\
\hline 04/28/05 & 1:00 & 60 & $3 \& 4$ & & & 44 \\
\hline 04/28/05 & $1: 00$ & 60 & $1 \& 2$ & $A-5 B$ & 7 & 93 \\
\hline 04/28/05 & $16: 30$ & 140 & $3 \& 4$ & & & 14 \\
\hline 04/28/05 & $16: 30$ & 140 & $1 \& 2$ & $A-10 B$ & 7 & 43 \\
\hline 04/29/05 & $1: 00$ & 60 & $3 \& 4$ & & & 28 \\
\hline 04/29/05 & $1: 00$ & 60 & $1 \& 2$ & $A-10 B$ & 7 & 132 \\
\hline 04/30/05 & $0: 20$ & 100 & $3 \& 4$ & & & 35 \\
\hline 04/30/05 & $0: 20$ & 100 & $1 \& 2$ & $A-10 B$ & 10 & 160 \\
\hline 04/30/05 & $23: 45$ & 100 & $3 \& 4$ & & & 36 \\
\hline 04/30/05 & $23: 45$ & 100 & $1 \& 2$ & $A-5 B$ & 7 & 134 \\
\hline 05/03/05 & $13: 00$ & 140 & $3 \& 4$ & & & 29 \\
\hline 05/03/05 & $13: 00$ & 140 & $1 \& 2$ & Norit & 7 & 58 \\
\hline
\end{tabular}

The fly ash mercury content is clearly higher in the samples collected on the treated side. However, it is impossible to accurately calculate a mercury mass balance based upon fly ash samples from parametric tests since an unknown amount of native ash is collected with each sample. The coal analyses from the parametric test period are shown in Table 35.

\begin{tabular}{|c|c|c|c|c|c|c|c|}
\hline \multicolumn{8}{|c|}{$\underline{\text { Table } 35 \text { Coal Analyses from the Parametric Testing Period at Buck Station }}$} \\
\hline \multicolumn{8}{|c|}{ (BTU, ash, moisture and sulfur on an As Received Basis, the rest on a Dry Basis) } \\
\hline Date & BTU/lb & Ash, \% & Moisture, \% & Sulfur, \% & Hg, ppm & $\underline{\mathrm{Cl}} 2, \mathrm{ppm}$ & Fl2, ppm \\
\hline $4 \overline{4 / 14 / 05}$ & $\overline{12,629}$ & 9.73 & 7.65 & 0.67 & 0.06 & 1588 & 78 \\
\hline 4/15/05 & 12,677 & 8.87 & 7.83 & 0.73 & 0.07 & 1554 & 72 \\
\hline 4/16/05 & 12,607 & 9.27 & 7.99 & 0.72 & 0.05 & 1598 & 79 \\
\hline 4/17/05 & 12,036 & 10.58 & 10.06 & 0.70 & 0.06 & 1525 & 87 \\
\hline 4/23/05 & 12,098 & 11.08 & 9.17 & 0.70 & 0.07 & 1533 & 94 \\
\hline $4 / 25 / 05$ & 12,177 & 11.38 & 7.88 & 0.71 & 0.06 & 1437 & 90 \\
\hline 4/26/05 & 12,202 & 11.15 & 8.37 & 0.69 & 0.07 & 1543 & 94 \\
\hline 4/27/05 & 11,592 & 14.51 & 8.19 & 0.68 & 0.06 & 1285 & 118 \\
\hline 4/28/05 & 11,431 & 16.00 & 8.45 & 0.65 & 0.06 & 1242 & 123 \\
\hline 4/28/05 & 11,152 & 16.74 & 8.56 & 0.61 & 0.05 & 1133 & 135 \\
\hline 4/29/05 & 12,082 & 13.75 & 6.77 & 0.71 & 0.08 & 1351 & 108 \\
\hline 4/30/05 & 12,251 & 12.61 & 6.77 & 0.70 & 0.07 & 1446 & 106 \\
\hline $5 / 1 / 05$ & 12,204 & 12.16 & 7.69 & 0.66 & 0.08 & 1385 & 109 \\
\hline Average & 12,088 & 12.14 & 8.11 & 0.69 & 0.065 & 1432 & 99 \\
\hline
\end{tabular}


The coal analyses from the parametric testing are typical of that for a bituminous coal blend. This blend was composed of approximately $1 / 3^{\text {rd }}$ high ash coal and $2 / 3^{\text {rd }}$ low ash coal. The blend averaged about $12 \%$ ash, as received, but this varied from over $16 \%$ to under $9 \%$ during the parametric testing. The coal heat content on an as received basis averaged near $12,000 \mathrm{BTU} / \mathrm{lb}$ while the moisture content averaged slightly more than $8 \%$. The sulfur content was low averaging $0.69 \%$ on an as received basis.

The coal mercury content averaged $0.065 \mathrm{ppm}$ on a dry basis and was very stable during the testing. The coal chlorine and fluorine contents were high as expected in a bituminous coal. Flue gas with these levels of halogens would be expected to have high oxidized mercury content.

\section{Operating Data}

Buck Station Unit 6 is not a base-loaded unit. It operates at the required load during the daylight hours (up to the full load of $140 \mathrm{MW}$ ) and at reduced load (down to $60 \mathrm{MW}$ ) during the evening hours. The boiler loads during the parametric testing period are presented in Figure 51. This data represents five minute averages.

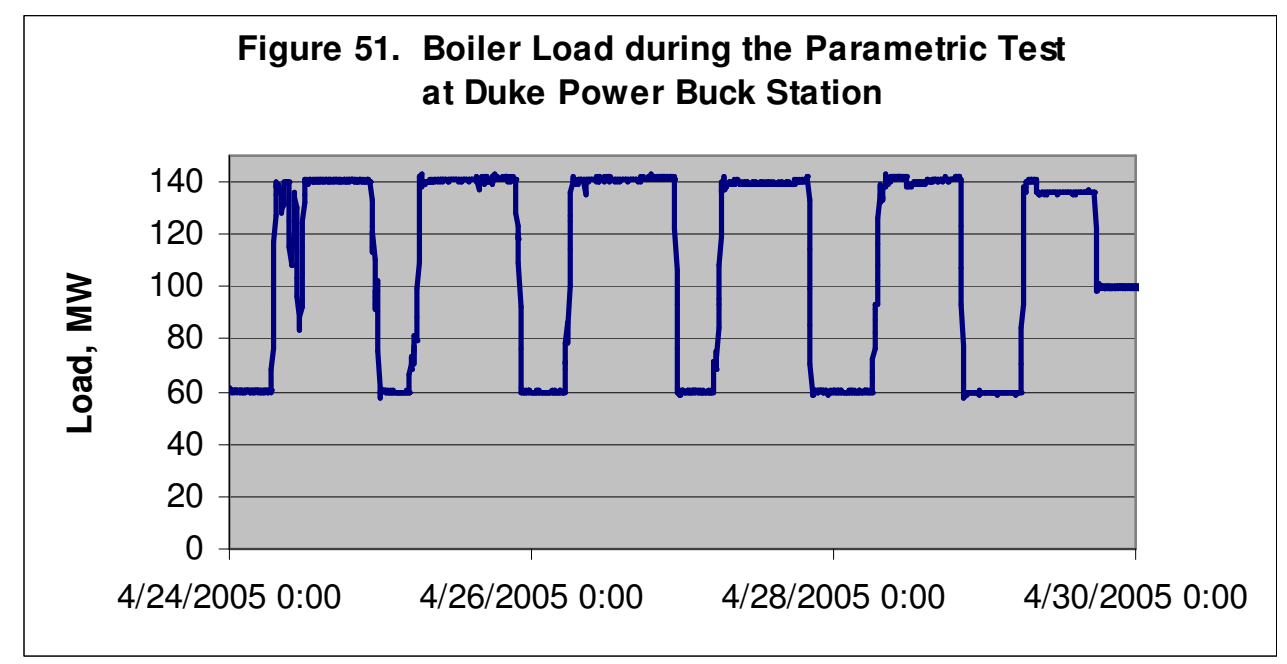

The boiler load was stable through most of the test period merely going from one load level to another. Boiler stability is of great importance since the lack of such causes perturbations in the mercury measurements.

The boiler cuts the flue gas flow rate with load but not directly proportional. Thus, the flue gas temperature in the gas leading to the ESP drops when the load is reduced. The temperature data for the injection location is presented in Figure 52. 


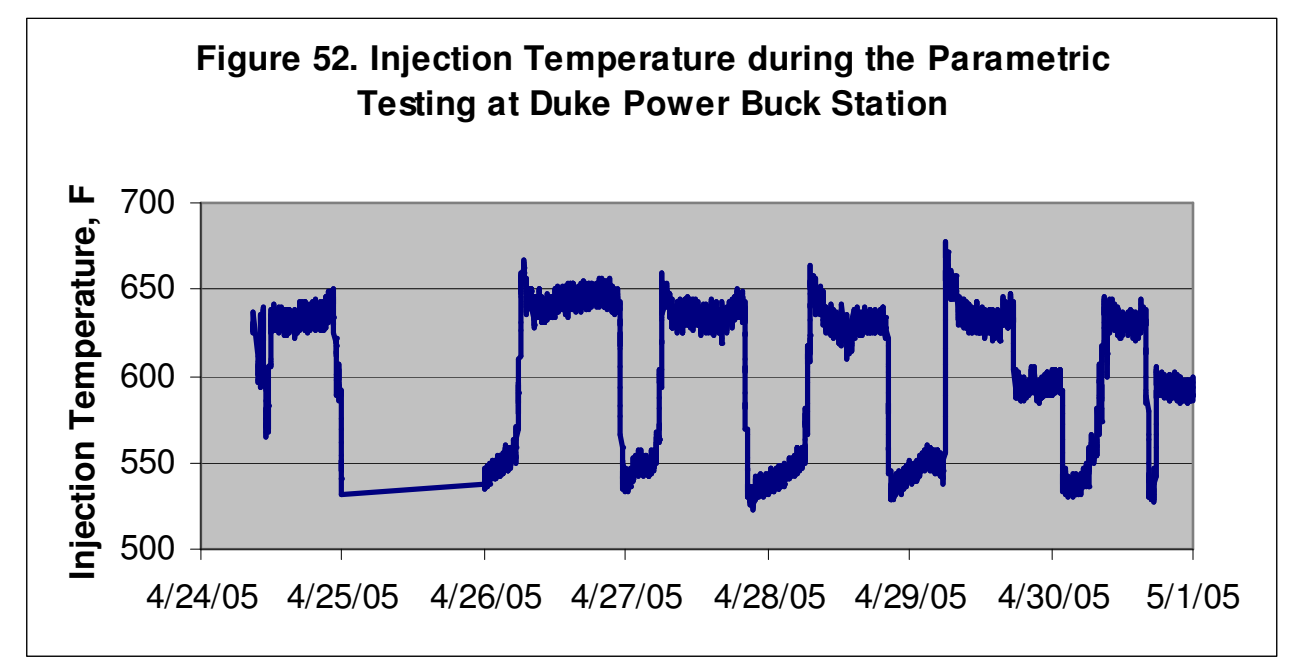

At full load, the boiler exit gas temperature averages about $640^{\circ} \mathrm{F}$. There are periods, usually associated with changing loads, when the flue gas temperature is varying. This variation, along with the change in other boiler operating parameters, causes the mercury data to be scattered until the boiler operation stabilizes. This temperature drops to about $540^{\circ} \mathrm{F}$ at low load.

The five minute average flue gas oxygen content for the parametric test period is presented in Figure 53.

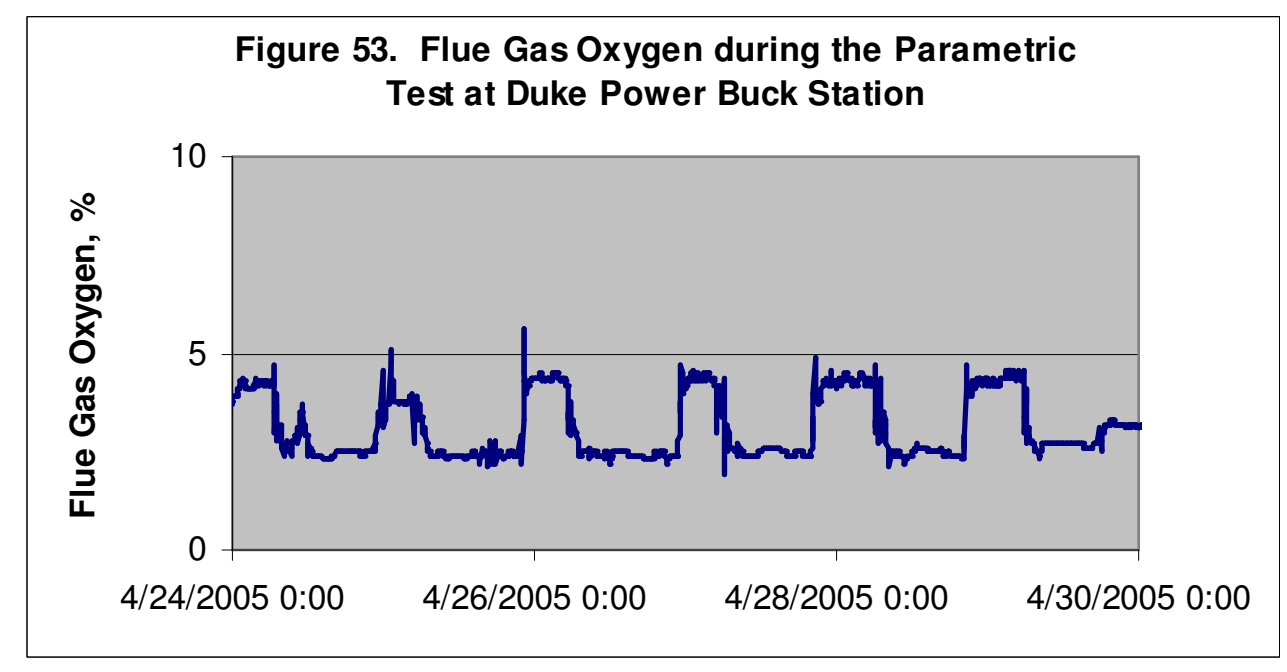

At full load the flue gas oxygen content averages about $2.5 \%$ while it is slightly below $5 \%$ at low load. The flue gas oxygen content is fairly stable once the boiler stabilizes at a given load.

The major concern of sorbent injection, in regard to a potential impact upon boiler operation, relates to opacity. The six minute average opacity observed during the parametric test period is presented in Figure 54. 


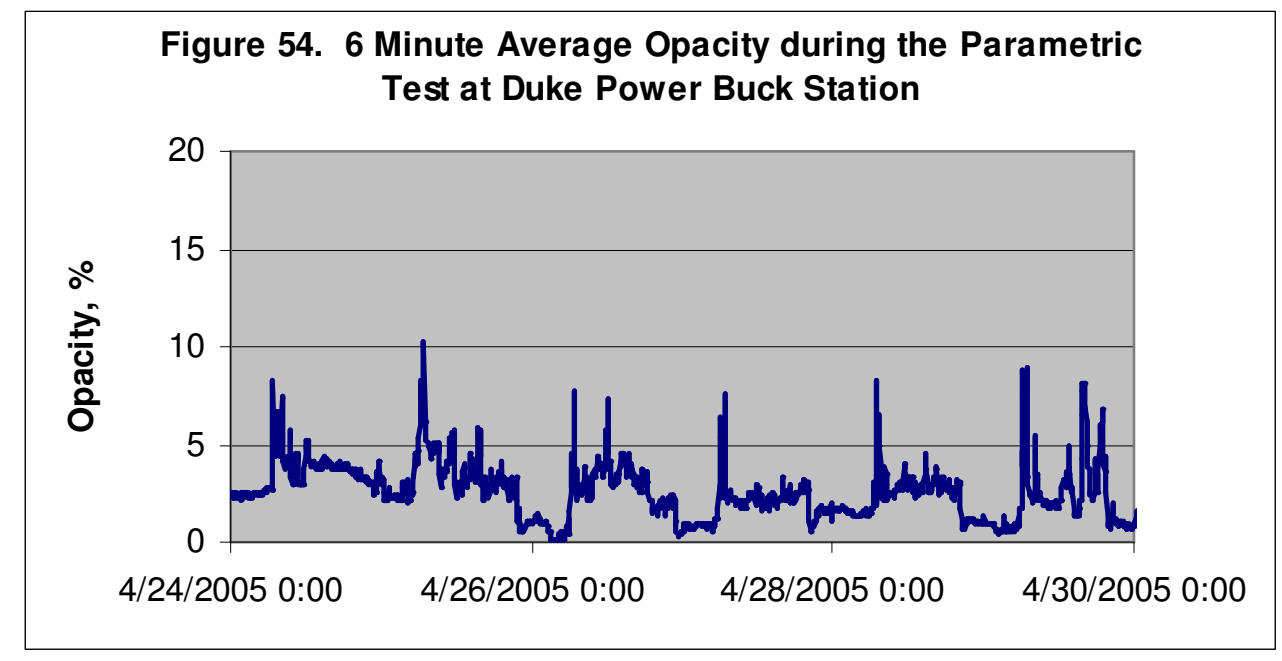

The boiler opacity was very low during the entire parametric testing period. There were a few moments over $5 \%$ opacity but these were short-lived and generally associated with a change in loads. The opacity averaged less than $3 \%$ for the entire period. Each injection period was examined to insure that there was no impact on opacity. The data is presented in Table 36.

\begin{tabular}{|c|c|c|c|c|}
\hline \multicolumn{5}{|c|}{ Table 36. Buck Parametric Testing Results - Injection Data } \\
\hline Date & $\begin{array}{l}\text { Start } \\
\text { Time }\end{array}$ & $\begin{array}{c}\text { End/Change } \\
\text { Time }\end{array}$ & $\begin{array}{l}\text { Injection Rate } \\
\text { Ib/MMacfm }\end{array}$ & Opacity, \% \\
\hline $4 / 25 / 2005$ & $11: 50$ & $\overline{12: 15}$ & & 2.7 \\
\hline $4 / 25 / 2005$ & $12: 15$ & $14: 30$ & 4 & 3.4 \\
\hline $4 / 25 / 2005$ & $14: 30$ & $17: 45$ & 7 & 3.3 \\
\hline $4 / 25 / 2005$ & $18: 43$ & 23:00 & & 3.0 \\
\hline $4 / 26 / 2005$ & 9:24 & $10: 10$ & & 3.2 \\
\hline $4 / 26 / 2005$ & $10: 10$ & 13:30 & 7 & 3.9 \\
\hline $4 / 27 / 2005$ & $21: 20$ & $22: 06$ & & 1.6 \\
\hline $4 / 27-28 / 05$ & $22: 06$ & 0:06 & 4 & 1.6 \\
\hline $4 / 28 / 2005$ & 0:06 & $1: 40$ & 7 & 1.7 \\
\hline $4 / 28 / 2005$ & $13: 30$ & $14: 11$ & & 2.6 \\
\hline 4/28/2005 & $14: 11$ & $16: 45$ & 7 & 3.2 \\
\hline $4 / 28 / 2005$ & $20: 32$ & $21: 44$ & & 1.0 \\
\hline $4 / 28 / 2005$ & $21: 44$ & $23: 32$ & 4 & 1.0 \\
\hline $4 / 28-29 / 05$ & $23: 32$ & $1: 30$ & 7 & 1.0 \\
\hline 4/29/2005 & $3: 45$ & $5: 30$ & & 1.1 \\
\hline $4 / 29 / 2005$ & $18: 43$ & $19: 20$ & & 1.8 \\
\hline 4/29/2005 & $19: 20$ & $20: 44$ & 2 & 1.0 \\
\hline 4/29/2005 & $20: 44$ & 22:34 & 7 & 1.0 \\
\hline $4 / 29-30 / 05$ & 22:34 & $0: 40$ & 10 & 1.0 \\
\hline $4 / 30 / 2005$ & $18: 54$ & $19: 24$ & & 1.9 \\
\hline $4 / 30 / 2005$ & $19: 24$ & $21: 26$ & 2 & 1.9 \\
\hline $4 / 30 / 2005$ & $21: 26$ & $22: 47$ & 5 & 2.1 \\
\hline $4 / 30 / 2005$ & $22: 47$ & $23: 45$ & 7 & 2.2 \\
\hline
\end{tabular}


The opacity during each injection run was always about the same as before the injection run. Thus, the sorbent injection did not have a significant impact on the boiler opacity.

\section{Long-Term Test Sorbent Selection}

Based upon these results, the A-5B H-PAC was selected for the long-term test. This sorbent was far superior to the plain PAC and as good as the other $\mathrm{H}-\mathrm{PAC}$ tested. It was decided to start the long-term testing at a relatively low injection rate of $4.0 \mathrm{lb} / \mathrm{MMacf}$ to see if a mercury removal rate between $50 \%$ and $70 \%$ could be maintained. 


\section{Long-Term Test}

The long-term test at the Duke Power Buck Station experienced many difficulties. The coal used in most of this test averaged nearly twice the ash content as in the parametric test program. There were ash removal problems, partially because of the additional ash. Near the end of the long-term test, the coal blend was changed to a blend containing some subbituminous coal which helped to reduce the ash load but hurt the boiler operation. There were three major boiler outages plus boiler flame-outs and opacity spikes. There were additional inlet monitor problems, which led to the relocation of this mercury monitor to the untreated ESP stack. There were two sorbent injection stoppages: one caused by a computer error and one to repair a problem with the injection system. The long-term test was conducted after the boiler had converted to low $\mathrm{NO}_{x}$ operation. All of these events complicated the test and the interpretation of the results.

\section{Operating Data}

A discussion of the operating data leads this section in order to further define the operating problems encountered during the long-term test. Graphs similar to those that were presented in the discussion of the parametric testing are presented here and the differences are noted.

The five minute average boiler load for the long-term test period is presented in Figure 55.

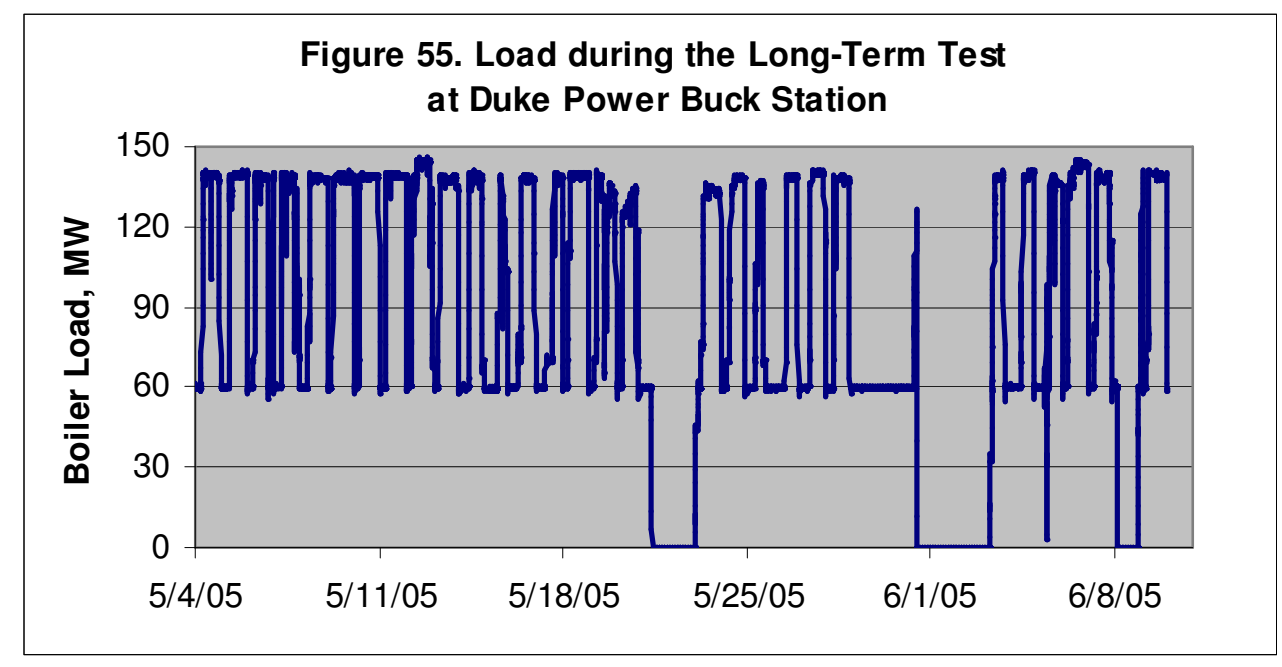

The boiler load was much more erratic during the long-term test as compared to the parametric test. There were many days when the boiler load varied throughout a period when it is normally stable at high load. In addition, there were three major boiler outages and one minor one. These can be seen in the figure when the load went to zero.

The injection temperature data is presented in Figures 56 to 59. 

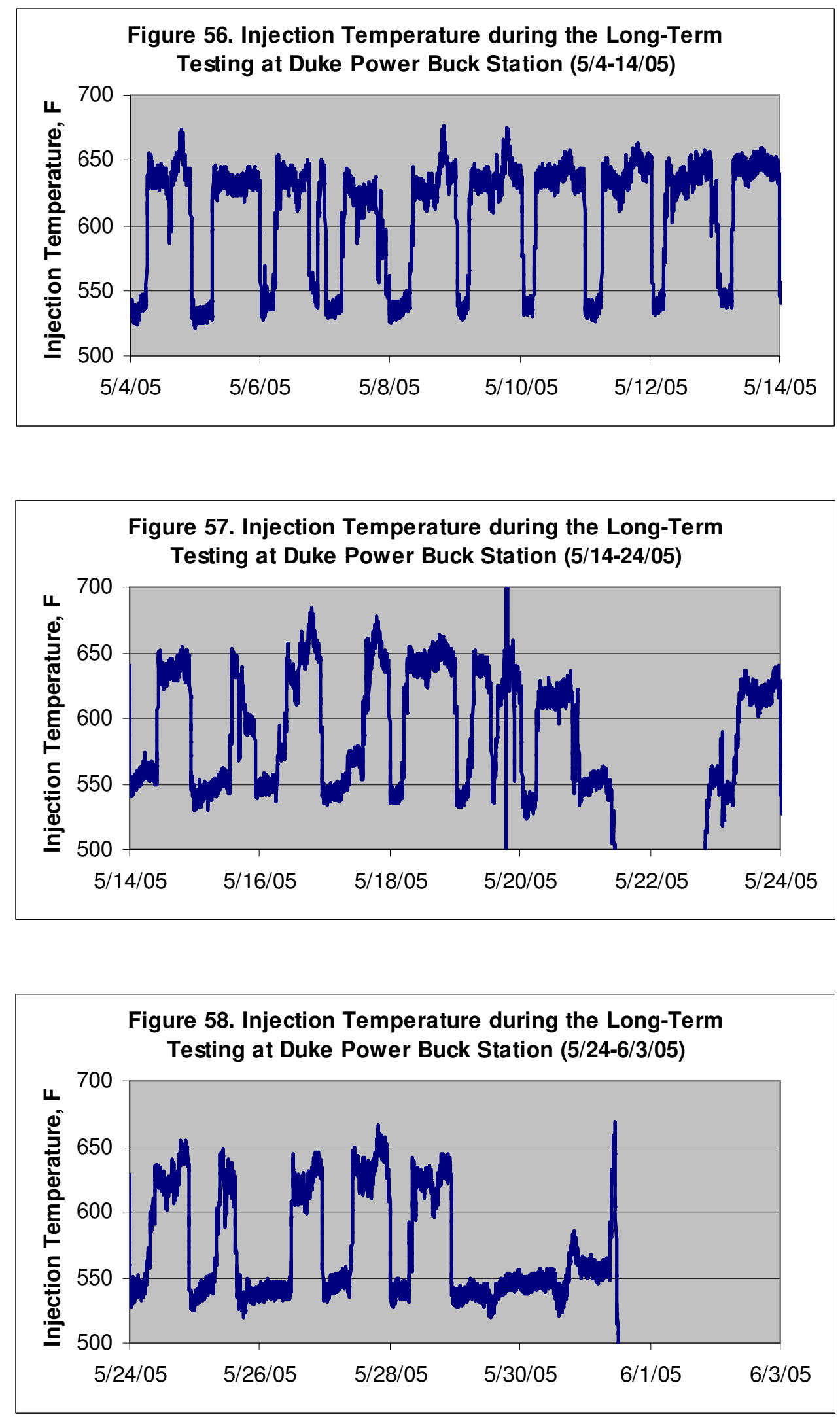


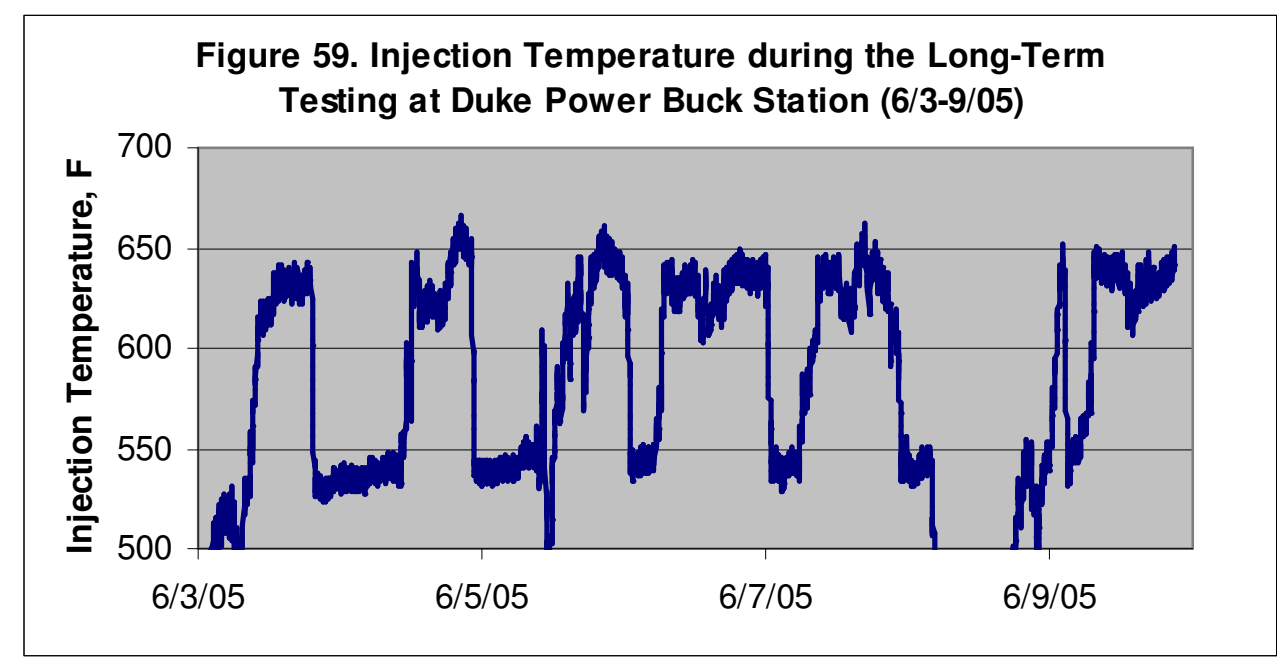

The long-term test period was broken into four sections in order to show more details. As can be seen, the temperature at the injection location was highly variable when the boiler was at full load. There was a temperature spike on May 19, 2005, which reached $1000^{\circ} \mathrm{F}$. In addition, there were many periods of time where the injection temperature exceeded $675^{\circ} \mathrm{F}$. The boiler was the most stable at low loads. In fact, the most stable period during the long-term test was over the Memorial Day Holiday weekend of May 2830 when the boiler was at low load the entire time.

The five minute average flue gas oxygen data for the long-term test period is presented in Figure 60.

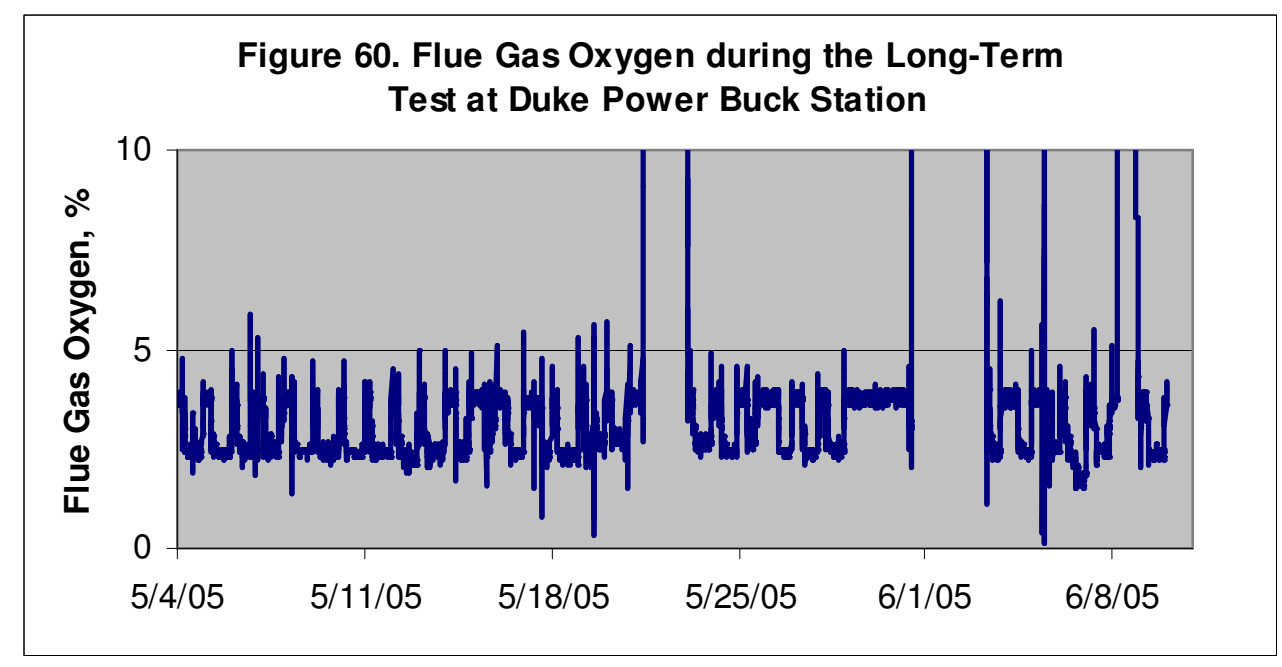

As with the other boiler parameters, the flue gas oxygen content was much more variable during the long-term test as compared to the parametric test period. There were numerous spikes in flue gas oxygen above $5 \%$, even discounting the times the boiler was down. There were only two spikes above $5 \%$ oxygen during the parametric test period. 
The most striking difference between the parametric and long-term test periods is in the opacity. The 6 minute average opacity data for the long-term test is shown in Figure 61.

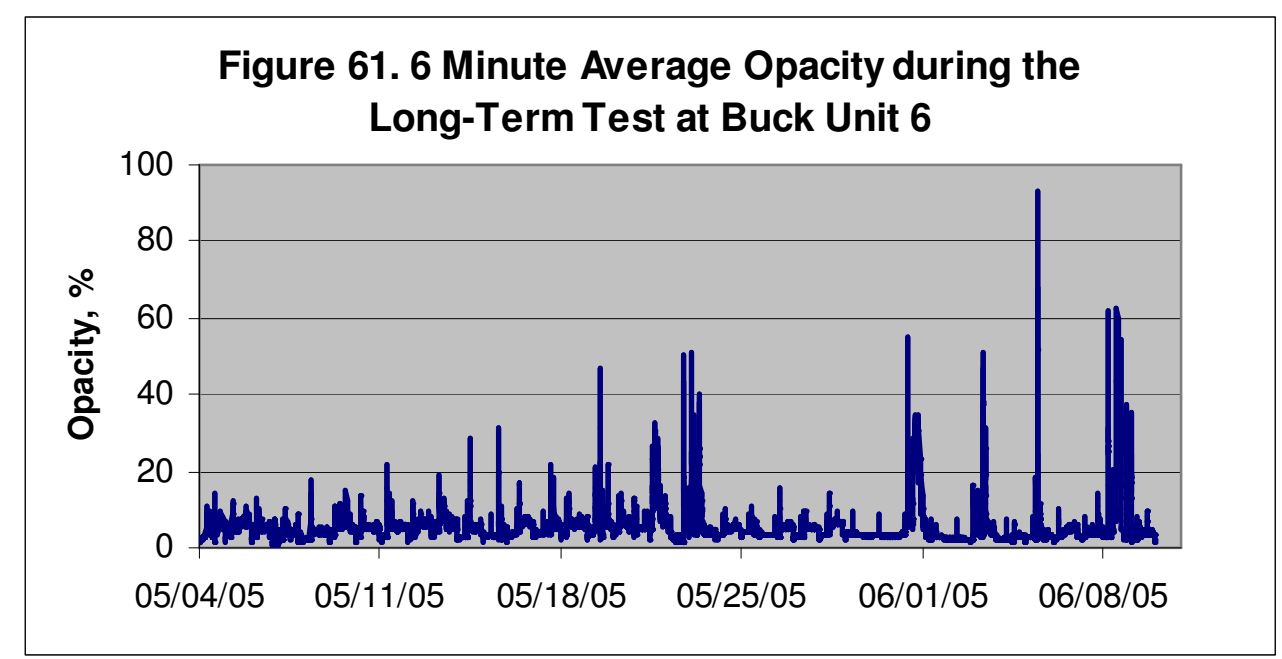

Note the difference in scales for the opacity data. The scale for the opacity chart for the parametric test period was $0 \%$ to $20 \%$ while the scale for this figure is $0 \%$ to $100 \%$. In the parametric test period, the opacity was under $10 \%$ except for one reading. The opacity during the long-term test was over $10 \%$ many times and even over $40 \%, 50 \%$, and $60 \%$ on a few occasions. The parametric testing clearly showed that the sorbent did not impact the flue gas opacity. Thus, something else impacted the opacity. As will be seen in the following section, coal quality appears to be the cause of the operational problems during the long-term testing.

The parametric test program was conducted before the $\mathrm{NO}_{x}$ control season began. The $\mathrm{NO}_{x}$ emissions averaged $0.25 \mathrm{lb} / \mathrm{MMBtu}$ during the parametric test period. The longterm test was conducted during the $\mathrm{NO}_{x}$ control season. The $\mathrm{NO}_{x}$ emissions averaged $0.17 \mathrm{lb} / \mathrm{MMBtu}$ during the long-term test.

\section{$\underline{\text { Coal Analyses }}$}

The coal analyses section is placed here to further explain the difficult boiler operation during the long-term test. The proximate coal analyses from the long-term test period are presented in Tables 37 and 38 . The first table covers the time that the blend of bituminous coals was in use while the second covers the period when the bituminous/subbituminous blend was used during the last few days of testing. 


\begin{tabular}{|c|c|c|c|c|}
\hline \multicolumn{5}{|c|}{$\begin{array}{c}\text { Table 37. Long-Term Test Coal Analyses at Duke Power Buck } \\
\text { Using Blend of High and Low Ash Bituminous Coals } \\
\text { (As received basis) }\end{array}$} \\
\hline Date & BTU/Ib & Ash, \% & Moisture, \% & Sulfur, \% \\
\hline $05 / 04 / 05$ & $\overline{10,808}$ & 20.0 & 7.2 & 0.67 \\
\hline 05/05/05 & 10,496 & 19.6 & 9.2 & 0.66 \\
\hline 05/06/05 & 11,462 & 15.9 & 8.1 & 0.70 \\
\hline 05/07/05 & 10,935 & 19.0 & 7.5 & 0.71 \\
\hline 05/08/05 & 10,822 & 20.0 & 7.0 & 0.68 \\
\hline 05/09/05 & 10,749 & 20.0 & 7.5 & 0.64 \\
\hline 05/10/05 & 10,819 & 19.1 & 8.1 & 0.69 \\
\hline $05 / 11 / 05$ & 10,965 & 19.1 & 7.6 & 0.68 \\
\hline $05 / 12 / 05$ & 11,353 & 16.9 & 6.7 & 0.68 \\
\hline 05/13/05 & 12,390 & 11.7 & 6.6 & 0.71 \\
\hline $05 / 14 / 05$ & 11,164 & 19.1 & 6.1 & 0.69 \\
\hline $05 / 15 / 05$ & 11,092 & 19.8 & 6.1 & 0.73 \\
\hline $05 / 16 / 05$ & 10,862 & 19.9 & 7.3 & 0.74 \\
\hline 05/17/05 & 11,085 & 19.2 & 7.0 & 0.68 \\
\hline 05/18/05 & 11,003 & 20.6 & 5.9 & 0.74 \\
\hline 05/19/05 & 10,799 & 20.8 & 6.6 & 0.65 \\
\hline 05/20/05 & 10,988 & 17.9 & 8.7 & 0.64 \\
\hline 05/21/05 & 10,962 & 18.5 & 8.8 & 0.61 \\
\hline $05 / 22 / 05$ & 11,276 & 18.7 & 6.4 & 0.65 \\
\hline 05/23/05 & 10,995 & 19.8 & 7.1 & 0.62 \\
\hline $05 / 24 / 05$ & 11,310 & 18.5 & 5.9 & 0.66 \\
\hline 05/25/05 & 11,745 & 15.6 & 6.9 & 0.64 \\
\hline 05/26/05 & 11,843 & 16.4 & 5.0 & 0.64 \\
\hline 05/27/05 & 11,030 & 19.2 & 7.4 & 0.62 \\
\hline 05/28/05 & 11,003 & 20.1 & 6.4 & 0.63 \\
\hline 05/29/05 & 11,482 & 17.8 & 5.7 & 0.64 \\
\hline 05/30/05 & 11,852 & 16.0 & 5.6 & 0.64 \\
\hline $05 / 31 / 05$ & 11,398 & 17.1 & 7.3 & 0.64 \\
\hline Average & 11,167 & 18.4 & 7.0 & 0.67 \\
\hline
\end{tabular}

The coal used during the long-term test was completely different than that used during the parametric testing. The normal coal blend is two thirds low ash bituminous coal ( $7 \%$ ash as received) and one third high ash bituminous coal ( $\sim 27 \%$ ash as received). There was a shortage of the low ash coal during the long-term test and, as a result, the blend ratio was nearly reversed. The resulting coal blend had more than $18 \%$ ash and a heating value $1000 \mathrm{Btu} / \mathrm{lb}$ lower than that of the coal used in the parametric test period. Buck Station operators noted on several occasions that the coal was hard to burn. The coal quality translated into the boiler operating problems observed in the long-term test.

The coal had chlorine and fluorine contents about the same as in the parametric test program, approximately $1400 \mathrm{ppm}$ and $100 \mathrm{ppm}$, respectively. The mercury content on a dry basis averaged $0.059 \mathrm{ppm}$, slightly lower than the $0.065 \mathrm{ppm}$ measured in the coal during the parametric test program. 
The last few days of the long-term test a blend containing $75 \%$ of the low ash bituminous coal and $25 \%$ of a subbituminous coal was tested. The results of the coal analyses are presented in Table 38.

\begin{tabular}{|c|c|c|c|c|}
\hline \multicolumn{5}{|c|}{$\frac{\text { Table 38. Long-Term Test Coal Analyses at Duke Power Buck }}{\text { Using Blend of Bituminous and Subbituminous Coals }}$} \\
\hline & & (As rece & d basis) & \\
\hline Date & BTU/lb & Ash, \% & Moisture, \% & Sulfur, \% \\
\hline $06 / 07 / 05$ & $\overline{11,448}$ & 9.7 & 12.7 & 0.53 \\
\hline 06/08/05 & 11,149 & 9.9 & 13.4 & 0.60 \\
\hline 06/09/05 & 11,717 & 9.8 & 11.7 & 0.61 \\
\hline Average & 11,438 & 9.8 & 12.6 & 0.58 \\
\hline
\end{tabular}

This coal blend had about the same heating value as did the bituminous coal blend but about half the ash and $80 \%$ more moisture. The latter took time to adjust the boiler operation. The sulfur content was about $15 \%$ lower than the bituminous coal blend. The coal chlorine and fluorine contents were slightly lower than for the bituminous coal blend. The mercury content averaged 0.60 ppm nearly the same as the bituminous coal blend.

\section{Mercury Measurements}

The long-term test began at 13:00 on May 4 and ran to 16:00 June 9, 2005. The results of the first two days of the long-term test were instructive. The outlet mercury data and the injection temperature for selected periods on those days are presented in Figure 62.

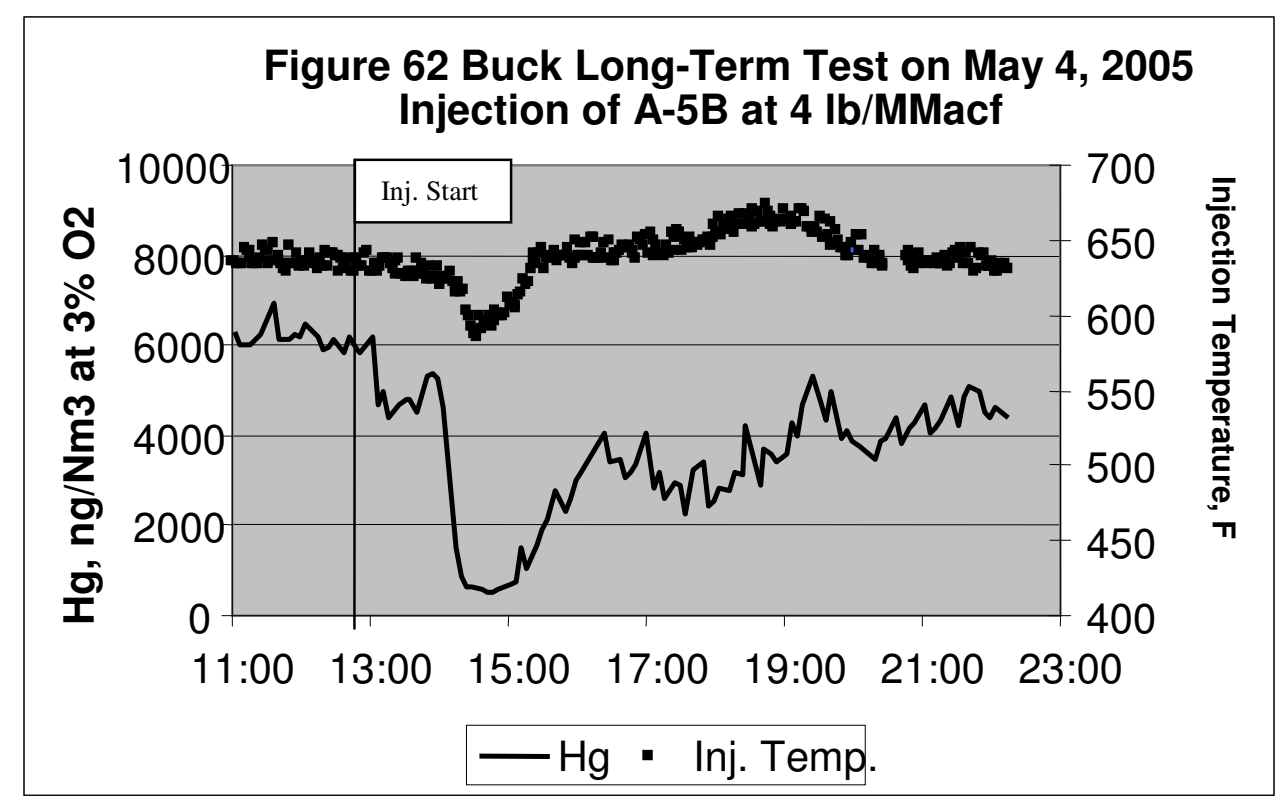

The long-term test began with the injection of $A-5 B$ at a rate of $4 \mathrm{lb} / \mathrm{MMacf}$. This is a lower rate than was used in much of the parametric tests but it was decided that this might provide the desired $50-70 \%$ mercury removal. The outlet mercury level dropped when sorbent injection began but only by about 30\%. Then the boiler encountered one of what was to be many problems. There was a dip in the flue gas temperature and the mercury level dropped drastically. The boiler recovered and the mercury level rose but 
not to the level it was before the temperature drop. The boiler temperature increased above the expected $625-640^{\circ} \mathrm{F}$ to near $675^{\circ} \mathrm{F}$ and the mercury level continued upward. The mercury level decreased as the temperature dropped back down to the normal range and stayed in this range until the boiler load was reduced at 22:15. The boiler was much more stable during the parametric testing with lower injection temperatures. The boiler instability on this day was apparently related to the poor coal quality.

On May $5^{\text {th }}$, it was decided to stop the injection system, clean the monitors and resume at a higher injection rate of $5 \mathrm{lb} / \mathrm{MMacf}$. The outlet $\mathrm{Hg}$ data and the injection temperature are presented in Figure 63 for the period of time just before and after the termination of sorbent injection.

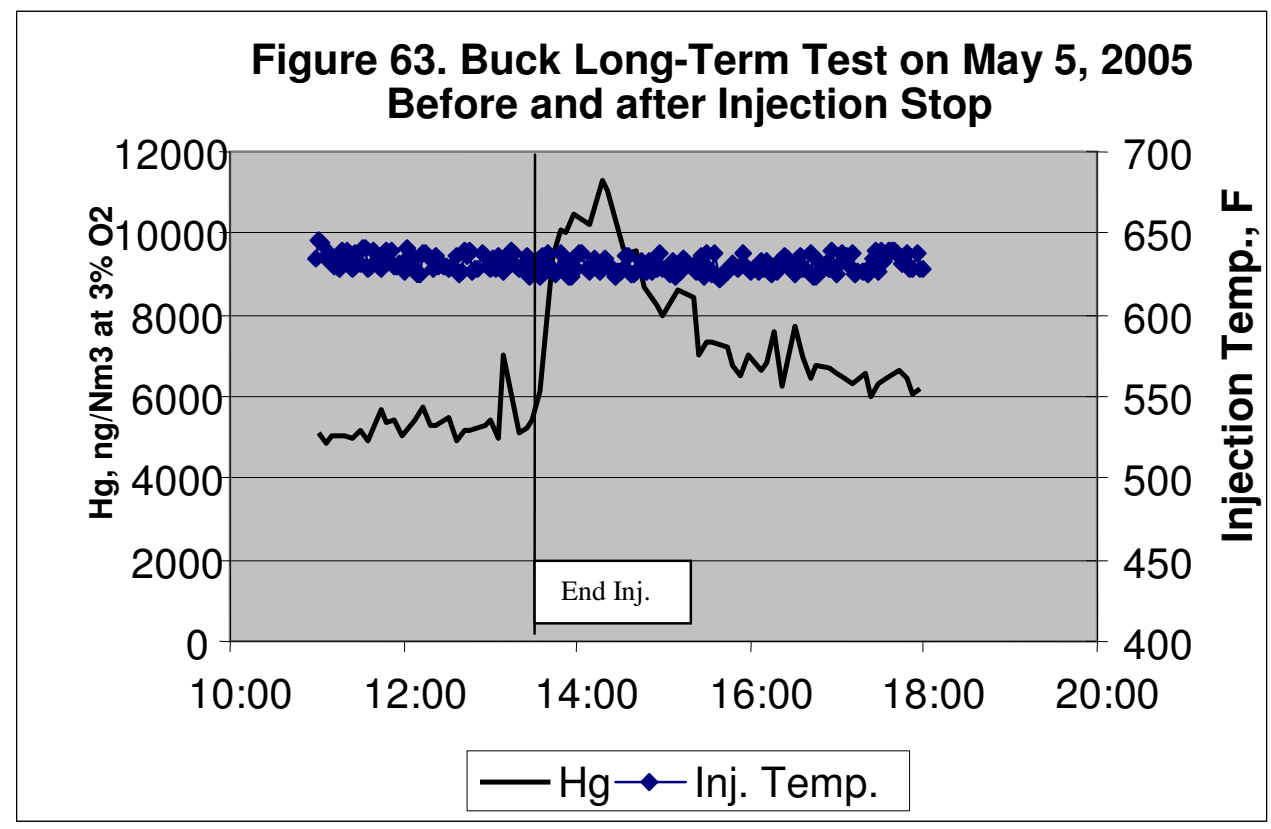

The boiler was stable on this day, much as it was during the parametric tests. This is exemplified by the stable flue gas temperatures at the injection location. Once the injection was stopped, the mercury level jumped not to the expected baseline level but much higher. The mercury level then slowly decreased to the expected baseline level. This was first observed in the Duke Power Cliffside I test. It was minimized there by operating the ash removal system continuously. Unfortunately, the ash removal system at Buck was operating as fast as it could but this was not fast enough to prevent mercury re-emission. The problem was magnified because of the very large volume of fly ash to be removed when using a high ash coal.

Buck Unit 6 appears to have another problem in regard to sorbent removal from the system. The flue gas flow in the ductwork leading to the ESP is skewed. The flue gas flow at full load is only 16 feet per second in some parts of the duct. This is far below the design minimum of 40 feet per second to insure no dust drop-out. It is even worse at low loads since the Buck units cut flow with boiler load and thus the flow rate in some locations is far less than 10 feet per second. This allows the build-up of ash and sorbent which adds to the potential mercury loss by extending the sorbents time in the boiler. The spike in mercury level after injection is stopped clearly indicates that the mercury removal process at the high temperatures of a hot-side ESP is reversible. This phenomenon is observed on every occasion that the injection system was stopped. 
Thus, the mercury level measured is the net between the mercury captured by the new sorbent being injected and the loss of mercury from the sorbent until it is removed from the system.

The erratic boiler operation caused the mercury readings also to be erratic. The data for the long-term test period was divided into stable boiler operating periods to define the mercury removal achieved during this test. The results of the analysis of the mercury CEM data are presented in Table 39.

\begin{tabular}{|c|c|c|}
\hline \multicolumn{3}{|c|}{ Table 39 Buck Long-Term Test Hg Removal Based Upon CEM } \\
\hline Date & $\underline{\text { Hours }}$ & Hg Removal, \% \\
\hline Low Load - $5.0 \mathrm{lb} / \mathrm{MMacf}$ & & \\
\hline 05/10/05 & 4 & 25.1 \\
\hline 05/12/05 & 4 & 38.9 \\
\hline 05/13/05 & 5 & 58.0 \\
\hline 05/14/05 & 10 & 44.1 \\
\hline 05/17/05 & 8 & 38.3 \\
\hline 05/21/05 & 9 & 58.9 \\
\hline 05/24/05 & 5 & 63.5 \\
\hline 05/27/05 & 9 & 51.9 \\
\hline 05/28/05 & 7 & 30.3 \\
\hline 6/3-4/05 & 13 & 61.4 \\
\hline 06/05/05 & 8 & 48.0 \\
\hline Total & 82 & \\
\hline High & & 63.5 \\
\hline Low & & 25.1 \\
\hline Weighted Average & & 48.8 \\
\hline Low Load - $10.0 \mathrm{lb} / \mathrm{MMacf}$ & & \\
\hline $5 / 29-31 / 05$ & 57 & 70.9 \\
\hline High Load - $5.0 \mathrm{lb} / \mathrm{MMacf}$ & & \\
\hline 05/09/05 & 13 & 51.2 \\
\hline 05/10/05 & 2 & 74.6 \\
\hline 05/11/05 & 16 & 62.0 \\
\hline $05 / 12 / 05$ & 3 & 63.5 \\
\hline 05/13/05 & 13 & 58.0 \\
\hline $05 / 14 / 05$ & 3 & 64.1 \\
\hline 05/19/05 & 8 & 79.1 \\
\hline 05/24/05 & 9 & 63.5 \\
\hline 05/26/05 & 9 & 48.8 \\
\hline 05/27/05 & 7 & 25.1 \\
\hline 05/28/05 & 13 & 47.9 \\
\hline 06/03/05 & 3 & 35.6 \\
\hline 06/04/05 & 6 & 35.5 \\
\hline 06/05/05 & 6 & 29.0 \\
\hline 06/06/05 & 7 & 25.3 \\
\hline 06/09/05 & 9 & 29.4 \\
\hline Total & 127 & \\
\hline High & & 79.1 \\
\hline Low & & 25.1 \\
\hline Weighted Average & & 49.8 \\
\hline
\end{tabular}


Two of the three periods were during the time that A-5B was being injected at 5 lb/MMacf: One at high load and one at low load. The third period was at low load and an injection rate of $10 \mathrm{lb} /$ MMacf. This last test period was over the Memorial Day weekend when the boiler operation was stable at low load.

The average mercury removal at an injection rate of $5 \mathrm{lb} /$ MMacf was about $50 \%$ whether at high load or low load. However, the measured removal rate varied from about $25 \%$ to about $80 \%$. It is believed that the difference in performance is a function of rate the fly ash is removed from the system and, to a lesser degree injection temperature. The use of high ash coal slowed the rate of ash removal drastically. When measured, the time required to remove the ash from the ESP hoppers was about five minutes during the parametric test program but varied between 15 minutes and several hours during the long-term test. Unfortunately, data on the operation of the ash removal system is not collected electronically.

The period at low load and the higher injection rate provided a stable mercury removal value of slightly more than $70 \%$. At low loads, the problem with the ash removal system cleaning time is reduced since there is much less ash to handle.

The $\mathrm{Hg}$ CEM data from the long-term test is presented in the next four figures (64-67). A discussion of the major occurrences during each time period is provided.

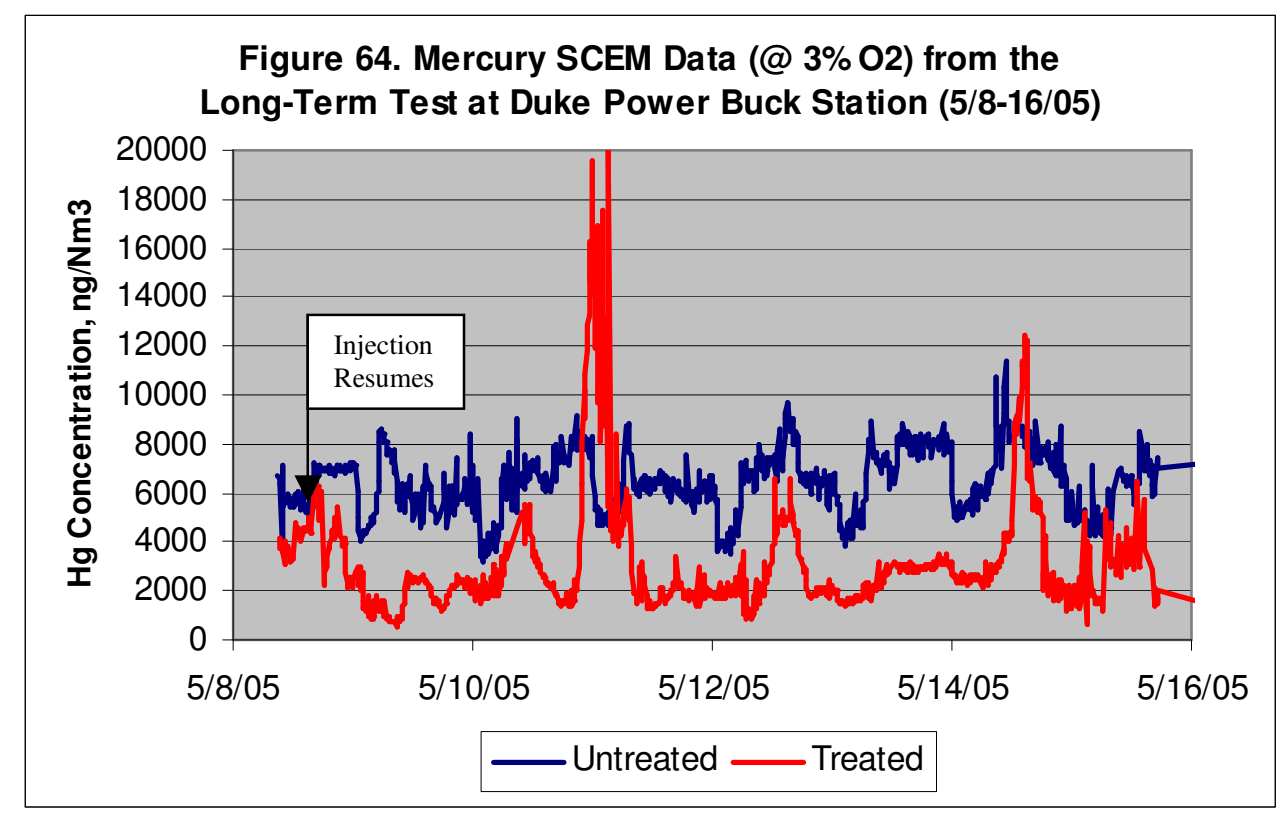

The sorbent injection resumed at 18:00 on May 8, 2005. The Hg CEMs were then both located on the stacks of the two ESPs which collect the fly ash from Buck 6 . The monitors are labeled as treated and untreated to represent the flue gas stream which they are monitoring.

Late on the night of May $10^{\text {th }}$ there was a computer error which prevented the injection hopper from refilling with sorbent. Thus, the feeder ran out of sorbent. The result was the gigantic mercury spike above the level of the mercury in the untreated gas that night 
and the next morning before the injection was resumed. When resumed, the mercury level decreased to the level previously observed.

On May $12^{\text {th }}$, the ash removal system was down for about 3 hours which caused the mercury level in the treated side to rise. On May $14^{\text {th }}$, the injection system was shut down for 3 hours to repair a leaking flange. The result was the mercury spike observed on that day. On May $15^{\text {th }}$, there was a problem with fly ash plugging the pitot tube in the flow measurement system. The injection system monitors flow rate and varies the injection rate in terms of $\mathrm{lb} / \mathrm{hr}$ to meet the desired injection rate in terms of $\mathrm{lb} / \mathrm{MMacf}$. The erratic injection rate on May $15^{\text {th }}$ caused the mercury on the treated side to be erratic also. Finally, on the same date, the mercury CEMs lost their argon supply and they were off line until the morning of the May $16^{\text {th }}$.

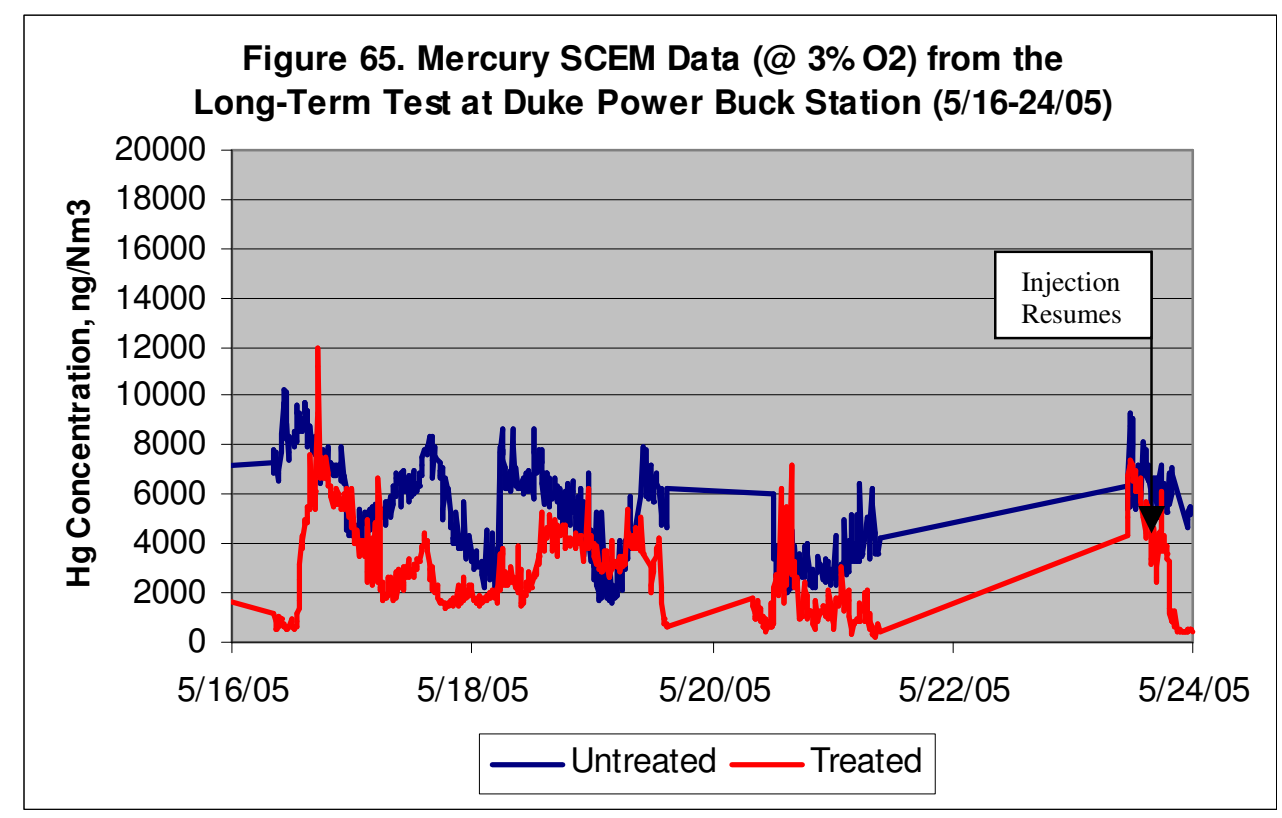

Late on May $16^{\text {th }}$, the injection temperature surged to about $685^{\circ} \mathrm{F}$ and the treated outlet mercury level jumped upward to approximately the same as the untreated outlet. The treated mercury level dropped once the temperature dropped. On May $19^{\text {th }}$, the boiler had a $1000^{\circ} \mathrm{F}$ temperature spike which damaged one CEM and required both to be cleaned. The boiler was down for repairs much of May 21-23. Injection resumed at 19:00 on May $23^{\text {rd }}$. 


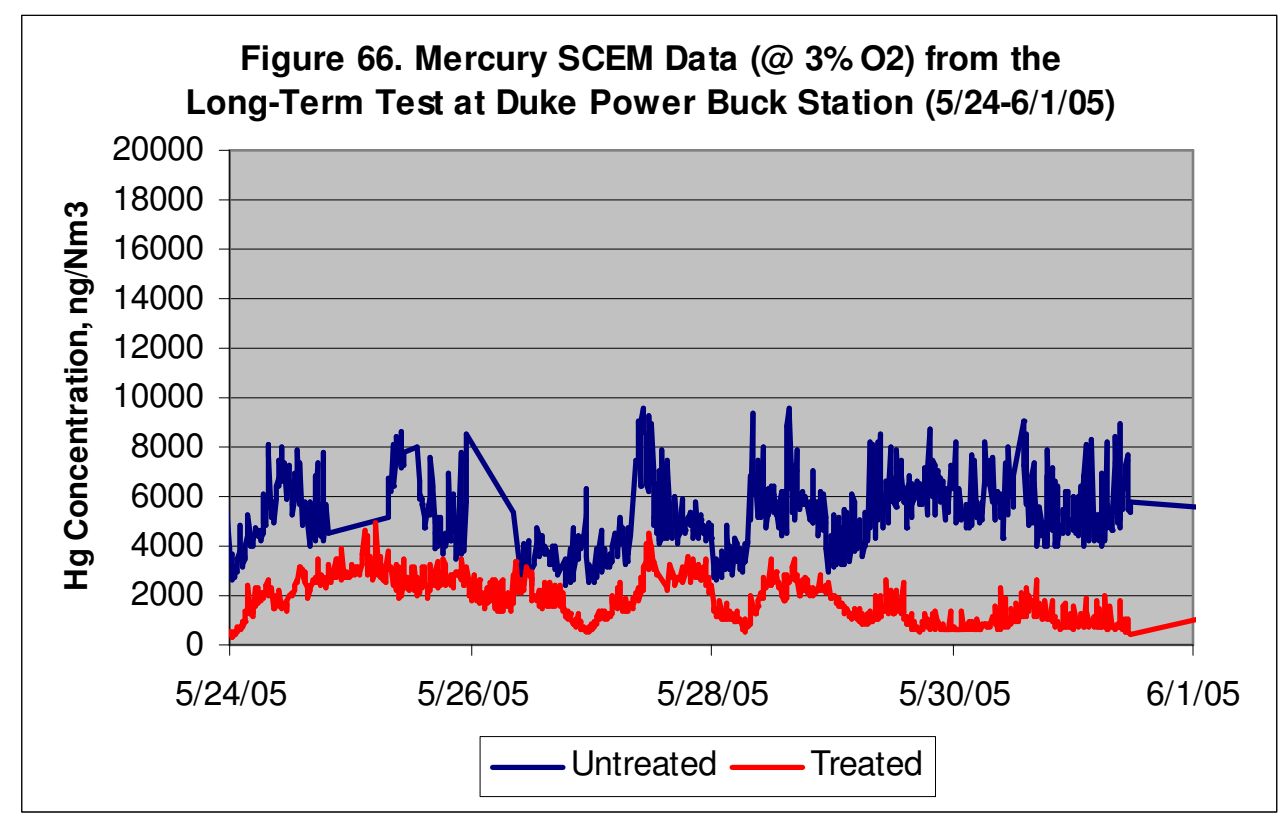

The CEM measuring the untreated flue gas was lost twice, once on May $24^{\text {th }}$ and once on May $25^{\text {th }}$. An impinger pluggage caused both problems. The most stable period of the long-term test began on the morning of May $29^{\text {th }}$ and ended at 11:30 on May $31^{\text {st }}$. The boiler was at low load this entire period. The mercury measurements were also the most stable of the long-term test. The low load period ended when there was an attempt to increase boiler load on May $31^{\text {st }}$ and the boiler operation was lost.

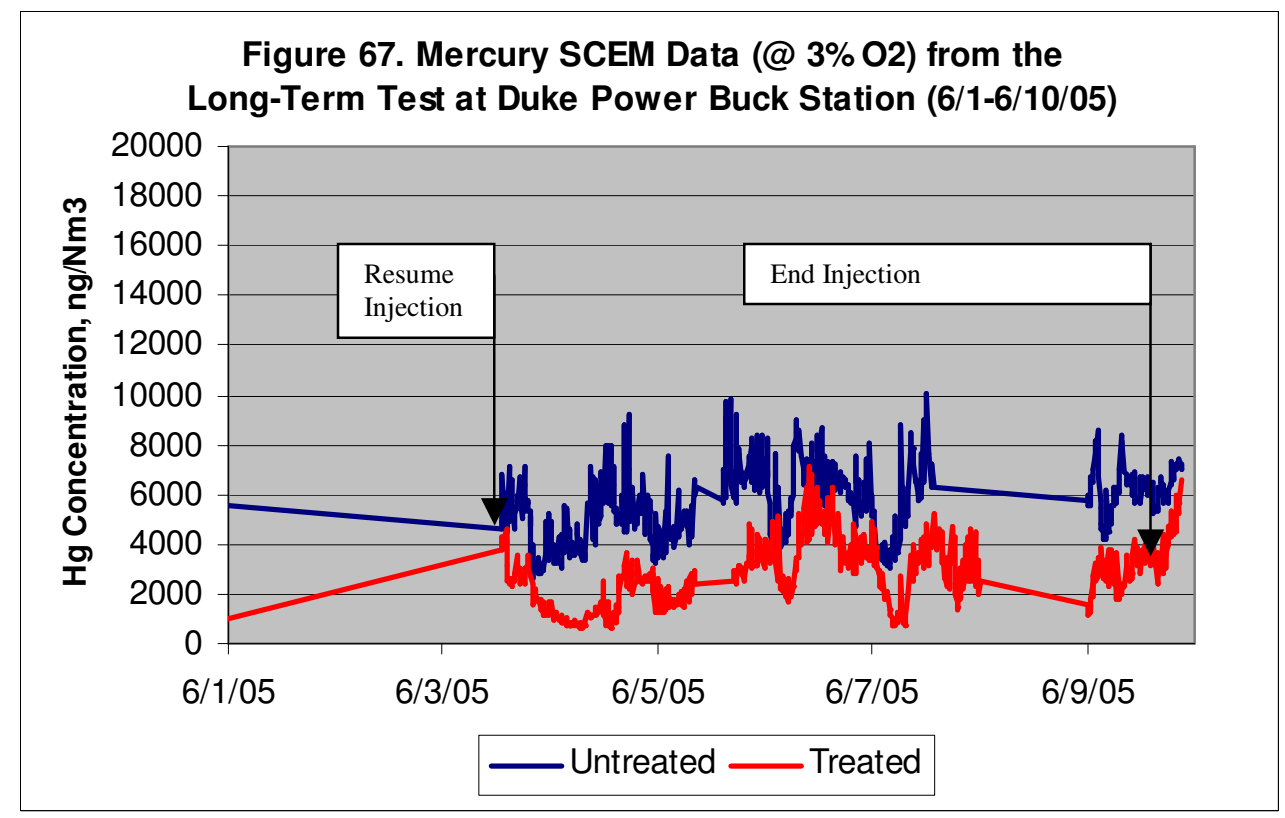

The boiler was down until June $3^{\text {rd }}$. Sorbent injection resumed at 14:15, soon after the boiler resumed operation. The Hg CEMs were down for cleaning for several hours on June $5^{\text {th }}$ due to a large opacity spike which blinded the inertial separators. The fly ash removal system was down for repairs for several hours on June $6^{\text {th }}$ causing the treated 
mercury level to rise. The boiler was down again on $8^{\text {th }}$ and resumed operation on June $9^{\text {th }}$. The injection system was stopped at 16:00 on June $9^{\text {th }}$ and the mercury level in the treated flue gas immediately began to rise.

Two sets of OHM tests were performed during the long-term test at the Buck Station. The first set was collected on May $18^{\text {th }}$ when the bituminous coal blend was in use and the second on June $7^{\text {th }}$ when the bituminous/subbituminous blend was in use. The boiler operation was not very stable on either day but it was impossible to predict when to sample during the long-term test.

The results from the May OHM measurements are presented in Table 40, along with the Hg CEM data.

\begin{tabular}{|c|c|c|c|c|c|c|c|c|c|}
\hline \multicolumn{10}{|c|}{ Table 40. Buck Long-Term OHM Testing - 5/18/05 } \\
\hline $\begin{array}{l}\text { Note: All Hg } \\
\text { in } \mathrm{ng} / \mathrm{dscm} \\
\text { at } 3 \% \mathrm{O} 2\end{array}$ & \multicolumn{2}{|c|}{$\underline{\text { Test } 1}$} & \multicolumn{2}{|c|}{ Test 2} & \multicolumn{2}{|c|}{ Test 3} & & & \multirow[b]{2}{*}{$\begin{array}{l}\text { Delta, \% } \\
\text { PSA/OHM }\end{array}$} \\
\hline \multicolumn{7}{|c|}{ Mercury Emissions - Outlet (Untreated) } & $\begin{array}{c}\text { Average } \\
\text { OHM }\end{array}$ & $\begin{array}{c}\text { Average } \\
\text { PSA }\end{array}$ & \\
\hline Particulate & 10 & $\overline{N D}$ & 10 & ND & 5 & ND & 8 & ND & ND \\
\hline Oxidized & 3744 & ND & 3883 & ND & 3693 & ND & 3773 & ND & ND \\
\hline Elemental & 2962 & ND & 2786 & ND & 2698 & ND & 2815 & ND & ND \\
\hline $\begin{array}{l}\text { Total } \\
\text { Vapor } \\
\text { Phase }\end{array}$ & 6706 & 6764 & 6668 & 6878 & 6391 & 6422 & 6589 & 6688 & $1.5 \%$ \\
\hline $\begin{array}{l}\text { Mercury Emi } \\
\text { (Treated) }\end{array}$ & ions - C & utlet & & & & & & & \\
\hline Particulate & 105 & ND & 66 & ND & 48 & ND & $<4$ & ND & ND \\
\hline Oxidized & 4815 & ND & 4664 & ND & 4513 & ND & 4664 & ND & ND \\
\hline Elemental & 1161 & ND & 1180 & ND & 1324 & ND & 1221 & ND & ND \\
\hline $\begin{array}{l}\text { Total } \\
\text { Vapor }\end{array}$ & 5976 & 2993 & 5844 & 3281 & 5836 & 5395 & 5886 & 3890 & $-33.9 \%$ \\
\hline Phase & & & & & & & & & \\
\hline
\end{tabular}

There was a small amount of particulate mercury measured in the May tests, being highest in the treated flue gas. Even this small amount of particulate mercury is surprising since these samples were collected after the ESPs. The amount of particulate mercury was far higher than observed during the baseline OHM measurements. The oxidized mercury to elemental mercury ratio, as measured by the OHM tests, was $57 \%$ oxidized and $43 \%$ elemental in the untreated flue gas. This ratio was $79 \%$ oxidized and $21 \%$ elemental in the treated flue gas. 
The OHM data agreed well with the $\mathrm{Hg}$ CEM data for the untreated flue gas stream being only $1.5 \%$ apart on average. However, the data from the treated flue gas stream were widely different averaging 34\% apart.

The results from the June OHM testing are presented in Table 41.

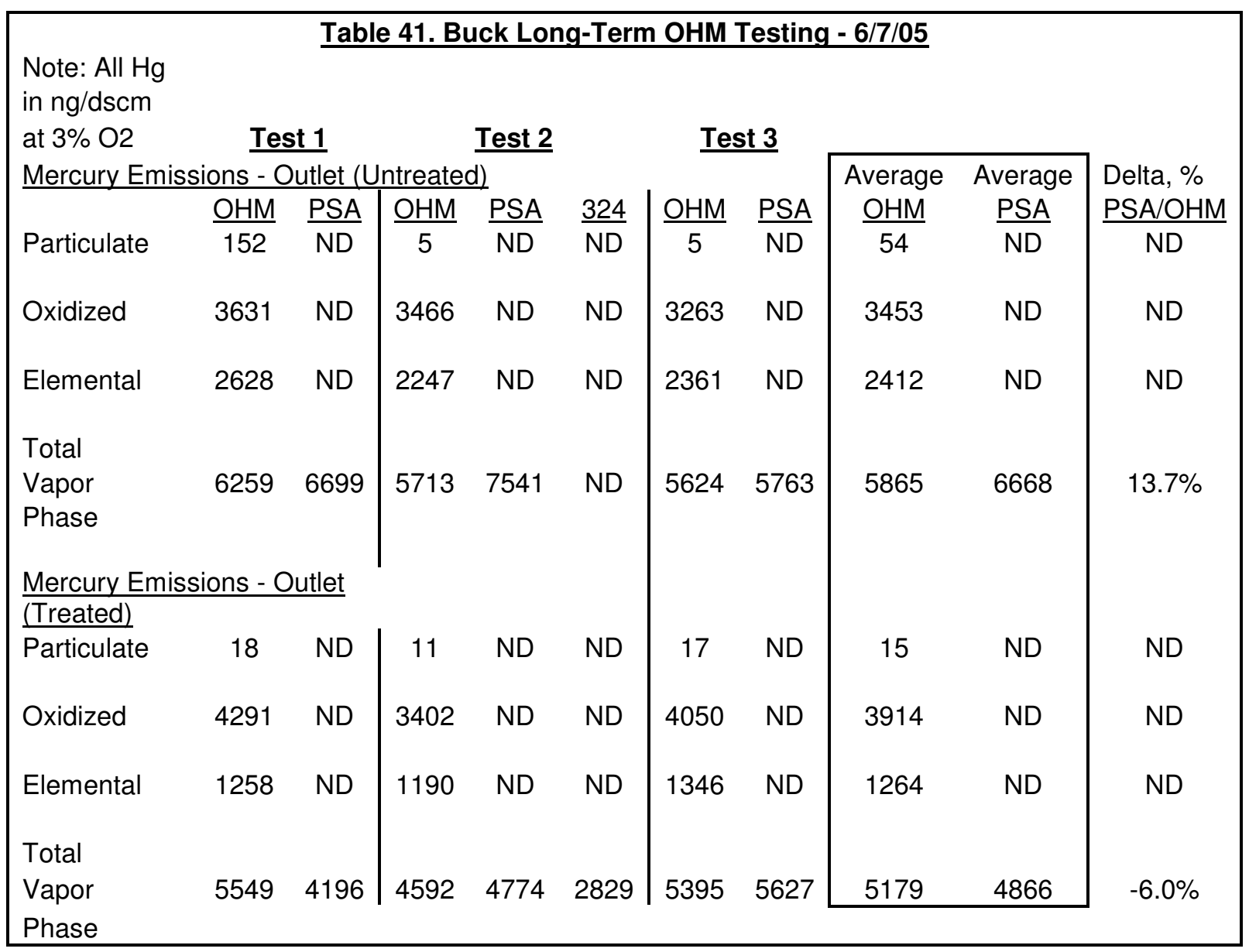

Low levels of particulate mercury were measured in this test. The oxidized to elemental ratio on average was $59 \%$ oxidized to $41 \%$ elemental in the untreated flue gas and $76 \%$ oxidized to $24 \%$ elemental in the treated flue gas. The OHM measurements and the $\mathrm{Hg}$ CEM data differed by about $14 \%$ in the untreated flue gas stream and $6 \%$ in the treated flue gas stream. It is interesting to note that the Method 324 test conducted during $\mathrm{OHM}$ test 2 gave a lower mercury reading than either the OHM or $\mathrm{Hg}$ CEM.

Albemarle Environmental, $\mathrm{f} / \mathrm{k} / \mathrm{a}$ Sorbent Technologies personnel conducted a series of Method 324 tests throughout the long-term test. This testing was not in the original statement of work and the cost was covered solely by Albemarle Environmental, $\mathrm{f} / \mathrm{k} / \mathrm{a}$ Sorbent Technologies. This work was conducted to provide additional information about the mercury removal achieved during the long-term test. The problem was that only one Method 324 sampling system was available and, thus, simultaneous mercury measurements could not be made in the treated and untreated gas streams. In order to provide a comparison of mercury data, the Method 324 data for a given time and 
sampling location is compared to the mercury monitor data for the same period and both monitoring locations in the table below.

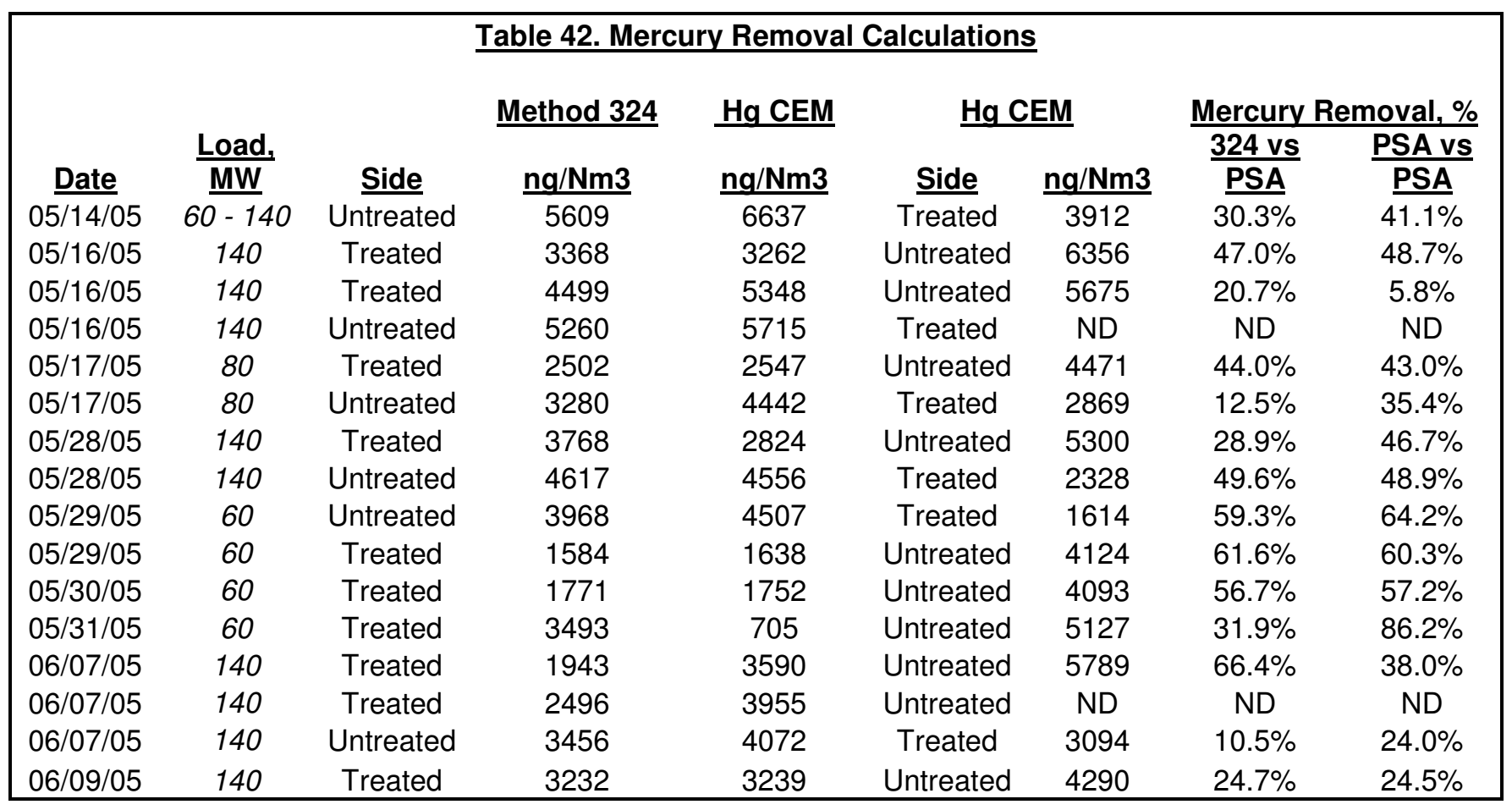

There were 16 Method 324 tests performed during the long-term test at the Buck Station. Ten of the sixteen tests were performed on the treated ESP gas stream. The agreement between the Method 324 data and the $\mathrm{Hg}$ CEM data is fairly good. The Method 324 data gave similar mercury removal results in 7 tests, higher results in two tests and lower in five tests. Two tests were performed when there was incomplete mercury CEM data. There does not appear to be a simple explanation for the tests where the mercury removal results varied. However, only in one test did the $\mathrm{Hg}$ concentration measured by the Method 324 test grossly differ with the mercury CEM result. The Method 324 tests support the findings of the Hg CEMs in regard to the mercury removal rate achieved in the long-term test.

In addition to the Method 324 testing, Albemarle Environmental, $\mathrm{f} / \mathrm{k} / \mathrm{a}$ Sorbent Technologies contracted Apogee Scientific to come to the Buck Station with their mercury monitor. Apogee operated their monitor at the same locations and at the same time as Western Kentucky University operated the PS Analytical system.

The start of the test was delayed by one of the three boiler outages during the long-term test. The test eventually began on June 3, 2005. Apogee operated their system for three days. There was another boiler event, a boiler flame-out, that disrupted the operation of all of the monitors for several hours on June $5^{\text {th }}$. The event was so catastrophic that one of the filters in the QSIS probes in the PSA system fractured and had to be replaced.

The operation of the Apogee $\mathrm{Hg}$ monitors was not without problems. For whatever reason, the mercury levels measured in the treated and untreated stacks by the Apogee monitor were different at the resumption of sorbent injection. The sorbent injection system had been off due to the boiler outage. The mercury data from the PSA monitor 
was similar for both stacks before the injection resumed, as would be expected. The mercury data at the beginning of the test is presented in Figure 68.

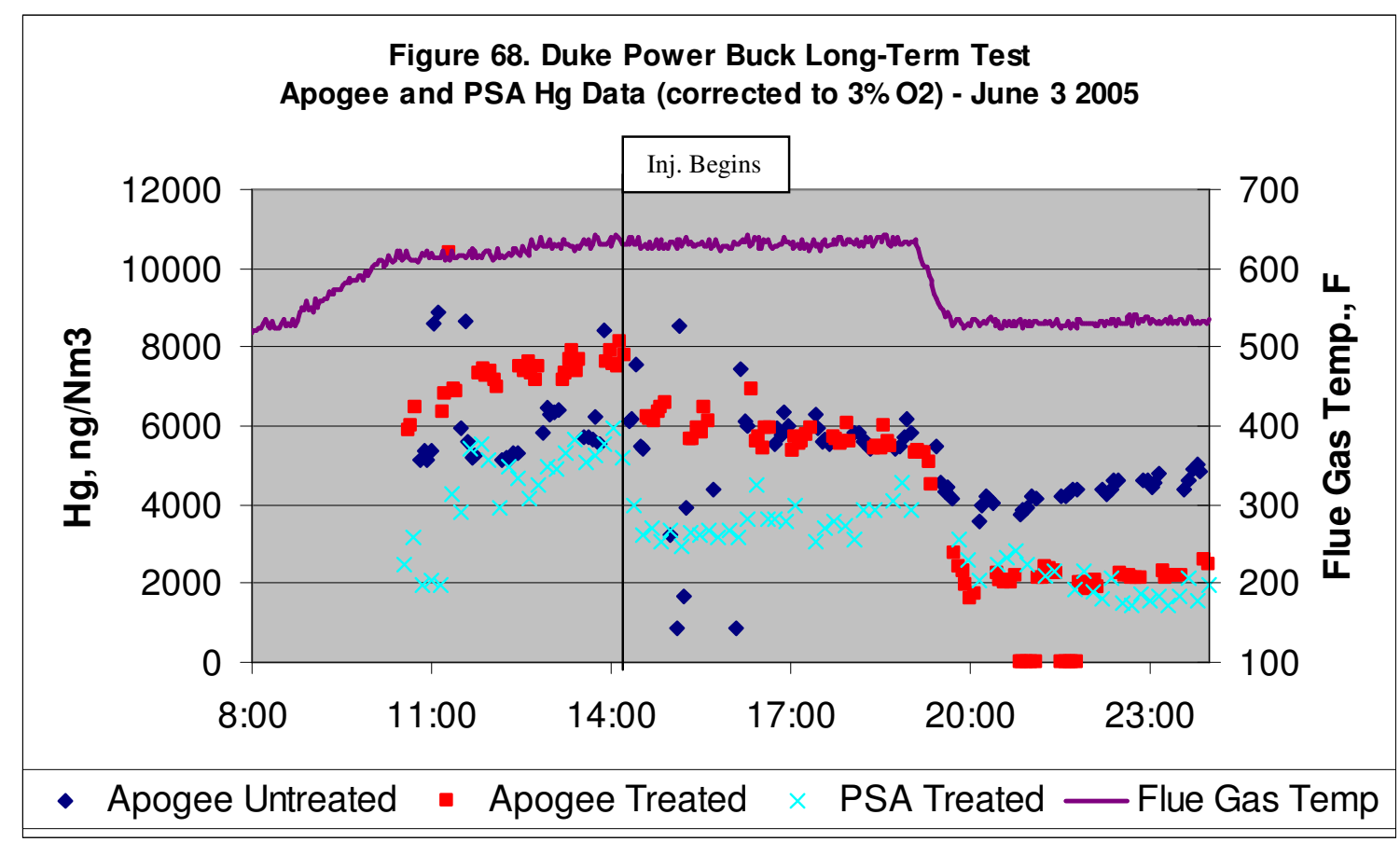

When injection resumed, both monitors recorded a drop in $\mathrm{Hg}$ level; that of the PSA monitor being somewhat larger. The Apogee monitor continued to experience problems for sometime after the injection began. The Apogee engineer on site believed that he found the problem in the untreated conversion system but this change did not bring the mercury data from that side up to the level at which the treated side had begun before injection. Thus, the Apogee untreated stack $\mathrm{Hg}$ data was corrected for this difference in order to provide mercury removal information.

The test period when both monitors were in operation was divided into smaller periods based upon boiler operating temperature. The results are presented in the table below.

\begin{tabular}{|c|c|c|c|c|c|c|c|c|c|c|c|}
\hline \multirow[b]{2}{*}{ Date } & \multirow{2}{*}{$\begin{array}{l}\text { Start } \\
\text { Time }\end{array}$} & \multirow{2}{*}{$\begin{array}{l}\text { End } \\
\text { Time }\end{array}$} & \multirow{2}{*}{$\begin{array}{l}\text { Operating } \\
\text { Temp., F }\end{array}$} & \multicolumn{5}{|c|}{ Apogee } & \multicolumn{3}{|c|}{ PSA } \\
\hline & & & & Untreated & Corrected & $\underline{\text { Treated }}$ & Removal & Corrected & Untreated & $\underline{\text { Treated }}$ & Removal \\
\hline 06/03/05 & $13: 15$ & $14: 15$ & 632 & 6224 & 7668 & 7671 & $-23.2 \%$ & $0.0 \%$ & 5517 & 5425 & $1.7 \%$ \\
\hline 06/03/05 & $16: 23$ & 19:07 & 633 & 5778 & 7118 & 5643 & $2.3 \%$ & $20.7 \%$ & 5820 & 3748 & $35.6 \%$ \\
\hline $6 / 3-4 / 05$ & $19: 50$ & $8: 30$ & 534 & 4763 & 5868 & 2107 & $55.8 \%$ & $64.1 \%$ & 3752 & 1448 & $61.4 \%$ \\
\hline $06 / 04 / 05$ & $16: 00$ & $22: 13$ & 639 & 5315 & 6548 & 4838 & $9.0 \%$ & $26.1 \%$ & 5525 & 3566 & $35.5 \%$ \\
\hline 06/05/05 & 0:00 & 8:00 & 540 & 5351 & 6592 & 3474 & $35.1 \%$ & $47.3 \%$ & 4587 & 2383 & $48.0 \%$ \\
\hline 06/05/05 & $18: 07$ & 23:59 & 642 & 5706 & 7030 & 4815 & $15.6 \%$ & $31.5 \%$ & 6958 & 4938 & $29.0 \%$ \\
\hline 06/06/05 & $1: 24$ & 5:00 & 543 & 3911 & 4818 & 1918 & $51.0 \%$ & $60.2 \%$ & 4652 & 3760 & $19.2 \%$ \\
\hline
\end{tabular}

There was a high temperature baseline period and three high temperature injection periods. There were also three low temperature injection periods. Without correction, the Apogee monitor provided a baseline increase of 23\%; the untreated side being lower 
than the treated side. The Apogee data corrected is obviously $0 \%$ while the PSA baseline removal was $1.7 \%$.

For the three high temperature injection periods, the corrected mercury removal rates for the Apogee monitor averaged $26.1 \%$ while the PSA data averaged $33.4 \%$. This difference is reasonable considering the methodology. In either case, the removal levels achieved on these days was half that expected based upon the parametric tests. It is believed that the difference is due to the difference in operating conditions between these two periods.

The PSA data for the last low temperature injection period has been discarded since it was taken during the conditioning period for the replacement inertial filter. The Apogee monitor indicated a mercury removal rate of $64.1 \%$ and $47.3 \%$ for the first two low temperature injection periods, respectively, while the PSA monitor indicated a mercury removal rate of $61.4 \%$ and $48.0 \%$, respectively. The Apogee monitor indicated a mercury removal rate of $60.2 \%$ for the last low temperature injection period, for which there was no PSA data for comparison. Clearly, higher mercury removal rates were achieved at lower temperature during this test but there is a complication of low load and, thus low temperature operation. At low load, the ash removal system operates much more efficiently, greatly reducing the time the fly ash stays at temperature. This more rapid removal of the sorbent with the fly ash from the system may elevate the mercury removal results at low load. 


\section{Fly Ash Analyses}

The results of the fly ash mercury analyses from the long-term test are presented in Table 44.

\begin{tabular}{|c|c|c|c|c|}
\hline Date & $\begin{array}{c}\text { Treated } \\
\text { Hoppers } 1 \& 2\end{array}$ & $\begin{array}{c}(\mathrm{Hg} \text { in } \mathrm{ppb}) \\
\text { Untreated } \\
\text { Hoppers } 3 \text { \& } 4 \\
\end{array}$ & $\begin{array}{l}\text { Sampling } \\
\text { Method }\end{array}$ & $\begin{array}{c}\text { Boiler } \\
\text { Load, MW }\end{array}$ \\
\hline$\overline{5 / 4 / 05}$ & 43 & 13 & Plant & 140 \\
\hline $5 / 7 / 05$ & 55 & 30 & Plant & 140 \\
\hline $5 / 8 / 05$ & 44 & 28 & Plant & 140 \\
\hline $5 / 9 / 05$ & 45 & 21 & Plant & 140 \\
\hline $5 / 10 / 05$ & 36 & 26 & Plant & 140 \\
\hline $5 / 11 / 05$ & 46 & 15 & Plant & 140 \\
\hline $5 / 12 / 05$ & 52 & 22 & Plant & 140 \\
\hline $5 / 13 / 05$ & 47 & 16 & Plant & 140 \\
\hline $5 / 15 / 05$ & 95 & & Plant & 100 \\
\hline $5 / 16 / 05$ & 51 & 18 & Plant & 140 \\
\hline $5 / 17 / 05$ & 53 & 28 & Plant & 140 \\
\hline $5 / 18 / 05$ & 46 & 19 & Plant & 140 \\
\hline $5 / 19 / 05$ & 40 & 8 & Plant & 140 \\
\hline 5/19/05 & 48 & 14 & Plant & 120 \\
\hline $5 / 20 / 05$ & 28 & 6 & Plant & 130 \\
\hline $5 / 20 / 05$ & 39 & 10 & Plant & 60 \\
\hline $5 / 21 / 05$ & 37 & 18 & Plant & 60 \\
\hline $5 / 24 / 05$ & 34 & 12 & Plant & 140 \\
\hline $5 / 25 / 05$ & 44 & 12 & Plant & 140 \\
\hline 5/25/05 & 83 & 18 & Thief & 60 \\
\hline $5 / 26 / 05$ & 50 & 23 & Thief & 140 \\
\hline $5 / 27 / 05$ & 44 & 15 & Thief & 140 \\
\hline $5 / 28 / 05$ & 100 & 26 & Thief & 140 \\
\hline $5 / 28 / 05$ & 236 & 59 & Thief & 140 \\
\hline $5 / 28 / 05$ & 44 & 17 & Thief & 140 \\
\hline $5 / 29 / 05$ & 236 & 43 & Thief & 60 \\
\hline $5 / 30 / 05$ & 190 & 43 & Thief & 60 \\
\hline $5 / 31 / 05$ & 144 & 41 & Thief & 60 \\
\hline $6 / 3 / 05$ & 226 & 31 & Thief & 60 \\
\hline $6 / 4 / 05$ & 209 & 60 & High Volume & 60 \\
\hline $6 / 4 / 05$ & 211 & & High Volume & 60 \\
\hline $6 / 4 / 05$ & 60 & & High Volume & 140 \\
\hline $6 / 5 / 05$ & 142 & & High Volume & 90 \\
\hline $6 / 7 / 05$ & 78 & 28 & Thief & 140 \\
\hline $6 / 7 / 05$ & 85 & 20 & High Volume & 140 \\
\hline $6 / 9 / 05$ & 97 & 31 & Thief & 140 \\
\hline $6 / 9 / 05$ & 85 & 34 & Thief & 140 \\
\hline
\end{tabular}

It turned out to be difficult, if not impossible, to obtain a representative fly ash sample at Buck 6, especially at high boiler loads with the high volume of fly ash generated.

Obtaining a representative sample from the Duke Power Cliffside Station had not been a 
problem but this facility had a different design of fly ash hoppers and a lower ash coal was used.

At Buck, at least $75 \%$ of the fly ash is collected in the first field of a two field ESP, increasing the fly ash holding time. At high loads, the fly ash should be at temperatures well over $600^{\circ} \mathrm{F}$ but fly ash samples approaching this temperature could never be collected. In fact, no fly ash sample was collected with a temperature within $250^{\circ} \mathrm{F}$ of the flue gas temperature. Thus, the fly ash sampled had been at high temperature for some time and probably had lost some mercury. The sampling was easier, but possibly no more representative, at low loads due to the lower fly ash generation.

Over the course of the long-term test, four fly ash sampling methods were tested. Each was better than the first but it appears that none gave truly representative fly ash samples. The first method used was that developed by the Buck personnel and is called "Plant" under the method of sampling in Table 44. The key to this methodology was a 1" pipe installed at the bottom of the ash hopper. A valve was connected to the end of the pipe which could be opened when a fly ash sample was needed. Merely opening the valve did not provide the sample since the fly ash was bridged somewhere above this location. In order to get a sample, an air line was connected above the 1" pipe and air pumped into the ash hopper to fluidize the fly ash.

The plant fly ash sampling method was used in the first portion of the long-term test until the first fly ash mercury analyses did not find the level of mercury that had been found in the Cliffside tests. This finding led to the development of the other sampling methods.

The second technique evaluated was the in-fight capture of fly ash in the ductwork leading to the ESP. Unfortunately, this failed since the collection device was at a temperature below the flue gas and it acted as a mercury sink. Thus, high mercury values were measured in the samples.

The third fly ash sampling method consisted of using a thief through the 1 " line to take a sample just as the hopper was being emptied. This was better but aged ash was probably still being sampled to some undetermined degree. This method is called "Thief" in Table 44. The collected fly ash samples contained considerably more mercury when sampled in this manner. However, the variability of the method can be illustrated by examining the results from the three samples collected on May $28^{\text {th }}$. The fly ash mercury content varied from 44 to $236 \mathrm{ppb}$, even though the same boiler loads and injection rates were in use at the times of collection.

Finally, an evacuation system was used to collect a large volume of fly ash for use in further work by DOE and Sorbent Technologies. The samples were collected through the 1" pipe as the hopper was being emptied. This method was called "high volume" in Table 44. It was hoped that this would provide a better opportunity to capture fresh ash. The samples collected using the high volume method did not appear to be any less variable than those collected by the thief method.

The development of the thief sampling method allowed for samples to be collected from the back field of the ESP. The results of the analyses of these samples are presented in Table 45. 


\begin{tabular}{|c|c|c|c|c|}
\hline \multicolumn{5}{|c|}{ Table 45. Duke Power Buck Long-Term Fly Ash Hg Data } \\
\hline Date & $\begin{array}{l}\text { Treated } \\
\text { Hopper } 5\end{array}$ & $\begin{array}{c}\text { Treated } \\
\text { Hopper } 6\end{array}$ & $\begin{array}{l}\text { Sampling } \\
\text { Method }\end{array}$ & $\begin{array}{c}\text { Boiler } \\
\text { Load, MW }\end{array}$ \\
\hline $5 \overline{25 / 05}$ & & 81 & Thief & 60 \\
\hline $5 / 26 / 05$ & 194 & 74 & Thief & 140 \\
\hline $5 / 27 / 05$ & 102 & 78 & Thief & 140 \\
\hline $5 / 28 / 05$ & & 83 & Thief & 140 \\
\hline $5 / 30 / 05$ & & 84 & Thief & 60 \\
\hline $5 / 31 / 05$ & & 211 & Thief & 60 \\
\hline $6 / 7 / 05$ & & 171 & Thief & 140 \\
\hline $6 / 9 / 05$ & & 177 & Thief & 140 \\
\hline
\end{tabular}

Hoppers 5 and 6 are from the treated ESP. There were some high mercury values in the samples from the back field of the ESP but no higher than some from the front field. The variability of the mercury in the back field appears to be the same as in the front.

There has always been a question if the mercury sorbent captured anything besides mercury in the gas stream. Two components of interest are arsenic and selenium. The arsenic should primarily be in the solid phase at the injection temperatures present in the testing at the Duke Power Buck Station while the selenium should primarily be in the liquid phase. Thus, it would not be expected that the mercury sorbent designed to react with gas phase components would "capture" these metals.

This program provided an opportunity to examine the arsenic and selenium contents of fly ash samples collected during the long-term test. The results are in Table 46.

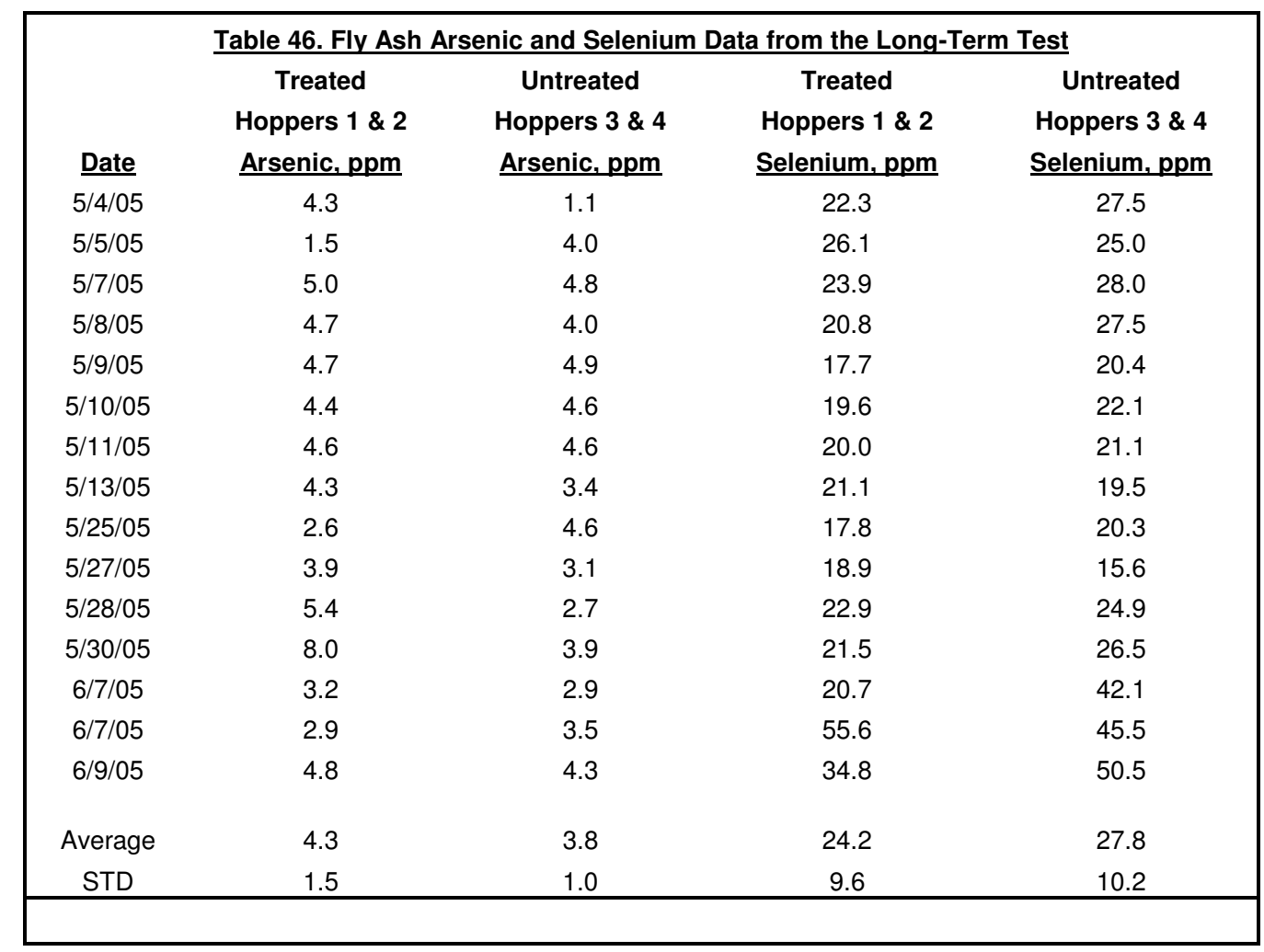


The arsenic content of the fly ash from both the treated and untreated flue gas streams are very similar. The same can be said of the selenium data. Thus, it does not appear that, in this application, the mercury sorbent added in the capture of these metals.

\section{Mercury Mass Balances}

Mercury mass balances are constructed using the coal, fly ash and flue gas mercury measurements along with the appropriate boiler operating data. The first calculation that can be made is the amount of mercury in the fly ash if $100 \%$ of the $\mathrm{Hg}$ were to be captured.

Duke Power Buck 6 requires about 1,287 MMBtu per hour to operate at full load. This translates into 53.6 tons per hour of a $12,000 \mathrm{Btu} / \mathrm{lb}$ coal, such as was used in the parametric test program or 58.5 tons per hour of an $11,000 \mathrm{Btu} / \mathrm{lb}$ coal, such as was used in the long-term test. The ash content of the coal during the long-term test was $18.4 \%$, on an as received basis. The mercury content of the coal during the same period was $0.059 \mathrm{ppm}$. If $100 \%$ of the mercury were captured in the fly ash, the mercury content would be near $300 \mathrm{ppb}$. This is a lower number than originally expected based upon the Cliffside tests but a much lower ash coal was used in those tests.

The fly ash samples may not be fully representative of the ash generated. However, once the improved sampling techniques were applied, the measured fly ash mercury content on several occasions was higher than $200 \mathrm{ppb}$. Thus, $67 \%$ of the mercury could have been captured at the time these samples were collected.

Another use of the mercury data is to calculate the expected mercury concentration in the flue gas for the baseline period. This calculation can be made using the same data as before plus the flue gas flow rate. The calculated average flue gas mercury concentration at actual the actual oxygen level is $4,916 \mathrm{ng} / \mathrm{Nm}^{3}$ for the baseline period. The expected range is from $3,781 \mathrm{ng} / \mathrm{Nm}^{3}$ to $6,050 \mathrm{ng} / \mathrm{Nm}^{3}$, based upon the range of measured coal mercury concentrations. This calculation assumes that all of the mercury goes to the flue gas. The OHM and the outlet mercury CEM measurements for the baseline period are within the expected range while the inlet $\mathrm{Hg}$ CEM data appears to be low. This is why the sampling at the inlet location was abandoned in favor of a position at the stack in the untreated flue gas stream.

A similar calculation was performed to determine the expected mercury concentration in the untreated flue gas stream during the long-term test. The expected average flue gas mercury concentration at actual the actual oxygen level is $4,870 \mathrm{ng} / \mathrm{Nm}^{3}$ for the longterm period. The expected range is from $3,302 \mathrm{ng} / \mathrm{Nm}^{3}$ to $6,603 \mathrm{ng} / \mathrm{Nm}^{3}$ based upon the range of measured coal mercury concentrations. The flue gas mercury concentration in the untreated stream was within this band of mercury concentration.

The coal used during most of the long-term test at the Duke Power Buck Station had a mercury content of $0.59 \mathrm{ppm}$ (dry basis), a heating value of 11,167 Btu/lb (as received) and a moisture content of $7.0 \%$. This translates into a mercury input of about 5.0 $\mathrm{lb} / \mathrm{TBtu}$. A mercury removal rate of $50 \%$ reduces this mercury emission rate to 2.5 $\mathrm{lb} / \mathrm{TBtu}$. 


\section{$\underline{\text { Halogen and Dioxin Measurements }}$}

Method 26A Halogen tests were performed on two days during the long-term test at the Duke Power Buck Station. Each test was performed simultaneously in the untreated and treated flue gas streams at the two stacks and repeated twice. This provided a total of three tests at both stacks. The results of these measurements are presented in Table 47.

\begin{tabular}{|c|c|c|c|c|c|c|c|c|}
\hline \multirow[b]{3}{*}{ Date } & \multicolumn{8}{|c|}{ Table 47. Duke Power Buck Station Halogen Data (lb/h) } \\
\hline & \multicolumn{4}{|c|}{ Untreated Flue Gas } & \multicolumn{4}{|c|}{ Treated Flue Gas } \\
\hline & $\mathrm{Cl} 2$ & $\underline{B r 2}$ & $\mathrm{HCl}$ & $\underline{\mathrm{HBr}}$ & $\mathrm{Cl} 2$ & $\underline{B r 2}$ & $\underline{\mathrm{HCl}}$ & $\underline{\mathrm{HBr}}$ \\
\hline $05 / 19 / 05$ & $\overline{0.41}$ & $<\overline{0.19}$ & $\overline{62.5}$ & $\overline{1.2}$ & $\overline{0.45}$ & $\overline{<0.21}$ & $\overline{58.1}$ & $\overline{5.8}$ \\
\hline 05/19/05 & 0.38 & $<0.19$ & 61.3 & 1.1 & 0.42 & $<0.21$ & 59.8 & 6.0 \\
\hline 05/19/05 & 0.34 & $<0.19$ & 62.0 & 1.1 & 0.45 & $<0.21$ & 53.4 & 5.3 \\
\hline Average & 0.38 & $<0.19$ & 61.9 & 1.1 & 0.44 & $<0.21$ & 57.1 & 5.7 \\
\hline 06/09/05 & 0.38 & $<0.20$ & 70.8 & 1.1 & 0.45 & $<0.21$ & 70.5 & 6.0 \\
\hline 06/09/05 & 0.20 & $<0.20$ & 71.5 & 1.1 & 0.46 & $<0.21$ & 70.3 & 5.9 \\
\hline 06/09/05 & 0.20 & $<0.20$ & 71.5 & 1.0 & 0.46 & $<0.21$ & 70.8 & 6.0 \\
\hline Average & 0.26 & $<0.20$ & 71.3 & 1.1 & 0.46 & $<0.21$ & 70.5 & 6.0 \\
\hline
\end{tabular}

There is a slight amount of chlorine in the flue gas. The amount of bromine in the flue gas is below the detection limits in both the treated and untreated flue gas streams. There are high levels of $\mathrm{HCl}$ in the flue gas as would be expected from the coal analyses. There is much more $\mathrm{HBr}$ in the treated flue gas stream than in the untreated flue gas. This $\mathrm{HBr}$ must be coming from the sorbent, although its concentration is low.

During the long-term test, a United States Environmental Protection Agency contractor took flue gas samples to measure the chlorinated and brominated dioxin content. The purpose was to determine if brominated $\mathrm{Hg}$ sorbents generated increased dioxin emissions. These tests were not part of the original scope of the project but they were included since all parties (Duke Power, EPA, DOE and Sorbent Technologies) were willing to support this effort.

The preliminary results are presented in Table 48.

Table 48. Duke Power Buck Station Dioxin Measurements during the Long-Term Test (All concentrations in $\mathrm{ng} / \mathrm{Nm} 3$ )

\begin{tabular}{ccccccc} 
Dioxin Type & Gas Stream & $\underline{\text { Test 1 }}$ & $\underline{\text { Test 2 }}$ & $\underline{\text { Test 3 }}$ & Average & Std. Dev. \\
\cline { 2 - 3 } PCDD/F & Untreated & 0.3908 & 1.8059 & 0.3903 & 0.8623 & 0.8172 \\
PCDD/F & Treated & 1.6149 & 1.2213 & 0.2489 & 1.0284 & 0.7031 \\
& & & & & & \\
PBrDD/F & Untreated & 0.0732 & 0.1386 & 1.0785 & 0.4301 & 0.5625 \\
PBrDD/F & Treated & 0.1145 & 0.1521 & 1.2892 & 0.5186 & 0.6676 \\
\hline
\end{tabular}

The chlorinated dioxin (PCDD/F) concentration in the untreated flue gas averaged $0.8623 \mathrm{ng} / \mathrm{Nm}^{3}$ and averaged $1.0284 \mathrm{ng} / \mathrm{Nm}^{3}$ in the treated flue gas stream. These concentrations are not statistically different. The brominated dioxin (PBrDD/F) 
concentration in both the treated and untreated flue gas streams were about half of the chlorinated dioxin concentration. Again, the average concentration between the treated and untreated gas stream were not statistically different. Therefore, the use of H-PAC does not appear to generate brominated dioxins in hot-side ESP applications. It should be noted that the concentration of the dioxin species measured at the Buck Station are far below the dioxin standard for municipal waste combustors of $60 \mathrm{ng} / \mathrm{Nm}^{3}$.

\section{Mercury Leaching Analyses}

Fly ash samples taken from both the treated and untreated flue gas streams were evaluated for their mercury leaching potential using the standard TCLP methodology. The results of these tests are presented in Figure 69.

Figure 69. Leaching Results from Duke Power

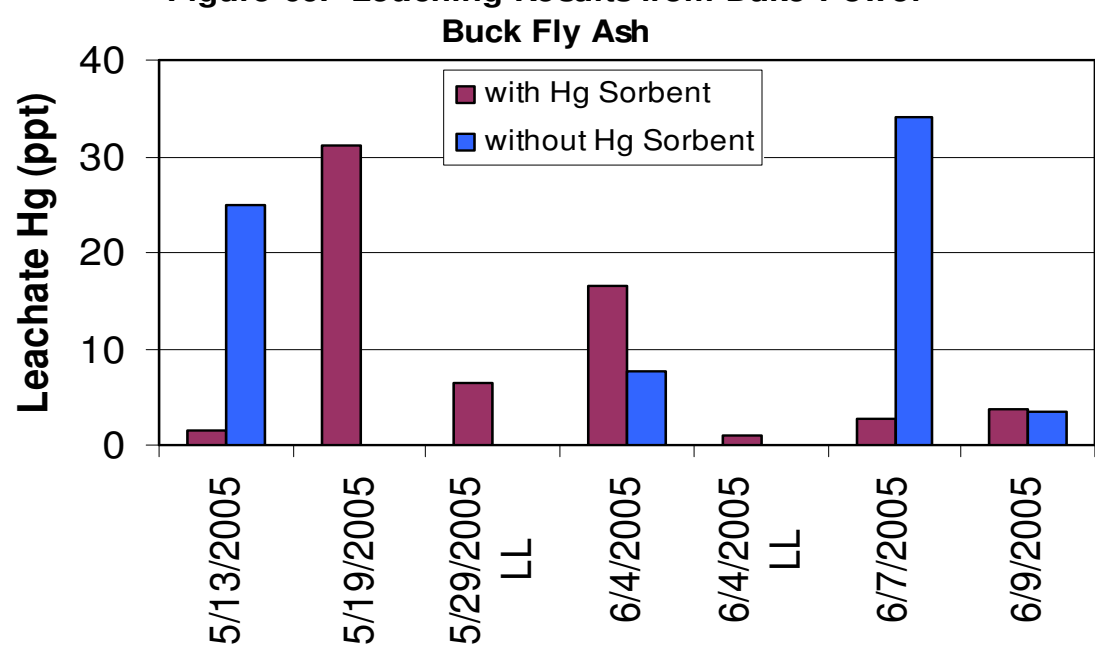

The mercury in the leachate was low for all tests. In addition, the mercury in the leachate from fly ash samples that did not contain mercury sorbent were, on several occasions, higher than those that did.

\section{Corrosion Analysis}

Corrosion coupons were installed in the horizontal ductwork leading to the hot-side ESP on the treated flue gas stream. These coupons were to be compared to ones placed in the same location after the completion of the long-term test. It was not possible to have corrosion coupons in place before the testing at the Duke Power Buck Station began since the boiler was down for a planned major outage right before the testing began.

The coupons were installed On May 4, 2005, just before the long-term test began. Unfortunately, the coupons were spoiled by three separate events. First, the boiler had several outages during the long-term test which allowed the coupons to be exposed to ambient moisture. Second, at least two of the coupons resided in a dust pile and not in the flue gas stream. Third, and most damaging, the ductwork leaked during several heavy rain storms allowing water on the coupons. Thus, the corrosion coupons were discarded, since they could not possibly provide a representative picture of the corrosion during normal boiler operation. 


\section{TECHNOLOGY TRANSFER ACTIVITIES}

The purpose of the technology transfer activities was to provide the results of the testing at the Detroit Edison St. Clair Plant and the two Duke Power Stations to the widest possible number of utilities for use in their planning and mercury control activities. This was accomplished by two means. After the testing at the Detroit Edison Plant, a technical presentation and plant tour was provided. In addition, the results of these tests were presented at several conferences. The results form the testing at the Detroit Edison St. Clair Plant and the Duke Power Cliffside and Buck Stations were presented at the 2004 Mega Symposium ${ }^{(2,3)}$, 2005 Electric Utility Environmental Conference ${ }^{(4)}$ and the 2005 Air Quality V Conference. ${ }^{(5)}$ The results from these tests have been referenced in numerous other papers and presentations. In addition, Sorbent Technologies has presented an update on these tests at the annual DOE NETL Technology Transfer meetings in 2004, 2005 and 2006.

\section{CONCLUSIONS}

These tests were designed to address two of the major misconceptions about mercury sorbents. These misconceptions were that it was impossible to obtain high mercury removal efficiencies at a facility that primarily used a low rank fuel such as PRB subbituminous coal. The second misconception was that carbon-based mercury sorbents could not be used to capture mercury at the elevated temperatures present in a hot-side ESP. From this testing the following conclusions are drawn:

1. Brominated activated carbon based B-PAC can be used to capture more than $90 \%$ of the mercury present in the flue gas from a facility that burns either blend mostly containing subbituminous coal and some bituminous coal or $100 \%$ subbituminous coal. This was demonstrated in both the parametric and longterm tests at Detroit Edison St. Clair. In the long-term test, a mercury capture rate of $94 \%$ was achieved with a B-PAC injection rate of only $3.0 \mathrm{lb} / \mathrm{MMacf}$.

2. Brominated activated carbon based B-PAC can be used to capture more than $50 \%$ of the mercury present in the flue gas from a facility that uses a hot-side ESP for particulate control. This finding was proven at both the Duke Power Cliffside Station and Buck Station.

3. The injection of B-PAC at these facilities gave no measurable detrimental balance of plant effects, especially on opacity.

4. The use of B-PAC did not increase the concentration of either chlorinated or brominated dioxins at either plant.

5. Fly ash mercury analyses are essential in providing a basis for mercury mass balances. Obtaining representative fly ash samples is nearly impossible in parametric tests, since the samples are mixed with an unknown percentage of native fly ash. Obtaining a representative sample of fly ash from a hot-side ESP is also difficult for several reasons. First, the ash is very hot and can be a safety concern. Second, aged fly ash has a different mercury content than does fresh fly ash. Better fly ash sampling systems are needed to insure representative fly ash samples. 
6. The fly ash from the long-term tests at both plants was subjected to leaching analysis using the TCLP methodology. In all cases the mercury content of the leachate was very low and similar to that of the fly ash which did not contain mercury sorbent.

7. The current reference method for measuring flue gas mercury (Ontario Hydro Method) is very costly, slow to provide data and can provide widely spread results. The prime example of this was at the Detroit Edison St. Clair Plant where the data from the baseline OHM tests was not received until the long-term test was underway and which indicated that $25 \%$ more mercury was emitted from the cold-side ESP than entered. Mercury mass balances proved this data to be erroneous. Emphasis needs to be placed on making the mercury CEM and the sorbent trap the reference method for measuring flue gas mercury.

8. In a cold-side application, it appears that very little of the bromine on the B-PAC is released and any that is released is in the form of hydrogen bromide not bromine. In the hot-side application, a significant amount of the bromine is released as hydrogen bromide but the concentration of this gas is an order of magnitude lower than the hydrogen chloride present in the flue gas when bituminous coal is used.

9. The cost for mercury control can now be expected to be up to an order of magnitude below the $\$ 50,000$ to $\$ 70,000$ per pound of mercury removed. The projected control costs for the Detroit Edison St. Clair Plant were about $\$ 7,000$ per pound of mercury for $70 \%$ control and about $\$ 15,500$ per pound of mercury for $90 \%+$ control. 


\section{REFERENCES}

1. Feeley, T., “Overview of DOE/NETL's Mercury and CUB R\&D Program”, Mercury Control Technology R\&D Program Review, Pittsburgh, PA, July 2005.

2. Nelson, S. Jr., "Sorbents and Methods for the Removal of Mercury from Combustion Gases", United States Patent No. US 6,953,494 B2, 10/11/05.

3. Landreth, R., et al., "Full-Scale Mercury Sorbent Injection Testing at DTE Energy's St. Clair Station”, The Mega Symposium, Washington, D.C., September 2004.

4. Nelson, S. Jr., et al., "Accumulated Power-Plant Mercury-Removal Experience with Brominated PAC Injection", The Mega Symposium, Washington, D.C., September, 2004.

5. Landreth, R., et al., "Full-Scale B-PAC Mercury Control with Bituminous, subbituminous, Lignite and Blended Coals with Cold-Side ESPs, Fabric Filters, and Hot-Side ESPs", Electric Utility Environmental Conference, Tucson, AZ, January 2005.

6. Nelson, S. Jr., et al., "Power-Plant Mercury Control Results with Brominated PAC and ESPs", Air Quality V Conference, Arlington, VA, September 2005. 